\title{
Development Assistance for Peacebuilding
}

Development assistance to fragile states and conflict-affected areas can be a core component of peacebuilding, providing support for the restoration of government functions, delivery of basic services, the rule of law, and economic revitalization. What has worked, why it has worked, and what is scalable and transferable are key questions for both development practice and research into how peace is built and the interactive role of domestic and international processes therein. Despite a wealth of research into these questions, significant gaps remain.

This volume speaks to these gaps through new analysis of a selected set of well-regarded aid interventions. Drawing on diverse scholarly and policy expertise, eight case study chapters span multiple domains and regions to analyse Afghanistan's National Solidarity Programme, the Yemen Social Fund for Development, public financial management reform in Sierra Leone, Finn Church Aid's assistance in Somalia, Liberia's gender-sensitive police reform, the judicial facilitators programme in Nicaragua, UNICEF's education projects in Somalia, and World Bank health projects in Timor-Leste. Analysis illustrates the significance of three broad factors in understanding why some aid interventions work better than others: the area of intervention and related degree of engagement with state institutions, local contextual factors such as windows of opportunity and the degree of local support, and programme design and management.

This book was originally published as a special issue of the journal International Peacekeeping, and is available online as an Open Access monograph.

Rachel M. Gisselquist is a political scientist and currently a research fellow with the United Nations University World Institute for Development Economics Research (UNU-WIDER). She works on the politics of the developing world, with particular attention to ethnic politics and group-based inequality, state fragility, governance, and democratization in sub-Saharan Africa. She holds a $\mathrm{PhD}$ from MIT, USA. 



\section{Development Assistance for Peacebuilding}

Edited by

Rachel M. Gisselquist 
First published 2018

by Routledge

2 Park Square, Milton Park, Abingdon, Oxon, OX14 4RN, UK

and by Routledge

711 Third Avenue, New York, NY 10017, USA

Routledge is an imprint of the Taylor \& Francis Group, an informa business

(C) 2018 UNU-WIDER. Originally published as Open Access.

The Open Access version of this book, available at www.tandfebooks.com, has been made available under a Creative Commons Attribution-Non Commercial-No Derivatives 4.0 license.

Trademark notice: Product or corporate names may be trademarks or registered trademarks, and are used only for identification and explanation without intent to infringe.

British Library Cataloguing in Publication Data

A catalogue record for this book is available from the British Library

ISBN 13: 978-1-138-08046-1

Typeset in Sabon

by diacriTech, Chennai

\section{Publisher's Note}

The publisher accepts responsibility for any inconsistencies that may have arisen during the conversion of this book from journal articles to book chapters, namely the possible inclusion of journal terminology.

\section{Disclaimer}

Every effort has been made to contact copyright holders for their permission to reprint material in this book. The publishers would be grateful to hear from any copyright holder who is not here acknowledged and will undertake to rectify any errors or omissions in future editions of this book. 


\section{Contents}

Citation Information vii

Notes on Contributors ix

1 Good Aid in Hard Places: Learning from 'Successful' Interventions in Fragile Situations

Rachel M. Gisselquist

2 The National Solidarity Programme: Assessing the Effects of Community-Driven Development in Afghanistan Andrew Beath, Fotini Christia and Ruben Enikolopov

3 The Yemen Social Fund for Development: An Effective Community-Based Approach amid Political Instability Lamis Al-Iryani, Alain De Janvry and Elisabeth Sadoulet

4 Substantial but Uneven Achievement: Selected Success When Stars Align. Public Financial Management Reforms in Sierra Leone

Heidi Tavakoli, Ismaila B. Cessay and Winston Percy Onipede Cole

5 'Embedded' Assistance: Finn Church Aid's Secondment in Somalia

Rauli S. Lepistö, Rachel M. Gisselquist and Jussi Ojala

6 Liberia's Gender-Sensitive Police Reform: Improving Representation and Responsiveness in a Post-Conflict Setting Laura Bacon 


\section{CONTENTS}

7 Impact Assessment of the Facilitadores Judiciales

Programme in Nicaragua

Martin Gramatikov, Maurits Barendrecht, Margot Kokke, Robert Porter, Morly Frishman and Andrea Morales

8 Education from the Bottom Up: UNICEF's Education Programme in Somalia

James H. Williams and William C. Cummings

9 The World Bank's Health Projects in Timor-Leste:

The Political Economy of Effective Aid

Andrew Rosser and Sharna Bremner

Index 


\section{Citation Information}

The chapters in this book were originally published in International Peacekeeping, volume 22, issue 4 (August 2015). When citing this material, please use the original page numbering for each article, as follows:

\section{Chapter 1}

Good Aid in Hard Places: Learning from 'Successful' Interventions in Fragile Situations

Rachel M. Gisselquist

International Peacekeeping, volume 22, issue 4 (August 2015) pp. 283-301

\section{Chapter 2}

The National Solidarity Programme: Assessing the Effects of Community-Driven Development in Afghanistan

Andrew Beath, Fotini Christia and Ruben Enikolopov

International Peacekeeping, volume 22, issue 4 (August 2015) pp. 302-320

\section{Chapter 3}

The Yemen Social Fund for Development: An Effective Community-Based Approach amid Political Instability

Lamis Al-Iryani, Alain De Janvry and Elisabeth Sadoulet

International Peacekeeping, volume 22, issue 4 (August 2015) pp. 321-336

\section{Chapter 4}

Substantial but Uneven Achievement: Selected Success When Stars Align. Public Financial Management Reforms in Sierra Leone Heidi Tavakoli, Ismaila B. Cessay and Winston Percy Onipede Cole International Peacekeeping, volume 22, issue 4 (August 2015) pp. 337-353

\section{Chapter 5}

'Embedded' Assistance: Finn Church Aid's Secondment in Somalia Rauli S. Lepistö, Rachel M. Gisselquist and Jussi Ojala International Peacekeeping, volume 22, issue 4 (August 2015) pp. 354-371 


\section{CITATION INFORMATION}

\section{Chapter 6}

Liberia's Gender-Sensitive Police Reform: Improving Representation and Responsiveness in a Post-Conflict Setting

Laura Bacon

International Peacekeeping, volume 22, issue 4 (August 2015) pp. 372-397

\section{Chapter 7}

Impact Assessment of the Facilitadores Judiciales Programme in Nicaragua Martin Gramatikov, Maurits Barendrecht, Margot Kokke, Robert Porter, Morly Frishman and Andrea Morales

International Peacekeeping, volume 22, issue 4 (August 2015) pp. 398-418

\section{Chapter 8}

Education from the Bottom Up: UNICEF's Education Programme in Somalia

James H. Williams and William C. Cummings

International Peacekeeping, volume 22, issue 4 (August 2015) pp. 419-434

\section{Chapter 9}

The World Bank's Health Projects in Timor-Leste: The Political Economy of Effective Aid

Andrew Rosser and Sharna Bremner

International Peacekeeping, volume 22, issue 4 (August 2015) pp. 435-451

For any permission-related enquiries please visit:

http://www.tandfonline.com/page/help/permissions 


\section{Notes on Contributors}

Lamis Al-Iryani is Head of the monitoring and evaluation unit of the Social Fund for Development (SFD) in Yemen. She led all major internal evaluations of the SFD since 2003 and has been providing strategic, policy and operational advice to the Fund's management.

Laura Bacon is Principal, Policy for the Governance and Citizen Engagement Initiative at Omidyar Network, a philanthropic investing firm. She is based in London, UK.

Maurits Barendrecht is a full professor in private law and conflict systems at Tilburg University, the Netherlands.

Andrew Beath works for the World Bank's Office of the Chief Economist for East Asia and the Pacific.

Sharna Bremner is a PhD candidate in Development Studies at the University of Adelaide, Australia.

Ismaila B. Cessay is currently a lead financial management specialist of the World Bank in the Governance Global Practice.

Fotini Christia is an associate professor of political science at MIT, USA. She has carried out extensive ethnographic, survey, and experimental research in Afghanistan and Bosnia and is currently working on projects in Yemen and Iraq.

William C. Cummings is Professor Emeritus of International Education and International Affairs at the George Washington University, USA.

Winston Percy Onipede Cole is currently a senior financial management specialist of the World Bank in the Governance Global Practice and has led wide-ranging Public Financial Management (PFM) reforms in Nigeria, Liberia, Ghana, the Gambia, Kenya, Rwanda, and Somalia. 


\section{NOTES ON CONTRIBUTORS}

Alain De Janvry is professor of Agricultural and Resource Economics and Public Policy at the University of California at Berkeley, USA, where he teaches development economics.

Ruben Enikolopov is ICREA Research Professor at Barcelona Institute of Political Economy and Governance, UPF, and Associate Professor of economics at the New Economic School, Moscow.

Morly Frishman studied law at the Hebrew University of Jerusalem, Israel, and the University of Amsterdam, the Netherlands. His work experience includes diverse positions such as a justice sector advisor at HiiL Innovating Justice and legal clerk at the International Criminal Court, The Hague, the Netherlands.

Rachel M. Gisselquist is a research fellow with the United Nations University World Institute for Development Economics Research (UNU-WIDER). She works on the politics of the developing world, with particular attention to ethnic politics and group-based inequality, state fragility, governance and democratization in sub-Saharan Africa.

Martin Gramatikov is Head of Measuring and Evaluation at HiiL Innovating Justice, The Hague, the Netherlands.

Margot Kokke is a trainee judge at the District Court of The Hague. Previously she was a research fellow at the Tilburg University Law School, the Netherlands.

Rauli S. Lepistö is an independent researcher. His expertise is on conflict studies, studying both war and peace with a particular focus on subSaharan Africa and the Middle East.

Andrea Morales studied law at the Pontificia Universidad Católica de Chile in Equador, the Hanzehogeschool in Groningen, the Netherlands, and Leiden University, the Netherlands.

Jussi Ojala is a senior adviser on right to peace with Finn Church Aid, Finland. His work is focused on Africa, peace mediation and situations of fragility.

Robert Porter is a researcher at Tilburg University, the Netherlands, and at HiiL Innovating Justice, The Hague, the Netherlands.

Andrew Rosser is Professor of Southeast Asian Studiese at the University of Melbourne, Australia. His research focuses on the political economy of development issues in Indonesia and Timor-Leste. 


\section{NOTES ON CONTRIBUTORS}

Elisabeth Sadoulet is Professor of Agricultural and Resource Economics at the University of California at Berkeley, USA. She teaches econometrics and development economics.

Heidi Tavakoli is an aid and public finance specialist. She is an economic advisor at the Commonwealth Secretariat and has held senior positions at the Bill and Melinda Gates' Foundation and the Overseas Development Institute (ODI).

James H. Williams is Professor of International Education and International Affairs at the George Washington University, USA, where he is the UNESCO Chair in International Education for Development and the Director of the International Education Programme. 



\title{
Good Aid in Hard Places: Learning from 'Successful' Interventions in Fragile Situations
}

\author{
RACHEL M. GISSELQUIST
}

\begin{abstract}
Development assistance to fragile states and conflict-affected areas can be a core component of peacebuilding, providing support for the restoration of government functions, delivery of basic services, the rule of law and economic revitalization. Despite a wealth of research, however, significant gaps remain in our knowledge about what has worked, why and the transferability and scalability of findings. The project presented in this special issue offers new research on 'successful' projects and programmes in diverse domains and contexts in an effort to address these gaps. This article introduces the special issue and eight case studies included in this volume. Three broad factors are highlighted as significant in understanding why some interventions work better than others: the area of intervention and the related degree of engagement with state institutions; local contextual factors such as capacity and the existence of local supporters; and programme design and management. The article concludes with discussion of how these case studies and similar research can speak to broader debates in the literature on how peace is built, and in particular on the interaction between external actors and endogenous processes.
\end{abstract}

Development assistance to fragile states and situations is a core component of efforts to assist conflict-ridden countries in creating the conditions for sustainable peace. ${ }^{1}$ Indeed, aid is intended to support activities at the heart of peacebuilding, including the restoration of core government functions, delivery of basic services, the rule of law and access to justice, and economic revitalization. Recent statistics suggest that Official Development Assistance (ODA) represents the largest financial inflow to fragile states - about $\$ 53$ billion in 2011 or 38 per cent of ODA. ${ }^{2}$ Nevertheless, fragile states have clearly lagged behind other countries in achieving the Millennium Development Goals. Fragile states and conflict-affected areas thus will remain a focus for donors in the post-2015 development agenda. ${ }^{3}$

Among the core and continuing challenges for both scholars and practitioners in this area is the question of how change occurs, peace is built and fragile states become more 'resilient'. ${ }^{4}$ In particular, how do external interventions interact with local institutions and endogenous processes to influence outcomes? ${ }^{5}$ In the field of international development, this is manifested clearly in the need for better answers to questions about what precisely has worked to support peacebuilding in fragile situations, why and whether experience in one context can be expected to transfer elsewhere or to be scaled up successfully. Despite large

This is an Open Access article distributed under the terms of the Creative Commons Attribution-NonCommercial-NoDerivatives License (http://creativecommons.org/Licenses/by-nc-nd/4.0/), which permits noncommercial re-use, distribution, and reproduction in any medium, provided the original work is properly cited, and is not altered, transformed, or built upon in any way. 


\section{DEVELOPMENT ASSISTANCE FOR PEACEBUILDING}

and rich related literatures, there are major gaps in existing work in relation to these key questions.

This special issue emerges from research conducted under the Governance and Fragility theme of UNU-WIDER's Research and Communication on Foreign Aid (ReCom) programme (2011-13), and specifically the project on 'Good Aid in Hard Places: Learning from What Works in Fragile Contexts'.

The 'Good Aid' project centred around in-depth case studies of 'successful' aid-supported projects and programmes, eight of which are included in this special issue. This article introduces the project and situates it within the literature on state fragility, impact evaluation and aid successes, to show how these analyses can contribute to both better policy making and more rigorous theory-building. Drawing on the literature and the case studies presented in this collection, this article identifies and discusses three sets of factors as important in understanding why some interventions work better than others: (1) the area of the intervention and the related degree of engagement with domestic state institutions; (2) local contextual factors, in particular windows of opportunity, capacity and the existence of local supporters; and (3) programme design and management. While the third set of factors is largely transferrable and scalable, the first two are less so and should be considered carefully in assessment of the feasibility of extending project and programme models to new contexts and in considering adjustments to improve their viability. It concludes with discussion of broader implications and avenues for future research. This article reflects the views of the author and is not intended as a summary of collective conclusions reached by contributors.

\section{What Can New Analysis of 'Successful' Aid Interventions Add?}

Development assistance to fragile states and conflict-affected areas is a core component of peacebuilding, with the potential to support each of the five Peacebuilding and Statebuilding Goals (PSGs) advanced by the International Dialogue on Peacebuilding and Statebuilding and set out in the New Deal for Engagement in Fragile States announced at Busan in 2011: legitimate politics, security, justice, economic foundations, and revenues and services. In terms of 'how to' best address these goals, policy discussions highlight the ten 'Fragile States Principles' first adopted by OECD ministers in 2007:

1. Take context as the starting point.

2. Ensure all activities do no harm.

3. Focus on statebuilding as the central objective.

4. Prioritize prevention.

5. Recognize the links between political, security and development objectives.

6. Promote non-discrimination as a basis for inclusive and stable societies.

7. Align with local priorities in different ways and in different contexts.

8. Agree on practical co-ordination mechanisms between international actors.

9. Act fast ... but stay engaged long enough to give success a chance.

10. Avoid pockets of exclusion ('aid orphans'). ${ }^{6}$ 


\section{DEVELOPMENT ASSISTANCE FOR PEACEBUILDING}

Yet, despite broad agreement (at least among practitioners) and a large body of related research, such principles provide only very loose guidance as to what precisely development actors should be doing in fragile situations. How precisely should they take context into account, design and implement activities that do no harm and so on? How should they balance the tensions and challenges inherent in the application of such broad principles? Such guidelines also provide little insight into which projects and programmes donors should support, that is, based on past experience, which have worked, why and why should (or shouldn't) we expect the same outcomes elsewhere?

This article and special issue focus on this last set of questions, building on a large research and policy literature on aid, peacebuilding and development in conflict and post-conflict states. Three areas of research are especially relevant, offering important - but also incomplete - insights.

The first focuses on why and how states become fragile and fall into conflict, including considerable discussion of how external interventions have contributed to, or failed to stop, these processes. ${ }^{7}$ This work often serves as the basis for policy guidance on peacebuilding, with the assumption that 'successful' peacebuilding will result from taking steps to address the factors that lead to failure. ${ }^{8}$ Likewise, this work provides empirical support to many of the Fragile States Principles. Analyses highlighting the diverse nature of fragile situations, for instance, underscore the value of taking local context into account; research into the role of aid in contributing to 'structural violence' highlights the value of 'doing no harm'; ' and work on horizontal inequality and conflict is consistent with the principle of promoting non-discrimination and inclusive societies. ${ }^{10}$

With respect to our central questions, however, this work has clear shortcomings. Analysis tends to be done at the country level, offering relatively little traction on the specifics of projects and programmes. In addition, it has paid more attention to failure and failed interventions than to success and successful interventions. This lopsided focus can be misleading: processes that lead to peace are not necessarily the converse of those leading to conflict. ${ }^{11}$ Conflict itself may have momentum such that addressing its initial causes, once started, is not enough to trigger and sustain peaceful change. Moreover, research that focuses solely on situations that share the same outcome (here, failure) suffers from a basic methodological flaw; in selecting on the dependent variable, it cannot test causal hypotheses about the influences of particular factors on variation in the dependent variable. ${ }^{12}$

A second major body of work relevant to our central questions is the literature on impact evaluation and in particular the 'gold standard' of experimental research using randomized controlled trials (RCTs). Project and programme evaluations of various types have long been carried out, but this literature has increased dramatically since 2008. ${ }^{13}$ Systematic reviews of impact evaluations also help to consolidate findings from multiple studies. RCTs in particular have the potential to isolate the impact of development interventions from other potential influences, thus providing strong leverage on the questions of 'what has worked' and 'what could work' in development programming. Drawing on findings from RCTs, Karlan and Appel, for instance, identify 'seven ideas that work': 


\section{DEVELOPMENT ASSISTANCE FOR PEACEBUILDING}

microsavings; reminders to save; prepaid fertilizer sales; deworming; remedial education in small groups; chlorine dispensers for clean water; and commitment devices. ${ }^{14}$ Likewise, Banerjee and Duflo draw on experimental studies to identify a host of promising interventions in areas ranging from health and education to policing. ${ }^{15}$

This body of work also has several clear shortcomings. For one, in terms of peacebuilding, the existing evidence base from impact evaluations is underdeveloped in key areas. A recent 'evidence gap map' review of impact evaluations relevant to 25 categories across the five PSGs, for instance, found that there is little to no evidence on most categories and identifies only two (community-driven reconstruction and psycho-social programmes for victims) as having a large enough number of studies to be promising for evidence synthesis. ${ }^{16}$

While some such knowledge gaps might be remedied by prioritizing new research in understudied areas, the nature of experiments also imposes limits on what they can study. ${ }^{17}$ Randomized study of some interventions may be impractical or unethical. ${ }^{18}$ RCTs also need a large number of observations in order to gain precise estimates, meaning that they are best employed to study interventions that can be randomized at a relatively low level of aggregation such as the village, in a manner that cannot be done for some national reforms. Some interventions can be expected to show effects only over years, meaning that impact is not captured within the time-frame of most impact evaluations. Further, RCTs are difficult to implement well in any situation - and situations of conflict pose additional logistical and practical challenges.

Additionally, while RCTs can have strong internal validity, critics contend they may have weak external validity. ${ }^{19}$ In other words, they can provide strong evidence that a given intervention had a specific impact in a given context, but tend to offer much weaker leverage on assessing whether factors specific to that context were necessary for this measured impact. Thus, they are limited in their ability to speak to broader 'why' questions and in particular to assess whether and why the same intervention applied in a different context should have the same impact - that is, to issues of transferability and scalability.

A third body of work relevant to our central questions consists of aid success stories, many of which have been elaborated by bilateral and multilateral development organizations. Just a handful of examples include the US Agency for International Development's 'Success Stories'; the UK Department for International Development's 'Development Tracker'; the World Bank's Aid That Works (2007) and Yes Africa Can (2011); and the Overseas Development Institute's 'Development Progress' studies funded by the Gates Foundation. ${ }^{20}$

This body of work has played, for one, a useful role for donors in providing justification for development assistance at a time of contracting resources and strong criticism of aid. ${ }^{21}$ While many of these success stories fall more into the realm of advocacy than scientific research - and thus call for further examination - an emerging number suggest a movement towards more rigorous and independent discussion of success and best practices, including some specific attention to aid to fragile situations. 


\section{DEVELOPMENT ASSISTANCE FOR PEACEBUILDING}

The project presented in this special issue extends this third approach to focus on the lessons that can be learned from relatively detailed case studies of a set of generally well-regarded aid-supported initiatives in fragile situations. The approach is inspired in particular by Judith Tendler's Good Government in the Tropics which also explores what can be learned from a set of case studies of 'successful' reform efforts - in Tendler's case of four government sectors in the state of Ceará, Brazil. ${ }^{22}$ As Tendler sought to address gaps in a literature on development focused on poor government and failed public sector reform by analysing 'good government', this project seeks to speak to gaps in a literature on development assistance for peacebuilding drawn disproportionately from analysis of the causes of fragility and failed interventions, by analysing 'good aid'. In so doing, it provides new traction on some of the questions left unanswered in the rich bodies of work summarized above.

\section{This Collection}

The 'Good Aid' project began with a review of the literature, on the basis of which well-regarded aid-supported projects and programmes in fragile states were identified. As case studies were intended to contribute collectively to broader theorybuilding, cases were then chosen to include both a diversity of peacebuilding areas and geographic regions. Attention was also paid to research gaps in the sense that (with a few exceptions) priority was given to cases for which relatively little in-depth peer-reviewed analysis had already been published. Authors for each case study were then sought and invited on the basis of their knowledge of selected initiatives and ability to provide independent analysis complemented by their scholarly or policy expertise. ${ }^{23} \mathrm{~A}$ variety of disciplinary approaches, including political science, economics, law and education, are thus reflected in the case studies. A contributors' workshop provided an opportunity for discussion of the case studies and reflection on collective findings. ${ }^{24}$

In order to facilitate comparison across cases, contributors were asked to address several common issues in their analyses, in particular to evaluate outcomes critically and to analyse causal processes and drivers of success, including - but not necessarily limited to - the role of local context, aid modalities, local ownership, project/programme design and timing. Beyond these guidelines, contributors were free to develop their case studies as they saw fit. Some of the articles in this special issue thus focus more on impact, while others more on explanation. Most early versions of articles discussed explicitly each of the causal factors noted above, but by the final versions included here, discussion of some factors judged less significant was dropped. Case studies also draw on a range of methodological tools and data sources.

The first two case studies in this special issue focus on community-driven development (CDD), that is, programmes that involve 'community control and management of funds and emphasize community inputs into the planning and decision-making process'. ${ }^{25}$ Social funds may also be included under this broad category. CDD has received considerable attention by donors. As of 2012, the World Bank for instance supported approximately 400 CDD projects in 94 countries. $^{26}$ The first study by Andrew Beath, Fotini Christia and Ruben 


\section{DEVELOPMENT ASSISTANCE FOR PEACEBUILDING}

Enikolopov considers the National Solidarity Programme (NSP), Afghanistan's largest development programme. The NSP is among the best known CDD projects and has been widely cited as a positive example. ${ }^{27}$ Beath et al.'s analysis draws on the NSP Impact Evaluation (NSP-IE), which they led, an RCT including 500 villages across ten districts. The article presents detailed discussion of the NSP's impact - showing in particular positive effects on access to drinking water and electricity, acceptance of democratic processes, perceptions of economic well-being and participation of and attitudes towards women, and more limited effects on perceptions of local and national government performance and economic outcomes. It builds on highly detailed analysis of impact to consider causal processes and wider implications for aid.

The second case study, by Lamis Al-Iryani, Alain de Janvry and Elisabeth Sadoulet, focuses on the Yemen Social Fund for Development (SFD). Like the NSP, the SFD has been widely cited as a positive example of CDD in a fragile environment. ${ }^{28} \mathrm{~A}$ national programme, it operates through nine regional offices and by 2012 reached almost a quarter of Yemen's villages for instance. Drawing on review of multiple external assessments, internal documents and first-hand experience with the SFD over more than 16 years, the authors argue that four factors are particularly important to the SFD's achievements: stakeholder ownership and a demand-driven approach; trust stemming from political neutrality in the allocation of resources; flexibility; and the relevance of interventions for beneficiaries.

The next two case studies address initiatives to support the restoration of core government functions. As the Peacebuilding and Statebuilding Goals underscore, strengthening public financial management (PFM) is a key component of building more capable states. PFM has thus become a major area for donor engagement in fragile states, although recent analyses stress that more research is needed to assess the degree to which donor support to PFM systems in fact 'works'. ${ }^{29}$ This case study builds on an initiative by the World Bank to address the knowledge gap on PFM in post-conflict states, drawing on eight country case studies. ${ }^{30}$ Of these, Afghanistan, Kosovo, Sierra Leone and West Bank and Gaza were rated as having made 'substantial progress'. Heidi Tavakoli, Ismaila Ceesay and Winston Cole build on and extend this analysis in examining the Sierra Leone case. Their article highlights four factors in the country's relatively successful reforms: local ownership and support of reforms; a cadre of motivated and well-qualified local technical advisers; a relatively strong starting point in terms of PFM performance after the cease-fire; and considerable international assistance coordinated through budget support operations.

Support for core government functions, along with legitimate politics, is also the focus of Rauli S. Lepistö, Rachel M. Gisselquist and Jussi Ojala's analysis of Finn Church Aid's 2012 initiative to provide assistance in the form of a seconded staff member to the process of setting up the Federal Government of Somalia. A small-scale initiative, the FCA secondment is considered in the context of other aid-funded programmes to support external advisers within developing country government ministries. A number of such initiatives exist in post-conflict countries - the best known of which is probably the Scott Family Liberia 


\section{DEVELOPMENT ASSISTANCE FOR PEACEBUILDING}

Fellows Programme - and they are generally well regarded. However, very little research has been done to assess critically whether, why and how they ultimately support peacebuilding and statebuilding. The article argues that the secondment contributed in significant ways to the Somali transitional government's capacity to implement the transition roadmap, despite some major limitations. While the initiative benefited overall from a high degree of local ownership, the case study also illustrates some of the tensions faced by external actors in supporting such truly locally owned initiatives.

The subsequent two articles address interventions in the areas of rule of law, security and justice. Laura Bacon considers Liberia's post-conflict gender-sensitive police reforms. Liberia's policing and security sector reforms have been described as arguably among the more successful in sub-Saharan Africa, and Bacon's analysis complements a considerable literature by providing new discussion of issues relevant to women, peace and security. ${ }^{31}$ The article discusses the reform as a qualified success in terms of the Liberia National Police's two key goals, representation and responsiveness. It illustrates the positive impacts of timing, context, local ownership and foreign assistance, as well as the challenges due to low technical capacity and weak existing rule of law.

In the next study, a team of researchers led by Martin Gramatikov considers the Judicial Facilitators Programme in Nicaragua, which was first implemented in selected rural communities in 1998 as a pilot project of the Organization of American States. As Nicaragua is not currently a fragile state, it is worth remembering that it was then less than a decade out of its civil war, and the programme operated first in areas in which the judicial reach of the state was weakest. The programme has since been scaled up within the country and used as a model for pilots in other countries in the region, testament to its positive reputation. ${ }^{32}$ More broadly, community-based paralegal programmes are widely considered to be a promising way of supporting improved access to justice in developing countries. The 'Timap' programme in post-conflict Sierra Leone in particular is the subject of several analyses. ${ }^{33}$ Other examples can be found in Bangladesh, India, Malawi, the Philippines, South Africa and Zimbabwe. Focusing on the scaling up of the Judicial Facilitators Programme from rural to urban areas within Nicaragua, the article approaches evaluation of the community-based paralegal model from a new perspective, building on previous evaluations and drawing on original survey data and in-depth interviews. The data suggest that the expanded programme had some positive impacts on access to justice and levels of conflict, but that these were more modest than expected based on previous experience with the programme in rural areas. Discussion suggests for one that the different characteristics of urban versus rural communities may have influenced outcomes as the success of the programme has been due heavily, for instance, to communities' trust in facilitators.

The final two articles in this special issue focus on the delivery of basic services in the areas of education and health. Returning to the quintessential failed state of Somalia, ${ }^{34}$ James H. Williams and William C. Cummings consider UNICEF's generally well-regarded Education Programme, which operated from 1996 to $2010 .^{35}$ Although other international agencies also supported education in 


\section{DEVELOPMENT ASSISTANCE FOR PEACEBUILDING}

Somalia during this period, UNICEF took a leading role. As the article highlights, enrolment rates remain low, but they have improved from an even lower base. It finds that the programme's achievements can be attributed to a variety of factors, including attention to local context, community ownership and particular programme design elements. The article thus provides valuable discussion on how aid supported education, and through it peacebuilding, even in the most fragile of contexts.

The final article in this special issue, by Andrew Rosser and Sharna Bremner addresses the World Bank's health projects in Timor Leste - specifically, the Health Sector Rehabilitation and Development Project (HSRDP I) and the Second Health Sector Rehabilitation and Development Project (HSRDP II). The study builds on and extends Rosser's previous analysis of these projects for the World Bank's Aid That Works volume. ${ }^{36}$ By considering developments since this analysis was completed, it offers new assessment of why the projects had the outcomes they did and the relative importance of various factors. The article underscores in particular the role of political economy factors in shaping the relative success of these projects. More broadly, the authors argue, the case illustrates that aid effectiveness is 'a function not just of the technical quality of project design and the administrative competence of project managers but also the extent to which there is congruence between donor and local elites' agendas'. ${ }^{37}$

\section{What Works, Why and Implications for Transferability and Scalability}

\section{Evaluating Outcomes Using Diverse Methods}

The studies in this special issue illustrate the qualified and contingent nature of 'success' even in some of the most well-regarded initiatives. Some aspects of each initiative are clearly less successful than others, and some have positive results but arguably could have been more successful under other circumstances.

Precise indicators of 'success' differ across the cases, but in general the focus is on broader 'outcomes' relevant to peacebuilding objectives, rather than on 'outputs'. Beath et al.'s analysis of the NSP in Afghanistan, for instance, does not focus on how many grants were distributed but on a host of economic, political and social indicators of impact. Indeed, the NSP-IE collected information on 21 groups of indicators across five categories: access to utilities; economic welfare; governance; political attitudes; and social norms. Alternatively, Bacon's analysis of Liberian police reform highlights representation and responsiveness as ultimate goals and uses a variety of metrics to evaluate performance against these goals.

In assessing outcomes and impact, a key question concerns the appropriate baseline or counterfactual against which impact should be assessed. ${ }^{38}$ Several approaches are typical. For one, analyses may focus on the state of affairs within a country 'before' and 'after' project or programme implementation. As other factors that occurred in the interim may influence outcomes, analyses further seek to isolate the impact of the intervention from these other influences. 


\section{DEVELOPMENT ASSISTANCE FOR PEACEBUILDING}

Experimental and quasi-experimental methods, such as employed by Beath et al. and Gramatikov et al. in this special issue, can draw on sophisticated quantitative techniques to control for such factors.

Non-experimental and qualitative work may also rely on counterfactual reasoning and inference. ${ }^{39}$ Lepistö et al., for instance, consider whether the political transition in Somalia would have been the same absent Finn Church Aid's secondment. Their counterfactual is drawn largely on the basis of assessments by participants in the process, who reason that the transition process would still likely have proceeded without the secondment, but that it would have been less successful given that the Ministry of Constitutional Affairs and Reconciliation would have had lower capacity to pursue its core activities.

Another approach involves considering the impact of the intervention against that of other projects within the same country, which presumably are also subject to many of the same national influences. This approach is developed in Rosser and Bremner's analysis of the World Bank's health projects in Timor Leste. The impacts of these projects, they argue, rate comparatively well against the achievements of donor-supported educational projects in Timor Leste during the same period. As explored further below, this comparison also helps Rosser and Bremner to identify some of the unique contextual factors that supported more positive outcomes in health than in education.

In addition, outcomes may be assessed through comparative consideration of similar initiatives in other countries. As noted above, for instance, PFM reforms in Sierra Leone are identified as a relative success based on comparative study of PFM reforms in eight post-conflict countries. ${ }^{40}$ One challenge in using such cross-country comparisons is that countries in fact may not be comparable, in the sense that other factors - beyond the initiative itself - may explain why projects in some countries show better outcomes than in others. For this reason, combining cross-country evaluation with within-case comparison is a promising strategy.

A further approach to evaluating outcomes is process tracing. ${ }^{41}$ While this approach receives relatively little attention in most work on impact evaluation, it is a standard qualitative tool for social scientists in evaluating causal hypotheses. If we consider, for instance, the hypothesis that Liberia's gender-sensitive police reforms had an impact on representation and responsiveness, Bacon's tracing of the trial and error process through which Liberia's reforms evolved to achieve these goals better, provides a loose example of process tracing. While none of the case studies in this special issue explicitly employ this method, it is a tool that could be further developed in future research.

\section{Beyond Impact Evaluation: Considering Causal Processes and 'Drivers' of Success}

Assessment of development projects and programmes has in some circles become synonymous with impact evaluation. This special issue seeks to push beyond standard impact evaluation approaches towards greater focus on causal processes and 'drivers' of success. Impact evaluations and RCTs also address causal hypotheses, but their focus has been different. ${ }^{42}$ For one, they tend to focus on establishing a 


\section{DEVELOPMENT ASSISTANCE FOR PEACEBUILDING}

(causal) link between an intervention and various outcomes, but not on the intermediate steps and process through which the intervention leads to these outcomes. A focus on causal processes and drivers also suggests more disaggregation in the sense that it may take note of how particular aspects of a project or programme - rather than necessarily the project or programme as a whole - led to outcomes. RCTs may also do this, but it is arguably less common. (Beath et al.'s analysis of Afghanistan's NSP offers several such examples. For instance, it considers separately the impact of NSP-funded projects in different sectors, showing different impacts for projects in water and electricity versus irrigation and transportation. ${ }^{43}$ ) Analysis along these lines can provide new traction on policy by offering insight into whether specific changes or 'tweaks' to projects and programmes may improve outcomes.

Causal processes and drivers can be explored in multiple ways. One approach - adopted by the majority of studies in this special issue - is to consider in turn the role of key factors identified in the literature as important for aid success and to explore how each played out in a given case. An example of this is Williams and Cummings's discussion of the role of local context, aid modalities, local ownership and programme design elements. They both explore how each is manifested in UNICEF's education programme in Somalia and tie these factors to specific effects. They find, for instance, that local ownership took the form of community ownership as it was the local communities that largely assumed responsibility for managing schools when the central government collapsed. While this community ownership had some drawbacks, it was valuable in the sense that it supported considerable resilience for activities at the local level, regardless of the fragility of the central government.

An alternative approach is to present a more comprehensive theory or argument that identifies the most significant factors and how they interact to create outcomes, and then to test or demonstrate the plausibility of this argument through the case study. Rosser and Bremner, for instance, adopt this approach in their study of health interventions in Timor Leste, arguing that 'the HSRDPs benefitted from (a) a political economy context that was relatively conducive to aid effectiveness in general and (b) the fact that there was relatively little elite resistance to the World Bank's agenda in the health sector'. ${ }^{44}$ The key factors noted above are then implicitly considered within the context of this central argument.

A variety of causal factors and explanatory arguments are identified in the case studies. Building both on the literature and a collective reading of the case studies, three sets of factors emerge as especially relevant in understanding more broadly the outcomes of development assistance for peacebuilding in fragile environments.

The first concerns the area of intervention and whether it requires extensive or weak involvement and reform of domestic state institutions. ${ }^{45}$ This speaks to the inherent difficulty and likelihood of change in a particular domain. Fragile states,

by definition, have extremely weak state authority, capacity and legitimacy. ${ }^{46}$ Interventions that thus rely on the authority, capacity and legitimacy of the state to work - or that centre around strengthening of the state - thus face 


\section{DEVELOPMENT ASSISTANCE FOR PEACEBUILDING}

clear challenges. While all development interventions potentially involve the state, some might be structured to do so less than others. Discrete interventions to address specific health issues such as the international guinea worm eradication campaign, an aid-supported success, offer one example. ${ }^{47}$ In the cases explored in this special issue, several initiatives work in whole or in part through collaboration with non-governmental or sub-national partners, sometimes alongside national state agencies. Examples include community-driven development like Afghanistan's NSP and Yemen's SFD, and UNICEF's collaboration on education with local communities. The Judicial Facilitators Programme in Nicaragua is another example. Although run by the Organization of American States (OAS) and the Nicaraguan judiciary, it is designed in recognition of the fact that the judiciary does not adequately function throughout the country and relies on the use of community leaders as local proxies. The underlying logic here is broadly similar to Paul Collier's recommendation that one promising strategy for donors to have impact in fragile states is to work outside the state by supporting independent public service agencies. ${ }^{48}$

Likewise, it may be especially difficult to show progress from interventions in areas hinging on core functions of the state that are not easily privatized or handled by other actors, or in which reform of the state is the main objective. Examples from this special issue include support for political transition in Somalia (Lepistö et al.), policing and security sector reform in Liberia (Bacon) and reform of the public financial management (PFM) system in Sierra Leone (Tavakoli et al.). That said, even in these areas, the cases illustrate some room for manoeuvre. In Sierra Leone, for instance, Tavakoli et al. argue that one way in which civil service capacity limitations within government were addressed was through the use of a highly skilled 'parallel public service' responsible for high-level policy development, planning and implementation. Similarly, Lepistö et al. argue that the use of 'embedded' advisers within core government ministries can support greater functional state capacity.

That said, strengthening the authority, capacity and legitimacy of the fragile state is at the heart of statebuilding and thus ultimately core to peacebuilding. While circumventing the state may improve the chances that particular initiatives show results, development assistance for peacebuilding ultimately should support - or at the least not undermine - the building of a capable, legitimate and authoritative state. Indeed, for instance, as Beath et al. point out, Afghanistan's NSP was designed in part to extend the state's administrative reach. It also appears to have had effects on government legitimacy - and arguably by extension, state legitimacy - as data show a positive impact on perceptions of the favourability of government. This effect notably fades over time with the completion of NSP-funded projects, suggesting that impact on government legitimacy could be maximized through regularized and frequent project activity. Likewise, in Yemen, Al-Iryani et al. find that the SFD's broad, nationwide coverage and transparent, participatory processes contributed to the country's institutional development and statebuilding process.

A second set of factors falls broadly under the label 'local context', in particular windows of opportunity, capacity and the existence of local supporters or 


\section{DEVELOPMENT ASSISTANCE FOR PEACEBUILDING}

champions. This set of factors speaks broadly to the 'ripeness' of particular situations for intervention and reform. While donors for the most part cannot control these factors directly, they can take them into account in assessing whether to attempt a particular project in a given context and in adapting, as possible, to improve a project's viability. Major events such as the cessation of conflict or the election of new leaders can provide windows of opportunity to introduce institutional changes that might not otherwise be possible. ${ }^{49}$ Changes in one area may also facilitate changes in others. As Bacon discusses, for instance, post-conflict security sector reforms in Liberia, which involved deactivating police officers and inviting them to re-apply for the new service, were an opportunity to bring in new recruits and build a new policing culture.

Weak civil service capacity - and by extension weak state capacity - are also highlighted in the case studies as important to the ability of donors to work through and with state actors. To a large extent, this is a chicken and egg problem: the success of interventions in supporting better state institutions is affected by the underlying quality of public institutions themselves. As discussed above, fragile states as a group suffer from relatively weak capacity in comparison to non-fragile states, but some clearly have weaker capacity than others. Capacity for instance is likely to differ between a post-conflict state that was previously a functional state before hostilities began, and one which was not. ${ }^{50}$ Donors may also, over time, seek to influence change in capacity, for instance through training and capacity-building initiatives. However, such activities take time to show results.

The issue of local support and local champions is particularly interesting and closely connected to the growing recognition in development circles that politics and political economy should be more fully considered in aid policy. ${ }^{51}$ Indeed, it is telling that some form of country ownership - whether at the level of national government, sub-national government or non-state actors - can be seen in all of the cases explored in this special issue. The majority of the cases explored here are in fact described as largely national reform processes or initiatives that are supported by foreign assistance, rather than donor-initiated or donor-led efforts.

Rosser and Bremner's article on health interventions in Timor Leste is one exception. Their discussion underscores the differences that may exist between the priorities of donors and those of local actors, as well the fact that local actors may back donor-supported initiatives for strategic reasons. Indeed, reliance on foreign assistance can provide strong incentives for local cooperation. Nevertheless, as the literature suggests, local support or 'ownership' generally facilitates better results - perhaps even when it is tactical. In Timor Leste, Rosser and Bremner find that Fretilin and Falintil leaderships provided broad support to the World Bank's health projects, which greatly facilitated their relative success. The donor agenda on education, however, was less attractive for local leaderships to support as it was in conflict with their own nation-building efforts, which included use of Portuguese in schools - rather than Bahasa Indonesia or Tetun (an indigenous language), as favoured by some donors. This made for much weaker local support on education projects, which were also in turn relatively less successful. 


\section{DEVELOPMENT ASSISTANCE FOR PEACEBUILDING}

Further, while the literature underscores that donors should take politics into account, it also notes the risks of engaging in politics directly. This point is supported in particular in Al-Iryani et al.'s analysis of the SFD in Yemen, which identifies its political neutrality and impartial mechanisms for delivering resources as a key to stakeholders' trust and the SFD's performance.

Finally, while local contextual factors are often treated as fixed constraints, they can change - and indeed the objective of some aid-supported initiatives is precisely such change. This special issue presents several examples in the area of gender. Gender-sensitive policing reforms in Liberia, for one, were a clear effort to change traditional cultural norms and the male-domination of the security sector. Likewise in Afghanistan, the NSP's policy of mandating female participation was purposely contrary to recognized local customs.

A third set of factors relates to project and programme design and management. Thus, they are largely within the control of development administrators and are the most clearly transferrable and scalable elements of 'successful' projects and programmes. One of the truisms of recent discussions in development is that 'one-size-fits-all' policies do not work and that context must be taken into account in the design of aid interventions. That said, it is clear in examining aid projects and programmes that some models could be a decent starting point for interventions across multiple contexts. Several examples highlighted in this special issue include community-driven development, communitybased paralegal programmes and specific project components like the 'teachers/school kits' and 'pupil kits' employed in UNICEF's education programme in Somalia.

Another promising element of programme design and management identified in the cases relates to internal organizational mechanisms that allow for continued operations during periods of crisis. This point is highlighted in particular in Al-Iryani et al.'s discussion of how Yemen's SFD was able to continue its operations (including implementation of over 80 per cent of its projects) during Yemen's 2011 economic and political crisis. While some donors stopped funding during the crisis, Al-Iryani et al. find that the SFD's reliance on multiple sources of funding helped to make possible continued activities. In addition, in terms of implementation, continued operations were facilitated for instance by shifting interventions more towards cash-for-work and water projects implemented directly by beneficiaries using local materials, and with immediate impact on local livelihoods.

Broadly, design and management that is flexible enough to be responsive to local context, local priorities and an unstable environment is highlighted in many of the cases. This approach is similar to what Lant Pritchett, Michael Woolcock and Matt Andrews label 'Problem Driven Iterative Adaptation' (PDIA) and advocate for as a promising way to do development that can address key weaknesses in how development has been done. ${ }^{52}$ PDIA is based on four principles: (1) addressing locally identified problems; (2) creating an authorizing environment for experimentation; (3) supporting iterative and rapid experiential learning through tight feedback loops; and (4) engaging broad sets of local agents to promote viable, legitimate interventions. ${ }^{53}$ 


\section{DEVELOPMENT ASSISTANCE FOR PEACEBUILDING}

\section{External Validity, Transferability and Scalability}

The third set of factors identified above is largely transferrable and scalable, while the first two sets of factors are less so. In assessing whether a project or programme is likely to transfer successfully to another environment (or to be scaled up successfully), consideration of the first two sets of factors then is particularly important. Narrowly focused studies on the impact of specific projects do not provide this leverage as they cannot separate out the influence of local contextual factors, which may be necessary for initiatives to function as they do. Gramatikov et al.'s analysis of the scaling up of the Judicial Facilitators Programme in Nicaragua provides one illustration of how contextual factors - such as community-level trust - may provide a necessary condition for an initiative to function in one environment that may not be obvious until the programme is extended to other environments.

This then underscores the gaps in the literature on aid effectiveness left by a focus on impact evaluation using experimental methods, as discussed above. From a theoretical standpoint, external validity is important in theory-building and theory-testing. While an internally valid argument can tell us about a particular case, without some traction on external validity, we cannot use the particular case to speak to broader relationships and generalizable theories. From a more practical standpoint, if we do not know whether and how factors external to the intervention influenced results, we cannot say how the same intervention will function in a different environment. The approach adopted above moving beyond a narrow approach to impact evaluation to focus more on explanation and causal processes - thus is one way to begin to address such concerns.

We might gain even more traction by pushing such analysis to engage and build more directly on broader theoretical frameworks. ${ }^{54} \mathrm{~A}$ simple example is suggested by Gramatikov et al.'s discussion. In retrospect, if early assessment of the Judicial Facilitators Programme had identified social trust and the authority of community leaders as potential 'drivers' of the success of the programme, consideration of theories of social capital might have helped to refine expectations about the transferability and scalability of the programme. Relevant theoretical and empirical work generally suggests lower levels of social capital in urban versus rural areas; thus, to the extent that the success of the programme is due to strong social capital, we can predict weaker impact for the same programme implemented in other regions, such as urban areas, with weaker social capital. ${ }^{55}$ Further work along these lines remains one topic for future research.

\section{Conclusion and Extensions}

Among the core and continuing challenges for both scholars and practitioners of peacebuilding is the question of how positive change occurs, peace is built and fragile states become more resilient. As this article has argued, despite a large and rich literature, there are major gaps in existing work. New analysis of 'good aid' performance, as presented in this special issue, thus can be useful, both from 


\section{DEVELOPMENT ASSISTANCE FOR PEACEBUILDING}

a practical and theoretical perspective. In terms of how positive change occurs, the discussion above underscores both limits and potential for external actors to support peacebuilding. In particular, external actors have direct control over project and programme design and management, but only limited influence over local contextual factors as well as the area of particular inventions and how much they necessarily involve domestic state institutions. In these latter areas, local actors and institutions and endogenous processes play a more decisive role.

One key area for future research is to elaborate further and build theory on experience with reform efforts and processes. One way to proceed is to apply more widely and consider implications based on existing models of policy making (including consideration of how such models might be adjusted for fragile states). A simple application of John Kingdon's agenda-setting model provides one example. ${ }^{56}$

Kingdon's model posits three process streams - problems, proposals and politics. Windows of opportunity for policy change emerge when these three streams combine, and they may be predictable (such as due to a scheduled vote on legislation) or sudden. Such windows provide policy entrepreneurs with the opportunity to push forward their agendas and policy solutions. Within this model, development actors might be seen as one type of policy entrepreneur. They can also contribute to problem and proposals streams by bringing issues to the attention of policy-makers, advancing proposals, and creating incentives for policy-makers to identify issues as problems and to support donor proposals to address them. However, they generally do not act directly within the domestic politics stream. Likewise, domestic interest groups may play analogous roles. While they may have more limited resources and perhaps information than development actors with which to influence policymakers in the problem and proposals streams, they may act directly and have additional leverage within the politics stream.

Applying Kingdon's model in this way, it should not be surprising that the influence of development actors on reforms and policy outcomes in developing countries is indirect and sometimes quite limited. However, the same might also be said of local actors. Extending this application thus would seem to offer some potentially interesting points of discussion with recent scholarly literature on peacebuilding, which has tended to highlight the importance of local over external actors in explaining outcomes. This recent focus in turn might be understood as a response to an opposite emphasis in earlier literature and policy discussions.

As this special issue also suggests, reality is likely somewhere in the middle. The case studies offer eight analyses of instances in which development assistance, through interaction with local actors and processes, supported some positive peacebuilding change. Still, none are unambiguous successes and all underscore that development assistance provides no easy fix for peacebuilding.

\section{ACKNOWLEDGEMENTS}

This special issue was supported by UNU-WIDER, and in particular presents work developed under its Research and Communication on Foreign Aid (ReCom) programme (2011-13). 


\section{DEVELOPMENT ASSISTANCE FOR PEACEBUILDING}

We gratefully acknowledge specific programme contributions from the governments of Denmark (Ministry of Foreign Affairs, Danida) and Sweden (Swedish International Development Cooperation Agency - Sida) for ReCom, as well as core financial support to the UNU-WIDER work programme from the governments of Denmark, Finland, Sweden and the United Kingdom. Shohini Banerjee provided valuable research assistance. For helpful comments, a special thanks to Tony Addison, Neil Cooper, Philip Cunliffe, David Gisselquist, Omar McDoom, Finn Tarp and all project participants.

\section{NOTES}

1. Stephen Baranyi and Marie-Eve Desrosiers, 'Development Cooperation in Fragile States: Filling or Perpetuating Gaps?', Conflict, Security \& Development, Vol.12, No.5, 2012, pp.443-59; Keith Krause and Oliver Jütersonke, 'Peace, Security and Development in Post-Conflict Environments', Security Dialogue, Vol.36, No.4, 2005, pp.447-62; Peter Uvin, 'The Development/ Peacebuilding Nexus: A Typology and History of Changing Paradigms', Journal of Peacebuilding \& Development, Vol.1, No.1, 2002, pp.5-24; Pieter van Houten, 'The World Bank's (Post-) Conflict Agenda: The Challenge of Integrating Development and Security', Cambridge Review of International Affairs, Vol.20, No.4, 2007, pp.639-57; J. David Whaley, 'Improving UN Developmental Co-ordination within Peace Missions', International Peacekeeping, Vol.3, No.2, 1996, pp.107-22; World Bank, World Development Report: Conflict, Security, and Development, Washington, DC: World Bank, 2011.

2. OECD, Fragile States 2014: Domestic Revenue Mobilisation in Fragile States, Paris: OECD, 2014.

3. OECD, States of Fragility 2015: Meeting Post-2015 Ambitions, Paris: OECD, 2015.

4. It is worth noting the considerable debate in the literature over the concept of fragility. See, e.g., Lars Engberg-Pedersen, Louise Andersen and Finn Stepputat, 'Fragile Situations: Current Debates and Central Dilemmas', DIIS Report, Copenhagen: Danish Institute for International Studies (DIIS), 2008; Rachel M. Gisselquist, 'Varieties of Fragility: Implications for Aid', Third World Quarterly, Vol.36, No.7, forthcoming 2015, doi: 10.1080/01436597.2015.1041104; Sonja Grimm, Nicolas Lemay-Hébert and Olivier Nay, "Fragile States": Introducing a Political Concept', Third World Quarterly, Vol.35, No.2, 2014, pp.197-209.

5. Stephen D. Krasner and Thomas Risse, 'External Actors, State-Building, and Service Provision in Areas of Limited Statehood: Introduction', Governance, Vol.27, No.4, 2014, pp.545-67; Gearoid Millar, Jaïr van der Lijn and Willemijn Verkoren, 'Peacebuilding Plans and Local Reconfigurations: Frictions between Imported Processes and Indigenous Practices', International Peacekeeping, Vol.20, No.2, 2013, pp.137-43.

6. From 'The 10 Fragile States Principles' http://www.oecd.org/dacfragilestates/ (at: www.oecd.org/ dacfragilestates/).

7. A few examples include Robert H. Bates, When Things Fell Apart: State Failure in Late-Century Africa, Cambridge: Cambridge University Press, 2008; Jack A. Goldstone, 'Pathways to State Failure', Conflict Management and Peace Science, Vol.25, No.4, 2008, pp.285-96; National Academy of Public Administration, Why Foreign Aid to Haiti Failed, Washington, DC: National Academy of Public Administration, 2006; Robert I. Rotberg (ed.), State Failure and State Weakness in a Time of Terror, Washington, DC: Brookings Institution, 2003.

8. The OECD's 2012 report, 'Think Global, Act Global', for instance, draws on analysis of the causes of conflict and fragility to identify nine 'entry points' and 'global initiatives for action' to confront these factors.

9. See, e.g., Peter Uvin, Aiding Violence: The Development Enterprise in Rwanda, West Hartford, CT: Kumarian Press, 1998. 


\section{DEVELOPMENT ASSISTANCE FOR PEACEBUILDING}

10. See, e.g., Frances Stewart (ed.), Horizontal Inequalities and Conflict: Understanding Group Violence in Multiethnic Societies, Basingstoke, Hampshire: Palgrave Macmillan, 2008.

11. Rachel M. Gisselquist, 'Aid and Institution-Building in Fragile States: What Do We Know? What Can Comparative Analysis Add?', Annals of the American Academy of Political and Social Science, Vol.656, No.1, 2014, pp.6-21.

12. Barbara Geddes, 'How the Cases You Choose Affect the Answers You Get: Selection Bias in Comparative Politics', Political Analysis, Vol.2, No.1, 1990, pp.131-50; Gary King, Robert O. Keohane and Sidney Verba, Designing Social Inquiry: Scientific Inference in Qualitative Research, Princeton, NJ: Princeton University Press, 1994.

13. Drew B. Cameron, Anjini Mishra and Annette N. Brown, 'The Growth of Impact Evaluation for International Development: How Much Have We Learned?', Journal of Development Effectiveness, DOI: 10.1080/19439342.2015.1034156. Published online: 28 Apr. 2015.

14. Dean Karlan and Jacob Appel, More Than Good Intentions: Improving the Ways the World's Poor Borrow, Save, Farm, Learn, and Stay Healthy, New York: Plume, 2012.

15. Abhijit Banerjee and Esther Duflo, Poor Economics: A Radical Rethinking of the Way to Fight Global Poverty, New York: Public Affairs, 2012.

16. Drew B. Cameron, Annette N. Brown, Anjini Mishra, Mario Picon, Hisham Esper, Flor Calvo and Katia Peterson, 'Evidence for Peacebuilding: An Evidence Gap Map', Evidence Gap Map Report 1, New Delhi: International Initiative for Impact Evaluation (3ie), 2015.

17. See, e.g., Angus Deaton, 'Instruments, Randomization, and Learning about Development', Journal of Economic Literature, Vol.48, No.2, 2010, pp.424-55; Rachel M. Gisselquist and Miguel Niño-Zarazúa, 'What Can Experiments Tell Us about How to Improve Government Performance?', Journal of Globalization and Development, Vol.6, No.1, 2015, pp.1-45.

18. Macartan Humphreys, 'Reflections on the Ethics of Social Experimentation', Journal of Globalization and Development, Vol.6, No.1, 2015, pp.87-112.

19. See, e.g., Rajeev Dehejia, 'Experimental and Non-Experimental Methods in Development Economics: A Porous Dialectic', Journal of Globalization and Development, Vol.6, No.1, 2015, pp.47-69; Lant Pritchett and Justin Sandefur, 'Context Matters for Size: Why External Validity Claims and Development Practice Don't Mix', Working Paper 336, Washington, DC: Center for Global Development, 2013.

20. See www.usaid.gov/results-data/success-stories; http://devtracker.dfid.gov.uk/; www.odi.org/ programmes/development-progress; Punam Chuhan-Pole and Manka Angwafo, Yes Africa Can: Success Stories from a Dynamic Continent, Washington, DC: World Bank, 2011; James Manor (ed.), Aid That Works: Successful Development in Fragile States, Washington, DC: World Bank, 2007.

21. E.g. William Easterly, The White Man's Burden: Why the West's Efforts to Aid the Rest Have Done So Much Ill and So Little Good, New York: Penguin Press, 2006; Dambisa Moyo, Dead Aid: Why Aid Is Not Working and How There Is a Better Way for Africa, New York: Farrar, Straus and Giroux, 2009.

22. Judith Tendler, Good Government in the Tropics, Baltimore, MD: Johns Hopkins University Press, 1997.

23. Qualified contributors could not be found for several selected cases and these cases thus had to be dropped. The project included nine case studies.

24. The workshop was held 12-13 Dec. 2013.

25. Susan Wong, What Have Been the Impacts of World Bank Community-Driven Development Programs? CDD Impact Evaluation Review and Operational \& Research Implications, Washington, DC: World Bank, 2012, p.4.

26. Ibid.

27. See, e.g., Ashraf Ghani and Clare Lockhart, Fixing Failed States: A Framework for Rebuilding a Fractured World, Oxford and New York: Oxford University Press, 2008; John A. Nagl, Andrew M. Exum and Ahmed A. Humayun, A Pathway to Success in Afghanistan: The National Solidarity Program, Washington, DC: Center for a New American Strategy, 2009; Robert B. Zoellick, 'The Key to Rebuilding Afghanistan', Washington Post, 22 Aug. 2008 (at: http://www.washingtonpost.com/ wp-dyn/content/article/2008/08/21/AR2008082103110.html), last accessed 24 June 2015.

28. See, e.g., Lawrence Chandy and Johannes F. Linn, Taking Development Activities to Scale in Fragile and Low Capacity Environments, Washington, DC: The Brookings Institution, 2011; Marcus Cox and Nigel Thornton, Managing Results in Conflict-Affected and Fragile States: A Stock-Take of Lessons, Experience and Practice, London: DFID, 2010.

29. Paolo de Renzio, Matt Andrews and Zac Mills, 'Does Donor Support to Public Financial Management Reforms in Developing Countries Work? An Analytical Study of Quantitative CrossCountry Evidence', Working Paper, London: ODI, 2011. 


\section{DEVELOPMENT ASSISTANCE FOR PEACEBUILDING}

30. World Bank, 'Public Financial Management Reforms in Post-Conflict Countries: Synthesis Report', Washington, DC: World Bank, 2012.

31. See, e.g., Laura M. Bacon, Building an Inclusive, Responsive National Police Service: GenderSensitive Reform in Liberia, 2005-2011, Princeton, NJ: Innovations for Successful Societies, Princeton University, 2012; Otwin Marenin, 'Styles of Policing and Economic Development in African States', Public Administration and Development, Vol.34, No.3, 2014, pp.149-61; Karen Barnes Robinson and Craig Valters, Progress in Small Steps: Security Against the Odds in Liberia, London: Overseas Development Institute, 2015.

32. Margot Kokke and Pedro Vuskovic, 'Legal Empowerment of the Poor in Nicaragua: Microjustice avant-la-lettre?', Social Science Research Network, 2010. In 2011, it received an 'Innovating Justice' award (at: http://papers.ssrn.com/sol3/papers.cfm?abstract_id=1674020), last accessed 24 June 2015.

33. Pamela Dale, Delivering Justice to Sierra Leone's Poor: An Analysis of the Work of Timap for Justice, Washington, DC: World Bank, 2009; Vivek Maru, 'Between Law and Society: Paralegals and the Provision of Justice Services in Sierra Leone and Worldwide', Yale Journal of International Law, Vol.31, No.2, 2006, pp.427-75.

34. Ken Menkhaus, 'State Failure, State-Building, and Prospects for a "Functional Failed State" in Somalia', The ANNALS of the American Academy of Political and Social Science, Vol.656, No.1, 2014, pp.154-72.

35. See, e.g., Chris Berry, 'A Framework for Assessing the Effectiveness of the Delivery of Education Aid in Fragile States', Journal of Education for International Development, Vol.4, No.1, 2009 (at: http://www.equip123.net/jeid/articles/8/Berry-FrameworkAssessingtheEffectivenessDeliveryEducat ionAidFragileStates.pdf), last accessed 24 June 2015; Lawrence Chandy and Johannes F. Linn, Taking Development Activities to Scale in Fragile and Low Capacity Environments, Washington, DC: The Brookings Institution, 2011.

36. James Manor (ed.), Aid That Works: Successful Development in Fragile States, Washington, DC: World Bank, 2007.

37. Andrew Rosser and Sharna Bremner, 'The World Bank's Health Projects in Timor-Leste: The Political Economy of Effective Aid', International Peacekeeping, Vol.22, No.4, 2015, pp.435-51. doi: 10.1080/13533312.2015.1059731

38. Howard White, 'A Contribution to Current Debates in Impact Evaluation', Evaluation, Vol.16, No.2, 2010, pp.153-64.

39. Philip E. Tetlock and Aaron Belkin (eds), Counterfactual Thought Experiments in World Politics: Logical, Methodology, and Psychological Perspectives, Princeton, NJ: Princeton University Press, 1996.

40. World Bank (see n.30 above).

41. David Collier, 'Understanding Process Tracing', PS: Political Science \& Politics, Vol.44, No.4, 2011, pp.823-30.

42. Note also that some argue that impact evaluation has moved towards greater focus on explanation. See, e.g., Elliot Stern, 'Impact Evaluation: A Guide for Commissioners and Managers', Report prepared for the Big Lottery Fund, Bond, Comic Relief and the Department for International Development, London: Bond, 2015.

43. Some impact evaluations are indeed designed to explore the impact of particular project components as well. See, e.g., Abhijit Banerjee, Esther Duflo, Daniel Keniston and Nina Singh, 'Making Police Reform Real: The Rajasthan Experiment', Cambridge, MA: Massachusetts Institute of Technology, n.d.

44. Andrew Rosser and Sharna Bremner (see n.37 above).

45. A related issue concerns how sector characteristics may influence service delivery. Claire Mcloughlin and Richard Batley, 'The Effects of Sector Characteristics on Accountability Relationships in Service Delivery', Working Paper 350, London: Overseas Development Institute, 2012. See also Marco Schäferhoff, 'External Actors and the Provision of Public Health Services in Somalia', Governance, Vol.27, No.4, 2014, pp.675-95.

46. See, e.g., David Carment, Stewart Prest and Yiagadeesen Samy, Security, Development, and the Fragile State: Bridging the Gap between Theory and Policy, London: Routledge, 2010; Jörn Grävingholt, Sebastian Ziaja and Merle Kreibaum, 'Disaggregating State Fragility: A Method to Establish a Multidimensional Empirical Typology', Third World Quarterly, Vol.36, No.7, forthcoming 2015.

47. Sandy Cairncross, Ralph Muller and Nevio Zagaria, 'Dracunculiasis (Guinea Worm Disease) and the Eradication Initiative', Clinical Microbiology Reviews, Vol.15, No.2, 2002, pp.223-46; Frank O. Richards, Ernesto Ruiz-Tiben and Donald R. Hopkins, 'Dracunculiasis Eradication 


\section{DEVELOPMENT ASSISTANCE FOR PEACEBUILDING}

and the Legacy of the Smallpox Campaign: What's New and Innovative? What's Old and Principled?', Vaccine, Vol.29, Suppl.4, 2011, pp.D86-D90.

48. Paul Collier, 'How to Spend It: The Organization of Public Spending and Aid Effectiveness', WIDER Working Paper, Helsinki: UNU-WIDER, 2012.

49. See, e.g., Maria Koinova, Ethnonationalist Conflict in Postcommunist States: Varieties of Governance in Bulgaria, Macedonia, and Kosovo, Philadelphia, PA: University of Pennsylvania Press, 2013; Richard J. Samuels, Machiavelli's Children: Leaders and Their Legacies in Italy and Japan, Ithaca, NY: Cornell University Press, 2003.

50. Gisselquist (see n.4 above).

51. See David Booth, 'Aid Effectiveness: Bringing Country Ownership (and Politics) Back In', Conflict, Security \& Development, Vol.12, No.5, 2012, pp.537-58.

52. Lant Pritchett, Michael Woolcock and Matt Andrews, 'Looking Like a State: Techniques of Persistent Failure in State Capability for Implementation', Journal of Development Studies, Vol.49, No.1, 2013, pp.1-18.

53. Matt Andrews, Lant Pritchett and Michael Woolcock, 'Escaping Capability Traps through Problem Driven Iterative Adaptation (PDIA)', World Development, Vol.51, 2013, pp.234-44.

54. This approach is also a way to improve external validity in experimental work. Fernando Martel Garcia and Leonard Wantchekon, 'Theory, External Validity, and Experimental Inference: Some Conjectures', The ANNALS of the American Academy of Political and Social Science, Vol.628, 2010, pp.132-47.

55. Jens F.L. Sørensen, 'Rural-Urban Differences in Bonding and Bridging Social Capital', Regional Studies, DOI: 10.1080/00343404.2014.918945. Published online: 1 Jul. 2014.

56. John W. Kingdon, Agendas, Alternatives, and Public Policies, New York: HarperCollins, 1995. 


\title{
The National Solidarity Programme: Assessing the Effects of Community-Driven Development in Afghanistan
}

\author{
ANDREW BEATH, FOTINI CHRISTIA and \\ RUBEN ENIKOLOPOV
}

\begin{abstract}
Over the past two decades, community-based approaches to project delivery have become a popular means for governments and development agencies to improve the alignment of projects with the needs of rural communities and to increase the participation of villagers in project design and implementation. This article briefly summarizes the results of an impact evaluation of the National Solidarity Programme (NSP), a community-driven development programme in Afghanistan that created democratically-elected community development councils and funded small-scale development projects. Using a randomized controlled trial across 500 villages, the evaluation finds that NSP had a positive effect on access to drinking water and electricity, acceptance of democratic processes, perceptions of economic well-being and attitudes towards women. Effects on perceptions of local and national government performance and material economic outcomes were, however, more limited or short-lived.
\end{abstract}

\section{Introduction}

Since the mid-1980s, community-based approaches to project delivery have become increasingly popular with governments and development agencies. ${ }^{1}$ Such approaches - termed Community-Driven Development (CDD) - grew out of the perceived lack of responsiveness of 'top-down' programmatic modalities to local needs. ${ }^{2}$ Spurred by academic studies that affirmed the ability of communities to solve collective action problems, ${ }^{3} \mathrm{CDD}$ programmes sought to emphasize participatory planning modalities by which community members identify projects that address their specific priorities. ${ }^{4}$ Such processes, it is often hypothesized, may not just provide for better-targeted and more efficient projects, but also can increase participation in local institutions and, with it, build social capital. ${ }^{5}$

Of the myriad CDD initiatives throughout the developing world, few have garnered as much attention as the National Solidarity Programme (NSP), Afghanistan's largest development programme. Conceived soon after the fall of the Taliban regime, NSP was designed to extend the administrative reach of the state, build representative institutions for local governance and deliver critical services to the rural population. In villages covered by the programme, NSP has created gender-balanced Community Development Councils (CDC)

This is an Open Access article distributed under the terms of the Creative Commons Attribution-NonCommercial-NoDerivatives License (http://creativecommons.org/Licenses/by-nc-nd/4.0/), which permits noncommercial re-use, distribution, and reproduction in any medium, provided the original work is properly cited, and is not altered, transformed, or built upon in any way. 


\section{DEVELOPMENT ASSISTANCE FOR PEACEBUILDING}

through a secret-ballot, universal suffrage elections. Once constituted, CDCs have drafted community-development plans and developed proposals for village-level development projects that, subject to basic criteria being met, have been funded by NSP through the disbursement of block grants.

Following the implementation of the first phase of NSP from 2003 to 2007, international donors and the Government of the Islamic Republic of Afghanistan requested that the impacts of the programme be rigorously evaluated by independent researchers, resulting in the NSP Impact Evaluation (NSP-IE). In the initial stages of the design of the NSP-IE, a financial constraint arose that limited the number of villages in each district that could be covered by the programme between 2007 and 2011. This financial constraint, in conjunction with demands from stakeholders for a rigorous impact evaluation, informed a joint decision by NSP, stakeholders and the NSP-IE research team to randomize the roll-out of NSP across 500 villages in 10 districts spanning northern, eastern, central and western Afghanistan, with 250 'treatment' villages receiving NSP in 2007 and 250 'control' villages not receiving NSP until 2012. NSP-IE midline estimates were provided by a comparison of economic, political and social indicators in treatment and control villages in 2009 , with endline estimates provided by a comparison of the same indicators in 2011.

The collective NSP-IE findings provide some instructive lessons for development interventions in fragile contexts. That NSP provides a fleeting impetus to perceptions of central and sub-national government indicates that government legitimacy is contingent on the continued delivery of services rather than improved development outcomes per se. The durable positive effects of NSP on acceptance of democratic norms and female participation further suggest that the mandating of such practices by development programmes can spur social change. However, the relative ineffectiveness of CDCs in changing de facto village leadership structures and the negative impact on perceived local governance quality indicates that the creation of new institutions in parallel to customary structures may not have the desired effect, particularly in cases in which the roles of new institutions are not well defined.

The NSP-IE falls within a class of four rigorous evaluations of CDD programmes conducted across fragile contexts in the late 2000s. ${ }^{6}$ King and Samii synthesize the findings of these studies, concluding that attempts by CDD programmes to build local institutions in conflict-affected areas have generally been unsuccessful in generating durable and transferable increases in collective action. $^{7}$ They note that the low intensity of these interventions, coupled with mismatches between evaluation and programmatic time-frames, may explain part of the underperformance. On the basis of a similar review, Bennett and D'Onofrio, attribute the mixed evidence of CDD programmes in conflict-affected contexts to the lack of a coherent and explicit theory of change. ${ }^{8}$ It should be noted that NSP has expressed the view that some of the findings, interpretations, and conclusions expressed in this summary - and particularly those pertaining to the impacts of the programme on the quality of local governance and of the impacts of infrastructure projects - do not reflect its observations and are accordingly disputed. 


\section{DEVELOPMENT ASSISTANCE FOR PEACEBUILDING}

The remainder of this article is organized as follows: section two describes the history and characteristics of NSP; section three examines the development context in Afghanistan; section four reviews the NSP-IE methodology and data sources; section five summarizes the effects of NSP on economic, institutional and social outcomes; section six discusses the implications of the findings for development projects in Afghanistan and other fragile environments; and section seven concludes.

\section{Programmatic Context}

NSP is executed by the Ministry of Rural Rehabilitation and Development, funded by the World Bank and a consortium of bilateral donors, and facilitated by 8 national and 21 international NGOs. Programme implementation is structured around two major interventions at the village level: ${ }^{9}$

- The election of a gender-balanced CDC through a secret-ballot, universal suffrage election centred on democratic processes and women's participation. ${ }^{10}$

- The provision of 'block grants' - valued at US $\$ 200$ per household, up to a village maximum of US\$60,000 and averaging US\$33,000 - to fund villagelevel projects designed and selected by CDCs in consultation with villagers. ${ }^{11}$
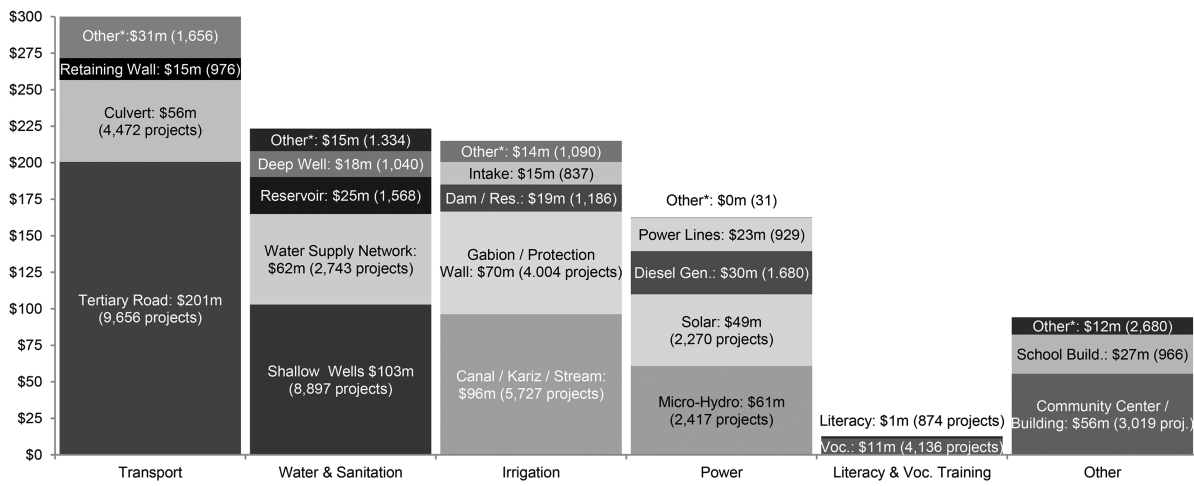

Note: Data obtained from NSP sub-project monitoring database and covers 64,188 phase I, II and III projects initiated in 29,705 communities between 12 July 2003 and 9 January 2013. 'Other' transport projects include pathways (US\$10m, 643 projects); bridges (US\$7m, 297); and secondary roads (US\$6m, 303). 'Other' water and sanitation projects include latrines (US\$5m, 566); public baths (US\$5m, 306); and hand pumps (US\$4m, 328). 'Other' irrigation projects include water divider construction (US\$5m, 421); pipe schemes (US\$3m, 205); and aqueducts (US\$3 m, 265). 'Other' other projects include livelihoods projects (US\$9 m, 2,549) and health facilities (US\$2 $\mathrm{m}, 122$ ).

Source: A. Beath, F. Christia and R. Enikolopov, 2013. Randomized Impact Evaluation of Afghanistan's National Solidarity Programme-Final Report. World Bank Report No. 81107, Washington, DC: World Bank, 2013 (at: http:// documents.worldbank.org/curated/en/2013/07/18273450/randomized-impact-evaluation-afghanistans-nationalsolidarity-programme). 


\section{DEVELOPMENT ASSISTANCE FOR PEACEBUILDING}

Projects financed by NSP generally fall into one of six categories: transport; water and sanitation; irrigation; power; literacy and vocational training; and other (Figure 1). Between mid-2003 and early 2013, over 64,000 projects were funded by NSP, at a combined cost of US $\$ 1.01$ billion. ${ }^{12}$

In each village, NSP implementation takes approximately three years. The process of facilitating CDC elections usually takes about 6 months, after which an average of 12 months elapse before project implementation starts. During this period, CDCs design projects in conjunction with villagers, submit proposals, receive funds and, if necessary, procure contractors. Project construction lasts an average of nine months.

Once implementation of NSP in a village concludes, villages have no assurance of when - or if - they will receive further NSP activities, either in the form of facilitated CDC elections or block grants. However, in the current third phase of the programme, NSP is extending repeater block grants to around 12,000 villages mobilized in the programme's first phase between 2003 and 2007. ${ }^{13}$

\section{Country Context}

Afghanistan's population is overwhelmingly rural, with 80 per cent of the population living outside the country's regional and provincial centres. ${ }^{14}$ Generally, those living in rural areas suffer from tenuous agriculture-based livelihoods and limited access to basic amenities, such as clean drinking water, reliable irrigation and electricity. During the past ten years, various donor-funded interventions have attempted to enhance food security, improve economic opportunities and provide access to basic infrastructure. However, the incidence of poverty in rural areas remains very high, with Afghanistan ranking among the bottom 15 countries in UNDP's Human Development Index.

Due to conflict and a lack of state consolidation, Afghanistan's central government has historically been weak, with limited capacity for service provision. In response, rural communities throughout the country have developed informal yet sophisticated customary local governance structures. The foundation of these structures is the local jirga or shura, a participatory council that has traditionally managed local public goods and adjudicated disputes. ${ }^{15}$ Members of such councils are generally the elder males of families in the village. ${ }^{16}$ Villages also ordinarily have a headman (termed a malik, arbab or qariyadar) - usually a large landowner - who liaises with district, provincial and central authorities. ${ }^{17}$ The local religious authority, the mullah, is responsible for conducting rites and services and mediating disputes involving family or moral issues. ${ }^{18}$

In rural Afghanistan, women are generally barred from activities outside the

household. Such norms render local governance a male-dominated activity. ${ }^{19}$ Female mobility is also constrained by customs that require a woman travelling outside her village to have a male relative as an escort. As a result of these norms, girls are usually prevented from attending school beyond fourth grade and, without education or mobility, are constrained in their ability to generate income. 


\section{DEVELOPMENT ASSISTANCE FOR PEACEBUILDING}

\section{Methodology and Data Sources}

The NSP-IE represents a randomized controlled trial (RCT) of the second phase of NSP. In mid-2007, 500 villages eligible for the programme were selected jointly by the NSP-IE research team, NSP and facilitating partners. The 500 villages are equally spread across 10 districts in Balkh, Baghlan, Daykundi, Ghor, Herat and Nangarhar provinces. ${ }^{20}$ The ten districts depict Afghanistan's ethno-linguistic diversity, with five predominantly Tajik districts, four predominantly Pashtun districts and one predominantly Hazara district. However, due to ongoing violent conflict, villages from the southern provinces, such as Kandahar and Helmand, were not able to be included in the sample.

Using a matched-pair cluster randomization procedure, 250 of the 500 villages were randomly selected to receive NSP in 2007 and comprise the treatment group for the study, with the remaining villages assigned to the control group. ${ }^{21}$ The matched-pair cluster randomization facilitates a transparent and unbiased estimation of programme impacts by ensuring that the background characteristics of the treatment group are, on average, identical to the control group. ${ }^{22}$ Accordingly, any differences that arise between the two groups of villages are attributable to NSP.

Baseline, midline and endline surveys were administered to a random sample of village households, as well as to male and female focus groups of village leaders, between August 2007 and October 2011..$^{23}$ Collectively, the surveys comprised over 25,000 household interviews with male and female villagers, as well as more than 2,600 focus groups with male village leaders and women. The midline survey is used to estimate impacts of NSP two years after the start of NSP implementation and after all treatment villages had elected CDCs and selected projects, but prior to the completion of 82 per cent of NSP-funded projects. ${ }^{24}$ The endline survey is used to estimate impacts four years after implementation and after 99 per cent of NSP-funded projects had been completed, but prior to the implementation of NSP in control villages.

The hypotheses to be tested by the NSP-IE, constituent indicators and the survey questions and specifications used to form indicators were formalized in a pre-analysis plan. The pre-analysis plan was completed prior to the receipt of endline survey data and registered with the Experiments in Governance and Politics (EGAP) network. ${ }^{25}$ The pre-analysis plan groups hypotheses and indicators into five broad categories of outcomes of interest: (1) access to services, infrastructure and utilities; (2) economic welfare; (3) local governance; (4) political attitudes and state-building; and (5) social norms. ${ }^{26}$ The hypotheses were not formulated to judge the effectiveness of NSP in meeting pre-identified program objectives, but rather to more broadly explore the reaches of program impact. As such, the hypotheses include both formal 'project development objectives' for which the project should be held accountable as well outcomes of general interest identified by the research team. ${ }^{27}$

\section{Results $^{28}$}

This section presents estimates of the midline and endline impacts across the five categories listed above. 


\section{DEVELOPMENT ASSISTANCE FOR PEACEBUILDING}

\section{Access to Utilities, Services and Infrastructure}

NSP improves the access of villagers to basic utilities. NSP-funded drinking water projects increase access to clean drinking water, with the programme increasing usage of protected sources by 15 per cent at endline. NSP also reduces the time that households spend collecting water by 5 per cent, although the programme has no lasting impact on perceived water quality or on the incidence of water shortages. NSP substantially boosts electricity usage, which rises by 26 per cent. The size of these effects is substantially higher when the impacts of NSP-funded water and electricity projects are examined specifically, rather than the impact of NSP generally.

NSP also increases access to services, including education, health care and counselling services for women. As NSP does not usually fund such services, these impacts appear to arise indirectly from other changes induced by NSP. While there is no impact on boys' school attendance, NSP increases girls' school attendance and their quality of learning. NSP further increases child doctor and prenatal visits and the probability that a woman's illness or injury is attended to by a medical professional, although it does not affect other health outcomes. Finally, NSP more than doubles the proportion of women who have a group or person with whom they can discuss their problems.

NSP-funded infrastructure projects in irrigation and transportation, however, appear to be less successful. Specifically, irrigation projects have no impact on the ability of land-holding villagers to access sufficient irrigation. Although there is weak evidence that transportation projects increase village accessibility at midline, the impact does not persist and there is no evidence of impacts on the costs and times of traveling from the village to the district center or on the mobility of male villagers.

There is weak evidence to indicate that, once complete, NSP-funded projects fulfil the development needs of male villagers, as measured by relative changes in the types of projects that are identified as being most needed by the village. NSP appears to specifically fulfil demands for drinking water projects, which were identified as necessary by a higher proportion of male villagers than any other projects at baseline. The impacts of NSP on aggregate categories of indicators on access to utilities, services and infrastructure are presented in Table 1.

\section{Economic Welfare}

NSP impacts the economic perceptions and optimism of villagers, particularly women. Female villagers exhibit improved perceptions of the current economic situation and are more optimistic about future changes in the local economy, both at midline and endline. The economic perceptions and optimism of male villagers improve at midline, but there is only weak evidence of an impact at endline on optimism and no evidence of a longer-term impact on perceptions.

Despite the changes in economic perceptions, there are few impacts of NSP on objective economic outcomes. At midline, there is weak evidence that NSP induces small increases in the diversity of household income sources and in caloric intake, although both impacts do not persist after project completion. 
TABLE 1

AGGREGATE IMPACT OF NSP ON ACCESS TO UTILITIES, SERVICES AND INFRASTRUCTURE

\begin{tabular}{lccccc}
\hline & \multicolumn{2}{c}{ Midline } & & \multicolumn{2}{c}{ Endline } \\
\cline { 2 - 3 } & coefficient & p-value & & coefficient & $p$-value \\
\hline Access to utilities & 0.058 & 0.018 & & 0.071 & 0.006 \\
Access to clean drinking water & 0.060 & 0.023 & & 0.064 & 0.028 \\
Access to electricity & 0.051 & 0.300 & & 0.108 & 0.045 \\
Access to services & 0.022 & 0.065 & & 0.055 & 0.000 \\
Access to female counselling & 0.219 & 0.000 & & 0.192 & 0.001 \\
Access to education & - & - & & 0.058 & 0.035 \\
Health outcomes/access to health services & 0.040 & 0.597 & & 0.009 & 0.013 \\
Access to infrastructure & 0.023 & 0.209 & & 0.005 & 0.872 \\
Access to irrigation & - & - & & 0.015 & 0.696 \\
Village accessibility and villager mobility & 0.202 & 0.174 & & 0.026 & 0.669 \\
\hline
\end{tabular}

Note: Coefficients and $p$-values for the mean average treatment effect for all indicators grouped in the hypothesis or in hypotheses that pertain to the particular group or family.

Source: A. Beath, F. Christia and R. Enikolopov, 2013. Randomized Impact Evaluation of Afghanistan's National Solidarity Programme-Final Report. World Bank Report No. 81107, Washington, DC: World Bank, 2013 (at: http://documents.worldbank.org/curated/en/2013/07/18273450/randomized-impactevaluation-afghanistans-national-solidarity-pro gramme).

At endline, there is weak evidence of impact on the amount borrowed by households. NSP appears to have no robust impacts at midline or endline on income levels, income regularity, consumption levels, consumption allocations, assets or food insecurity.

There is also no evidence that NSP impacts general production and marketing outcomes. NSP has no discernible impacts on agricultural yields, productivity or the proportion of harvests sold, although the programme induces a fleeting increase at midline in agricultural sales revenue. NSP also does not affect whether households sell animals or animal products or the revenue derived from such activities. While NSP increases handicraft sales and sales revenue at midline, these impacts disappear following project completion.

At endline and midline, there is evidence that NSP reduces the net migration of households from villages, although both results lose statistical significance if migration patterns at baseline are controlled for. In addition, there is no evidence at endline that NSP induces any changes in net within-household migration.

The limited impact of NSP on economic welfare is potentially explained by the apparent ineffectiveness of infrastructure projects in inducing changes in agricultural productivity and access to markets and by the fact that more successful types of projects (such as water and electricity) are not designed to induce changes in local economic activity in the near-term. However, the sustained positive impact on female economic perceptions demonstrates the broader improvements brought to women's lives by female participation in CDC activities and by NSPfunded drinking water projects.

The impacts of NSP on aggregate economic welfare indicators are presented in Table 2. 
TABLE 2

AGGREGATE IMPACT OF NSP ON ECONOMIC WELFARE

\begin{tabular}{|c|c|c|c|c|}
\hline & \multicolumn{2}{|c|}{ Midline } & \multicolumn{2}{|c|}{ Endline } \\
\hline & coefficient & $p$-value & coefficient & $p$-value \\
\hline Perceptions & 0.118 & 0.000 & 0.080 & 0.001 \\
\hline Stocks and flows & 0.021 & 0.048 & 0.016 & 0.204 \\
\hline Security of household income & 0.049 & 0.059 & 0.023 & 0.355 \\
\hline Household consumption expenditure & 0.007 & 0.796 & -0.008 & 0.781 \\
\hline Household assets & 0.013 & 0.553 & 0.020 & 0.428 \\
\hline Borrowing for food and medical needs & 0.009 & 0.721 & 0.056 & 0.168 \\
\hline Food security & 0.016 & 0.282 & -0.004 & 0.831 \\
\hline Production and marketing & 0.026 & 0.669 & 0.202 & 0.174 \\
\hline Agricultural productivity & 0.034 & 0.773 & 0.411 & 0.163 \\
\hline Non-agricultural productivity & 0.018 & 0.358 & -0.007 & 0.843 \\
\hline Migration & 0.090 & 0.009 & 0.061 & 0.116 \\
\hline Net migration of households & 0.187 & 0.026 & 0.164 & 0.080 \\
\hline Net migration of household members & - & - & -0.036 & 0.161 \\
\hline
\end{tabular}

Note: Coefficients and $p$-values for the mean average treatment effect for all indicators grouped in the hypothesis or in hypotheses that pertain to the particular group or family.

Source: A. Beath, F. Christia and R. Enikolopov, 2013. Randomized Impact Evaluation of Afghanistan's National Solidarity Programme-Final Report. World Bank Report No. 81107, Washington, DC: World Bank, 2013 (at: http://documents.worldbank.org/curated/en/2013/07/18273450/randomized-impactevaluation-afghanistans-national-solidarity-pro gramme).

\section{Local Governance}

The creation of CDCs by NSP more than doubles the proportion of local assemblies that contain at least one female member. CDC creation also causes customary leaders to affiliate with representative assemblies during project implementation, although this effect is not sustained beyond project completion. There is no evidence that NSP changes the composition of local leadership or introduces new leaders into the core group of village decision-makers.

At midline, the creation of CDCs by NSP increases the provision of local governance services, the activity level of customary authorities and the role of representative assemblies in providing local governance services. These impacts generally do not persist following the completion of NSP activities in treatment villages, although NSP does result in a durable increase in the number of meetings held annually by representative assemblies. There is also strong evidence that NSP induces a durable increase in the provision of local governance services specific to women.

NSP increases villager participation in local governance at midline, as measured by meeting attendance and a desire to change leader decisions, and increases the proportion of villagers that prefer representative assemblies to be involved in local governance. However, while the desire to change leader decisions persists beyond project completion, NSP has neither a durable impact on the probability of villagers attending assembly meetings nor on the extent to which they believe assemblies should be involved in local governance. 
TABLE 3

AGGREGATE IMPACT OF NSP ON LOCAL GOVERNANCE

\begin{tabular}{lcccccc}
\hline & \multicolumn{2}{c}{ Midline } & & \multicolumn{2}{c}{ Endline } \\
\cline { 2 - 3 } & coefficient & $p$-value & & coefficient & $p$-value \\
\hline Structure & 0.226 & 0.000 & & 0.135 & 0.000 \\
Composition of village leadership & 0.001 & 0.977 & & 0.009 & 0.769 \\
Affiliation of leadership with representative assemblies & 0.172 & 0.000 & & 0.043 & 0.193 \\
Female representation in local governance & 1.261 & 0.000 & & 0.894 & 0.000 \\
Function & 0.074 & 0.000 & & 0.038 & 0.014 \\
Provision of local governance services & 0.030 & 0.054 & & 0.009 & 0.636 \\
Activity of village leadership \& institutions & 0.112 & 0.000 & & 0.067 & 0.013 \\
Role of representative assemblies & 0.061 & 0.002 & & 0.022 & 0.376 \\
Quality and participation & 0.033 & 0.004 & & -0.016 & 0.245 \\
Participation in local governance & 0.096 & 0.000 & & 0.082 & 0.001 \\
Perceptions of quality of local governance & 0.012 & 0.430 & & -0.073 & 0.002 \\
Informal taxation by village leaders & - & - & & -0.037 & 0.426 \\
Preferences for representative assemblies & 0.045 & 0.029 & & 0.031 & 0.149 \\
\hline
\end{tabular}

Note: Coefficients and $p$-values for the mean average treatment effect for all indicators grouped in the hypothesis or in hypotheses that pertain to the particular group or family.

Source: A. Beath, F. Christia and R. Enikolopov, 2013. Randomized Impact Evaluation of Afghanistan's National Solidarity Programme-Final Report. World Bank Report No. 81107, Washington, DC: World Bank, 2013 (at: http://documents.worldbank.org/curated/en/2013/07/18273450/randomized-impactevaluation-afghanistans-national-solidarity-pro gramme).

At endline, NSP has a negative impact on local governance quality as perceived by male villagers, reducing satisfaction with the work of local leaders by 8 per cent and almost doubling dissatisfaction with the recent decisions or actions of village leaders. While NSP induces an increase at midline in the extent to which village leaders are perceived as being responsive to the needs of women, this effect does not persist.

The impacts of NSP on aggregate local governance indicators are presented in Table 3.

\section{Political Attitudes and State-Building}

The evidence of NSP's impact on democratic values is mixed. There is strong evidence that NSP increased voting in the 2010 parliamentary elections, with the proportion of male and female villagers who claimed to have cast a ballot being 4 and 10 per cent higher, respectively, in treatment villages. NSP also appears to raise appreciation of democratic elections, at least as manifested by a 24 per cent increase in the proportion of male villagers who prefer that the village headman is subject to a secret-ballot election. However, NSP has no effect on female views of democratic elections, on participatory decisionmaking procedures or on the already-high proportion of male villagers who believe the President or provincial governor should be elected. NSP also has no impact on the proportion of villagers who believe it appropriate to discuss governance issues publicly or who support the participatory resolution of major village issues. 


\section{DEVELOPMENT ASSISTANCE FOR PEACEBUILDING}

There is only weak evidence that NSP increases the legitimacy of the central government. In particular, NSP has no impact on whether villagers believe that the government should exercise jurisdiction over local crimes, set the school curriculum, issue ID cards or collect income tax. Furthermore, NSP has no impact on whether villagers prefer a centralized state (as opposed to a weak federation) or who identify primarily as Afghan (as opposed to a member of a specific ethnic group). At midline, NSP increases linkages of villages with government officials and representatives of the Afghan National Security Forces, although these effects do not last beyond the period of project implementation.

There is strong evidence that NSP improves perceptions of government entities at midline, but only weak evidence of such impacts at endline. During project implementation, NSP induces a highly significant increase in the reported benevolence of a wide range of government entities, but this impact mostly fades following project completion, with weak positive impacts observed only for the President and central government officials. This pattern is also true of perceptions of NGO officials, although NSP has a durable positive impact on perceptions of International Security Assistance Force soldiers. While the impacts of NSP on perceptions of government at midline indicate that the programme is generally perceived as government-owned, the reversion of villagers to original attitudes vis-àvis the government once project funds are expended seems to imply that government legitimacy is tied more to the regularized provision of public goods than to development outcomes per se.

NSP does not appear to impact the likelihood of villages suffering violent attacks (at least as reported by villagers) at midline or endline. There is also no evidence that NSP affects the ability of insurgent groups to expropriate harvests. However, NSP improves perceptions of the local security situation among both male and female villagers at midline, although only the impacts observed for male villagers persist beyond project completion.

The impacts of NSP on aggregate categories of indicators measuring political attitudes and state-building are presented in Table 4.

\section{Social Norms}

In accordance with observations that public resource decisions can sometimes aggravate intra-communal divisions, we find weak evidence that, during project implementation, NSP increases the incidence of disputes and feuds, while reducing the rate at which such disputes are resolved. Once projects are complete, this general effect disappears, however, and there is weak evidence that NSP slightly reduces intra-village disputes at endline. There is also some evidence at endline that NSP increases interpersonal trust among male villagers, although no evidence of a midline impact for male villagers or an impact at midline or endline for female villagers. Given the small magnitude of the observed changes, there is no evidence of a discernible impact of NSP on aggregate measures of social cohesion.

During project implementation, NSP improves the basic literacy and computation skills of male and female villagers, although these impacts do not last. There is also some evidence that NSP makes villagers happier. Specifically, 
TABLE 4

AGGREGATE IMPACT OF NSP ON POLITICAL ATTITUDES AND STATEBUILDING

\begin{tabular}{|c|c|c|c|c|}
\hline & \multicolumn{2}{|c|}{ Midline } & \multicolumn{2}{|c|}{ Endline } \\
\hline & Coefficient & $p$-value & Coefficient & $p$-value \\
\hline Democratic values & 0.023 & 0.004 & 0.033 & 0.004 \\
\hline Acceptance of democratic norms & 0.033 & 0.001 & 0.022 & 0.076 \\
\hline Electoral participation/political knowledge & 0.004 & 0.801 & 0.054 & 0.014 \\
\hline State legitimacy & 0.066 & 0.000 & 0.041 & 0.050 \\
\hline Acceptance of central government authority & 0.009 & 0.454 & 0.028 & 0.093 \\
\hline Linkages between villages and government & 0.201 & 0.000 & 0.071 & 0.245 \\
\hline Perceptions of government & 0.063 & 0.000 & 0.038 & 0.051 \\
\hline Perceptions of central government & 0.051 & 0.000 & 0.036 & 0.080 \\
\hline Perceptions of sub-national government & 0.120 & 0.000 & 0.050 & 0.147 \\
\hline Perceptions of government-allied actors & 0.058 & 0.005 & 0.034 & 0.102 \\
\hline Security & 0.041 & 0.091 & 0.042 & 0.126 \\
\hline Violent incidents & 0.023 & 0.665 & 0.042 & 0.495 \\
\hline Informal taxation by insurgent groups & - & - & -0.042 & 0.266 \\
\hline Perceptions of local security & 0.061 & 0.030 & 0.045 & 0.168 \\
\hline
\end{tabular}

Note: Coefficients and $p$-values for the mean average treatment effect for all indicators grouped in the hypothesis or in hypotheses that pertain to the particular group or family.

Source: A. Beath, F. Christia and R. Enikolopov, 2013. Randomized Impact Evaluation of Afghanistan's National Solidarity Programme-Final Report. World Bank Report No. 81107, Washington, DC: World Bank, 2013 (at: http://documents.worldbank.org/curated/en/2013/07/18273450/randomized-impactevaluation-afghanistans-national-solidarity-pro gramme).

there is weak evidence of a reduction in the proportion of female villagers who report that they are unhappy, a result that could be caused by the increased availability of counselling services for women, increased female participation in local governance and/or increased access to basic utilities and services.

NSP increases men's acceptance of female participation in political activity and local governance. Specifically, the programme increases male acceptance of female electoral participation, national candidacy by women and women holding civil service or NGO positions by 3, 4 and 6 per cent respectively. NSP also causes a 22 per cent increase in acceptance of female membership of village councils and a 15 per cent increase in acceptance of female participation in the selection of the village headman. The impact of NSP on women's views on female participation in political activity and local governance is more marginal. NSP also appears to have limited impacts on reducing cultural constraints limiting female educational opportunities.

Beyond attitudes, NSP has positive impacts on gender outcomes. NSP has durable positive impacts on the participation of women in local governance. Specifically, a 21 per cent increase is observed in the participation of women in dispute mediation and a 14 per cent increase is observed in the involvement of women in aid allocation. Although NSP does not appear to impact intra-village mobility of women, female socialization or female participation in economic activity or household decision making, it does produce a durable increase in the ability of women to travel beyond their village. Specifically, women in NSP 
TABLE 5

AGGREGATE IMPACT OF NSP ON SOCIAL NORMS

\begin{tabular}{|c|c|c|c|c|}
\hline & \multicolumn{2}{|c|}{ Midline } & \multicolumn{2}{|c|}{ Endline } \\
\hline & Coefficient & $p$-value & Coefficient & $p$-value \\
\hline Social cohesion & -0.005 & 0.778 & 0.007 & 0.695 \\
\hline Disputes \& resolution rates & -0.060 & 0.096 & -0.009 & 0.800 \\
\hline Interpersonal trust & 0.032 & 0.044 & 0.018 & 0.363 \\
\hline Literacy and computational ability & 0.057 & 0.003 & -0.001 & 0.966 \\
\hline Happiness & 0.022 & 0.284 & 0.035 & 0.113 \\
\hline Gender attitudes & 0.016 & 0.010 & 0.037 & 0.000 \\
\hline Acceptance of female political participation & 0.006 & 0.535 & 0.046 & 0.005 \\
\hline $\begin{array}{l}\text { Acceptance of female economic and social } \\
\text { participation }\end{array}$ & 0.019 & 0.183 & 0.031 & 0.075 \\
\hline Cultural constraints to education of girls & 0.007 & 0.273 & 0.017 & 0.220 \\
\hline $\begin{array}{l}\text { Acceptance of female participation in local } \\
\text { governance }\end{array}$ & 0.029 & 0.026 & 0.059 & 0.001 \\
\hline Gender outcomes & 0.046 & 0.000 & 0.034 & 0.012 \\
\hline Women's involvement in local governance & 0.041 & 0.000 & 0.079 & 0.000 \\
\hline Social activity among women & 0.006 & 0.417 & -0.017 & 0.303 \\
\hline Women's mobility & 0.120 & 0.000 & 0.039 & 0.185 \\
\hline $\begin{array}{l}\text { Participation in economic activity \& household } \\
\text { decision making }\end{array}$ & 0.001 & 0.967 & 0.003 & 0.905 \\
\hline
\end{tabular}

Note: Coefficients and $p$-values for the mean average treatment effect for all indicators grouped in the hypothesis or in hypotheses that pertain to the particular group or family.

Source: A. Beath, F. Christia and R. Enikolopov, 2013. Randomized Impact Evaluation of Afghanistan's National Solidarity Programme-Final Report. World Bank Report No. 81107, Washington, DC: World Bank, 2013 (at: http://documents.worldbank.org/curated/en/2013/07/18273450/randomized-impactevaluation-afghanistans-national-solidarity-pro gramme).

villages are 13 per cent more likely to have visited the nearest village in the past year and 11 per cent more likely to have visited the district centre in the past month.

The size of the impact of these results in the aggregate categories of indicators is presented in Table 5 .

\section{Discussion}

The study's results provide a rigorous assessment of the absolute impact of NSP on a broad set of outcomes. Comprehensive though they may be, the results have important limitations. In the absence of other comparable evaluations on other development programmes in Afghanistan, the findings of the NSP-IE do not allow comparisons to be made between the effectiveness of NSP and other programmes. For the same reason, it is very difficult to make qualitative judgements concerning the relative size of the observed impacts or whether they collectively might be used to designate NSP as a 'successful' or 'unsuccessful' project.

The results nonetheless point to several areas of achievement and other areas of concern. The participatory approach adopted by NSP has borne fruit in developing a role for women in local public decision making and, in so doing, 


\section{DEVELOPMENT ASSISTANCE FOR PEACEBUILDING}

countering the traditional dominance of male elites over local governance. NSP bridges the considerable gap between villages and the central government, while drinking water and electricity projects funded by the programme address critical needs of villagers and improve their lives. On the other hand, the relative ineffectiveness of NSP-funded infrastructure projects calls for further investigation. Likewise, some of the results suggest that it may be necessary to assess whether the presence of CDCs inadvertently diffuses institutional accountability in Afghan villages.

The following sections discuss implications of the results for other development projects in post-conflict settings, with a focus on how projects can best enhance government legitimacy, strengthen local accountability and participation and facilitate the acceptance of the participation of marginalized groups in local public affairs.

\section{Effects on Government Legitimacy}

NSP is funded by the World Bank and bilateral aid agencies, managed by the Ministry of Rural Rehabilitation and Development and facilitated by 29 NGOs. This arrangement has allowed NSP to benefit from the substantial local knowledge and expertise built up by the NGO sector in Afghanistan during the two decades of conflict the country suffered prior to 2001, while also clearly linking the programme with the Government of Afghanistan.

The NSP-IE results suggest that, while NSP increases the favourability of individuals' views towards the government, this effect fades after the completion of NSP-funded projects. This, in turn, indicates that villagers perceive NSP as a government-sponsored intervention and that government support is contingent upon the continual provision of public goods and services, such as development projects. Thus, even though NSP-funded projects deliver a development impact in improving access to utilities, this is not sufficient to improve perceptions of government unless there is an expectation of future service provision. ${ }^{29}$ Accordingly, the effects of development interventions on government legitimacy in post-conflict settings may be maximized by instituting a regularized and frequent pattern of project activity.

\section{Accountability of Local Governance Structures}

Local ownership is a core principle of NSP, with the mandated election of CDCs and the participatory selection of public goods projects financed by NSP block grants. The process of establishing CDCs and involving villagers in project selection has produced a number of positive effects, such as increasing the number of meetings held by village assemblies, increasing participation in and preferences for democratic elections, increasing female participation in local governance and liberalizing men's attitudes to female participation in local governance.

Despite these positive effects, however, the study finds that, once NSP-funded projects are complete, the overall effect of NSP on male perceptions of the quality of local governance deteriorates. In addition, the institutional relevance of the CDC - relatively strong at midline - fades substantially following project completion. These results suggest that the diffusion of institutional authority created 


\section{DEVELOPMENT ASSISTANCE FOR PEACEBUILDING}

by the co-existence of CDCs with local customary institutions and the ambiguous mandates of CDCs following project completion may produce perverse effects on local governance. The results underscore the need to provide new local institutions with a clear mandate distinct from those of existing local institutions.

\section{Participation of Women}

The most positively surprising set of results in the study are those pertaining to the durable impacts wrought by NSP on perceptions of gender roles and on women's lives generally. Of particular note is that while other impacts - such as those on perceptions of government - are not sustained beyond project completion, the effects on gender norms and gender outcomes do not fade. These results provide a strong vindication of NSP's policy of mandating female participation in CDC elections, CDC composition, and the selection and management of subprojects, which have produced changes in women's lives that extend far beyond both the scope of programme activities and the lifecycle of programme implementation. Accordingly, similar approaches might be adopted in development projects in other post-conflict environments to facilitate acceptance of democratic norms and participation in public affairs of women and other marginalized groups.

\section{Conclusion}

By embracing bottom-up approaches to development, CDD empowers local communities to select and manage projects which best address local priorities. NSP, the largest development programme in Afghanistan, has brought CDD to all of Afghanistan's 34 provinces and in so doing has overcome vast challenges posed by insecurity, prevailing gender norms and suspicion of the central government. The NSP-IE provides a rigorous, large-scale quantitative evaluation of the impacts of NSP across a wide range of economic, institutional and social outcomes and can potentially serve as an important tool for policy making for CDD and other programmes in Afghanistan and other post-conflict settings.

The findings of the NSP-IE identified some aspects in which NSP is succeeding and other areas where performance has been more limited. Specifically, the results show that NSP positively affects the access of villagers to drinking water and electricity, increases acceptance of democratic processes, improves perceptions of economic well-being and lessens constraints to the participation of women in public affairs. However, positive effects on attitudes towards central and subnational government fade quickly following the completion of NSP-funded projects. Moreover, NSP negatively affected perceptions of local governance quality among male respondents, while the composition and behaviour of the customary village leadership appears to be unaffected by the intervention.

The results provide important lessons for development interventions in postconflict contexts. First, the positive and durable impacts observed on female participation and acceptance of democratic processes are a vindication of NSP's policy of mandating female participation and democratic CDC elections in a context in which such practices contrast with local customs. Second, the positive but temporary impact of NSP on perceptions of central government indicates that 


\section{DEVELOPMENT ASSISTANCE FOR PEACEBUILDING}

development projects can assist in building government legitimacy in fragile states, but that such improvements in legitimacy are reliant upon a predictable and continuous stream of public goods and services provided by the central government. Finally, the finding that local governance as perceived by male respondents did not improve suggests caution is called for when establishing new local institutions in parallel with customary structures. Particular care must be paid to ensure that the new local bodies are provided with specific mandates distinct from those of existing institutions.

The process of conducting the NSP-IE has also generated lessons that may be useful to the design and implementation of similar development interventions. First, it is important that studies present a precise account of the specifics of the intervention and the context in which it is implemented. As demonstrated by the results of the variations tested by the NSP-IE and reported elsewhere, ${ }^{30}$ relatively minor variations in programmatic components can result in pronounced differences in impacts. Accordingly, only when provided with a precise description of the components of the programme can policy-makers make informed decisions.

Second, further efforts must be made to ensure research designs are geared towards understanding the long-term impact of programmes on outcomes of interest to policy-makers. While academics are rewarded for original experimental interventions with relatively short gestation periods, practitioners and policymakers are often interested in understanding impacts on outcomes that may take many years to evolve and in establishing whether similar programmes have common impacts across different contexts.

Third, the ability to isolate rigorously the impact of CDD programmes - and to help them improve - is greatly enhanced where logical frameworks enumerate distinct and quantifiable outcome indicators that the programme aspires to impact. When outcome indicators are not well defined ex-ante by the programme, disagreements may arise ex-post between researchers and practitioners about whether a given outcome was measured correctly. Failures to adequately specify assumptions underlying a logical framework may meanwhile inhibit researchers from being able to isolate why a particular intervention failed to have the desired effect and provide recommendations to improve programmatic effectiveness.

\section{ACKNOWLEDGEMENTS}

This article directly draws from previous reports and papers. ${ }^{31}$ The analysis and interpretations here summarize particularly those presented in A. Beath, F. Christia and R. Enikolopov, 'Randomized Impact Evaluation of Afghanistan's National Solidarity Program-Final Report, World Bank Report No. 81107. Washington, DC: World Bank', 2013 (at: http://documents.worldbank.org/curated/en/2013/07/ 18273450/randomized-impact-evaluation-afghanistans-national-solidarity-programme). Financial and logistical support for the Randomized Impact Evaluation of the National Solidarity Programme, whose results are summarized in this article, was provided by the World Bank's Trust Fund for Environmental and Socially Sustainable Development (TFESSD), the World Bank's AusAid-SAR Afghanistan Strengthening Community-Level Service Delivery Trust Fund, the World Bank's Development Impact Evaluation (DIME) initiative and the World Bank's Afghanistan Country Management Unit; and by the Food and 


\section{DEVELOPMENT ASSISTANCE FOR PEACEBUILDING}

Agriculture Organization (FAO) of the United Nations. The Ministry of Rural Rehabilitation and Development of the Government of the Islamic Republic of Afghanistan financially supported data collection for the baseline, midline and endline surveys through the monitoring and evaluation budget of Phase-II of the National Solidarity Programme. The Village Benefit Distribution Analysis was supported by the World Food Programme, the US Agency for International Development; the International Growth Centre and the Canadian International Development Agency. The findings, interpretations and conclusions expressed in this summary are entirely those of the authors. They do not necessarily represent the views of the International Bank for Reconstruction and Development/World Bank and its affiliated organizations, or those of the Executive Directors of the World Bank or the governments they represent; the National Solidarity Programme, Ministry of Rural Rehabilitation and Development of the Government of the Islamic Republic of Afghanistan or the Government of the Islamic Republic of Afghanistan; Australian Aid; the United States Agency for International Development, the Canadian International Development Agency; the Food and Agriculture Organization of the United Nations; the World Food Programme; and/or the International Growth Center.

\section{NOTES}

1. P. Dongier et al., 'Community-Driven Development', in J. Klugman (ed.), A Sourcebook for Poverty Reduction Strategies, Vol. 1, Washington, DC: The World Bank, 2002, pp.303-31; G. Mansuri and V. Rao, 'Localizing Development: Does Participation Work?', World Bank Policy Research Report, Washington, DC: The World Bank, 2012; S. Wong, What Have Been the Impacts of World Bank Community-Driven Development Programmes? CDD Impact Evaluation Review and Operational and Research Implications, Washington, DC: World Bank, 2012. As of 2012, the World Bank supported approximately 400 community-driven development projects in 94 countries (Wong, What Have Been).

2. A. Escobar, Encountering Development: The Making and Unmaking of the Third World, Princeton, NJ: Princeton University Press, 1995; J. Scott, Seeing Like a State: How Certain Schemes to Improve the Human Condition Have Failed, New Haven, CT: Yale University Press, 1998.

3. M. Cernea (ed.), Putting People First: Sociological Variables in Rural Development, New York: Oxford University Press and World Bank, 1985; A.O. Hirschman, Exit, Voice, and Loyalty: Responses to Decline in Firms, Organizations, and States, Cambridge, MA: Harvard University 


\section{DEVELOPMENT ASSISTANCE FOR PEACEBUILDING}

Press, 1970; A.O. Hirschman, Getting Ahead Collectively: Grassroots Experiences in Latin America, New York: Pergamon Press, 1984; E. Ostrom, Governing the Commons: The Evolution of Institutions for Collective Action, New York: Cambridge University Press, 1990; A.K. Sen, Commodities and Capabilities, Amsterdam: Elsevier, 1985; A.K. Sen, Development as Freedom, New York: Knopf, 1999.

4. Dongier et al. (see n.1 above); Wong (see n.1 above); R. Chambers, Rural Development: Putting the First Last, London: Longman, 1983.

5. D. Narayan (ed.), Empowerment and Poverty Reduction: A Sourcebook, Washington, DC: World Bank, 2002.

6. Macartan Humphreys, Raul Sanchez de la Sierra and Peter van der Windt, 'Social and Economic Impacts of Tuungane: Final Report on the Effects of a Community Driven Reconstruction Program in Eastern Democratic Republic of Congo', Mimeo, Columbia University, Jun. 2012; J. Fearon, M. Humphreys and J. Weinstein, 'Democratic Institutions and Collective Action Capacity', (forthcoming in American Political Science Review); K. Casey, R. Glennerster and E. Miguel, 'Reshaping Institutions: Evidence on Aid Impacts Using a Preanalysis Plan*', The Quarterly Journal of Economics, Vol.127, No.4, 2012, pp.1755-812; A. Beath, F. Christia and R. Enikolopov, 'Randomized Impact Evaluation of Afghanistan's National Solidarity ProgramFinal Report, World Bank Report No. 81107. Washington, DC: World Bank', 2013 (at: http:// documents.worldbank.org/curated/en/2013/07/18273450/randomized-impact-evaluation-afghanis tans-national-solidarity-programme).

7. Elisabeth King and Cyrus Samii, 'Fast Track Institution Building in Conflict Affected Countries? Insights from Recent Field Experiments', World Development, Vol.64, Dec. 2014, pp.740-54.

8. Bennett Sheree and Alyoscia D'Onofrio, 'Community-Driven? Concepts, Clarity and Choices for CDD in Conflict-Affected Contexts', [International Rescue Committee Report] New York: International Rescue Committee, 23 Feb. 2015.

9. Villages must have more than 25 households to form a unitary CDC, although smaller villages may form joint CDCs with larger villages.

10. Villages are divided into 'clusters' of between 5 and 20 families, with each cluster electing a male and female representative to the CDC. The CDC is headed by an executive council composed of a president, deputy president, secretary and treasurer.

11. NSP features a 'negative list', which bans certain types of projects from receiving funding (including mosque construction, land purchases, payment of salaries to CDC members, purchase of weapons and cultivation of illegal crops). Eligible projects are generally approved by NSP provided they are endorsed through a village-wide consultation process; provide for equitable access; are technically and financially sound; include an operation and maintenance plan; and are funded by the community (including labour and material contributions) up to a level exceeding 10 per cent of the total cost.

12. A. Beath, F. Christia and R. Enikolopov, 2013. Randomized Impact Evaluation of Afghanistan's National Solidarity Programme-Final Report, World Bank Report No. 81107, Washington, DC: World Bank, 2013 (at: http://documents.worldbank.org/curated/en/2013/07/18273450/ randomized-impact-evaluation-afghanistans-nati onal-solidarity-programme). Seventy-three per cent of NSP funding is allocated to block grants, 18 per cent to facilitation costs and 9 per cent to administration.

13. NSP Phase-III also intends to mobilize the remaining 16,000 villages that have yet to receive the programme.

14. Icon-Institute, 'National Risk and Vulnerability Assessment 2007/08: A Profile of Afghanistan', [Main Report] Cologne: Icon-Institute, 2009.

15. T. Barfield, Weak Links on a Rusty Chain: Structural Weaknesses in Afghanistan's Provincial Government Administration, Berkeley, CA: Institute of International Studies, University of California, 1984; N. Nojumi, D. Mazurana and E. Stites, 'Afghanistan's Systems of Justice: Formal, Traditional, and Customary’, Working Paper, Medford: Feinstein International Famine Center, Youth and Community Programme, Tufts University, 2004.

16. A. Rahmani, The Role of Religious Institutions in Community Governance Affairs: How Are Communities Governed beyond the District Level?, Budapest, Hungary: Open Society Institute, Central European University Center for Policy Studies, 2006.

17. P. Kakar, Fine-Tuning the NSP: Discussions of Problems and Solutions with Facilitating Partners, Kabul: Afghanistan Research and Evaluation Unit, 2005.

18. Rahmani (see n.16 above).

19. I. Boesen, From Subjects to Citizens: Local Participation in the National Solidarity Programme, Kabul: Afghanistan Research and Evaluation Unit, 2004. 


\section{DEVELOPMENT ASSISTANCE FOR PEACEBUILDING}

20. The ten districts were purposively sampled to meet the following three criteria: they had not been mobilized by NSP before; the security situation was conducive to survey implementation; and they had at least 65 villages. For more see A. Beath, F. Christia and R. Enikolopov, Randomized Impact Evaluation of Afghanistan's National Solidarity Programme: Hypotheses and Methodology, Kabul: World Bank, 13 April 2008.

21. Villages assigned to the control group received NSP in 2012.

22. The matched-pair cluster randomization procedure used background village characteristics including village size (based on data collected a few years earlier by Afghanistan's Central Statistics Organization) and a set of geographic variables (distance to river, distance to major road, altitude and average slope). The procedure was successful in statistically balancing treatment and control groups across 19 key variables for which data were collected in the baseline survey. The difference between the means of the two groups is always smaller than 6 per cent of the standard deviation. For more see A. Beath, F. Christia, R. Enikolopov and S. Kabuli, Randomized Impact Evaluation of Phase-II of Afghanistan's National Solidarity Programme (NSP): Estimates of Interim Program Impact from First Follow-Up Survey, Washington, DC: World Bank, 8 July 2010.

23. See here http://www.nsp-ie.org/followups.html for the survey instruments in English, and in the relevant local languages, Dari and Pashto.

24. For the midline male household questionnaire, enumerators sought participation of baseline male household respondents or, in their absence, a relative or cohabitant of the respondent.

25. See here for the full pre-analysis plan that links specific survey questions to indicators and offers detailed specifications of the analysis that were run (at: http://www.nsp-ie.org/toolsanddata/paps/ NSP_IE_2FU_PAP_2012_02_07.pdf). This paper present the results of specification from the preanalysis plan. Appendices IV and V in Beath et al. (n.6 above) present results for an alternative specification with improved statistical power.

26. See Part II, Section VII of Beath et al. (n.6 above) for further discussion of the hypotheses of the study.

27. For the second phase of NSP (2006-10), the PDO was to "lay the foundations for a strengthening of community level governance, and to support community-managed subprojects comprising reconstruction and development that improve access of rural communities to social and productive infrastructure and services". The key outcome indicators were: (i) to enable "[a]round $21,600 \ldots$ CDCs across the country [to] avail of basic social and productive infrastructure and other services"; (ii) to achieve "ERRs for community projects [in excess of] $15 \%$ "; to ensure that "O\&M is in place for the completed projects and that the infrastructure services are use [sic] appropriately by the targeted communities for the purposes intended"; to ensure that "[a]t least $60 \%$ of CDCs [are] functioning to address critical development needs as identified by villages"; and (iv) to provide for "an increased level of participation of women in the community decision making [sic]" (World Bank [2006], p. 33). Note that the key outcome indicators identified by the program consist mainly of outputs specific to treatment areas and are thus inappropriate for this type of study, which includes control and treatment villages and seeks to explore impacts on general outcomes." World Bank (2006). Technical Annex for a Proposed Grant of SDR 81.2 Million (US\$120 Million Equivalent) to the Islamic Republic of Afghanistan for a Second Emergency National Solidarity Project (NSPII). Washington, DC: World Bank (November 10).

28. This section summarizes Part III of Beath et al. (see n.6 above).

29. Given the uncertainty over the future schedule of NSP block grant disbursement, villagers are unlikely to expect the implementation of further NSP-funded projects once the village's block grant allotment is completed.

30. A. Beath, F. Christia, G. Egorov, \& R. Enikolopov, Electoral Rules and the Quality of Politicians: Theory and Evidence from a Field Experiment, Working Paper: Massachusetts Institute of Technology, 2013; A. Beath, F. Christia and R. Enikolopov, 'Direct Democracy and Resource Allocation: Experimental Evidence from Afghanistan' [MIT Political Science Department Research Paper No. 2011-6], SSRN, 26 Apr. 2015; A. Beath, F. Christia and R. Enikolopov, 'Do Elected Councils Improve Governance?: Experimental Evidence on Local Institutions in Afghanistan' [MIT Political Science Department Research Paper No. 2013-24], SSRN, 15 Sept. 2013.

31. Beath et al. Electoral Rules and the Quality of Politicians (see n.29 above); A. Beath, F. Christia, $\&$ R. Enikolopov, Randomized Impact Evaluation of Afghanistan's National Solidarity Programme - Hypotheses and Methodology, Kabul: World Bank, 13 Apr. 2008a; A. Beath, F. Christia, \& R. Enikolopov, Randomized Impact Evaluation of Afghanistan's National Solidarity Programme - Report on Election Monitoring, Kabul: World Bank, 23 July 2008b; A. Beath, F. Christia, \& R. Enikolopov, Randomized Impact Evaluation of the National Solidarity 


\section{DEVELOPMENT ASSISTANCE FOR PEACEBUILDING}

Programme: Baseline Survey Report, Kabul: World Bank, 11 Dec. 2008c; A. Beath, F. Christia, $\&$ R. Enikolopov, Randomized Impact Evaluation of Afghanistan's National Solidarity Programme - Report on Monitoring of Sub-Project Selection, Kabul: World Bank, 17 Jan. 2009; A. Beath, F. Christia, \& R. Enikolopov, 'Randomized Impact Evaluation of the National Solidarity Programme - Village Benefit Distribution Analysis. Pre-Analysis Plan: Hypotheses, Methodology and Specifications'. EGAP Registered Design, 17 Jan. 2012a; A. Beath, F. Christia, \& R. Enikolopov, 'Randomized Impact Evaluation of the National Solidarity Programme - Final Report. Pre-Analysis Plan: Hypotheses, Methodology and Specifications'. EGAP Registered Design, 14 Feb. 2012b; A. Beath, F. Christia and R. Enikolopov, 'Empowering Women through Development Aid: Evidence from a Field Experiment in Afghanistan', American Political Science Review, Vol.107, No.3, 2013, pp.540-57; A. Beath, F. Christia and R. Enikolopov, 'Winning Hearts and Minds through Development: Experimental Evidence from Afghanistan' [MIT Political Science Department Research Paper No. 2011-14], SSRN, 13 Apr. 2012; Beath et al. Direct Democracy and Resource Allocation (see n.29 above); Beath et al. Do Elected Councils Improve Governance? (see n.29 above); A. Beath, F. Christia, R. Enikolopov, \& S. Kabuli, 'Randomized Impact Evaluation of the National Solidarity Programme: Sub-Treatment Interventions - Analysis of the Impact of Election Type on Electoral Outcomes', Kabul: World Bank, 2 July 2009a; A. Beath, F. Christia, R. Enikolopov, \& S. Kabuli, 'Randomized Impact Evaluation of the National Solidarity Programme: Sub-Treatment Interventions - Analysis of the Impact on Project Selection Outcomes of Variation in Selection Procedure and Election Types', Kabul: World Bank, 2 July 2009b; A. Beath, F. Christia, R. Enikolopov, \& S. Kabuli, (2010). 'Randomized Impact Evaluation of Phase-II of Afghanistan's National Solidarity Programme (NSP) - Estimates of Interim Program Impact from First Follow-Up Survey', Washington, DC: World Bank, 8 July 2010. 


\title{
The Yemen Social Fund for Development: An Effective Community-Based Approach amid Political Instability
}

\author{
LAMIS AL-IRYANI, ALAIN DE JANVRY and \\ ELISABETH SADOULET
}

The Yemen Social Fund for Development (SFD) was established in 1997 to combat national poverty and reinforce the limited existing social safety net. Since its inception, SFD has been widely viewed as effective in implementing programmes throughout the country and has steadily expanded its activities, despite Yemen's weak state and political unrest. In designing a novel approach to implementing its programmes, SFD provides a model of how to use the Social Fund approach to deliver good aid in hard places. Drawing on first hand experience with SFD and on a review of results from impact evaluations, this article argues that SFD's achievements have been primarily due to four factors: (1) stakeholder ownership over projects due to its close work relationship with local communities following a demand-driven approach; (2) trust based on its perceived political neutrality in allocating resources; (3) flexibility due to its mode of project funding and operations in a rapidly changing context; and (4) relevance of its interventions for beneficiaries who in reciprocity provide strong support and effective protection to its programmes. The article discusses how these factors may be transposed to other hard places using the social fund approach to deliver good aid under difficult conditions.

\section{Introduction}

In 2011, Yemen experienced an uprising similar to that of other Arab states in what has been described as the 'Arab Spring'. It was associated with widespread social protests, economic paralysis and a deterioration of already poor government services. By the end of 2011, Yemen's rival groups reached a precarious political settlement mediated by Saudi Arabia and the United Nations. At present, the political stalemate remains unresolved. In March 2015, in face of increasing violence, the UN warned that Yemen was 'on the verge of total collapse'. ${ }^{1}$

In 1991-95, the Yemeni economy was in a bad shape due to numerous high profile incidents that changed the country's landscape. The unification of Yemen in 1990 integrated two different civil service systems which placed a heavy burden on the national budget. The strain on the budget was mainly caused by the decision to keep all civil servants and to apply the higher salary scale in place in the north for the new government. In 1991, almost one million Yemeni workers were expelled from Saudi Arabia depriving the country of a large inflow of remittances and increasing the demand for jobs and social services. ${ }^{2}$

This is an Open Access article distributed under the terms of the Creative Commons Attribution-NonCommercial-NoDerivatives License (http://creativecommons.org/Licenses/by-nc-nd/4.0/), which permits noncommercial re-use, distribution, and reproduction in any medium, provided the original work is properly cited, and is not altered, transformed, or built upon in any way. 


\section{DEVELOPMENT ASSISTANCE FOR PEACEBUILDING}

The regional aid to Yemen was halted due to the country's political stand against the 1991 Gulf War. As a consequence Yemen experienced hyperinflation and entered into a political crisis that ended with a civil war in the summer of 1994.

In 1995, to stabilize the economy, Yemen put together an economic reform programme based on the advice of the World Bank and the International Monetary Fund. These reforms included gradual removal of the government subsidies to food and fuel. At the same time, Yemen put into place a more targeted social safety net programme comprised of several sub-programmes.

In fragile states like Yemen, a Social Fund approach has proven to be an effective option to channel foreign aid through weak government institutions. In 1997, the government of Yemen established the Yemen Social Fund for Development (SFD) with the support of the international community, and in particular of the World Bank, to combat national poverty and reinforce the limited existing social safety net. ${ }^{3}$

This article argues that, although not without its weaknesses, SFD's resilience and effectiveness in delivering aid for development in Yemen is in large part attributed to its direct relationship with communities, political neutrality, a flexible mode of project funding and operation and recognition by beneficiaries of the importance of its interventions. SFD's efforts have proved to be scalable within Yemen. This is demonstrated by its ability to attract and effectively spend increasingly large amounts of external funding.

The article makes use of SFD's external evaluations which include three consecutive studies conducted in $2003,{ }^{4} 2006^{5}$ and $2009^{6}$ visiting the same communities in addition to two consecutive institutional assessments. It also reviews SFD documents as well as aide memoires and case studies produced by SFD's donors. It builds its argument on the basis of consistent findings in these evaluations and extracts from these key elements believed to be the main factors explaining effectiveness. The article reviews literature on social funds from the Independent Evaluation Unit of the World Bank and from reports of the World Bank's Social Protection Group. Importantly, it also draws on our first-hand experiences with SFD over more than 16 years.

\section{Background}

Yemen is the poorest country in the Arab World, with a GDP per capita of US\$1, $160^{7}$ and a population of a little more than 24 million. $^{8}$ In 2014 , the Human Development Index ranked Yemen 154th out of 187 countries. This ranking reflected low average years of schooling among its population, modest life expectancies and low per capita income. Yemen has high population growth, low economic growth and limited natural resources, with water a worsening challenge for the country associated with climate change. Since the creation of a unified Yemen in 1990, the country has been going through cycles of conflicts and political crises.

In 1997, the World Bank provided the technical and financial support to establish SFD. It became the lead institution in terms of advocacy to raise financial resources from a multiplicity of donors. Although initially inspired from 


\section{DEVELOPMENT ASSISTANCE FOR PEACEBUILDING}

Egypt's Social Fund, SFD quickly evolved in its own direction in following a community-based approach. This approach consisting in working directly with local communities in compensating for the limited capacity or absence of $\mathrm{NGOs}^{9}$ as well as the weakness of local governments. ${ }^{10}$

Since its inception, SFD considered itself to be a non-traditional social protection programme providing medium- to long-term development opportunities targeted at poor communities. Its interventions are aimed at promoting human development through improved access to social and economic services such as education, water, health and infrastructure. Through intermediaries mostly established with its support, SFD also provides financial and nonfinancial services to micro and small entrepreneurs. SFD has evolved significantly since its beginnings to adapt to the ever-increasing challenges facing Yemen.

Although not without weaknesses (as discussed further below), it is broadly viewed by its donors as having been effective in assisting the target populations and in achieving resilience in its operations in the face of the politically volatile Yemeni context. The World Bank, ${ }^{11}$ for instance, noted that, 'due to its great success at delivery, the SFD is often considered the only institution that can address problems and support activities that have otherwise fallen through the cracks in Yemen'. Yet, it had also warned that the Fund was at risk of spreading thin with an increasing number of donor-funded projects. In an aide memoire issued in July 2011, DFID stated that, 'SFD's ability to carry on operations across most sectors and regions is testimony to the resilience and flexibility of SFD's systems and procedures'. ${ }^{2}$ In 2004, SFD was featured by the World Bank as a case of success from which to learn in a global conference to scale up poverty reduction efforts in Shanghai, China.

SFD has completed three phases of operations: the first in 1997-2000, the second in 2001-03 and the third in 2004-10, with the fourth phase currently underway over the period 2011-15.

In the years between the first operations of SFD and the 2011 crisis, Yemen's political situation remained fragile. The unrest manifested through six rounds of war between 2004-09 in the northern governorate of Sa'adah against the Houthi rebels, a separatist movement in the south, and an increased presence of Al-Qaida particularly in the southern governorates of Abyan and Shabwah. The political system is dominated by bargaining of powers and interests organized along patron-client relations in tribal groups and extended family systems. ${ }^{13}$ The government institutions are not only weak and ineffective outside the main cities, but are also widely untrusted. ${ }^{14}$ The social and economic indicators have been slowly progressing. Oil production had remained the main source of revenue and although production had been decreasing, this was offset by the increase in oil prices in international markets. GDP growth during these years ranged between 3 to 6 per cent with an average of 4 per cent. On the other hand, population growth has slowed down to less than 3 per cent. There had been an improvement in some social indicators such as increased school enrolment and decreased maternal mortality rates. A local administration law was passed in 2000 and the first local election was 


\section{DEVELOPMENT ASSISTANCE FOR PEACEBUILDING}

held in 2002. In 2003, the government drafted a Poverty Reduction Strategy that aimed at reducing poverty by means of increased allocations to basic social services and fostering economic growth. ${ }^{15}$

During these phases, an estimated US $\$ 1.98$ billion of donor and government funding was raised to fund SFD projects and the cumulative flow of disbursements amounted to US $\$ 1.2$ billion. While the World Bank was the lead donor in terms of funding during the first and second phases, contributing 30 per cent of SFD's funding in each, in the third phase the Government of Yemen became the major donor, contributing 19 per cent of the total budget. This increase in government funding might be attributed to the fact that in 2006 the SFD Managing Director had been appointed Minister of Planning and International Co-operation. The new cabinet therefore became more appreciative and understanding of SFD's role. In the third phase starting in 2004, DFID became a major donor to Yemen and channelled the majority of its financial aid through SFD. Other external donors have also participated in SFD funding, suggesting that it has gained widespread approval in the international community.

SFD's priorities have evolved over time, reflecting Yemen's changing needs. During the first phase, it focused on reducing poverty by creating income-generating opportunities. The second phase focused on community development, capacity building and microfinance programmes in order to improve the range of services and options available to poorer sections of the Yemeni population. The third phase focused on service provision to the poor by refining social service delivery approaches and empowering communities and local councils to take charge of their local development. The current fourth phase is focusing on scaling up the successful activities of previous phases and on enhancing SFD's role as a safety net programme to contribute to poverty reduction and help achieve Yemen's development goals. ${ }^{16}$

The evolution of SFD's objectives has been determined by several factors, most importantly its institutional development and its implementation capacity, new events in the country and the willingness of donors to provide funding to support the new realities, for example, supporting the decentralization process and contributing to improve food security through community-based labourintensive public works.

SFD now operates through four main programmes: Community and Local Development (CLD), Small and Microenterprise Development (SMED), Capacity Building (CB) and the Labour-Intensive Works Programme (LIWP). The latter is a community-driven workfare programme added in 2008 as a response to the global increase in food prices.

Within each of these four programmes, SFD implemented several sectoral activities dominated by basic infrastructure for schools, health facilities and rainwater harvesting. This dominance reflects the limited availability of basic infrastructure in most rural areas of Yemen. Expenditures on education have been the largest sector, accounting for 44 per cent of all expenditures, followed by water and environment (14 per cent), rural roads (12 per cent), labour-intensive cash for work ( 8 per cent), health (6 per cent) and microenterprise development (3 per cent). 


\section{DEVELOPMENT ASSISTANCE FOR PEACEBUILDING}

\section{SFD's Actual Expenditures by Sector and Phase of Activity}

The shares of the education and health sectors have been declining, while those of the Labour-Intensive Cash for Work Programme (LIWP) and rural roads have been increasing, reaching 40 per cent of total expenditures in the current fourth phase. This reflects the rising importance for donors of social protection and of interventions that generate income. The decline in the share of the health sector has been due to shortages in the human resources that operate the infrastructure built by SFD.

SFD is a national programme, and by 2012 , it had reached about 10,000 villages out of the country's 40,300, and 3,700 urban neighbourhoods located in 1,976 sub-districts within the country's 333 districts in the 21 governorates of Yemen. ${ }^{17}$

SFD operates through nine regional offices covering the whole of Yemen. The branches are servicing a variety of population and geographical areas, which means that a branch office could cover one governorate or up to four adjacent governorates based on population size and the resources allocated to each governorate. SFD distributes its resources at the beginning of each phase based on the number of poor people in each governorate and at the level of each district. While most of the administrative staff is located at headquarters, the project officers and implementation staff are concentrated at the regional level. In 2013, the number of core staff reached 334 along with 165 consultants whose contracts are tied to specific tasks and projects. Along with this, SFD heavily outsources short-term activities to local consultants who assist in carrying out tasks such as needs assessment, project design, training sessions and supervising fieldwork.

\section{Evaluation of SFD's Performance}

This section draws on SFD's three major external evaluations, as well as on donors' joint mission reports and other publications to evaluate SFD's performance. SFD went through three major external evaluations in 2003, 2006 and $2009 .{ }^{18}$ These evaluations were based on a quantitative survey in addition to a qualitative study. The quantitative evaluation methodology in 2003 and 2006 attempted to compare the results of the outcomes in communities that received projects with the social-economic conditions of communities that had not yet received the interventions. In 2009, the evaluation used a difference-in-differences approach ${ }^{19}$ to selected measurable indicators based on asking recall questions on the situation prior to intervention in the treated communities. Both the 2006 and 2009 evaluations included return visits to communities and households included in earlier evaluations in order to assess the sustainability of interventions; therefore, the evaluation sample continued to increase in each round of evaluation to include older project areas and households. Each evaluation assessed the effectiveness of SFD in terms of poverty targeting; community consultations and participation; the efficiency of SFD in terms of coverage; and outcomes attributable to SFD interventions in the areas of education, health, water, rural roads and 


\section{DEVELOPMENT ASSISTANCE FOR PEACEBUILDING}

microfinance which accounted for about 70 per cent of SFD's investments at that time.

These major evaluations were conducted at the end of each phase in order to measure the outcomes of the respective phase. The sample size for the 2003 evaluation was 4,000 households located in 200 communities, with 100 having received the interventions and 100 still in the pipeline waiting for the interventions. The 2006 sample was 6,000 households, including 2,000 in 200 project areas who were still waiting for the interventions and 4,000 households located in 400 project areas and were distributed in two groups, the first group having received the interventions between 1997 and 2002 and the second who received them between 2003 and 2005. The sample size in 2006 was increased to compensate for attrition in the sample size that occurred in the 2003 evaluation.

Since 2008, new programmes were added to SFD's portfolio of interventions including the Labour-Intensive Works Programme (LIWP) and the Rainfed Agriculture and Livestock Project (RALP), both of which were rigorously evaluated for impact. The LIWP evaluation was based on a community matched-pair randomized control trials design. ${ }^{20}$ The randomization was possible as the LIWP cash-for-work approach was only used by SFD and there was no possibility that other programmes would intervene in the control areas. Additionally SFD's capacity to intervene in both control and treatment areas at the same time was limited. As the LIWP was rolled out, control areas would become eligible for interventions after completion of the evaluation.

The LIWP evaluations confirmed SFD's capacity at targeting poor and deprived communities and at meeting their priority needs. ${ }^{21}$ In treated communities, 74 per cent of households had at least one member participating in LIWP. Benefits were, however, quite unequally distributed across participants due to the fact that the crisis attracted participation of households that would have normally self-selected out of enlisting for workfare. Wages were set on a piece-rate basis, creating greater rewards for workers involved in more skill-intensive tasks. In spite of this, benefits were progressively distributed, with more aggregate benefits going to the poor and a decline in intra-community Gini coefficients. Income gains were used to increase staple food consumption, reduce levels of indebtedness and protect durable goods ownership from decapitalization to cope with the crisis. There was however no detectable impact on animal asset ownership, consumption of higher value foods and ownership of goods such as clothing and household utensils. Few projects implemented through LIWP had been completed, but the evaluation showed improved access to water where projects focused on water availability. The evaluation of LIWP thus confirmed the value of the productive safety net approach in mitigating the impact of economic shocks.

In addition to these quantitative evaluations, two institutional assessments were conducted focusing on SFD's indirect contribution to national public/private implementation capacity, through both 'expertise transfer' and co-operative arrangements for implementation and policy development.

These institutional assessments, which use qualitative methods, added other dimensions to understand how SFD is operating in its fragile environment and 


\section{DEVELOPMENT ASSISTANCE FOR PEACEBUILDING}

how its practices contribute to the country's institutional development. SFD's operations have reached about 25 per cent of Yemen's 40,000 villages ${ }^{22}$ and more than 50 per cent of the rural population. ${ }^{23} \mathrm{SFD}$ is the only development programme in Yemen with such coverage. As such, dealing with conflicts and tensions is relevant to SFD's operations particularly in troubled geographical areas. The institutional assessments attributed SFD's ability to work in difficult areas to its clearly defined work procedures, its employing local staff and its close relationship with communities and local authorities that help it to overcome insecurity and operate in conflict situations. ${ }^{24}$

The institutional assessment described some of SFD's practices in attempting to raise the quality standard of development initiatives as well as the capacity of the national public administration. Some of these practices include continuously measuring the efficiency of interventions as part of a results-based management approach, targeting investment through the use of data and objective indicators, a participatory approach to decision making regarding projects and responsiveness to beneficiary needs. ${ }^{25}$

During Yemen's 2011 economic and political crisis, SFD was able to continue its operations with implementation of 82 per cent of its projects in 300 districts out of the country's $333 .^{26}$ This is attributed to several factors including the fact that SFD is relying on multiple sources of funding. SFD was funded by a multiplicity of donors and several of them did not stop their funding during the crisis. At the implementation level, SFD's resilience is attributed to the diversification of its approaches, with reliance not only on SFD contractors but also on contracting with the community. With the crisis, SFD had to re-prioritize its interventions, giving prominence to the labour-intensive cash-for-work and water projects not only because these interventions affect people's immediate livelihoods, particularly the cash-for-work programme, but also because they depend heavily on local materials and are implemented directly by beneficiaries who have interest in protecting the project operations.

The 2006 assessment noted that SFD had evolved into a 'model' organization in the Yemen context, operating on a nationwide basis and extending participatory development efforts to rural and remote areas. As the main supporter of NGOs, SFD promoted capacity development and good governance among NGOs. According to Jennings, ${ }^{27}$ the SFD's demand-led approach, pro-poor resource allocation on a nationwide basis, use of verified results as a basis for decision making, participatory processes, transparency principles at all levels and well-developed procurement systems have allowed it to contribute to the promotion of solid systems of governance that underscore state building. The 2006 institutional assessment asked a group of contractors: 'If the price that you offer SFD was 100 in a specific item, what would be your price for the next five actors including ministries?' All contractors agreed that they would give SFD the lowest unit price, attributing this to not having hidden costs when bidding for SFD-supported projects. ${ }^{28}$ A 2008 study, commissioned by KfW in partnership with the Ministry of Education on the provision of educational facilities, found SFD to be the most efficient in terms of procurement performance. The same study also found that SFD costs are at least 20 per cent lower than the 


\section{DEVELOPMENT ASSISTANCE FOR PEACEBUILDING}

education ministry and its projects implementation units. ${ }^{29}$ SFD's cost efficiency has been mainly attributed to its transparent procurement practices.

In 2009, the institutional assessment observed that SFD had made progress in aligning its activities with those of sectoral ministries and in contributing to the development of national strategies rather than continuing to pursue its own separate approach. The 2009 institutional assessment indicated that SFD has effectively managed conflict situations including rivalries among community interest groups over the location of projects, political divisions and the tendency to politicize interventions, tensions over community contributions, conflicts with contractors and also differences with line ministries over coordination issues.

The institutional assessment described how SFD has been dealing with such tensions in order to prevent, resolve or minimize conflict including establishing and respecting clear criteria to avoid bias in selecting and implementing projects that could offer equal opportunities to access resources. Also, SFD strived to ensure transparency at all times, including in the formation of community committees, the establishment of community contributions and community contracting as well as in providing access to its reports and procedures. A key factor in enlisting community support was to use local staff and consultants. When it comes to resolving an already existing problem, SFD's regional branches work with local leaders to address the issue. However, in a deeply entrenched patronage system like Yemen, this has not been problem free. The Parliament, where the majority of its members are elite community leaders, has several times reluctantly ratified SFD loans as they have been seen as a threat to their patronage role in their constituencies. While SFD has gained recognition by communities and development organizations, this has often not been the case among elites and central government officials.

The institutional assessment noted that SFD could remain functional when a crisis occurs. ${ }^{30}$ For example, it increased its investment in the Hadhramaut Governorate following the 2008 floods and loss of life. Similarly, it introduced a labour-intensive programme to create employment in local public goods projects as a response to rising food prices during the global food crisis.

\section{Factors Contributing to SFD's achievements}

Yemen has received a comparatively low level of international development aid. In 2003, it received US\$12.7 per capita in development aid compared to an average of US\$33.4 aid per capita in the least developed countries. This low level of international development assistance has in part been due to the low absorption capacity of its state institutions, and also to donors' strict project and financial management procedures that do not match Yemen's institutional capacity. ${ }^{31}$ Other difficulties facing the implementation of aid initiatives include lack of security in several parts of the county.

We argue that four factors have been essential in enabling SFD to implement its development interventions effectively. They are: 


\section{DEVELOPMENT ASSISTANCE FOR PEACEBUILDING}

(1) Ownership: A demand-driven approach allows the establishment of direct links with communities and the creation of community ownership of SFD projects.

(2) Trust: SFD's political neutrality has been established through objective and transparent resource allocation procedures. Such perceived neutrality earned SFD the trust of populations and continued access to the most difficult places in spite of tribal conflicts and insecurity.

(3) Flexibility: A flexible mode of funding allows SFD to respond to communities' changing needs and to sustain projects in spite of crisis conditions.

(4) Relevance: The quality and importance of its interventions for the lives of beneficiaries has given SFD visibility, recognition and support among stakeholders, the government and donors.

\section{Community Ownership through a Demand-Driven Approach}

SFD made the strategic option of involving communities in the process of project selection and implementation. This paid off in selecting projects that correspond to community priorities and facilitated the implementation of projects. Evaluations indicate that the majority of communities and households interviewed considered the projects to meet their priority needs effectively. Although there is as of yet no strong evidence that the community structures created for the demanddriven approach will survive to become agents of further development after completion of the projects, the approach introduced democratic processes as the communities have to decide what type of intervention is a priority and who represents them during and after project implementation using elections and meetings. This process has been encouraging women to participate in public events and to become members of community committees. The relationship established with communities and local people during such processes was effective in facilitating SFD's access to difficult regions and such relation proved to be essential in 2011 to enable continued SFD operations in a context of political mobilization and increasing insecurity.

SFD's success with the participatory approach stems from the social and political context where it operates. Yemen has never had a strong central government, and availability of state services has been low in most rural areas. As mentioned by Baas and Ali, 'Yemen has had a rich history of both community participation and grassroots-level community-based institutions. The tribe is the most prominent informal institution and is a crucial element of social, economic, cultural, and political life. ${ }^{32}$ SFD has adapted its strategy to this reality by giving an important role to the community in setting its priorities and implementing its programmes.

The demand-driven approach followed by SFD may, however, create inconsistencies with national sectoral strategies. Since 2004, there has been a call for SFD to align its interventions better with national sector strategies and this has become one of SFD's priorities. The development impact and the sustainability of SFD's projects depend on progress with local institutional capacity development. For this reason, in using the Social Fund approach, it is important to try 


\section{DEVELOPMENT ASSISTANCE FOR PEACEBUILDING}

to achieve a balance between support to community-led initiatives (to achieve community ownership) and alignment with national priorities (to secure consistency with national policies).

\section{Trust through Political Neutrality}

SFD has been able to operate in its environment because its stakeholders, both beneficiaries and donors, perceived it as neutral and impartial. It established systems and procedures based on the principle of transparency. It has used an operational manual, management information systems (MIS) and established procurement and disbursement procedures that are accountable to donors. SFD has continued to improve its operating processes, and expand its activities to reach the poor and vulnerable better. Based on these merits, SFD was able to work in difficult circumstances and continue to attract donor funding. SFD also prevented political interference by powerful groups, a characteristic that it had to defend rigorously in its early days when members of parliament were very reluctant to accept the presence of an independent organization. It considers that its neutrality is paramount to its performance. ${ }^{33}$ To achieve neutrality, every district in Yemen receives an allocation based on the number of people living in poverty. As a result, SFD has reached into almost every district. It makes efforts to penetrate districts where other government bodies cannot reach because of geographical remoteness or political or tribal disputes. For districts with a high poverty rate, SFD has designed special programmes that are introduced to target poor communities and to top up its resources.

Effective leadership since the early years of SFD, which was politically supported, was essential in increasing the size of SFD from a first phase planned to disburse US\$80 million (1997-2001) to a fourth phase (2011-15) expected to reach US\$1.1 billion. This leadership helped establish a politically neutral, nonpartisan organization. It is believed that high-level political support was instrumental in SFD's ability to survive during the first years of its establishment particularly with its unusual organizational practices that include financial and administrative autonomy, competition-based procurement and direct relationships with communities that bypass the traditional local power structure. Following the events of 2011 and the change in SFD management, it has maintained the same principles to operate as a 'neutral' organization. This was possible because of the solid systems, procedures and cultural organization that had been put into place with the support of its donors.

Social funds have been tagged as 'parallel' institutions of governance that do not have the legitimacy and trust that would be ensured by membership of the regular administrative process. The perception of some development practitioners and government officials is that SFD is (1) taking over tasks that could be carried out by existing national agencies, and (2) carrying out its activities in a way that may marginalize national and local administrative agencies whose corporate mandate covers such activities, depriving them of opportunities to build their own capacity. Such arguments have been toned down as the development and humanitarian situation in Yemen deteriorated and SFD was seen as an instrument 


\section{DEVELOPMENT ASSISTANCE FOR PEACEBUILDING}

for social protection with no close substitute in the public sector. In a briefing paper, Oxfam thus called on the international community to 'scale up technical and financial assistance to enable the continuation and expansion of existing social protection and welfare programmes, such as the Social Welfare Fund (SWF) and the Social Fund for Development (SFD), ${ }^{34}$ Given the situation in Yemen, it is unlikely that strong line agencies and decentralized administrations will emerge and SFD will continue to be trusted for the services it delivers in a non-partisan fashion. The Social Fund approach, properly adapted to local circumstances, may thus remain the most viable option for some time in countries with lingering conflicts, weak civil society organizations and fragile governance.

\section{Flexibility through Donor Core Funding}

SFD's flexible mode of funding made a demand-driven approach possible. It uses an overall flexible plan with an average five years time horizon. SFD and its lead donors set an overall budgetary estimate for the phase based on performance in previous years. During this time, SFD with support from its lead donors conducts fundraising for that phase. The flow of funds from various donors continues during the phase. It takes time for projects to start disbursements as the participatory process and procurement are time consuming. Therefore, SFD continuously identifies project proposals that are registered in its MIS, ready for further field assessments and procurement once funds are made available. In each phase, the substantial amount of funding raised is provided as core funding for various lines of projects. Some donors earmark their funding for specific sectors that are among planned activities for the corresponding phase.

SFD acquired visibility with communities and donors as a result of its expansion throughout Yemen. As a consequence, it has been able to attract the attention and support of government and donors. It expanded the delivery of basic infrastructure by outsourcing project implementation to national and community contractors who expanded their capacities over the years. This contributed not only to speedy disbursements but also gave SFD time to experiment with new interventions and to improve progressively its participatory approach without the pressure of slow disbursements.

SFD has not only expanded in terms of geographical areas covered but also into new areas of intervention corresponding to the changing demand for projects. In 2007/08, new programmes and interventions were added to SFD's menu, including the Labour-Intensive Works Programme and the Agriculture and Rural Development Programme to respond to emerging needs as food insecurity was increasing in Yemen.

In 2008, the World Bank approached SFD to implement a rapid response project to the rise in international food prices that had a large negative impact on Yemenis' food security. Yemen imports more than three-quarters of its grain consumption from the international market. SFD responded by designing the community-based labour-intensive works, which expanded rapidly to become a major SFD programme.

In the context of the 2011 political crisis, SFD was almost the only national institution (along with the Social Welfare Fund, which is the government's 


\section{DEVELOPMENT ASSISTANCE FOR PEACEBUILDING}

major social cash assistance programme) that continued to operate, focusing on its cash-for-work programme and on its water supply interventions that were considered top priority needs at that time.

Yemen's SFD relies heavily on external aid, with foreign donors providing approximately 80-85 per cent of its financial resources. SFD believes that good performance is key to sustaining the flow of funds from donors and maintaining a diversity of sources of funding. International experiences with Social Funds confirm this observation. In their cross-country study of Social Funds, Rawlings et al. found that Social Funds have been instrumental in attracting funding from foreign donors that would not otherwise have been available. ${ }^{35}$ In a country like Yemen, where the absorptive and institutional capacity of public institutions is limited, a Social Fund has proven to be a valuable instrument to mobilize funding and use it for development and social protection. However, for the long term, SFD may have to invest in income-generating social enterprises to cover large parts of its financial needs more flexibly and predictably, thereby pursuing a model similar to Bangladesh Rural Advancement Committee's in Bangladesh. Securing the long-term funding of Social Funds is important to allow the approach to flexibly and rapidly meet communities' changing needs.

\section{Relevance through Quality of Impacts on Livelihoods}

The demand-driven approach allows SFD to respond to what communities believe will serve them best at a particular time. Rural and urban Yemen typically lack basic infrastructure services. Access to these tangible assets was considered a priority by a majority of communities. The demand-driven approach made community and local development SFD's largest component. In the 2009 evaluation, 90 per cent of respondents indicated that the projects supported by SFD were a priority to them. SFD planned these projects with the communities and involved them in implementation, and people responded that this is what they really wanted. Findings from the evaluations clearly show that these assets produced results in increasing access to school and student enrolment, particularly girls in rural areas, ${ }^{36}$ improving access to health services and reducing the time needed to fetch water or access markets and services through rural road interventions. The LIWP projects improved livelihoods in poor rural areas that had been constrained by limited local public goods. As SFD evaluations (except for the LIWP) were not based on randomized control trials, it is not possible to confirm that the outcomes were solely due to SFD's interventions. However, it can be confirmed that SFD's projects have been instrumental to achieving such an impact. It is important to note that in 2006, it was not possible to measure the outcomes of the water sector as SFD interventions were focused on community rainwater harvesting schemes. In 2010, results from water interventions were positively measured and could be attributed to the fact that SFD had changed its interventions to smaller water harvesting schemes that are closer to the beneficiaries' households.

Reviewing the external evaluations and the reports from joint-donor missions shows that SFD has been able to improve its interventions over time. This is in terms of programmes, management, as well as coverage and technical 


\section{DEVELOPMENT ASSISTANCE FOR PEACEBUILDING}

implementation. SFD has been able to learn from its actions and to achieve sustainable pro-poor results in part through importance given to evaluations. It is noticeable from beneficiary surveys that issues that had been mentioned to be problems in an evaluation were no longer considered to be problems by survey respondents in the subsequent evaluation.

SFD is working on four programmes that provide a range of short- to longterm development services. A key issue that has been debated is how SFD can better position itself as part of Yemen's poverty reduction strategy, with both its donors and the government understanding and supporting this role. Recently SFD, its donors and the government have agreed that SFD should take on the following two roles: first, contribute to long-term development goals by providing and improving access to socio-economic services and community assets with the objective of enhancing income opportunities for the poor; and second, form part of the country's social safety net to reduce vulnerability to poverty by (1) alleviating the impact of shocks through the provision of employment opportunities, and (2) reducing vulnerability to shocks through the enhancement of social assets and capacity building. Continued relevance and effectiveness of SFD, and of the Social Fund approach, will derive from fulfilling these generic roles in a context where delivering aid is fraught with difficulties.

\section{SFD's Expansion}

With low capacity among government agencies to absorb donor funding, SFD has been one of the country's main institutions with absorptive capacity, permitted by its flexible operating procedures, efficient delivery record, quick disbursing capacity and internal learning ability.

SFD can still increase its implementation and outreach capacity through indirect modalities in working with local authorities, national NGOs and communitybased organizations. At the same time, SFD management indicated that direct implementation by SFD will continue to be necessary until a sufficient number of local service providers and NGOs become available to be contracted by SFD for indirect implementation. This creates a dilemma for SFD as there exists a risk that expansion may affect the quality of its direct interventions. If, however, SFD opts for more indirect implementation, it might lose its close collaboration with communities which has been essential to secure support and protection in a context of rising insecurity.

It is important to note that one of the issues SFD is facing in its future expansion is predictability of funding, particularly in the context of volatile and politicized foreign aid and an uncertain domestic political situation.

\section{Future Role in Supporting Local Development and Governance}

Since the first election of Yemen's local councils in 2002, which was conducted according to the 2000 local authority law, SFD has launched a series of initiatives to build gradually the capacity of local authorities ${ }^{37}$ and prepare them to implement projects directly on behalf of SFD. Supporting local councils was 


\section{DEVELOPMENT ASSISTANCE FOR PEACEBUILDING}

reflected in SFD's statement of development objectives for the third phase (200410). Since 2002, working through local authorities became a worldwide priority in the agenda of Social Funds. This came about as Social Funds direct relationship with communities was perceived to diminish the local government's accountability to the population and inhibit its budgeting function. ${ }^{38}$ In 2008, SFD participated in drafting Yemen's Local Authority Strategy and continued to work closely with the Ministry of Local Authority. However, this might have been viewed as sufficient as SFD maintained its direct implementation mechanism with communities and rarely transferred funds through the local authority that remained weak and strongly affected by political instability in the country. ${ }^{39}$ In January 2014, The Yemen National Dialogue was concluded calling for the transition of Yemen to a federal state and to the emergence of a new political order. In May 2014, SFD drafted a vision paper to outline its orientation towards the support of genuine local development. SFD stated that its vision and mission is a response to (1) Yemen's most pressing developmental challenges and (2) the outcomes of the National Dialogue Conference with respect to Yemen's future system of sub-national governance and public administration. ${ }^{40}$ In September 2014, Yemen entered a new cycle of turmoil when Al-Houthis or 'Ansar Allah' captured the capital Sana'a and rejected the draft of the new constitution. In March 2015, a civil war erupted in Yemen ${ }^{41}$ which has changed the development priority towards a humanitarian response prioritizing early recovery.

\section{Conclusion}

The Social Fund (SF) modality in delivering foreign aid started in 1980. Evaluations of the performance of SFs have produced mixed results. The majority of SFs are known to share traits such as good management, relative operational autonomy and flexibility in allocating budgets among alternatives investments. ${ }^{42}$ While Yemen's SFD has its own operational details that are unique to it and to its social, political and economic environment, the above-mentioned evidence of effectiveness suggests that the core design may be replicated in other environments, including in countries experiencing failing states, tribal conflicts and post-conflict transitional regimes.

As we have seen above, Yemen's SFD has been performing effectively in spite of a particularly hard context due to its collaborative relationships with local communities, its perceived political neutrality, its flexible mode of project funding and operation and the importance of its interventions to beneficiaries enlisting their support and protection. These four pillars create the singularity of its approach. How SFD has implemented them provides lessons for using the Social Fund approach to deliver aid in hard places across the world. 


\section{DEVELOPMENT ASSISTANCE FOR PEACEBUILDING}

\section{NOTES}

1. See www.bbc.com/news/world-middle-east-14704951.

2. Abdulmajeed Al-Batuly, Mohamed Al-Hawri, Ministry of Planning and International Cooperation of Yemen, Martin Cicowiez, CEDLAS-UNLP, La Plata, Argentina Hans Lofgren, World Bank, Washington, DC, Mohammad Pournik, UNDP, Regional Bureau for Arab States, Cairo, 'Assessing Development Strategies to Achieve the MDGs in the Republic of Yemen', Country Case Study, New York: United Nations Department for Economic and Social Affairs, Jul. 2011.

3. Government of Yemen, Social Fund for Development Establishment Law number 10, 1997.

4. ESA Consultores Internacional, 'Yemen Social Fund for Development 2003: Impact Evaluation Study', Final Client Report, World Bank, 2003.

5. ESA Consultores Internacional/Environmental Resources Management, 'Yemen Social Fund for Development 2006 Impact Evaluation Study. Final Report', Client Report, DFID, 2007.

6. DFID Yemen Social Fund for Development - Impact Evaluation Final Report Nov. 2010. The Recovery and Development Consortium: Maxwell Stamp PLC, the Post-Conflict Reconstruction Unit, the University of York and COWI.

7. World Bank, United Nations, the European Union and the Islamic Development Bank, Joint Social and Economic Assessment for the Republic of Yemen, Sana'a: World Bank, 2012.

8. Yemen Central Statistics Organization, The Yearly Statistics Book, Sana'a: Central Statistics Organization, 2011.

9. Marta Colburn, 'Yemeni Non Governmental NGO Assessment', Report to SFD, Jun. 2009.

10. Daniel Egel, 'Tribal Diversity, Political Patronage and the Yemeni Decentralization Experiment', $\mathrm{PhD}$ thesis, University of California at Berkeley, 2010 (at: www.cgdev.org/doc/events/PostDoc\%20Seminars/Daniel_Egel.pdfwww.cgdev.org/doc/events/Post-Doc\%20Seminars/Daniel_ Egel.pdf).

11. World Bank, 'Republic of Yemen Poverty Update', Volume 1: The Main Report, Report No. 24422, Washington, DC: World Bank, 2002, p.55.

12. DFID, Aide Memoire on SFD-DFID Discussions, London: DFID, 2011, para. 3.

13. April Alley, 'The Rules of the Game: Unpacking Patronage Politics in Yemen', Middle East Journal, Vol.64, No.3, 2010, pp.385-409.

14. Nadwa Al-Dawsari, 'Tribal Governance and Stability in Yemen', Carnegie Foundation, 2012 (at: http://carnegieendowment.org/2012/04/24/tribal-governance-and-stability-in-yemen).

15. Al-Batuly et al. (see n.2 above).

16. World Bank, 'Project Appraisal Document on a Proposed Grant to the Republic of Yemen for a Social Fund for Development Phase IV Project', Report No. 52365 YE, 2010.

17. SFD Management Information System.

18. Data collection, analysis and report finalization were completed in 2010. However, the evaluation title is the S2009 Impact Evaluation as the process started in 2009.

19. Statistical technique to calculate the average change over time in the outcome variable for the treatment group to the average change over time for the control group.

20. Communities are randomly allocated to the different treatments of the study. In this case, the communities' pairs are randomly allocated for the interventions in 2010 and those of the interventions in 2013 .

21. S. Christian, A. de Janvry, D. Egel and E. Sadoulet, Quantitative Evaluation of the Social Fund for Development Labor Intensive Works Program (LIWP), Berkeley, CA: University of California, 2013.

22. SFD Management Information System, Jul. 2013. 


\section{DEVELOPMENT ASSISTANCE FOR PEACEBUILDING}

23. Based on the 2004 Yemen Population Census, 73 per cent of Yemen's 19.3 million population live in rural areas.

24. M. Jennings, 'DFID Yemen Social Fund for Development - Institutional Evaluation SFD Evaluation 2009', Final Institutional Evaluation Report, Contract No. CNTR 200808562, The Recovery and Development Consortium: Maxwell Stamp PLC, the Post-Conflict Reconstruction Unit, The University of York and COWI, 2009.

25. Ibid.

26. SFD Management Information System.

27. M. Jennings, Institutional Analysis of Social Fund for Development, Republic of Yemen, London: DFID, 2006.

28. Ibid.

29. Ministry of Education, Republic of Yemen and KfW Entwicklungsbank, 'School Construction Costs in Yemen Cross-Sector and Multi-Institutional Assessment Study', Draft Report on Findings SEF No. 199270 182, Prepared by GET German Education and Training GmbH, 2008.

30. Jennings (see n.24 above).

31. Ministry of Planning and International Cooperation, 'Developing Yemen's Aid Policy', Working Paper No. 6, Sana'a: Aid Harmonization Unit, Ministry of Planning and International Cooperation, 2006.

32. S. Baas and A.O. Ali, Community-Based Organizations in Yemen: Good Practices and Lessons Learned, Rome: FAO Rural Institutions and Participation Service, 2004, p.2 (at: www.fao.org/ docrep/008/y $7218 \mathrm{t} / \mathrm{y} 7218 \mathrm{t} 07 . \mathrm{htm})$.

33. Jennings (see n.24 above).

34. Oxfam, 'Yemen: Fragile Lives in Hungry Times', Oxfam Briefing Paper No. 152, 2011, p.4.

35. Laura Rawlings, Lynne Sherburne-Benz and Julie Van Domelen, Evaluating Social Funds: A Cross-Country Analysis of Community Investments, Washington, DC: World Bank, 2003.

36. The 2009 evaluation reported an increase in enrolment rates between 2006 and 2010 of 14 per cent $(6$ per cent for boys and 27 per cent for girls).

37. Local authorities consist of elected local councils and line ministries offices at the district level.

38. Soniya Carvalho and Howard White, 'Theory-Based Evaluation: The Case of Social Funds', American Journal of Evaluation 2004 (at: http://lnweb90.worldbank.org/oed/oeddoclib.nsf/ DocUNIDViewForJavaSearch/A0E7163ED9E3E43985256BA600563482/\$file/Social_Funds. pdf).

39. Egel (see n.10 above).

40. Yemen Social Fund for Development, A Vision for the 5th Cycle, Sana'a: SFD, 2014.

41. Please see http://en.wikipedia.org/wiki/Yemeni_Civil_War_\%282015\%29.

42. World Bank Operation Evaluation Department, Social Funds: Assessing Effectiveness, Washington, DC: World Bank, 2002. 


\title{
Substantial but Uneven Achievement: Selected Success When Stars Align. Public Financial Management Reforms in Sierra Leone
}

\author{
HEIDI TAVAKOLI, ISMAILA B. CESSAY and \\ WINSTON PERCY ONIPEDE COLE
}

\begin{abstract}
In the decade following the end of the civil war, the Government of Sierra Leone made substantial progress in strengthening public financial management. Improvements were achieved across all aspects of the budget cycle and were particularly notable with regard to budget execution functions. The main factors that appear to have contributed to these improvements are a strong starting position at the beginning of the cease-fire; political appetite for public financial management reforms; a cadre of motivated and professional local technical advisers; and considerable international support co-ordinated through budget support operations.
\end{abstract}

\section{Introduction}

Since the end of the civil war, the Government of Sierra Leone (GoSL) has made substantial progress in improving its public financial management (PFM) system. By 2007, it had achieved public expenditure and financial accountability (PEFA) assessment scores equivalent to those attained by other countries in the region, despite its more fragile context. ${ }^{1}$ Key achievements primarily relate to budget execution functions, including accounting, reporting and establishing the internal audit function. Budget formulation has received a similar level of attention but results have been less successful, while improvements in external audit and parliamentary scrutiny have transpired more recently.

A number of factors appear to have contributed to the successful improvement of PFM performance in Sierra Leone. This article suggests that strong ownership and commitment to reforms by the Ministry of Finance and Economic Development (MoFED) matched by human capacity to deliver on reform agendas were key drivers of success. This conducive environment for progress was facilitated by strong PFM performance immediately after the cease-fire and further catalysed by the substantial incentives for performance created by international support over the following decade. In some areas the concentration and sequencing of reforms were also important, yet substantial attention given to certain PFM functions has delivered limited returns.

This article focuses on the decade immediately after the end of the civil war. It looks to factors both prior to and during this period to help explain performance.

This is an Open Access article distributed under the terms of the Creative Commons Attribution-NonCommercial-NoDerivatives License (http://creativecommons.org/Licenses/by-nc-nd/4.0/), which permits noncommercial re-use, distribution, and reproduction in any medium, provided the original work is properly cited, and is not altered, transformed, or built upon in any way. 


\section{DEVELOPMENT ASSISTANCE FOR PEACEBUILDING}

It draws heavily on research carried out by the authors as part of a World Bank study on public financial management reforms in post-conflict states. The wider World Bank study attempted to answer two overarching questions. How were PFM reforms affected by the challenges associated with state fragility? Did the design and implementation of PFM reforms contribute to achieving sustainable progress in the development of PFM systems, as well as to supporting wider state- and peace-building objectives? The cross-regional findings illustrate that significant progress with improving PFM is possible in countries that suffer conflict legacies, including low and depleted human capacity, levels of continuing insecurity and acute levels of underdevelopment. Sierra Leone, along with Afghanistan, Kosovo and the West Bank and Gaza, achieved 'substantial' progress in this regard, whereas Cambodia and Liberia delivered immediate progress, while the Democratic Republic of Congo and Tajikistan showed limited improvement. In line with Sierra Leone's experience, progress has been uneven across the dimensions of the budget cycle in these countries, with some areas faring better than others.

This article draws on and extends this and other work by the authors, including adding new perspectives on the challenges and opportunities of such reforms drawn from first hand involvement in the reform process in Sierra Leone both immediately after the cease-fire and in the later years. ${ }^{2}$

\section{Country Context}

The devastating consequences of a series of military coups and a protracted civil war between 1991 and 2002 are still visible in Sierra Leone. During the last ten years of the conflict, killings, looting and the destruction of property were widespread, resulting in the displacement of a third of the population. The impact of such devastation is most acutely illustrated in Sierra Leone's position on the Human Development Index (HDI), where it was recently ranked 183rd out of 187 participating countries. ${ }^{3}$

Yet such stark performance does not capture the considerable progress in macro-economic and social development achieved since the end of the civil war. During the decade following the civil war Sierra Leone exceeded growth rates for most other Sub-Saharan African (SSA) and low human development countries; recording an average of 7 per cent Gross Domestic Product (GDP) growth between 2003 and 2012, with real growth rates not far behind (World Development Indicators, International Monetary Fund (IMF databases)). This was achieved despite periods of high inflation, the suspension of budget support in 2007 and the disruptive effects of the global economic crisis in the following year. Such growth was largely driven by strong performance in agriculture, mining, manufacturing and construction sectors. Alongside the initialization of iron ore exports, these high growth rates look set to continue. Economic improvements have been matched by improvements in most social development indicators. Despite Sierra Leone's poor positioning on the HDI, since 2000 HDI growth rates have exceeded those for most low human development countries and marked improvements in areas such as gender equity in 


\section{DEVELOPMENT ASSISTANCE FOR PEACEBUILDING}

primary education have been achieved. This has been facilitated by a rise in social sector spending - reversing a trend which saw the proportion spent on health, social security and welfare fall between 2003 and 2007 - and the implementation of activities outlined in the government's national development plan: 'Agenda for Change 2008-2012'. ${ }^{4}$

It is not uncommon to experience similar positive development trajectories in post-conflict environments. Yet, in the case of Sierra Leone, this performance coupled with the successful introduction of other reforms to strengthen democratic governance and public service delivery - fostered the conditions for transition from fragile and conflict-affected state (FCAS) status less than ten years after the cease-fire. ${ }^{5}$

\section{The Public Financial Management Approach}

PFM concerns the institutional arrangements that affect the design and implementation of the government's fiscal plans and its overall fiscal performance. Institutional arrangements refer to the agencies, laws, systems and procedures and capabilities that influence the effectiveness of fiscal performance. Even though PFM traditionally covers ways in which public finances are generated, allocated, spent and accounted for, this article focuses on issues and processes related to the expenditure side only. In Sierra Leone, the primary institutions of concern are the Ministry of Finance and Economic Development (MoFED), the Independent Auditor General, the National Public Procurement Authority and Parliament (including the Public Accounts Committee). ${ }^{6}$

There have been four main PFM reform action plans since the end of the civil war. ${ }^{7}$ The first, following the cease-fire, was primarily based on the recommendations of the World Bank-funded Country Financial Accountability Assessment (CFAA) undertaken in March 2002. Steps to implement the recommendations were undoubtedly followed by GoSL and the World Bank, the Department for International Development (DFID), African Development Bank (AfDB) and the $\mathrm{EU}$, but the extent to which this became the central and exclusive reform agenda in MoFED is unclear.

The second plan was developed at the end of 2004. It was initially referred to as the Common Action Plan (CAP) because it was a 'common' plan whereby donors could collectively align their support. The aim was to amalgamate all donor supported PFM initiatives into one comprehensive strategy document in an attempt to harmonize support and reduce the growing level of transaction costs the government faced. ${ }^{8}$

The Common Action Plan eventually transformed into the National Action Plan, incorporating further PFM targets and plans. ${ }^{9}$ The National Action Plan became the main government-donor monitoring tool and the Secretariat for the Oversight Committee was moved to the Public Financial Management Reform Unit. ${ }^{10}$

In 2008, the Integrated Public Financial Management Reform project was developed. The programme set out reforms according to specific platform stages and focused on both supply- and demand-side elements of reform, 


\section{DEVELOPMENT ASSISTANCE FOR PEACEBUILDING}

including non-state actor engagement. Similar to previous plans, its design was heavily directed by PFM diagnostic instruments ${ }^{11}$ and attempted to integrate recommendations from more recent relevant initiatives. The fourth PFM reform strategy will run from 2014 to $2017 .{ }^{12}$

Two patterns have emerged over the development of PFM reform plans in Sierra Leone. First, all the PFM reform plans have been heavily directed by PFM diagnostic instruments funded primarily by the international community. Initially this led to a collection of activities that were organized with limited attention given to their proper sequencing. Second, over time however, there has been a clear attempt to improve the comprehensiveness and conceptual coherence of each successive reform plan so as to streamline government-donor effort and strengthen the reinforcing nature of some reforms. ${ }^{13}$

\section{An Uneven Success across the Budget Cycle}

Since 2002, the GoSL has made good progress in terms of improving its overall PFM performance and has initiated an ambitious set of reforms. ${ }^{14}$ But improvements have not been consistent across the budget cycle, with some areas faring better than others. A cursory presentation of reforms and progress in the ten years following the cease-fire is presented below followed by a more detailed discussion of the contributing factors of performance.

\section{Legal and Institutional Framework}

Between 2003 and 2007, considerable attention was paid to developing the legal and regulatory framework for budgeting, accountability and procurement. A number of new acts and procedures were developed and supplemented by the establishment of several new entities some of which were tasked to co-ordinate PFM reforms. ${ }^{15}$ This considerable attention ensured an adequate and generally appropriate regulatory framework had been developed by $2007,{ }^{16}$ which compared well with that of most developing countries. ${ }^{17}$

Since then, however, contradictory conclusions have been reached on the appropriateness of this legal framework. For instance a commission appointed to review the 1991 Constitution made no recommendations for change, ${ }^{18}$ whereas a 2010 review of the government budgeting act and financial regulations noted that 'much still needs to be done to streamline, strengthen and harmonize the PFM legislation'. ${ }^{19}$ Nevertheless, there is agreement on the disconnect between the legal framework and common practice; 'perhaps the most pressing issue with regard to the legal framework is its implementation'. ${ }^{20}$

\section{Planning and Budgeting}

Introducing a policy-based, medium-term budget formulation process was an early reform priority and saw the introduction of a medium-term expenditure framework (MTEF) in 2001. Yet, despite this early and somewhat continuous attention in the post-war PFM reform effort, limited results have actually been achieved in terms of the use and quality of medium-term strategic fiscal planning. ${ }^{21}$ 


\section{DEVELOPMENT ASSISTANCE FOR PEACEBUILDING}

A number of factors explain this poor performance: burdensome budget planning requirements; the fragmentation and separation of investment and recurrent budget planning; weak planning and costing capacity; and poor knowledge of strategic documents (such as the second Poverty Reduction Strategy Paper $(\mathrm{PRSP}))$. Collectively this translates into inconsistencies across budget and planning documentation, late submissions and unreliable outer year projections which often bear little resemblance to policy plans. ${ }^{22}$

\section{Budget Execution}

Relative to other dimensions of the budget cycle, budget execution functions reforms have been more successful and the Accountant General's Department (AGD) has been instrumental in achieving these results.

During the civil war, strong expenditure control was delivered by the AGD and achieved through a heavily centralized Financial Management and Accounting System. Since the cease-fire, the same department has spearheaded two key PFM achievements. First, the implementation of the Integrated Financial Management Information System (IFMIS), which - alongside the introduction of the first written procedures for budget execution in 2006 - helped address the poor budget execution rates and budget credibility that have historically plagued Sierra Leone. ${ }^{23}$ It also helped improve in-year budget reporting. So even though the benefits of the IFMIS were not being initially maximized, its implementation allowed a larger variety of data to be transferred to ministries, departments and agencies to assist them in decision making. ${ }^{24}$ The AGD also facilitated a second key PFM achievement - increasing the timeliness of financial statements and bank reconciliations, both of which are up to-date. Alongside these reforms, there was also significant effort to establish credible internal audit systems in the public sector; a relatively new concept for Sierra Leone. ${ }^{25}$

\section{External Audit and Scrutiny}

Compared to other stages of the budget cycle, external audit and scrutiny received proportionately less attention until several years after the cease-fire. This may be because these activities received relatively little coverage in early PFM assessments (e.g. the CFAA and the HIPC-AAP) which formed the basis of Sierra Leone's initial PFM reform plans, and there was a higher concentration of local technical advisers (LTAs) in the area of budget execution rather than planning and implementation oversight. Institutional and political challenges related to fostering strengthened domestic accountability mechanisms may also have delayed their attention. As a result, this has been one of the poorest performing areas of PFM.

External audit: Weaknesses in the comprehensiveness of audits, as well as severe delays in the submission of the Auditor General's annual reports to parliament, have historically undermined the impact of the Auditor General's work. ${ }^{26}$ These areas were eventually addressed and the performance of the external audit function started slowly catching up with other aspects of the budget cycle.

Parliamentary and civil society oversight: Parliamentary scrutiny of budgets and external audits have also improved, despite poor past performance. Yet it 


\section{DEVELOPMENT ASSISTANCE FOR PEACEBUILDING}

continued to be undermined by short time-frames allocated to parliamentary review, bilateral discussions between the Minister of Finance and other ministers and poor credibility of the macroeconomic and fiscal framework. ${ }^{27}$

Mechanisms such as manpower hearings, policy hearings and participatory budget discussions were established to encourage greater participation in the budget formulation process. However in practice engagement appeared fairly limited and not particularly meaningful, raising questions about its value.

\section{Drivers of Public Financial Management Reform Success}

Five main contributing factors appear to have influenced the choice and success of the reform approach pursued. Particular attention is paid to the interaction of aid processes and other contributory factors. The findings support conventional wisdom that international assistance can positively bolster change processes when the interests of government/sector officials are aligned with those of the international development community. In Sierra Leone, the international community were able to catalyse positively political drive and capacity for reform within MoFED. Together, this contributed to considerable improvements in PFM. In addition to these factors, success can also be explained by the favourable local conditions prior to the cease-fire, as well as the timing and distribution of reforms over the time period. ${ }^{28}$

\section{Local Context: Conditions at the Time of the Cease-Fire}

The first contributory factor concerns the local context at the time of cease-fire. According to the CFAA's findings the PFM system was functioning 'surprisingly well $^{29}$ at the time of the cease-fire, despite the severe depletion of human and physical capacity during the conflict; not only was there a loss of skilled personnel but the building that housed the Ministry of Finance and Economic Development was destroyed in $1997 .^{30}$

Two factors explain this relatively strong performance and the creation of an environment conducive for future PFM reforms:

- First, during the civil war, a highly centralized management system was maintained by a few well-qualified and financed technical assistance experts who ensured strong expenditure control and adherence to the legal and regulatory framework. ${ }^{31}$ At the time, the Accountant General was a foreign adviser, supported by eight local contract staff members, all funded by international donors. The strong discipline in commitment control, payment and accounting was primarily due to the fact that the Financial Management and Accounting System, implemented in 1998, was designed and administrated solely by the Accountant General. Although this ensured strong expenditure control, it also created associated problems related to accountability and sustainability.

- Second, between 1996 and 2002, incremental policy initiatives, as well as the continued provision of some public services to restricted areas of the country, served to strengthen governance structures. Even though most of the GoSL's energies were focused on security, the government was able to launch a wide- 


\section{DEVELOPMENT ASSISTANCE FOR PEACEBUILDING}

ranging National Strategy for Good Governance in 1997 and to establish the Governance Reform Secretariat. This initiated work on civil service and local government reform, including laying the foundations for anti-corruption reform. In terms of PFM reform, the government started implementing the Financial Management Accounting System and a MTEF towards the end of the civil war period, and established a small but influential Economic Policy and Research Unit responsible for macroeconomic management. ${ }^{32}$

In addition there are other economic conditions that appear to affect PFM performance. ${ }^{33}$ Research suggests that state fragility has a negative effect on performance, as does a low population size, growth rates and per capita income. ${ }^{34}$ In this regard Sierra Leone is somewhat of an outlier as it has made great strides in PFM performance despite reflecting many such characteristics. The exception is high growth rates which may have counterbalanced such effects. ${ }^{35}$

\section{Local Ownership: Political Appetite for Public Financial Management and Wider Public Sector Reforms}

The second influencing factor concerns the political appetite for PFM reforms. Evidence continues to indicate that political commitment to PFM and public sector reform, as well as local ownership of the agenda, is instrumental to its success. ${ }^{36}$ Such support is often stronger in countries where PFM reform performance is considered to be a function of greater state-building efforts. ${ }^{37}$ In the case of Sierra Leone, two patterns emerge regarding the political appetite for PFM reforms. First, within MoFED (the lead central finance agency in the country), certain champions have been instrumental in spearheading reform efforts. One such champion is the current Minister of Foreign Affairs who has filled the role of both financial secretary and minister for long periods since the peace agreements. Trained as an economist, he quickly developed a strong technical understanding of the reforms. This, in conjunction with his political clout within the cabinet and his previous experience at international financial institutions, meant he was uniquely placed to navigate successfully the complex political influencing opportunities both within government and between government and donors, and to drive reforms forward. ${ }^{38}$

Second, it is unclear whether this commitment to reform was matched by the political establishment beyond MoFED. On the one hand, Sierra Leone's second PRSP considers macroeconomic stability and PFM performance to be a foundation of sustained pro-poor growth. Furthermore, the fact that the Minister sold the reforms in Cabinet indicates that there were other, perhaps silent, champions. On the other hand, a World Bank political economy study suggested there was little enthusiasm for the reforms at the highest echelons of state authority. This was attributed to the fact that planned reforms focused on building institutions and processes that limited the patrimonial discretion of state authorities. ${ }^{39}$ According to the report, reforms were instead pushed through because of the GoSL's dependence on financial and technical support from the international donors, which meant the latter dominated policy options, programmes and activities. 


\section{DEVELOPMENT ASSISTANCE FOR PEACEBUILDING}

It is similarly difficult to decipher the real nature of support for wider public sector reforms in Sierra Leone. For public sector reform activities there has been a similar divergence between public policy pronouncements for reform (tied with significant increases in funding) and the achievement of improved public sector performance. For example, in the early stages of his tenure, President Kabbah's government prioritized civil service reform alongside fighting corruption, and it formed a key part of the 1999 Governance Reform Secretariat. Kabbah spoke of a 'lean, efficient and effective, performance-orientated civil service'40 and pumped significant resources into public administration. By the time he left office in 2007, general public services received 32 per cent (the largest proportion) of total recurrent expenditure. Yet, over his tenure, inadequate improvements in civil service salaries, insufficient tightening of local patronage practices within the civil service and limited reduction of corruption, meant the Kabbah government made little progress towards implementing his vision.

Since then, public sector reform efforts have continued to be sluggish. ${ }^{41}$ Even though a reasonable expectation of reform results must be acknowledged, ${ }^{42}$ the evidence of the impact of the substantial growth in spending is mixed and does not seem to have been very effective. Much like his predecessor, President Koroma has made strong political pronouncements regarding his commitment to public sector reform. At the launch of the GoSL's second PRSP in 2009, he noted: 'It is our conviction that no economic transformation is possible without a transparent, accountable and effective public sector dedicated to providing supportive policies and actions. ${ }^{43}$ To deliver this mission, he set up a donor-supported Strategy and Policy Unit in the Office of the President tasked with overseeing the intended transformation and supporting the delivery of key reforms. This helped focus implementation effort and advance some key economic reforms, but government-wide performance remains weak.

\section{Capability of the Government of Sierra Leone to Deliver on the Reform Agenda}

The third factor concerns MoFED's administrative and technical capability to deliver on the reform agenda. It is relevant to both discussions of local context as well as local ownership. In fragile states, reform aspirations and the activities accepted by decision-makers are often not in line with the capacity endowment to deliver on such reforms. ${ }^{44}$ This sentiment is aligned with findings from the recent PFM evaluation which suggests a necessary condition for reform success is the tailoring of reform designs and implementation models to the institutional and capacity context. ${ }^{45}$

In Sierra Leone, in the context of weak civil service capacity and ambitious development agendas, the GoSL and donors hired several categories of personnel to operate alongside the civil service. These highly skilled personnel formed what became known as the 'parallel public service'. They were responsible for performing the highest level of policy development, planning and policy implementation functions, while routine administration procedures were left to the mainstream civil service. ${ }^{46}$ In an attempt to retain these highly qualified and motivated staff, they received salaries above the civil service pay scale and were almost exclusively paid by donors. 


\section{DEVELOPMENT ASSISTANCE FOR PEACEBUILDING}

One type of such personnel, are local technical advisers (LTAs), who became instrumental in PFM reform efforts in Sierra Leone. Their role and influence was first established during the conflict, when a small group of LTAs alongside international consultants maintained key PFM functions in the AGD. Following the cease-fire, many more LTAs were hired and by 2008 they significantly outnumbered regular civil servants at professional grades. ${ }^{47}$ Furthermore, all the government entities established to support the co-ordination of PFM reform agendas were staffed with LTAs. A common theme in interviews with government officials and donors in Sierra Leone was that this cadre of motivated, highly experienced and well-remunerated staff (both technocratic and ministerial) was crucial to the implementation of certain reforms. ${ }^{48}$ They not only helped drive the implementation of reforms, but also further strengthened capacity in MoFED by incentivizing others to pursue further education and training.

The existence and performance of LTAs and other off-civil service officials are intertwined with the two other main drivers of reforms in Sierra Leone: the incentives created by the multi-donor budget support donors and the governance and leadership of MoFED. LTAs and other off-civil service officials had prominent positions in MoFED. In fact, the vast majority of senior managers in the ministry were classed as such staff. This meant they played a significant role in the design and implementation of reforms. Furthermore, such officials often were reliant on donors for their existence. Until recently, the vast majority if not all of such officials have been paid directly (or fungibly) from donor resources. As a result, the LTAs' professional interest in maintaining donor relations and reform success has, in part, secured the donors' influence. ${ }^{49}$

A number of concerns have been raised about the extensive use of LTAs. Not only are there questions about the sustainability of reform efforts spearheaded by parallel structures, but evidence also points to the corrosive impact sharp salary disparities between civil servants and off-civil service line position officials has on morale and the feeling that such arrangements have siphoned critical skills out of government. ${ }^{50}$ Therefore, even if such capacity helped deliver short-term reform success in Sierra Leone it has come at a heavy cost in terms of building sustainable and affordable human capital. Between 2011 and 2012, many of the LTAs were brought onto the civil service, but their salaries have largely remained multiples higher than other civil service grades.

\section{International Co-operation and Aid Modalities}

The fourth contributory factor is the international communities' involvement. External actors have been heavily engaged in Sierra Leone, both during and since the end of the conflict. During the civil war, multilateral and bilateral assistance provided financial and technical assistance to maintain some state functions, stabilize the security situation and eventually help secure the peace process. Sierra Leone has since been viewed as a 'success story of international intervention to put an end to a brutal civil war'. 51

At the turn of the century, UN, IMF, World Bank, DFID and EU aid programmes provided essential financing for the government's budget and helped maintain a functioning government at a time when other sources of revenue 


\section{DEVELOPMENT ASSISTANCE FOR PEACEBUILDING}

were very scarce. Beyond providing financial support, these donors provided support to the development of government strategy and policy. For instance, following the forced exile of the Sierra Leone People's Party government in 1997, cabinet advisers took part in a DFID-funded conference in the UK, which led to the production of a ' 90 day programme' outlining a development reform project for the restoration of the government. ${ }^{52}$

Since the end of the war, the international community have played a prominent role in supporting the public sector, including PFM performance. This role was primarily assured by the substantial budget support programme, which equated to a quarter of all discretionary spending between 2001 and $2006 ;{ }^{53}$ surpassed by few. ${ }^{54}$ The programme became a key focal point for policy dialogue between the GoSL and budget support donors (AfDB, DFID, the EU and the World Bank). Its importance and leverage was driven by two reinforcing factors:

- First, it remained a significant source of revenue for the government: between 2008 and 2012, equivalent to between 20 to 30 per cent of total recurrent expenditure. This high degree of aid-dependency shored up the importance of the budget support donors' voice at the policy table.

- Second, the withholding of budget support funds in $2007^{55}$ not only had a considerable effect on fiscal management but was also considered by some to be a contributory factor to the election of a new government in $2007 . .^{56}$

The budget support donors were inevitably interested in supporting the PFM systems used to spend government revenue and grants, including budget support finances. During 2005 and 2006, reacting to the renewed expression of the principles of aid effectiveness in the Paris Declaration, the budget support donors joined together to form the multi-donor budget support group. A joint Performance Assessment Framework was developed to harmonize donor monitoring procedures for the budget support operations. The proposed actions and indicators related to PFM made up the largest theme among all proposed actions in the Performance Assessment Framework between 2007 and 2013.

The multi-donor budget support donors' interest in strengthening PFM, alongside the sustained dependency of the GoSL on budget support and the real risk of donors withholding funds, meant that the GoSL faced strong incentives to push forward and implement PFM reforms tied to the budget support operations. Numerous budget support evaluations and related evidence on the role of budget support on PFM performance supports this conclusion. ${ }^{57}$

Four clear examples of the influence of the multi-donor budget support donors on the PFM reform agenda and PFM performance stand out:

- First, donors have heavily fed into the design and development of the PFM reform plans. For example, the primary motivation for the Common Action Plan - the second GoSL PFM reform plan post-2002 - was to consolidate the numerous donor PFM reform plans and initiatives that existed at the time. Following this attempt - which was considered to produce a plan too unmanageable to implement - the Integrated Public Financial Management 


\section{DEVELOPMENT ASSISTANCE FOR PEACEBUILDING}

Reform Project (funded by the budget support donors) was developed to further harmonize and align donor efforts with government priorities.

- Second, there have been improvements in PFM performance across the budget cycle, yet it is perhaps unsurprising that performance in areas included in the budget support Performance Assessment Framework appear to have been prioritized, because good performance is often a requirement for the continuation of donor support. For example, the variance in expenditure composition is better for sectors included in the budget support Performance Assessment Framework, suggesting their performance was prioritized vis-à-vis other budget heads. There have been similar improvements in the predictability of funds to local councils, which improved soon after it became a Performance Assessment Framework indicator. ${ }^{58}$

- Third, the budget support donors have been the predominant providers of significant project and technical advisory assistance to targeted areas of PFM (such as support to the Audit Service of Sierra Leone (ASSL)) and have funded the establishment of key PFM units in MoFED, for example the Public Financial Management Reform Unit and the Local Government Finance Department. ${ }^{59}$ - Finally, the budget support donors paid the salaries of the majority of LTAs in MoFED. So there was a strong incentive to preserve donor involvement and financial support.

Table 1 presents the main PFM programmes funded by donors in Sierra Leone between 2002 and 2013.

\section{Sequencing and Concentration of Reform Effort}

The final contributory factor relates to the sequencing of PFM reforms and the distribution of the reform effort. Intuitively, one would expect that PFM performance should be partly determined by the longevity of the reform effort - intuition that is supported by evidence. ${ }^{60}$ So one would expect, activities and functions receiving greatest attention over time should show greater levels of progress. This is partly true in Sierra Leone. Budget execution functions of the AGD, which have been heavily supported since the cease-fire, have shown fairly consistent improvement. In contrast, however, other functions that received similar levels of attention over the last 15 years continued to deliver relatively poor results, such as the MTEF. The finding that budget execution has actually faired better than budget formulation in Sierra Leone is contrary to conventional wisdom about more successful reform areas, where the reverse is often considered to be true. ${ }^{61}$ Yet this finding is mirrored in the wider PFM study and not surprising, given the problems associated with implementing MTEFs in fragile states. ${ }^{62}$ The rationale for focusing more on perfecting budget execution functions was largely to ensure first the existence of a fair degree of strengthened expenditure control and reporting, especially in the light of availability of very scarce resources beyond those provided by development partners. Equally, development partners have tended to support the prioritization of 'embedded controls' through the budget execution function, as a way to demonstrate the effective use of their taxpayers' resources put at the disposal of the fragile state. 


\section{DEVELOPMENT ASSISTANCE FOR PEACEBUILDING}

TABLE 1

DONOR SUPPORT TO PUBLIC FINANCIAL MANAGEMENT IN SIERRA LEONE

\begin{tabular}{ll}
\hline Donor & Type of support to PFM (primary projects) \\
\hline AfDB & 1. Integrated Public Financial Management Reform Project (IPFMRP) (2009-13) \\
DFID & 2. Support to the AGD, ASSL and the Public Debt Management Unit \\
& 1. Institutional Reform and Capacity Building Project (IRCBP) (2004-11) focused on \\
decentralized PFM \\
2. IPFMRP (2009-13) \\
3. Support to the Auditor General's Office \\
4. Support to the ASSL \\
5. Assistance to the National Commission for Privatization \\
6. Assistance on records management \\
7. Extensive support to the Anti-Corruption Commission (ACC) via technical \\
assistance and operational costs \\
8. Support to the National Democratic Institute to improve the operational and \\
reporting capacities of parliamentary committees (no longer operational) \\
In addition, through the provision of consultancy, DFID supported the implementation \\
of the National Action Plan (NAP) and PFM aspects of budget support; the \\
Government/Donor PFM Oversight Committee; and the National Revenue Authority. \\
1. IRCBP (2004-11) \\
2. IPFMRP (2009-13), including the Public Financial Management Reform Unit \\
(PFMRU) \\
3. The Decentralized Service Delivery Programme, approved in 2009, which will \\
provide grants to local councils and technical assistance to support decentralized service \\
delivery \\
In addition, the World Bank has provided support in this area through a series of \\
economic reconstruction and recovery credits, governance reform and growth \\
programmes and public sector management support programmes. \\
1. IRCBP (2004-11) \\
2. IPFMRP (2009-13) \\
3. Institutional capacity building of the finance ministry - which is a wide support \\
package to the key MoFED departments, including the AGD, the Budget Bureau, the \\
AGD, the Economic Policy and Research Unit, the Tax Policy Division and the Internal \\
Audit Unit \\
1. Support to non-tax revenue in the extractive industry \\
EU
\end{tabular}

Sources: Edited from H. Tavakoli, Public Financial Management Reforms in Fragile States: The Case of Sierra Leone, London: Overseas Development Institute, 2012, based on various sources, including the PEFA 2010. For further details, see GoSL, 'Republic of Sierra Leone: Public Financial Management Performance Assessment Report', Draft, Freetown: GoSL, 2010b.

Note: GIZ, Deutsche Gesellschaft für Internationale Zusammenarbeit.

In the ten years following the cease-fire the sequencing of specific reforms were largely driven by the results of diagnostic assessments rather than based on a change management theory. These assessments would throw light on poor performing areas and the associated set of remedial activities would form the basis of the subsequent PFM reform plans. So PFM reform effort mirrored the focus of diagnostic assessments. Sections of the budget cycle, such as external audit and oversight, have for the most part received reform attention later in the process because some diagnostic instruments (such as the Country Financial Accountability Assessment) gave them limited attention. Only with 


\section{DEVELOPMENT ASSISTANCE FOR PEACEBUILDING}

the introduction of the platform approach, have there been efforts to introduce a conceptual logic to reform sequencing based on an understanding of the necessary conditions and steps, and their ordering, to build stronger PFM functionality.

\section{Conclusions}

Having emerged from decades of conflict and civil war at the turn of the century, Sierra Leone has made good progress in PFM. It has performed particularly well against certain budget execution functions, strengthened the PFM legal framework and budget planning and overseen more recent improvements in audit and oversight.

What does this mean for other post-conflict countries embarking on similar reform trajectories? Well, it is clear that significant improvement in PFM is achievable even in the most fragile of contexts. Sierra Leone's experience in the decade after the conflict is illustrative of this, as is wider evidence on PFM reforms in fragile states. ${ }^{63}$ The wider research also shows that performance across the budget cycle is fairly similar for fragile countries, illustrating that improvements in budget execution functions seem to out-perform other areas in post-conflict countries. ${ }^{64}$

Furthermore, the conditions for success in post-conflict countries appear to mirror closely those in less fragile contexts. According to a recent cross-country PFM evaluation, PFM reforms deliver results when three conditions coincide:

- strong political commitment to the implementation of reforms;

- reform designs and implementation models tailored to the institutional and capacity context; and

- effective government-led co-ordination arrangements to monitor and guide reforms. ${ }^{65}$

These three conditions were clearly in place in Sierra Leone. Strong political commitment to the PFM reform agenda within MoFED was supported by wider political appetite for public sector development. Ambitious reforms were implemented by highly qualified, motivated and experienced LTAs and the GoSL undertook various initiatives to co-ordinate and harmonize PFM reforms in the post-conflict period. All this, coupled with financial support and incentives provided by the international community, created the necessary conditions for success in Sierra Leone.

\section{ACKNOWLEDGEMENTS}

The authors would like to thank Verena Fritz and the team contributing to the World Bank's flagship report on public financial management reforms in post-conflict countries for providing the basis for the initial research on this topic. They would also like to thank Rachel Gisselguist at WIDER who helped guide and shape the current version of this article. 


\section{ABBREVIATIONS}

$\begin{array}{ll}\text { AAP } & \text { Assessment and Action Plan } \\ \text { ACC } & \text { Anti-Corruption Commission } \\ \text { AGD } & \text { Accountant General's Department } \\ \text { AfDB } & \text { African Development Bank } \\ \text { ASSL } & \text { Audit Service of Sierra Leone } \\ \text { CAP } & \text { Common Action Plan } \\ \text { CFAA } & \text { Country Financial Accountability Assessment } \\ \text { CPIA } & \text { Country Policy and Institutional Assessment } \\ \text { DFID } & \text { Department for International Development } \\ \text { EC } & \text { European Commission } \\ \text { FCAS } & \text { Fragile and Conflict-Affected State } \\ \text { GDP } & \text { Gross Domestic Product } \\ \text { GIZ } & \text { Deutsche Gesellschaft für Internationale Zusammenarbeit } \\ \text { GoSL } & \text { Government of Sierra Leone } \\ \text { HDI } & \text { Human Development Index } \\ \text { HIPC } & \text { Heavily Indebted Poor Countries } \\ \text { IFMIS } & \text { Integrated Financial Management Information System } \\ \text { IMF } & \text { International Monetary Fund } \\ \text { IPFMRP } & \text { Integrated Public Financial Management Reform Project } \\ \text { IRCBP } & \text { Institutional Reform and Capacity Building Project } \\ \text { LTA } & \text { Local Technical Adviser }\end{array}$




\section{DEVELOPMENT ASSISTANCE FOR PEACEBUILDING}

$\begin{array}{ll}\text { MoFED } & \text { Ministry of Finance and Economic Development } \\ \text { MTEF } & \text { Medium-Term Expenditure Framework } \\ \text { NAP } & \text { National Action Plan } \\ \text { OECD } & \text { Organization for Economic Co-operation and Development } \\ \text { PEFA } & \text { Public Expenditure and Financial Accountability } \\ \text { PFM } & \text { Public Financial Management } \\ \text { PFMRU } & \text { Public Financial Management Reform Unit } \\ \text { PRSP } & \text { Poverty Reduction Strategy Paper } \\ \text { SSA } & \text { Sub-Saharan Africa }\end{array}$

\section{NOTES}

1. GoSL (Government of Sierra Leone), 'Republic of Sierra Leone: Public Financial Management Performance Assessment Report', Final Draft, Freetown: GoSL, 2007; World Bank, 'Proposed Grant in the Amount of SDR2.7 Million to the Republic of Sierra Leone for an Integrated Public Financial Management Reform Process', Project Appraisal Document, Washington, DC: Public Sector Reform and Capacity Building Unit, Country Department of West Africa 1, Africa Region, World Bank, 2009.

2. The initial version of this article is presented in the WIDER paper under the same title and authorship.

3. 2013, HDI website. 24 July 2014 (at: http://hdr.undp.org/en/content/human-development-indexhdi)

4. IMF, Sierra Leone: Selected Issues and Statistical Annex, Washington, DC: IMF, 2009.

5. Sierra Leone has recorded an overall CPIA score not lower than 3.2 (the World Bank FCAS benchmark) for the last three years.

6. GoSL, 'Republic of Sierra Leone: Public Financial Management Performance Assessment Report', Draft, Freetown: GoSL, 2010b.

7. H. Tavakoli, Public Financial Management Reforms in Fragile States: The Case of Sierra Leone, London: Overseas Development Institute, 2012.

8. This included recommendations and targets from the Heavily Indebted Poor Countries (HIPC) Assessment and Action Plan (AAP) 2004, the European Commission (EC) audit; remaining actions from the CFAA; and the monitoring frameworks for the World Bank's Economic Rehabilitation and Recovery Grant and the IMF's Poverty and Growth Facility. To strengthen co-ordination further, an oversight committee was developed to monitor the implementation of the plan.

9. This included recommendations and targets from GoSL (see n.1 above), the PRSP and MultiDonor Budget Support Operation's Performance Assessment Framework, the Institutional Reform and Capacity Building Project and the Improved Governance and Accountability Pact.

10. GoSL (see n.1 above).

11. Ibid.

12. The strategy aims to deal with weaknesses noted in diagnostic work and places a greater emphasis on revenue management, especially mining revenues, and strengthening local government public financial management. GoSL, 'Sierra Leone Public Financial Management Reform Strategy 2014-2017: Revised Draft', Ministry of Finance and Economic Development, Government of Sierra Leone, Freetown: GoSL, 2013.

13. GoSL (see n.1 above).

14. A. Lawson, DFID Multi-Donor Budget Support to Sierra Leone 2004-2007. DFID Budget Support to Sierra Leone, 2004-2007: Achievements \& Lessons for the Future, London: ODI, 2007; GoSL (see n.1 above); World Bank (see n.1 above).

15. World Bank (see n.1 above).

16. Lawson (see n.14 above).

17. World Bank, 'Public Expenditure Review', Draft, Washington, DC: World Bank, 2010.

18. Ibid. 


\section{DEVELOPMENT ASSISTANCE FOR PEACEBUILDING}

19. GoSL, 'Review of the Government Budgeting and Accountability Act and the Financial Management Regulations, Issues and Options, Executive Summary', Draft, Freetown: GoSL, 2010c.

20. World Bank (see n.17 above), p.41; GoSL (see n.12 above).

21. GoSL (see n.1 above); World Bank (see n.17 above); IMF, Sierra Leone: Determination and Implementation of a Fiscal Rule, Washington, DC: IMF, 2012a.

22. GoSL (see n.6 above); Tavakoli (see n.7 above); World Bank (see n.17 above); IMF, Sierra Leone: Public Financial Management: Reform Priorities in the New Fiscal Environment, Washington, DC: IMF, 2012b.

23. GoSL (see n.1 above); GoSL, '2010 Review of the Progress Assessment Framework: Multi-Donor Budget Support', Joint Aide-Memoire, Freetown: GoSL, AfDB, DFID, EU and World Bank, 2010a.

24. GoSL (see n.6 above).

25. Ibid.

26. Ibid.

27. IMF (see n.22 above).

28. Tavakoli (see n.7 above).

29. The CFAA published less than three months after the civil war was officially declared over states that 'given the acute period of civil collapse from which the Republic of Sierra Leone only recently emerged, financial management in the country functions surprisingly well'. World Bank, 'Republic of Sierra Leone: Country Financial Accountability Assessment, an Assessment of the Central Government', Final Report, Washington, DC: World Bank, 2002. This was supported by a subsequent IMF assessment which suggested the conflict caused only a low to moderate degree of institutional and social disruption compared to other post-conflict states. IMF, Rebuilding Fiscal Institutions in Post-conflict Countries, Washington, DC: IMF, 2004.

30. GoSL (see n.1 above).

31. World Bank (see n.29 above).

32. Tavakoli (see n.7 above).

33. P. De Renzio, M. Andrews and Z. Mills, Evaluation of Donor Support to Public Financial Management in Developing Countries: Analytical Study of Quantitative Cross-County Evidence, London: Overseas Development Institute, 2010; M. Andrews, 'How Far Have Public Financial Management Reforms Come in Africa?', Faculty Research Working Paper Series, FRW 10018, Cambridge, MA: Harvard University, 2010; IMF (see n.29 above).

34. De Renzio et al. (see n.33 above).

35. Ibid.; Andrews (see n.33 above).

36. A. Lawson, 'Evaluation of Public Financial Management Reform, Burkina Faso, Ghana, Malawi 2001-2010, Final Synthesis Report', Sida, Danida and AfDB, 2012.

37. C. Pretorius and N. Pretorius, A Review of Public Financial Management Reform Literature, London: DFID, 2008.

38. World Bank, 'Public Financial Management Reforms in Post-Conflict Countries, Synthesis Report', 69964, Washington, DC: World Bank, 2012.

39. World Bank, Political Economy of Public Financial Management Reform in Sierra Leone, Washington, DC: World Bank, 2008.

40. B. Thomson, Sierra Leone: Reform or Relapse? Conflict and Governance Reform, London: Chatham House, 2007 p.26.

41. GoSL (see n.23 above).

42. P. Morgan, Draft Parallel Implementation Systems, Capacity and Performance in Sierra Leone, Washington, DC: World Bank Institute and New York: UNDP, BCPR, 2009.

43. World Bank (see n.17 above), p.84.

44. P. Collier, Accountability in the Provision of Social Services: A Framework for African Research, Oxford: CSAE, 2007.

45. Lawson (see n.36 above).

46. S. Ingram, 'State-Building - Key Concepts and Operational Implications in Two Fragile States', Joint Initiative by the World Bank's OPCFC and UNDP's BCPR, London: World Bank's OPCFC and UNDP's BCPR, 2010; World Bank (see n.17 above).

47. GoSL (see n.23 above).

48. Tavakoli (see n.7 above).

49. World Bank (see n.39 above).

50. Ingram (see n.46 above); Morgan (see n.42 above).

51. Thomson (see $n .40$ above).

52. Ibid.

53. GoSL (see n.1 above). 


\section{DEVELOPMENT ASSISTANCE FOR PEACEBUILDING}

54. Lawson (see n.14 above).

55. An exceptional volatility of disbursements against original forecasts occurred between 2007 and 2009: 0 per cent in 2007, 65.6 per cent in 2008 and 139 per cent in 2009.

56. Tavakoli (see n.7 above).

57. IDD and Associates, 'Joint Evaluation of General Budget Support Synthesis Report', Birmingham: International Development Department, 2006; Lawson (see n.36 above); De Renzio et al. (see n.33 above).

58. Tavakoli (see n.7 above); GoSL (see n.23 above).

59. Tavakoli (see n.7 above).

60. De Renzio et al. (see n.33 above).

61. Andrews (see n.33 above).

62. Pretorius and Pretorius (see n.37 above); World Bank (see n.38 above).

63. World Bank (see n.38 above).

64. Ibid.

65. Lawson (see n.36 above). 


\title{
'Embedded' Assistance: Finn Church Aid's Secondment in Somalia
}

\author{
RAULI S. LEPISTÖ, RACHEL M. GISSELQUIST and \\ JUSSI OJALA
}

\begin{abstract}
Donors face distinct challenges in operating in fragile states and supporting the building of state capacity. This article explores one type of assistance - the 'embedding' of highly skilled staff members within local government agencies - through a unique case study of Finn Church Aid's experience with secondment in Somalia. Building upon FCA's previous work in Somalia, its staff member worked as part of the Transitional Federal Government's Ministry of Constitutional Affairs and Reconciliation to assist in the implementation of the roadmap designed to end transitional governance in the country. Although a number of such initiatives exist, few studies have explored how, why and whether they work. Drawing on unique access to FCA staff and documents, as well as interviews with Somali stakeholders, donor representatives and others, the article explores FCA's experience and impact through this initiative, one way in which a non-state actor has provided tangible, relatively low-cost support to a fragile state.
\end{abstract}

On 2 April 2012, three Finn Church Aid (FCA) specialists met with the Transitional Federal Government of Somalia's (TFG) Minister of Constitutional Affairs and Reconciliation, Abdi Hosh. They asked Hosh how FCA could support his Ministry, which had just been entrusted with the responsibility of overseeing significant parts of the implementation of a roadmap to guide the ending of political transition in Somalia by 20 August $2012 .{ }^{1}$ The TFG had been established in 2004 with the goal of restoring national institutions to Somalia following the country's 1991 collapse. In August 2012, the TFG was set to be replaced by elected representatives of the Somali people serving under a new constitution in the new Federal Government of Somalia (FGS), marking the achievement of a crucial statebuilding process. Minister Hosh replied that he wanted FCA peacebuilding specialist Mahdi Abdile seconded to work with him at the Ministry of Constitutional Affairs and Reconciliation (henceforth the Ministry). Abdile assumed his post on 23 April 2012, charged with the task of supporting the Ministry in its assigned duties.

Operating in fragile states represents a distinct challenge for donors and NGOs. Indeed, in the worst case, their interventions are criticized for serving to erode state capabilities. ${ }^{2}$ This article presents an example of how a non-state actor has provided tangible support to a fragile state government, assisting in the process of building capacity to guide the country towards resilience.

This is an Open Access article distributed under the terms of the Creative Commons Attribution-NonCommercial-NoDerivatives License (http://creativecommons.org/Licenses/by-nc-nd/4.0/), which permits noncommercial re-use, distribution, and reproduction in any medium, provided the original work is properly cited, and is not altered, transformed, or built upon in any way. 


\section{DEVELOPMENT ASSISTANCE FOR PEACEBUILDING}

Development agencies provide a variety of types of assistance towards such ends. Within the broader framework of statebuilding and peacebuilding development assistance, FCA's secondment may be grouped together with other aid-funded programmes to support external advisers within government ministries - a form of technical assistance, in this case 'embedded' within local institutions. While a number of such initiatives exist, very little publicly available documentation is available on how, why and whether they work - on the process, challenges, tensions and lessons learned from such embedded assistance. Benefiting from unique entrée into FCA's experience in Somalia, this case study speaks directly to this lacuna in the literature. At the same time, it also highlights several aspects of FCA's initiative that make it unique, and may be worth consideration by other organizations operating in fragile state environments. Given Abdile's position within the Ministry, the case speaks in particular to issues of 'local ownership' in aid, illustrating some of the tensions faced by external actors in supporting truly locally owned initiatives. Thus, through a detailed case study of a relatively small-scale project, we hope to speak to several broader issues in the literature.

Overall, the article argues that Abdile contributed in significant ways to the Ministry's capacity to implement the transition roadmap, despite his overall limited ability to influence changes in policy. The embedded assistance provided by Abdile's secondment gave the Ministry additional means to achieve its main goal of overseeing the successful political transition in Somalia. Although FCA was not willing to set specific objectives for the secondment as Abdile reported directly to Minister Hosh, the initiative nonetheless gave FCA indirect, albeit limited, presence at the core of the Somali statebuilding process. Thus, even while Abdile worked within an environment that did not always carry out activities as FCA might have preferred, his presence within the Ministry also allowed for the promotion of some of FCA's guiding principles. From FCA's perspective, as well as that of the Minister, the secondment was an overall success, offering a model that both would hope to build upon in future.

The article draws on interviews with Somali stakeholders, selected FCA staff and donor representatives. It also builds on FCA's organizational memory and relevant written documents as well as on secondary sources. Further support is sought from e-mail correspondence that the lead author was given access to during the research phase of the article. This study is intended as an objective study of the secondment arrangement. It should however be noted that one of the authors is a senior adviser on the right to peace at FCA and has worked with FCA since 2008, allowing the article to benefit from FCA's institutional memory.

The first part of this article situates this study within the broader policy and research literature, highlighting FCA's secondment as a form of 'embedded' assistance for statebuilding with strong potential for helping to address challenges of local ownership. The second situates the case study within the context of FCA's mandate, history and current projects in Somalia. It explores how the organization's understanding of its mandate and role in supporting fragile states evolved to the degree where providing capacity support to a fragile government became possible, and reviews the secondment from a programmatic point of 


\section{DEVELOPMENT ASSISTANCE FOR PEACEBUILDING}

view. The third section explores the impact of the secondment, in particular highlighting the assessments of both participants and observers. In so doing, it also considers some of the extenuating factors in assessing impact, in particular the capacity limitations faced by Abdile during the secondment. A final section concludes.

\section{Supporting Statebuilding and Local Ownership through 'Embedded' Assistance}

Fragile states and conflict situations have some of the most pressing development and humanitarian needs and addressing these needs will remain central to development assistance post-2015. ${ }^{3}$ Operating in fragile environments thus remains core to the mandates of many development and humanitarian NGOs, including FCA. Somalia, the quintessential 'failed' state, has long occupied one extreme of the fragility spectrum, with humanitarian and development needs well documented. ${ }^{4}$

Operating in fragile environments poses distinct challenges in comparison to development assistance in more stable environments - even ones in which economic indicators and levels of poverty may be similar. For instance, addressing issues of security for operations and personnel clearly imposes additional costs, risks and complexity. At a more abstract level, one of the most fundamental tensions relates to issues of local ownership. Donors have committed to local ownership in aid operations, one of the core principles of the Paris Declaration on Aid Effectiveness (2005), reaffirmed in the Accra Agenda for Action (2008) and the New Deal for Engagement in Fragile States (2011). At the same time, fragile states are particularly ill-equipped to 'own' fully their development processes; notwithstanding the strong will and capacity of many individuals and some organizations within them, a fragile state - by definition - has extremely weak state capacity, legitimacy and authority. ${ }^{5}$ How to support fragile states to build the capacity, legitimacy and authority required to lead and manage effectively and fully their own development processes, in a manner at the same time consistent with local ownership, is thus a major tension for donors operating in these environments. ${ }^{6}$

Likewise, supporting local ownership while also facilitating improvements in state capacity and better governance remains a major tension for donors in developing countries more generally. ${ }^{7}$ Indeed, critics argue that development assistance can both contribute to the weakening of state capacity and legitimacy, as well as effectively hinder the ability of states to raise their own revenues. ${ }^{8}$ In addition, in terms of 'how to' support more capable and legitimate states, there remains considerable debate among researchers and practitioners over best practices in core thematic areas, such as reform of the civil service, public financial management, tax systems and policing. ${ }^{9}$

Efforts by development actors to support the emergence of more capable and legitimate states can be grouped into four broad categories. The first consists of support or incentives for institutional reforms of existing state organizations and practices, such as major restructuring of the civil service, public financial management system, judiciary, legislature or electoral system. A second broad category consists of capacity building efforts, such as job training or 'train the 


\section{DEVELOPMENT ASSISTANCE FOR PEACEBUILDING}

trainers' initiatives, geared to developing the skills and experience of individuals working within such institutions. A third broad category, technical and capacity assistance, provides additional external support when domestic capacity is insufficient. Finally, a fourth category includes efforts to act in place of the state to fulfil functions normally undertaken by more capable states, such as the provision of public services - labelled 'parallel institutions' for short. Humanitarian assistance might loosely be classified here. In terms of development, efforts tend to involve support for more durable 'independent' institutions operating in parallel to government agencies. Given the difficulties in reforming existing institutions, such institutions are seen to benefit for instance from their autonomy from existing (dysfunctional) organizations and their ability to work outside the traditional civil service, which may facilitate payment of higher salaries and attracting of more skilled employees. While development assistance has generally focused more on interventions of the other three types, Collier for one advocates more development attention to such parallel institutions for service provision. ${ }^{10}$

Within this framework, FCA's secondment may be grouped broadly with other aid-funded programmes to support external advisers within government ministries - a form of technical and capacity assistance. Within Somalia, during both the TFG and later the FGS, there were also several other external advisers supporting various Somali institutions: the International Organization for Migration (IOM) had several persons working for the Ministry of Finance, the United Kingdom seconded a person to the Ministry of Interior and National Security and an Irish security expert was responsible for the security arrangements of the meetings of the Elders Council. While more standard technical assistance often involves considerable coordination and work with government agencies, such assistance takes a step further in the degree to which external advisers are 'embedded' within local institutions and accountable directly to supervisors within these institutions. Some such initiatives also involve elements of capacity building as the embedding of external advisers may be seen as playing a role in building domestic capacity through example and interaction, 'knowledge transfer' and (sometimes) direct training of local colleagues. Depending on the size of such programmes, an element of 'parallel institutions' may also be at work.

Among such programmes internationally, the Overseas Development Institute (ODI)'s Fellowship Scheme is perhaps the best known. Since it began in 1963, it has placed over a thousand post-graduate economists and statisticians in the public sectors of developing countries to work as local civil servants. ${ }^{11}$

The Scott Family Liberia Fellows is another such programme, although smaller than the ODI's with roughly six fellows per year since it began operations in mid-2007. Initiated with a grant from Ed Scott, the programme was originally managed by the Center for Global Development (CGD) and subsequently by John Snow, Inc. (JSI). Liberia Fellows 'typically work as "special assistants" to Ministers or other officials, taking on a wide variety of tasks, ranging from economic affairs, public policy, agriculture, health, legal, speechwriting, ministerial coordination and administration'. They aim to 'support the Ministers in their full range of activities and to make them more effective and efficient in all that they do'. 12 


\section{DEVELOPMENT ASSISTANCE FOR PEACEBUILDING}

Also in Liberia is the more recently initiated Carter Center (TCC) and Transnational Law Institute of Washington and Lee University School of Law (W\&L) Liberia Law Fellows Programme, which expects to place law school graduates in government offices at the Ministry of Justice, Ministry of Commerce, Ministry of Internal Affairs, Ministry of Agriculture, Ministry of Public Works, Ministry of Health, Judicial Institute and Land Commission. Both the Carter Center and W\&L have been engaged in other projects on access to justice in Liberia, since 2006 and 2008, respectively, and the programme builds upon these activities. ${ }^{13}$

An earlier example is the Africa Fellows programme led by Professor Carroll Wilson of the Massachusetts Institute of Technology (MIT). It operated from 1959 to the mid-1960s, sending primarily MIT business and law school graduates to work in ministries in various African countries - most either newly independent or on the verge of independence. A report on the programme's founder notes that 'Wilson is said to have considered it the highest compliment to the program when the U.S. ambassador to Uganda complained that the African Fellow in Kampala was acting as if he were working for the Ugandans. "He is", Wilson agreed."14

While at least the first two of these initiatives are quite well-known within international development policy circles, to the best of our knowledge no major comprehensive study has been done to enumerate all such efforts, much less to analyse them systematically within the context of one of their key aims - to support governance and state capacity in weak and fragile states. Nor is there much publicly available documentation on the process, challenges, tensions and lessons learned from such efforts at embedding employees within local government institutions - in particular from the perspective of the external agencies supporting them. As Wilson's comment above underscores, clear tensions are apparent in terms of local versus external accountability and, by extension, ownership. How do the external agencies supporting such initiatives view and address such tensions? The unique entrée we had into FCA's experience in Somalia allows us to speak directly to this lacuna in the literature through this case study. Thus, while FCA's secondment in Somalia was a relatively small-scale project - even in comparison to other such initiatives of this broad type - this case can contribute to the discussion of broader issues in the literature on statebuilding and local ownership.

Finally, it is also worth noting that while FCA's secondment in Somalia is like these better-known international initiatives in many ways, it is also unique in some key ways, which might be built upon in other initiatives in future. First, as noted, it operated on a smaller-scale (one seconded employee only) and over a limited time period, without an expectation of continuation. Second, it functioned during a period of more extreme political instability than any of the other programmes outside of Somalia. While Liberia for instance is also a fragile state, the Scott Fellows programmes there began only in the post-conflict period.

Third, in terms of the core purposes of the initiative, FCA's sole purpose in the secondment was to support statebuilding in Somalia by lending capacity during a crucial phase of the peace process. By contrast, while support for state capacity is 


\section{DEVELOPMENT ASSISTANCE FOR PEACEBUILDING}

also a goal of the other better-known initiatives, all also equally highlight benefits for 'fellows' in addition to those for the host country. Fellows in turn generally apply through competitive recruitment processes and many, if not most, have few prior ties to their host countries. Abdile, on the other hand, is of Somalidecent, with strong personal ties and commitment to the development of the country. Perhaps only some of the Scott Fellows are somewhat similar in this latter sense - as a handful of Liberian fellows have participated, some of whom have stayed on in Liberian government. ${ }^{15}$

Fourth, in contrast to the other initiatives outside of Somalia, FCA's secondment provided more 'capacity' assistance than 'technical' assistance. Indeed, while clearly capable and highly skilled in peacebuilding work, Abdile did not possess the sort of technical skills in economics, statistics or law emphasized by the other programmes. Thus, the sharing or transfer of this sort of 'technical' knowledge was not core to the effort. Rather, Abdile brought a less clearly defined set of management and analytical skills and peacebuilding experience.

Fifth, the secondment is notable in the degree to which it supported local ownership of assistance. While local ownership plays a role in all of the initiatives noted above in the sense that fellows work directly for local government agencies and report to local supervisors, even if paid by external agencies, the FCA secondment was notable in that it was also locally initiated: the Minister specifically requested the secondment.

\section{FCA and Its Work in Somalia}

FCA is the largest development cooperation NGO in Finland, with an annual turnover of 35 million Euros. It works extensively in situations of fragility with a twin focus on advocacy and development support. FCA's work began in Somalia in 2007, that is, during the period of the TFG. Its programmatic entry in Somalia was focused, concentrating on supporting religious leaders in local-level conflict resolution in northern Somalia and Somaliland (Peace Initiative Project, PiP). Given the intertwined nature of religious and traditional (clan) leaders in Somalia, FCA and its partners, the Danish Refugee Council and International Horn University, broadened the scope of the conflict resolution project to encompass both social groups. Project reports note that it facilitated the resolution of more than a dozen clan-based conflicts in Somalia between 2008 and 2012. ${ }^{16}$

FCA discussed and decided upon key advocacy targets in 2009 and selected 'Peace in Somalia' as one of the main focuses. Within Somalia, FCA sought to support the advocacy of religious leaders for peace and reconciliation in mosques, communities and conflict hotspots (as part of PiP). Internationally, FCA's plan stressed influencing UN decision making on Somalia especially with the goal of supporting open and participatory peace processes. In Finland, FCA pursued closer coordination and collaboration with the Somali diaspora. ${ }^{17}$

FCA's engagement with the UN Political Office for Somalia (UNPOS) was initiated in earnest during the latter half of $2010 .{ }^{18}$ FCA and UNPOS formed a joint project in November 2010, Somalia Outreach and Reconciliation (SOR) Initiative, which sought to incorporate Somali religious and clan elders into the 


\section{DEVELOPMENT ASSISTANCE FOR PEACEBUILDING}

federal-level peace- and statebuilding work from which they had been sidelined for decades. ${ }^{19}$ This project was seen by FCA as a groundbreaking step as it provided a concrete case for the organization to facilitate dialogue and cooperation between grassroots actors (with whom FCA had cooperated for years) and the Security Council-mandated UN agency.

\section{FCA's Mandate: A Rights-Based Approach to Development Assistance in Fragile Situations}

FCA's commitment to a rights-based approach (RBA) underlies its programmatic work. It describes the core RBA principles as follows:

Contrary to needs, rights always trigger obligations. They exist in a relationship between rights-holders and duty-bearers, which highlights the importance of accountability and dialogue between them. Change requires working in a strategic way towards the duty-bearers that hold decisive positions of power and control. The recognition of this dual relationship is key to the practical implementation of RBA. ${ }^{20}$

Central to the approach is to identify the root causes of poverty and lack of realization of rights. As poverty is not considered merely as a lack of material goods but as injustice, denial of human rights and equal participation, the tools to promote positive development, derive from creating possibilities to access power and resources, for example through advocacy and capacity building.

RBA as a way of work stresses the imperative of local ownership. In FCA's work, this is highlighted in the stated focus on strengthening the accountability between (local) 'rights-holders' and 'duty-bearers', as well as in the emphasis that the process is as important as the outcome. ${ }^{21}$ Such was the approach adopted in Somalia; FCA's role in PiP was designed to be in the background, concentrating on facilitating mediation processes and capacity building, rather than driving them. Such a focus on process and participation implies that change is gradual and patience is required by all stakeholders.

In 2009, FCA assumed the lead in an advocacy working group that chose fragility as its main theme. ${ }^{22}$ Although fragility had been touched upon by the FCA prior to Abdile's secondment, FCA had not deeply discussed its own actions in support of a duty-bearers' capacity. Rather, the focus was on analysis of the implications of fragility to rights-holders and suggestions of action by the EU and international community as moral duty-bearers. ${ }^{23}$ After 2010, FCA's engagement with UNPOS as part of the SOR Initiative was an important step for FCA in this sense, in providing the organization an opportunity to move from theory to practice on RBA and its stated focus on 'the interrelationship between the individual at the micro level and the state and the international community at the macro level'.24

\section{FCA's Capacity Support to Somalia's TFG}

FCA's secondment of Abdile emerged through the SOR Initiative. In terms of addressing explicitly state fragility in Somalia, and the responsible duty-bearer, 


\section{DEVELOPMENT ASSISTANCE FOR PEACEBUILDING}

the TFG, the SOR Initiative started slowly. While dialogue between representatives of local communities and UNPOS was seen as successful, ${ }^{25}$ the TFG became part of the activities only towards its end. ${ }^{26}$ FCA representatives met Minister Hosh for the first time in November 2011 upon the recommendation of UNPOS's Deputy Special Representative of the Secretary General, Christian Manahl. Subsequently, FCA staff met the TFG's Ministers several times, especially Hosh and the Minister of Interior and National Security, but also the Prime Minister, in the margins of the London Somalia Conference in February 2012. ${ }^{27}$ Similarly FCA saw increasingly the significance of cooperation with the TFG as there was now a great convergence between the objectives of the SOR Initiative and the transition roadmap, which had been specified through the National Constitutional Conferences in Garowe in December 2011 and February 2012, the Galkayo Communique of the Principal Political Stakeholders from March 2012 and the Addis Ababa Communiqué from May 2012. In particular, the importance of participation by the clan elders was incrementally pronounced in the outcomes of these meetings.

FCA did not expect a request to second an FCA staff member to the TFG. While the proposed secondment was well aligned with the RBA and could be seen as a logical continuation of the SOR Initiative, it still posed several challenges for FCA, starting with the fact that Abdile was also involved in other ongoing projects at FCA. Financial issues were even more concerning. Even though the estimated cost of the secondment was quite small, FCA lacked the internal resources to support Abdile's secondment fully on its own and looked for additional sources of funding. ${ }^{28}$ UNPOS endorsement was considered at first, but it soon became clear that obtaining any funds or clearance from UNPOS, in a manner that Abdile could speak on behalf of UNPOS, was out of the question. FCA then turned to the Ministry for Foreign Affairs of Finland (MFA). MFA staff at the mediation unit immediately understood the value of the proposed secondment, yet it took until the end of May 2012 for FCA to receive the formal approval, during which time FCA continued working with the TFG through its own funding. ${ }^{29}$ Upon request, Minister Hosh submitted Abdile's Terms of Reference (ToR) to FCA. It was framed as follows: 'Mahdi Abdile would be a consultant on the implementation of Road map as it relates to end of transition processes, including the convening of the Constituent Assembly on May 15, 2012 and the traditional elders on April 25, 2012. ${ }^{30}$

Minister Hosh asked FCA not to second Abdile as FCA staff as this could provide ammunition for someone who would wish to harm the process of ending the transition by falsely portraying FCA as a missionary organization, and by doing so put not only the Minister himself, but also the whole government, under unwanted accusations. FCA thus let Abdile take a leave of absence for the duration of the secondment and hired him as consultant without formal bond to FCA, yet with the opportunity to take advantage of FCA's service functions such as contractual help, travels, financial arrangements and support on security arrangements. The secondment was extended twice, from the initial end date of 31 July 2012 to 20 August 2012 (end of transition) and, after a request by then caretaker Minister Hosh, to 15 September 2012. Already during the first term 


\section{DEVELOPMENT ASSISTANCE FOR PEACEBUILDING}

of the secondment, it was clear that the MFA's original funding would not be sufficient to cover all expenses. Security-related costs in particular burdened the budget more than anticipated. ${ }^{31}$ In the end, the secondment programme was 65 per cent covered through the MFA funds and 35 per cent through FCA's funds. ${ }^{32}$

\section{Assessing the Impact of FCA's Secondment}

Abdile's main responsibility during the secondment was to support the planning and organization of meetings of the traditional leaders (elders) held from 5 May 2012 until the end of the transition period. ${ }^{33}$ These meetings of the "Elders Council' played a crucial role in bringing about the end of the transition period. The composition of the Elders Council was decided in late March 2012 in Galkayo at the Consultative Meeting of the Somali Signatories of the Process for Ending the Transition. In Galkayo it was decided that the Elders Council would consist of 135 members chosen according to clan affiliation. A '4.5 clan' formula was adopted whereby the four main clans in Somalia (Darod, Dir, Hawiye and Rahanweyn) were given a representation of 30 elders in the council and the remaining 15 places were reserved for smaller clans. The Elders Council was given the responsibility to nominate the 825 members of the National Constituent Assembly, tasked with voting on the Provisional Constitution of Somalia. The Council also selected the member candidates for the 275 member Federal Parliament of Somalia, ${ }^{34}$ which, in addition to its legislative role, voted on the future President of Somalia and elected the Speaker of the Parliament.

A second key responsibility for Abdile was in designing and facilitating civic education workshops that provided information to the elders about their role in this process and a forum for discussion among them about this role, as well as training on reconciliation and mediation. Third, Abdile was responsible for acting as a coordinator and liaison on issues related to the transition roadmap with the elders, the TFG, UNPOS and other relevant actors, including government ministries and the United Nations Development Programme. As part of this work, he served as a focal point between the Ministry and project sponsors, such as the European Union. Although the EU was not present in the Mogadishu coordination meetings, EU representatives had regular bilateral meetings with the Ministry and UNPOS in Nairobi. These meetings aimed to support the timely execution of the roadmap. Finally, Abdile was also involved as necessary with other Ministry activities that supported the implementation of the roadmap, including consultations with women's groups and the drafting of concept notes and memos.

This section draws heavily on interviews with those involved in the secondment - particularly Abdile - to consider the impact of this initiative on the overall objective of supporting a locally owned statebuilding process. Such selfreporting should always be considered critically in assessing aid effectiveness, particularly as participants may have obvious incentives to view their role in favourable terms. However, in a small-scale project such as this one, such interviews also constitute an invaluable source of information. Thus, while we 


\section{DEVELOPMENT ASSISTANCE FOR PEACEBUILDING}

acknowledge key limitations of our approach, we also note that steps were taken to assess biases by comparing perspectives from multiple actors involved in the secondment. In addition, we note Abdile's own critical reflections on his role.

Overall, we find that the secondment contributed to the Ministry's capacity to implement the transition roadmap, despite Abdile's overall limited ability to influence changes in policy. The embedded assistance provided by the secondment gave the Ministry additional means to achieve its main goal, but the initiative was not without tensions and challenges. Broadly, we find clear tradeoffs between FCA's commitment to the local ownership of the secondment and some of FCA's core rights-based principles and objectives. In other words, in being directly accountable to the Minister, not FCA, Abdile did not always pursue activities as he would have had his work been directed by FCA. At the same time, his direct accountability to the Minister was a condition of his presence within the Ministry and his presence within the Ministry also allowed for the promotion of some of FCA's guiding principles and core commitment to supporting the statebuilding process in Somalia.

Essentially the work of the secondment was to oversee the implementation of a political process where significant decisions had already been made. Any perceived impact of the secondment further has to be considered as originating from the Ministry's work. Minister Hosh reports that Abdile's contribution was very valuable, but the process would also have been completed without him. ${ }^{35}$ Abdile's own account suggests the same. He describes how he had to remain constantly (in his words) 'neutral', including when he felt that some issues were not followed through in an ideal or sustainable manner. ${ }^{36}$ The Somali interlocutors were nonetheless content about the arrangement highlighting the benefits from the direct relationship between themselves and Abdile. ${ }^{37}$ Abdile's colleague from the Ministry stresses the fact that Abdile was able to come physically to Somalia and work with them on a daily basis, which was a most definite asset for them. ${ }^{38}$ For Hosh, it also seemed to increase the level of local ownership as Abdile worked directly under the Ministry, without outside entanglements. Indeed the direct relationship seemed to have extra meaning in this particular case, due to the politically charged nature of the secondment. Abdile also introduced ideas of his own during the process. He could not claim ownership of these ideas, however, and had to circulate the ideas through the Ministry's bureaucracy. This was another element that Hosh appreciated as it made him feel that Abdile was truly a part of his team and not a solo player with his own agenda. ${ }^{39}$

\section{Limited Capacity}

Among the key factors highlighted by those involved in the secondment in influencing Abdile's ability to perform within the Ministry was the existing capacity of the Ministry itself - which in turn was part and parcel of the fragile nature of the Somali state. Prior to Abdile's secondment, the Ministry was only two persons strong, consisting of Minister Hosh and his cabinet secretary. ${ }^{40}$ Limited resources prevented Hosh from hiring more staff and in this regard it was essential that Abdile's secondment was financed externally. ${ }^{41}$ In addition, Abdile notes the 


\section{DEVELOPMENT ASSISTANCE FOR PEACEBUILDING}

lack of expertise within the Ministry, particularly on the constitutional matters core to its work. While Minister Hosh had a legal education, he did not have experience on constitutional matters. The lack of institutional memory and basic recordkeeping within the institution further meant that basic and key documents such as concept notes and other memos had to be drafted from scratch, rather than based on existing models. ${ }^{42}$ Hosh narrates how during the long war several ministers had been killed and virtually everything had collapsed. Offices, ministries and libraries were destroyed which led to a 'loss of memory'. Hosh says that among other things, Abdile's assistance was much appreciated as there were no potential employees available with the required experience. ${ }^{43}$

During the SOR Initiative in 2010, UNPOS saw that there was a need to give political support to the elders in order to prevent them from being ridiculed or exposed to corruption. UNPOS worked together with FCA to inform the elders about the process of ending the transition. Due to this history, it did not come as a surprise to Abdile that the elders' limited experience with politics prior to the constitutional process formed a challenge for the overall process. Thus, it was natural that Abdile's ToR included a duty to provide for civic education, which essentially meant informing the elders about their role in the process via seminars and workshops which Abdile designed and facilitated. ${ }^{44}$ Regardless of the past support, there was still a great demand for such education as many of the elders had not yet been fully informed about their exact role and responsibility in the process. Sometimes this need to provide education for the elders meant that activities which would have required a day under more organized conditions, took a week. ${ }^{45}$

To summarize, Abdile's work was made more challenging because of lack of human resources, lack of technical expertise within the government and limited understanding of the elders regarding their exact role in the process of ending the transition. These obstacles illustrate the nature of some of the challenges that both the host government's officials and external actors come across when working within fragile states to support capacity development. What may follow is that extremely weak institutional capacity hinders the very initiatives designed to address it, even when political will supports capacity development - as in this case. While the definition of fragility does include both a lack of will and a lack of capacity, these two elements are a world apart. The risk of an unwilling state (duty-bearer), however, did not materialize with Abdile's secondment as the TFG explicitly expressed its willingness to receive capacity support to carry out its duties.

\section{Deficiencies in Representation}

The key focus of Abdile's work was to coordinate the Elders Council. Therefore it was imperative to find and invite the right people to the meeting. Finding the 'real' elders - that is, the ones who truly represented their communities - was, according to Abdile, the greatest single challenge that the Ministry had during the process. ${ }^{46}$ Abdile had struggled with the same problem already during the SOR Initiative. The questions that had to be constantly reassessed then were: who were the real elders who could truly represent the various Somali clans, and 


\section{DEVELOPMENT ASSISTANCE FOR PEACEBUILDING}

how to keep the delicate clan balance in order? It was initially thought that every Somali can tell the name of his or her clan elder, so consequently one should only ask and the list of elders would write itself. ${ }^{47}$ However, this was not the case. ${ }^{48}$ In Abdile's opinion, the identification of the elders posed some fundamental challenges that had the potential to put the whole process at risk. The process of ending the transition had a sense of urgency to meet the agreed deadline (20 August 2012) which accordingly had an impact on the appointment of elders. In Abdile's assessment, the clans did not always have enough time to discuss properly who would represent them. In such cases the resulting decisions suffered from a lack of consultation from the respective communities, paving the way for potentially wrong decisions. The potential for corruption and political manipulation also increased as the respective communities had less time to oversee properly the activities of their leaders. ${ }^{49}$

Abdile had to proceed in his work regardless of knowing that the Elders Council was formed on the basis of politics, not tradition. Traditional leaders are chosen however in a way that follows tradition, not politics, which raises a question over whether it is possible to apply the 4.5 formula and still have such representation as originally intended. Abdile estimates that the true number of 'first tier elders', that is Dubaabs, is somewhere between 60 and 70 in the whole of Somalia. ${ }^{50}$ Thus, 135 elders would have been too many. The Ministry estimated that from the 135 , between 37 and 40 could be described as 'real' elders. If the estimates are accurate, one can safely assume that politics did play a significant role when the composition of the Elders Council was decided, excluding some of the real elders from the process and adding some extra. In Abdile's view, the consultation process fell short in this regard as the primacy in the process of ending the transition was to take the process from one stage to another. Such prioritization limited the Somalis' chances to discuss thoroughly the quality of the process, potentially planting seeds for future tension. ${ }^{51}$ Some have even argued that the process reminded them more of a project than a genuine process, moving from one stage to another, aiming to meet deadlines rather than to build the necessary consensus among Somali actors. ${ }^{52}$

\section{Working for Gender Equality}

Another key issue highlighted in Abdile's reflections on his experience concerned issues of gender equality. For Abdile, gender equality was a familiar and natural priority in his work at FCA, where it had been one of FCA's strategic focuses since $2009^{53}$ and FCA had already advocated better inclusion of women into Somali politics. $^{54}$

In his embedded role within the Ministry, one of Abdile's tasks was working with women's rights groups which advocated for gender equality. The key issue in this regard was to see the fulfilment of a 30 per cent quota for female representation in the new Federal Parliament of Somalia, a quota which was introduced during the creation of the roadmap and was one of most noticeable features in the Garowe Principles. Subsequently, the quota was very much on the Ministry's agenda. ${ }^{55}$ Towards this end, Abdile met regularly with women's groups and worked to find ways to bring them together to discuss jointly how to promote 


\section{DEVELOPMENT ASSISTANCE FOR PEACEBUILDING}

their agenda. He also carried their message forward to the TFG and other Somali stakeholders. ${ }^{56}$ The elected parliament, however, did not meet the agreed quota. It included 275 representatives, of whom only 14 per cent were women. ${ }^{57}$ This was only a slight improvement from previous women's representation in the attempt to establish a parliament in Somalia (12 per cent in the Transitional Federal Parliament). In explaining this outcome, Abdile notes that the UN could have promoted the quota more forcefully, but did not wish to risk the implementation of the roadmap which was close to fulfilment. ${ }^{58}$ It was then left in the hands of Somalis and particularly to the elders to make sure that the quota would be met. As the principal guardians of the traditional customs of the Somali people, the elders however were not the force that would have driven change in gender equality. As one commentator noted: 'Putting the faith of women in the hands of elderly men in a patriarchal society was misguided ideology. ${ }^{59}$ The (female) co-chair of the Technical Selection Committee (of eligible Members of Parliament) also made a similar observation, arguing that the three main factors that kept women's representation lower than agreed were the male- dominant culture, (some) religious interpretations which argued against the inclusion of women into Somali politics and finally selfish views of too many men who did not want to share the results gained in the political process with women. ${ }^{60}$ While working with women's groups, Abdile also observed that women were divided in their opinion on whether they should focus on achieving the quota or rather should have strong women politicians as leaders who could drive change more forcefully. ${ }^{61}$

The example illustrates the difficulty of effectively implementing gender equality objectives, regardless of whether these objectives on paper enjoy a strong backing of the international community. Abdile draws an interesting comparison to peacebuilding: 'In peace work the state of affairs is such, that once a deal is done, there must be someone who will oversee its implementation. Otherwise everyone knows already beforehand that it will not hold. With political deals, it is almost the same. ${ }^{62}$

\section{Conclusion}

Although FCA's secondment in Somalia was a relatively small-scale project, analysis of this experience, we argue, can contribute to broader discussions in the literature on statebuilding and local ownership. In particular, it contributes to discussion on aid-funded programmes to support 'embedded' external advisers within government agencies - a form of technical and capacity assistance. A number of such initiatives exist, but little analysis is available about how, why and even whether they work. Drawing on unique entrée into FCA's experience in Somalia, this case study speaks directly to this lacuna in the literature. Several unique aspects of FCA's secondment - such as the fact that it was locally initiated and, in comparison to other 'embedded' assistance efforts, operated in a more unstable political environment - may also be worthy of consideration by other development actors. 


\section{DEVELOPMENT ASSISTANCE FOR PEACEBUILDING}

The relevance of FCA's experience to peacebuilding and statebuilding is underscored by the continuing emphasis on local ownership in development assistance and the New Deal's emphasis on 'country-owned and -led pathways out of fragility'. ${ }^{3}$ FCA's experience suggests that addressing fragility through such embedded assistance may well increase in popularity in the future. This would require that such assistance be seen by both fragile states and donors alike as an effective and 'locally owned' means to support state capacities. Notably, feedback from both Hosh and his cabinet secretary suggests that the secondment was praised especially from the perspective of perceived Somali ownership. Furthermore, it is clear that Abdile's secondment contributed to the Ministry's basic capacity: at the very least, Abdile's secondment increased the Ministry's staff from two to three individuals.

Although FCA was not willing to set definite objectives for the secondment, Abdile's mission was nonetheless considered a 'success' by FCA as well. Through Abdile, FCA received an indirect presence at the core of the transition process where it was able to support the TFG's capacity and simultaneously support Somali ownership. The secondment served FCA's commitment to a RBA, providing an opportunity to support an incapacitated duty-bearer. The secondment further took FCA forward in its thinking and action when operating in a fragile context. This experience helped to build FCA's own capacity and served to encourage FCA to expand its work to other fragile states, including through contributions to the International Dialogue on Peacebuilding and Statebuilding.

More broadly, it is still too early to say whether the successful ending of the transition will result in peaceful development in Somalia. At the time of this writing, there is no peace in Somalia. Somalia is still among the most fragile states in the world. On 20 August 2012, the Federal Parliament of Somalia took over its responsibilities, testament in part to the Ministry's successful overseeing of the roadmap. Observers have raised several strong critiques about the process. ${ }^{64}$ Indeed, several key critiques are suggested above, and it is worth noting the limitations faced during the secondment in terms of impact on key aspects of the transition process. For instance, as discussed above, the composition of the Elders Council was to some degree based on political interests and not genuine clan representation, and gender quotas were not met in parliament.

Such critiques notwithstanding, it is debatable whether alternative designs for the secondment would have resulted in greater impact on the process. In particular, although the Ministry's limited capacity certainly affected the degree to which Abdile could influence the transition process, it seems unlikely that Abdile would have had more influence had he been embedded within another government ministry, for example. The Ministry's limited capacity was reflective to a large extent of the limited capacity of Somali government institutions in general, and despite its limited capacity, the Ministry played a unique role within the TFG during the transition process. Furthermore, the degree of influence that Abdile exercised directly on outcomes reflected also the FCA's commitment to a locally owned process and the inherent challenges of this commitment. 


\section{DEVELOPMENT ASSISTANCE FOR PEACEBUILDING}

On balance then, the secondment provides a positive example of tangible external support to a fragile state, assisting in the process of building capacity to guide the country towards resilience. In Abdile's assessment, the most notable success of the process was the consultation and representation of the clans, which, while imperfect, was followed through better than in previous peace processes. Working with clans, he argues, is essential given the structure of Somali society:

If you want to build a state, you look at the clans... I for example am a Somali, a Muslim and a member of my clan, but the clan comes first. These three support each other but clan is the most important... If decisions are not done respecting this, agreed negotiation results are not respected because the clan support is not there. ${ }^{65}$

As Antti Pentikäinen stresses, the final outcome was generally accepted as legitimate, and the achieved result was not violently contested by the parties that participated. ${ }^{66}$ While opposition was raised, opposition groups - with the important exception of al Shabaab - did not resort to violence.

\section{ACKNOWLEDGEMENTS}

This study was commissioned by the United Nations University, World Institute for Development Economics Research (UNU-WIDER).

\section{NOTES}

1. Somalia has been a subject of interim governance since 2000 when Transitional National Government (TNG) was established. Transitional Federal Government replaced TNG in 2004. It should be noted that throughout the existence of these governance structures, their ability actually to govern has been very limited.

2. L. Zanotti, 'Cacophonies of Aid, Failed State Building and NGOs in Haiti: Setting the Stage for Disaster, Envisioning the Future', Third World Quarterly, Vol.31, No.5, 2010, pp.755-71; Rosan Smits and Deborah Wright, 'Engagement with Non-State Actors in Fragile States: Narrowing Definitions, Broadening Scope', CRU Report, The Hague: Clingendael Netherlands Institute of International Relations, 2012, p.8. 


\section{DEVELOPMENT ASSISTANCE FOR PEACEBUILDING}

3. OECD, Fragile States 2014: Domestic Revenue Mobilisation in Fragile States, Paris: OECD, 2014; World Bank, 'World Development Report: Conflict, Security, and Development', Washington, DC: World Bank, 2011.

4. See, e.g., Ken Menkhaus, 'State Failure, State-Building, and Prospects for a "Functional Failed State" in Somalia', ANNALS of the American Academy of Political and Social Science, Vol.656, No.1, pp.154-72.

5. Rachel M. Gisselquist, 'Aid and Institution-Building in Fragile States: What Do We Know? What Can Comparative Analysis Add?', ANNALS of the American Academy of Political and Social Science, Vol.656, No.1, pp.6-21; OECD, The Missing Piece: Improving International Support to the Peace Process, Paris: OECD, 2012; OECD/DAC, Principles for Good International Engagement in Fragile States and Situations, Paris: OECD, 2007.

6. Derrick W. Brinkerhoff, 'Developing Capacity in Fragile States', Public Administration and Development, Vol.30, No.1, pp.66-78; UNU-WIDER, 'Position Paper: Aid, Governance, and Fragility', Helsinki, Finland: UNU-WIDER, 2014.

7. David D. Booth, 'Aid Effectiveness: Bringing Country Ownership (and Politics) Back in', Conflict, Security \& Development, Vol.12, No.5, 2012, pp.537-58; Rachel M. Gisselquist and Danielle Resnick, 'Aiding Government Effectiveness in Developing Countries', Public Administration and Development, Vol.34, No.3, 2014, pp.141-8; Martin Sjöstedt, 'Aid Effectiveness and the Paris Declaration: A Mismatch between Ownership and ResultsBased Management?', Public Administration and Development, Vol.33, No.2, 2013, pp.143-55.

8. See, e.g., Deborah Bräutigam and Stephen Knack, 'Foreign Aid, Institutions and Governance in Sub-Saharan Africa', Economic Development and Cultural Change, Vol.52, No.2, 2004, pp.255-85; Lant Pritchett, Michael Woolcock and Matt Andrews, 'Looking Like a State: Techniques of Persistent Failure in State Capability for Implementation', Journal of Development Studies, Vol.49, No.1, 2013, pp.1-18.

9. See, e.g., Matt Andrews, The Limits of Institutional Reform in Development: Changing Rules for Realistic Solutions, Cambridge: Cambridge University Press, 2013; Odd-Helge Fjeldstad, 'Tax and Development: Donor Support to Strengthen Tax Systems in Developing Countries', Public Administration and Development, Vol.34, No.3, 2014, pp.182-93; Otwin Marenin, 'Styles of Policing and Economic Development in African States', Public Administration and Development, Vol.34, No.3, 2014, pp.149-61; Sarah Repucci, 'Designing Effective Civil Service Reform: Lessons from Past Experience', Public Administration and Development, Vol.34, No.3, 2014, pp.207-18.

10. Paul Collier, 'How to Spend It: The Organization of Public Spending and Aid Effectiveness', WIDER Working Paper WP/2012/005, Helsinki: United Nations University-World Institute for Development Economics Research (UNU-WIDER).

11. See www.odi.org/fellowship-scheme.

12. JSI, 'Liberia Fellows Program', n.d. (at: www.jsi.com/JSIInternet/IntlHealth/project/display.cfm? ctid=na\&cid=na\&tid=40\&id=5028), last accessed 11 Dec. 2014.

13. TCC and W\&L, 'Liberia Law Fellows Program', n.d. (at: law.wlu.edu/deptimages/carter\%20fellows/Law\%20Fellows\%20report-April\%2024.pdf), last accessed 11 Dec. 2014.

14. 'Activist on the World Stage: Carroll Wilson Remembered', The MIT Tech Review, Feb./Mar. 1984. Made available by Carroll L. Wilson Award Committee (at: web.mit.edu/idi/carroll_wilson_award/CLW-Activist.pdf).

15. Todd Moss and Stephanie Majerowicz, 'Beam Me Back, Scotty: How Young Liberians Are Coming Home', Center for Global Development, 17 Apr. 2012 (at: http://www.cgdev.org/ blog/beam-me-back-scotty-how-young-liberians-are-coming-home-0).

16. The PiP project is credited for having provided successful dispute resolution to 11 conflicts in Somaliland and Puntland between 2008 and 2010 and to 3 conflicts in Central Somalia regions of Mudug and Galguduud.

17. FCA, 'Peace in Somalia 2009-2012', unpublished document on advocacy plan, Helsinki, 2009.

18. See Rauli Lepistö, 'Building a Piece of Peace: Finn Church Aid's Outreach and Reconciliation Project in Somalia', CMC Finland Studies in Peacebuilding and Civilian Crisis Management, Vol.4, No.1, 2013, Kuopio: Crisis Management Centre Finland (CMC Finland), pp.12-14.

19. Ibid., p.5.

20. FCA, 'Rights Based Approach - Principles for FCA Programme Work', unpublished FCA document, Helsinki, 2012.

21. Ibid., p.1: 'We should always prioritize local ownership and the agency of the rights-holders.'

22. APRODEV (the Association of World Council of Churches related Development Organizations in Europe), 'Background Paper on Fragile States and Situations', unpublished paper, 


\section{DEVELOPMENT ASSISTANCE FOR PEACEBUILDING}

Brussels, Mar. 2009. The document emphasized the role of NGOs, coherence and local ownership in fragile settings. It also stressed the 'importance of supporting ... state-building focus to inclusive society building'.

23. Boesen J. Kirkemann and T. Martin, Applying a Rights-Based Approach - an Inspirational Guide for Civil Society, Copenhagen: Danish Institute of Human Rights, 2007 (at: http:// www.humanrights.dk/files/pdf/Publikationer/applying a rights based approach.pdf), p.12.

24. Ibid., p.12.

25. United Nations, Security Council, 'Report of the Secretary-General on Somalia', [S/2011/549, 30 Aug. 2011 (at: http://www.securitycouncilreport.org/atf/cf/\%7B65BFCF9B-6D27-4E9C-8CD3CF6E4FF96FF9\%7D/Somalia\%20S\%202011\%20549.pdf), the Secretary General of the UN offers a paragraph to the activities of the joint project. New York, 2011, p.9.

26. The funds of the final planned activity of the joint project with UNPOS were transferred to the TFG as it was convening the Somali elders in Mogadishu in April 2012. See Lepistö (n.18 above), p.28.

27. Interview regarding the role of Somali elders and FCA's contribution to ending the transition, with Prime Minister Abdiweli Mohamed Ali and Minister of Interior Abdisamad Moallim Mohamoud, London, 23 Feb. 2012.

28. The total budget of the capacity support to TFG was $€ 60,400$.

29. The MFA subsequently allowed FCA to count the start of the project from 22 Apr. 2012.

30. Telephone interview with Hosh, Helsinki, 8 Sept. 2013.

31. Abdile had personal security that cost roughly 400 USD per day.

32. Private donations and other un-earmarked funding.

33. This paragraph is based on the interview with Hosh (see n.30 above).

34. In practice the Elders Council carried the main responsibility in selecting the members of the Parliament. Technically the Elders Council proposed the names of Members of Parliament, who had to go through a vetting process by the Technical Selection Committee (TSC). The TSC excluded some 70 of the proposed names who did not meet the set criteria.

35. Interview with Hosh (see n.30 above).

36. Interview with Abdile, Helsinki, 2 Aug. 2013.

37. Telephone interview with Hosh (see n.30 above) and also telephone interview with K. Hassan, Helsinki, 2 Jul. 2013.

38. Interview, Hassan (see n.37 above).

39. Interview, Hosh (see n.30 above).

40. Interview with Abdile, Helsinki, 2 Jul. 2013.

41. Interview with Hosh (see n.30 above).

42. Interview, Abdile (see n.36 above).

43. Interview, Hosh (see n.30 above).

44. The topics also included reconciliation and mediation.

45. Interview, Abdile (see n.36 above).

46. Ibid.

47. Lepistö (see n.18 above), p.26.

48. Another complicating feature was the existence of many self-appointed elders, who were active in the media aiming to increase their status in the eyes of the public. Often it turned out that these people were not real elders.

49. Interview, Abdile (see n.36 above).

50. Ibid.

51. Ibid.

52. A. Atta-Asamoah, 'Situation Report. Long Walk to Restauration: Lesson from Somalia's Transition Process', Pretoria: Institute for Security Studies, report, Jul. 2013, pp.1-10.

53. FCA Strategy, 'Finn Church Aid's Strategy 2009-2012', Helsinki, 2009 (at: http://www.archivefi.com/page/34974/2012-06-02/http://www.kua.fi/filebank/811-Strategia_englanti.pdf), p.7.

54. FCA facilitated a workshop during the PiP where the elders had gathered to discuss sharia law. In this meeting, the role of women arose on the agenda resulting in an understanding that there were no theological obstacles to including women in politics.

55. Interview, Hosh (see n.30 above).

56. Telephone interview with H. Ismail, Helsinki, 28 Aug. 2013.

57. A. Cawo, 'Marginalising Women in Somali Politics', Al Jazeera, 24 Aug. 2013 (at: http://www. aljazeera.com/indepth/opinion/2012/08/201282385318698928.html).

58. Interview, Abdile (see n.40 above). 


\section{DEVELOPMENT ASSISTANCE FOR PEACEBUILDING}

59. A. Farhia, 'Somali Women Parliamentarians: The Predicament of Finding a Voice', Hiraan online, 15 May 2013 (at: http://www.hiiraan.com/op4/2013/may/29375/somali_women_ parliamentarians_the_predicament_of_finding_a_voice.aspx).

60. Interview, Ismail (see n.56 above).

61. Interview, Abdile (see n.36 above).

62. Ibid.

63. See www.newdeal4peace.org/.

64. For example, the International Crisis Group commented: 'The current political process has been as undemocratic as the one it seeks to replace, with unprecedented levels of political interference, corruption and intimidation.' See ICG, 'Somalia: From Troubled Transition to a Tarnished Transition?', press release, 20 Aug. 2012 (at: http://www.crisisgroup.org/en/publication-type/ media-releases/2012/africa/somalia-from-troubled-transition-to-a-tarnished-transition.aspx). The Economist wrote: 'In practice, the "wise men" were largely chosen by existing leaders of the UN-backed transitional federal government (TFG), which has spent the past eight years stealing aid money while leaving AU peacekeepers to fight the Shabab. Money has also played a role in the selection of new MPs. Parliamentary seats were apparently sold for up to $\$ 25,000$.' 'Somalia's Government, Baby Steps', 25 Aug. 2012 (at: http://www.economist.com/node/21560905).

65. Interview, Abdile (see n.36 above).

66. Interview with A. Pentikäinen, Helsinki, 13 Jun. 2013. 


\title{
Liberia's Gender-Sensitive Police Reform: Improving Representation and Responsiveness in a Post-Conflict Setting
}

\author{
LAURA BACON
}

This article presents a case study from Liberia that focuses on the relationship between police reform and women, peace and security. It explores the Liberia National Police's (LNP) innovative efforts between 2003 and 2013 to recruit more female officers and to train a specialized unit to address sexual- and gender-based violence (SGBV). The analysis focuses on two key goals of the LNP: representation, through the Education Support Programme, and responsiveness, through the Women and Children's Protection Section. Assessed by these two metrics, the Liberian police reform can be considered a qualified success, as the percentage of female officers rose from 2 to 17 per cent, and the LNP improved its response to SGBV reports. Success factors included the timing, context, local ownership and foreign development assistance. However, the sustainability and overall impact of the reforms was severely hindered by low technical capacity and weak rule of law.

\section{Introduction}

Security reform, and police reform specifically, is an integral part of peacebuilding, ${ }^{1}$ as is the relationship between 'women, peace and security'. ${ }^{2}$ This article bridges these two bodies of work in addressing issues of gender in police reform ${ }^{3}$ through a case study of Liberia's police reforms to recruit more women and respond better to sexual- and gender-based violence (SGBV).

Liberia is an important case for the study of post-conflict policing and security sector reform, and thus the subject of substantial research. ${ }^{4}$ In addressing important issues of gender in the process of reform in Liberia, this case study complements and provides new evidence on an important component of that reform.

As the case study illustrates, evaluating and explaining reform processes such as this one is challenging, given the number of factors that influence outcomes. In evaluating outcomes, this analysis focuses on representation and responsiveness, the two key goals of the Liberia National Police (LNP), arguing that in these terms, the Liberian police reform can be considered a qualified success that may offer useful insights for other situations. In explaining this assessment, it highlights the importance of political will, timing, conducive context ${ }^{5}$ and local ownership, ${ }^{6}$ as well as of the role of foreign assistance.

This is an Open Access article distributed under the terms of the Creative Commons Attribution-NonCommercial-NoDerivatives License (http://creativecommons.org/Licenses/by-nc-nd/4.0/), which permits noncommercial re-use, distribution, and reproduction in any medium, provided the original work is properly cited, and is not altered, transformed, or built upon in any way. 


\section{DEVELOPMENT ASSISTANCE FOR PEACEBUILDING}

\section{Background and Context}

Liberia's 14-year civil war ended with a peace agreement in 2003. Of a population of approximately 3 million, an estimated 270,000 Liberians were killed and hundreds of thousands were displaced. ${ }^{7}$

The post-war context was fragile. In the Liberian countryside - difficult to reach even during peaceful times - services such as education and health had been on hold for years. In Monrovia, the coastal capital city to which many Liberians fled during the war, residents were traumatized and infrastructure had crumbled. With a GDP per capita of US\$135 in 2003, an unemployment rate of 85 per cent and following one of the steepest economic collapses ever recorded in the world, Liberia's economy was flailing. ${ }^{8}$ Helping to maintain the tenuous peace was the United Nations Mission in Liberia (UNMIL), the largest peacekeeping mission in the United Nations history. ${ }^{9}$

Security was UNMIL's and Liberians' first concern. Although the disarmament and demobilization process mostly quieted the gunfire, a 'culture of violence' continued, especially against women and girls. ${ }^{10}$ During the war, many Liberians had been sexually or physically assaulted. ${ }^{11}$ After the war, sexualand gender-based violence (SGBV) and armed robbery continued to be the two primary security concerns in Liberia. ${ }^{12}$

Citizens had lost trust in the justice system during the war. Liberia's police service had been known as particularly incompetent and brutal. Some police units were known as perpetrators of rape and murder. ${ }^{13}$ After the war, the LNP had to build its reputation and gain the confidence of Liberians.

More broadly, Liberia's post-war rule of law needed massive reform. By the end of the war, Liberia had 15 different security agencies with overlapping functions and mandates. ${ }^{14}$ The peace agreement called for Liberia's police service to start from scratch. In 2003, the UNMIL Police Commissioner and Liberia National Police (LNP) Inspector General began to implement reforms through a Rule of Law Implementation Committee. ${ }^{15}$

In this post-conflict context, could Liberia's new police service prove to be more representative and responsive? Focusing particularly on context, timing, local ownership, project design and foreign assistance, this article explores how - from 2003 to 2013 - Liberia and its partners dealt with these challenges and opportunities. ${ }^{16}$ Section three provides background on the local context and aid in Liberia. Section four describes two programmes: one to recruit female police officers; one to train officers in addressing SGBV reports. Because failures in addressing SGBV were attributable to larger justice system bottlenecks, Liberia and the donor community took follow-up steps described in Section five. Section six analyses and discusses what worked well, what did not and offers analysis and explanations for the outcomes. This final section also offers what can be learned from Liberia's experience, as well as what was on Liberia's horizon for gendersensitive police reform.

The article's finding is that Liberia's gender-sensitive police reform towards better representativeness and responsiveness were innovative, with some positive outcomes. Success factors included timing, context, local ownership and extensive 


\section{DEVELOPMENT ASSISTANCE FOR PEACEBUILDING}

foreign assistance. However, results were mixed: ambitious recruitment efforts brought more female police on board, but the related fast-track programme was neither in-depth nor monitored enough to be effective and had some negative side-effects for women. The specialized unit increased awareness about and response to gender-based violence, but was impeded by a broken judicial system. The technical and financial sustainability of projects' successes remained questionable, given Liberia's extremely low capacity and weak rule of law.

\section{Gender-Sensitive Reform in a Fragile State Context: Opportunities and Challenges}

After the civil war, the Government of Liberia and its international partners had several opportunities to make progress on gender-sensitive police reform. First, women had built credibility as peace agents in Liberia by accelerating the war's end. As acknowledged by the 2011 Nobel Peace Prize committee, thousands of Liberian women joined together during the war in an interfaith peace movement, rallying for a cease-fire and barricading peace talks until negotiators reached an agreement. $^{17}$

Second, in 2005, Liberians elected the first female president in Africa. At her inauguration - an event brimming with hopeful Liberians and a supportive international community - President Johnson Sirleaf pledged to support the women in the country. The president followed through with this promise soon after her inauguration by appointing several women to high-level positions in her cabinet and the LNP.

A third window of opportunity for police reform was that Liberia's transition and post-war period was characterized by significant momentum for gender-sensitive reform. Liberian leaders and their international counterparts were mandated to act by United Nations Security Council Resolution 1325 on women, peace and security. Passed in 2000, Resolution 1325 - and follow-up resolutions such as 1820, 1888, 1889 and 1960 - urged countries to increase women's representation in the security sector and to take special measures to prevent SGBV. ${ }^{18}$ In 2005, the Liberian legislature passed a 'rape law' that expanded the definition of rape and set harsh penalties for sexual assault. ${ }^{19}$ The Government of Liberia and UNMIL set a goal to increase the percentage of female police officers from 2 per cent in 2005 to 20 per cent by $2014 .^{20}$ The United Nations, itself, set the same 20 per cent female target for itself for its peacekeeping missions. ${ }^{21}$

Domestic institutional support for gender-sensitive reform derived from many organizations and planning documents, including Liberia's Ministry of Gender and Development (founded during the war, in 2001, by the national legislature, and became more functional and donor-supported after the war) ${ }^{22}$ and the National Plan of Action for the Prevention and Management of Gender Based Violence in Liberia. The National Plan of Action for Gender Based Violence was developed from 2004 to 2006 by the Ministry of Gender and Development in collaboration with the World Health Organization and Liberian ministries and agencies. ${ }^{23}$ The national plan established the Gender Based Violence Taskforce, representatives from the police, ministries, donors, NGOs and other 


\section{DEVELOPMENT ASSISTANCE FOR PEACEBUILDING}

stakeholders who met regularly to share data and follow up on cases of genderbased violence. ${ }^{24}$

A fourth opportunity to strengthen Liberia's police reform was the presence of vast international support. Leaders around the globe were thrilled at the prospect of a peaceful, better-governed, gender-sensitive Liberia, and threw their support behind President Johnson Sirleaf, a Harvard-educated World Bank economist with a relatively clean record. ${ }^{25}$ International aid organizations and donors flooded into Liberia, determined to diminish the suffering and make their mark as the nation began to rebuild. ${ }^{26}$

Foremost among Liberia's external supporters after the war was the United Nations. UNMIL was founded in 2003 by United Nations Security Resolution $1509 .^{27}$ At that time, it was the largest peacekeeping force in the history of the United Nations, with 15,000 peacekeeping troops and 1,115 police officers from around the world. In the 2003 peace agreement, UNMIL was designated as the lead body in overhauling the police service and developing Liberia's civilian police capacity. The LNP's counterpart at UNMIL was the UN Police (UNPOL), whose role included recruiting police staff, developing training programmes and addressing violence against women and girls as a weapon of war. ${ }^{28}$

In addition to UNMIL's massive peacekeeping force and civilian police, other United Nations entities had a major presence in Liberia, all of which engaged and invested deeply in the LNP's gender-sensitive reforms. Examples included United Nations Development Programme (UNDP), United Nations Children's Fund (UNICEF), United Nations Peacebuilding Fund, United Nations Population Fund (UNFPA) and United Nations Development Fund for Women (UNIFEM, which in 2011 became part of UN Women).

Another window of opportunity was that the LNP was starting anew. The security sector reform process involved deactivating all former police officers and inviting them to apply to join the new service. Starting the police service nearly from scratch meant the opportunity to vet new officers, to weed out those who were unqualified or ill-suited for police service - including those affiliated with rebel groups and those who had committed war crimes - to train recruits, to build a different policing culture and to make a change. ${ }^{29}$

However, on the flip side of these opportunities were challenges. For one, as described by Friedman, there was little institutional memory, because officers were deactivated in the security sector overhaul. ${ }^{30}$ The post-war state of the police was abysmal and had little infrastructure on which to build. Furthermore, police officers' capacity to perform their duties was extremely low because the war had deprived them of over a decade of education, training and proper professional experience. Poor infrastructure and low technical capacity would be a constant constraint throughout Liberia's post-conflict police reforms.

Another challenge was that the LNP had a tarnished image after the war. Peace talk participants agreed to dissolve security units that developed reputations for corruption and predation. Such units included the former President Charles Taylor's notorious Anti-Terrorist Unit, known for committing murder, torture and rape. ${ }^{31}$ But the police's violent reputation would not disappear immediately. In addition, the LNP did a poor job handling cases of SGBV, such 


\section{DEVELOPMENT ASSISTANCE FOR PEACEBUILDING}

as domestic abuse, child abuse and sexual assault. The head of the SGBV Unit of Liberia's Ministry of Gender and Development recalled that, before and during the war: 'The police didn't know how to handle SGBV.... If a woman reported rape, the police would suggest she had caused it. They would make it worse, and women would be traumatized. ${ }^{32}$

A third challenge for enhancing responsiveness was the pattern of low reporting rates for rape. Stigmatization and taboos associated with rape in Liberia worsened the problem of underreporting that commonly characterized such crimes. ${ }^{33}$ In a study commissioned by the United Nations in 2008, only 12.5 per cent of Liberian women who had been raped said they had reported their cases to the police. ${ }^{34}$ Another underreporting factor was that an extraordinarily high rate of sexual assaults were committed against children. A 2006 report by Doctors without Borders indicated that 85 per cent of 658 rape victims treated at its clinic were younger than $18 ; 48$ per cent were under $12 .{ }^{35}$ Most sexual assault cases were settled outside of court, either privately or through traditional or customary structures. ${ }^{36}$

A fourth challenge both for recruiting women and for responding to SGBV was Liberia's culture and history: the security services had been predominantly male throughout Liberia's history, a pattern common to security services throughout the world. This would make it more difficult to recruit women to the police service. Furthermore, Liberia's history of male domination and violence against women meant that the country's 'rape epidemic' and 'culture of violence' would be extremely difficult to combat.

Finally, the donor presence in post-war Liberia provided resources and support, but also posed hazards. There was the danger - especially in a postwar context - that aid organizations could prioritize pet projects, proceed without a full understanding of the Liberian context or create reforms unsustainable in donors' absence. Of particular concern, outsiders' solutions could fail to consider Liberia's pre-existing customary, traditional and informal structures. ${ }^{37}$ Furthermore, donor projects would need to ensure that investments were not concentrated solely in the capital. The majority of Liberians lived in villages that were difficult to reach, especially during the rainy season, and were hours or days away from donor projects and development in Monrovia. ${ }^{38}$

\section{Initiatives to Improve Representation and Responsiveness}

After Liberia's civil war ended, the LNP - alongside UNMIL, and with support from other aid organizations - engaged in two major gender-sensitive initiatives. ${ }^{39}$ The first was to improve women's representation in the LNP, with the goal of reaching a 20 per cent female police service by 2014 . The second was to enhance responsiveness to SGBV.

The LNP's dual goals of representation and responsiveness were related. Poor responsiveness to SGBV was explicitly linked to a shortage of women in the security sector. ${ }^{40}$ Few women in police ranks meant few women to respond to and conduct the kind of sensitive investigations required for gender-based crimes, whose victims often preferred to speak with female officers. ${ }^{41}$ However, 


\section{DEVELOPMENT ASSISTANCE FOR PEACEBUILDING}

recruiting more female officers was also driven by beliefs that Liberia's leaders and public sector should be more representative of its citizens and that women would make important contributions to a security sector from which they had been discouraged previously.

In 2006, President Johnson Sirleaf appointed Beatrice Munah Sieh as Liberia's first female inspector general, the top position in the LNP, and in 2007, she appointed Asatu Bah-Kenneth as the LNP's deputy inspector general. ${ }^{42}$ Beginning in 2006, the LNP's leaders, as well as the LNP's gender, personnel and community services units, worked to recruit new officers and showcase the growing numbers and prominence of women in the police service.

By early 2007, the percentage of women in the LNP had more than doubled from 2 per cent to 5 per cent, but the 20 per cent goal remained distant. The key hurdle was that many women did not have the required high-school education. $^{43}$ In 2007 , because of the years of war and because parts of the country did not encourage girls' education, only 5 per cent of women had completed high-school. $^{44}$

In response to this obstacle, an Education Support Programme (ESP) was created to enable women between the ages of 18 and 35 who had completed at least ninth grade to earn the equivalent of a high-school degree and enter police training. The impetus for the ESP was a combined effort of UNMIL and UNPOL. ${ }^{45}$ In the first step of the ESP, the West African Examination Council (WAEC) determined female applicants' education level and assessed their ability to learn the required material. In the first cohort, fewer than half of the 350 applicants were accepted into the programme. ${ }^{46}$ Through the next three months, the accepted female police aspirants underwent intense schooling six full days per week. The programme provided lunches and transportation and housing stipends. Instructors, mostly Liberians and other West Africans, taught classes in 11 subjects and administered progress exams every month. ${ }^{47}$ After three months, the institute conducted final exams followed by official exams administered by WAEC. Successful candidates then followed the standard procedures to enter basic police training at the academy.

The ESP had three sessions - one pilot cohort in 2007, a second cohort in late 2007 and a third cohort in 2008 - and significantly improved the LNP's gender balance. As a result of the three cohorts in the programme between 2007 and 2008, approximately 300 women joined LNP training classes, increasing female enrolment from 5 per cent to 12 per cent. ${ }^{48}$

Recruitment efforts continued, led by UN Women, Liberia's Ministry of Justice, the Ministry of Gender and Development, UNMIL and the Women in Peacebuilding Network (WIPNET). ${ }^{49}$ By 2013, 767 of the LNP's 4,417 officers were women (17.4 per cent). ${ }^{50}$

Beyond recruitment for more balanced representation, the LNP worked to improve its responsiveness, particularly to sexual- and gender-based violence. In 2005, the LNP created a special unit, the Women and Children's Protection 


\section{DEVELOPMENT ASSISTANCE FOR PEACEBUILDING}

Section (WACPS), dedicated to responding to reports of domestic violence, sexual assault and crimes against children. UNMIL and UNICEF supported the creation of this section, and UNPOL were assigned to WACPS as colleagues and trainers. WACPS units throughout the country were funded through a grant from the Norwegian government, administered through UNDP. ${ }^{51}$

WACPS's mission was modelled after an innovative unit in neighbouring Sierra Leone. With the support of the UN Mission in Sierra Leone, Kadi Fakondo - a high-ranking police officer from Sierra Leone - had established Family Support Units in 2001 to encourage survivors of rape, domestic violence or sexual crimes to report the crimes to the police. ${ }^{52}$ Sponsored by UNICEF, Fakondo and another officer came from Sierra Leone to Liberia in 2005 to train the first two batches of LNP WACPS officers and to train trainers for future sessions. Each batch of Liberian trainees consisted of 25 male and female LNP officers, some of whom were new to the police, and some of whom were LNP veterans who had to repeat basic training due to the deactivation process. Training included instruction in topics such as creating case reports for crimes of domestic violence and sexual assault, investigating reports, collecting evidence and maintaining confidentiality.

WACPS began operations in September 2005, staffed by the first 25 trainees. Asatu Bah-Kenneth, who had been in the police service for two decades, attended the first WACPS training and was named to head the section in 2005. (She was later appointed as the LNP's deputy inspector general.) WACPS's organizational structure included a director, deputy director, chief of administration, chief of operations, chief investigator, three crime squad heads, as well as several investigators, officers and support staff. Two of WACPS's three squads - the Sexual Assault Unit and Juvenile Unit - had been independent LNP operations previously, while the third, Domestic Violence, was new.

Accurate record-keeping was crucial - collecting victims' statements, co-ordinating investigations and following up - and WACPS and UNPOL continued to hone the section's information management and investigation processes. On a monthly basis, WACPS compiled data from all of its units into a report, which it then sent to members of the Gender Based Violence Taskforce.

To spread awareness about WACPS to the Liberian people, UNICEF, UNMIL, the WACPS team and other supporters designed awareness campaigns, including leaflets, posters, school visits, community meetings, billboards and radio shows. Officers engaged with journalists on a regular basis to make sure their services were publicized. In its early months, the section also engaged in advocacy events such as marches and radio features to support the 2005 passage of Liberia's broadened and toughened law on rape. The section engaged in community outreach with other police units. For instance, the Community Policing Unit organized weekly community-discussion trips that included representatives from the Gender Unit, the Personnel Unit and the Traffic Patrol Unit. WACPS officers joined these outreach sessions, explaining how to report crimes and preserve evidence.

The Norwegian Refugee Council's gender-based violence programme worked with the LNP and others to devise a 'Sexual and Gender-Based Violence Referral Pathway'. The pathway - which was depicted on brochures, posters and LNP 


\section{DEVELOPMENT ASSISTANCE FOR PEACEBUILDING}

presentations - publicized proper reporting channels so that victims, police, hospitals, counsellors and courts understood victims' rights and reporting options. In clear language, it emphasized that survivors should never pay bribes or fees for reporting.

Changing cultural norms was an important responsibility of WACPS. Many Liberians did not realize that rape was a reportable crime and did not know how to preserve evidence or where to go for help. With support from UNMIL, WACPS and its counterparts posted billboards around Monrovia with messages like 'Rape is a crime' and 'Against my will is against the law', and co-ordinated a 'Stop Rape' campaign that culminated in an event at the sports stadium, with songs, skits and speeches by Liberian leaders and public figures. Through such campaigns, the Liberian public became increasingly aware of laws against rape and where to seek help.

In May 2011, the new WACPS headquarters in Monrovia was completed and dedicated with a launch ceremony. By June 2013, over 300 officers had received WACPS training. At any given time, approximately 180 active WACPS officers approximately one-third of whom were women - were stationed in 52 police stations spread across all of Liberia's 15 counties. ${ }^{53}$

\section{Addressing Broader Justice System Constraints to Responsiveness: Follow-up Projects}

During its reforms to enhance responsiveness to SGBV, the LNP and its partners encountered judicial hurdles. As more Liberians learned that they could report rape to the police, WACPS's caseload and the number of cases it sent to the courts grew. By 2009, a backlog of more than 100 cases had developed.

Although the backlog partly reflected the difficulties of investigating new allegations of crimes that had taken place years earlier, it was also a by-product of a slow-moving justice system. Police officers did not always co-ordinate well with prosecutors, and officers did not always have the technical capacity to follow proper procedures. Sometimes investigations did not collect enough evidence to support the case in court. As a result of insufficient evidence as well as low capacity, court proceedings moved at a glacial pace - when courts heard these cases at all. These challenges so deeply compromised WACPS's mission that donors and the Government of Liberia decided to act.

In February 2009, leaders at Liberia's Ministry of Justice took two steps, both of which were designed to address the LNP's obstacles in responding to genderbased violence. First, the ministry - with support from UNFPA and funded by the Government of Denmark - established Criminal Court E (known as a 'Special Court' or the 'rape court'), a fast-track mechanism intended to overcome Liberia's backlog of cases involving SGBV. ${ }^{54}$ The court used in camera hearings, in which a private witness room enabled the victim and any witnesses to testify and receive questions without having to face the accused perpetrator. ${ }^{55}$

Second, the justice ministry created the SGBV Crimes Unit in April 2009. ${ }^{56}$ The mission of the unit - intended as a pilot project - was to counsel victims, improve police officers' ability to run investigations, co-ordinate police officers 


\section{DEVELOPMENT ASSISTANCE FOR PEACEBUILDING}

and prosecutors, train prosecutors to tackle cases involving sexual violence and build public awareness. The SGBV Crimes Unit was set apart from both the Ministry of Justice and police headquarters for confidentiality reasons.

When Criminal Court E was created, there was a great deal of optimism and hope that the backlog of sexual violence cases would finally be resolved. For instance, UNMIL Independent Human Rights Expert Charlotte Abaka told reporters in 2008 that she was 'encouraged' by the creation of the new court dedicated to sexual assault, saying, 'The undue delay in prosecuting such cases will now be a thing of the past. ${ }^{, 57}$ Unfortunately, by 2013, almost everyone was discouraged as the backlogs and delays continued.

\section{Analysis and Discussion}

From 2003 to 2013, to mixed results, Liberians and their development partners recruited female officers to improve representation, and created and scaled-up a specialized police unit to address SGBV to improve responsiveness. This section first provides an evaluation of the two LNP projects. It next evaluates the two follow-up Ministry of Justice projects: Criminal Court E and the SGBV Unit. It then offers a broad analysis and discussion of which elements of Liberia's gender-sensitive police reforms were the strongest and weakest, and why.

\section{Assessments of the LNP's ESP and WACPS Reforms}

As a means of accelerating female officer recruitment, the ESP received mixed reviews. Champions believed it provided an accelerated professional gateway for women who were not able to complete high-school. On the whole, it was an innovative programme tackling a specific context-relevant problem, and fast-tracked a record number of women into the LNP.

However, some elements of the recruitment reforms were not as effective. Women were poorly represented in the LNP's specialized and elite forces such as the Police Support Unit (PSU) and Emergency Response Unit (ERU). For instance, of the 523 operations PSU officers in July of 2011, only 31 (6 per cent) were women. $^{58}$ Of 324 ERU officers in 2011, only 19 (6 per cent) were women. ${ }^{59}$ Furthermore, while the number of female police officers was rising, there were few female police officers deployed outside Monrovia. For instance in 2011, of the 71 female Women and Children Protection Section officers deployed around the country in 2011 , only five (7 per cent) were in rural counties. ${ }^{60}$

Nielsen, UNMIL's commissioner of police, said that the programme created a caste system and did a disservice to trainees: ${ }^{61}$ 'The real problem is, we condemned those young women to a career as a patrolman, because they can't read and write. ... How can they compete? They can't. ${ }^{62}$ Other observers were concerned that the female graduates of the ESP could become a liability to the LNP if not further trained and mentored, or that they might have extremely high rates of attrition going forward. ${ }^{63}$

A former police officer and top official at the Bureau of Immigration and Naturalization offered her assessment that the programme had been created in a desperate effort to reach the goal of 20 per cent women in the police service: 


\section{DEVELOPMENT ASSISTANCE FOR PEACEBUILDING}

'They were looking for numbers and not quality ... and so they didn't find the best. ${ }^{64}$ She noted that some men resented a fast-track education programme for women because men, too, had missed out on education during the war. ${ }^{65}$ Finally, she questioned the decision to seek new female recruits rather than tap into the LNP's pool of experienced women who had left the police in the deactivation process. ${ }^{66}$

UNMIL's Sylvia Bisanz, who helped coordinate the programme, said: 'I believe that overall the programme was successful. However, prolonging it a little might be beneficial.' 67

Outsiders' assessments of police responsiveness to SGBV were also mixed. First, it is important to note that assessing WACPS's precise impact on rates of gender-based violence would be impossible. Because few victims report rape not just in Liberia, but in most contexts - real rates of sexual assault will never be known. ${ }^{68}$ Furthermore, in a point discussed later in this article, most criminal cases in Liberia do not make their way through the formal system. Isser et al. estimate that 50 per cent of rape cases were never reported, 28 per cent were taken to an informal forum (e.g. family heads, traditional leaders, elders, secret society members, soothsayers, midwifes, chiefs) and 21 per cent were taken to a formal forum (e.g. police officers, magistrates, government officials). ${ }^{69}$ So the total amount of WACPS reports of gender-based violence would never reflect actual SGBV crime rates.

That said, after WACPS was founded, the number of Liberians reporting SGBV to the police rose - including the reporting of assaults that had happened years earlier. ${ }^{70}$ Many observers and internal actors believed that higher rates of reporting indicated enhanced trust in the LNP, rather than higher incidence of crime. ${ }^{71}$

Indeed, many observers praised WACPS. In a context of a supportive president and eager external community, WACPS enhanced awareness about and response to gender-based violence. In particular, WACPS emphasized that rape is a reportable crime. UNMIL's monthly reports heralded WACPS, as did the donors (especially the Norwegian government). The deputy director of training at the National Police Training Academy said that people never used to report sexual assault or domestic violence to the police, but now 'if there is a problem, people go to the WACPS first'. ${ }^{72}$ A United States Embassy officer said that the WACPS was 'highly regarded'. ${ }^{73}$ The Liberian community was more aware than ever about the illegality of and ability to report sexual crimes because of ubiquitous billboards, media announcements, community events, posters and other forms of publicity. Officials at the Ministry of Gender and Development, as well as taxi drivers and other non-government officials, noted that many Liberian women would respond to harassment by threatening to make a report to WACPS.

However, WACPS faced serious challenges. First, as in most Liberian institutions, WACPS needed further capacity building and training. Some officers lacked the skills needed to write reports, investigate crimes effectively and follow up. ${ }^{74}$

Second, like the rest of the LNP, WACPS also faced resource limitations. Most section officers did not have vehicles. Lack of transportation jeopardized confidentiality; for example, a former WACPS section head mentioned that she had often paid for private taxis for victims so that they would not have to travel 


\section{DEVELOPMENT ASSISTANCE FOR PEACEBUILDING}

from WACPS headquarters to the hospital in a shared taxi (as shared taxis are customary in Liberia). ${ }^{75}$ Furthermore, transportation difficulties compromised the integrity and feasibility of the investigation. The deployment of WACPS officers in 52 units across the country meant communities were closer to formal institutions than in the past, but some Liberians still had to walk hours to reach the nearest section office, and officers had to make the same trek to investigate the crime. Additionally, WACPS lacked communication resources, such as cellphones and computers. Most officers outside of Monrovia reported cases to headquarters through hard copy, via UNMIL vehicles passing through or by calling or sending text messages.

Third, officer attrition was another issue, because there were few incentives. WACPS officers did not receive an extra bonus for their specialized training, whereas members of other specialized units enjoyed higher salaries and greater access to per diem payments. ${ }^{76}$ Not surprisingly, some of the best WACPS officers transferred to other units. Interestingly, some critics complained that WACPS had more resources than other units at the police, because donors tended to prioritize WACPS. For instance, in some rural counties, WACPS had a motorcycle or car or better facilities than other units within the LNP. Sometimes, estimations of WACPS resources were inflated: the head of WACPS's Juvenile Unit noted that other officers had an inaccurate perception of WACPS's resources: 'Other police officers feel we have been sponsored by donors and think that we have extra wages for the work we do. They think there is a special fund for WACPS investigators. Then they go to WACPS training and realize there isn't. ${ }^{77}$

WACPS was a unique effort to address an important and intractable problem, but it was limited by extremely low capacity, in terms of both resources and technical ability to perform necessary duties. The critical setback was that WACPS was impeded by a broken judicial system (see later sections on 'Evaluation of Criminal Court E and SGBV Crimes Unit' and 'Overall Discussion and Analysis'). Vildana Sedo, acting UNPOL gender adviser and UNPOL officer at WACPS noted: 'LNP has made huge progress. The problem is that the criminal judicial system is unable to support what LNP achieves. ${ }^{78}$ The acting UNPOL gender adviser summed up LNP's progress on responding to SGBV: 'They're doing a good job given the challenging circumstances and resources they have. ${ }^{79}$ The UN Secretary-General's assessment of WACPS in 2012 was as follows: 'While intensive in-service training has improved the handling of cases involving SGBV and their referral by the police to the courts, the criminal justice system continues to face enormous challenges in dealing with such cases. ${ }^{80}$

Overall, the situation was still bleak, with Liberia's 'rape epidemic' persisting a decade after the war ended. In 2013, armed robbery and rape were still Liberia's two most commonly reported crimes. ${ }^{81}$ Of the victims of sexual assault, 70 per cent were minors and nearly 18 per cent were under 10 years old. ${ }^{82}$

\section{Evaluation of Criminal Court E and SGBV Crimes Unit}

Although the joint initiatives of the Criminal Court E and the SGBV Crimes Unit were promising steps, a shockingly small number of cases made it from the LNP to and through court. 


\section{DEVELOPMENT ASSISTANCE FOR PEACEBUILDING}

The SGBV Unit had a backlog of more than 100 cases when it was established. The leader of one donor project said: 'It's almost like the Crimes Unit was set up to fail, which I think is just really unfair, because potentially it could be amazing. It could be a really great resource for Liberia. ${ }^{83}$

From its founding in February 2009 through July 2011, the SGBV Crimes Unit was able to shepherd only 16 of approximately 200 cases through Criminal Court $\mathrm{E}$, eight of which ended in convictions ranging from seven years to life imprisonment. ${ }^{84}$ By 2013, the court had tried 34 rape cases: 18 defendants were found guilty, 15 were found not guilty and one verdict was not resolved due to a hung jury; 280 cases were dropped because of lack of sufficient evidence. ${ }^{85}$ Meanwhile, over 100 people accused of rape sat in prison waiting for trial and accusers waited for their day in court. ${ }^{86}$

Felicia Coleman, head of the SGBV Unit, explained that there were many difficulties and challenges in managing rape cases. She lamented that complaints often came to the police or the unit long after the evidence had been destroyed, rendering investigation and conviction more difficult. In rare instances when complaints were reported immediately, Liberia had no forensic laboratory to analyse the evidence. Finding witnesses was impossible in most cases.

One clear bottleneck was that only one judge was active at Criminal Court E, although the law technically provided for two judges. An independent evaluation of the SGBV Crimes Unit recommended that 'a second judge should be added to the one sitting judge ... because the time spent on one case by the long-present judge makes the trial process too slow and thus handles few cases only. ${ }^{87}$

Other bottlenecks in moving cases through the judicial system included lawyers, the jury and the note-taking process. First, according to an independent analysis, defence lawyers tended to file 'unnecessary and delay-tactic motions', which the Liberian system required be adjudicated before continuing the trial. ${ }^{88}$ Second, the analysis recommended that the Liberian government should empanel another grand jury for sexual offences and other related cases in order to help a greater number of cases move from grand jury level to trial stage. ${ }^{89}$ Furthermore, the analysis reported that, 'the Special Court typist is not a trained stenographer. The current arrangement is so slow that it distorts the flow of evidence as the witnesses testify. Persistently, the court would have to wait for the machine to catch up with the proceedings. 90

The overarching problem, Coleman said, was that a single court or crimes unit could not solve Liberia's broad and deep justice system problems. 'The entire criminal justice system needs to be reformed', she asserted. 'The jury system needs to be overhauled... The challenges are enormous and run across the entire system: the jury, the court, old laws, witnesses, the communities. ${ }^{91}$

\section{Overall Discussion and Analysis}

The following section takes a step back to consider the broader contextual issues that impacted recruitment and responsiveness - including timing, local context, foreign aid, sustainability, project design and rule of law. 


\section{DEVELOPMENT ASSISTANCE FOR PEACEBUILDING}

An overall framing for successes and failures of these projects could find support in Andrews et al.'s concept of 'problem-driven iterative adaptation' a pragmatic synthesis of development reform results describing interventions which:

(i) aim to solve particular problems in local contexts, (ii) through the creation of an 'authorizing environment' for decision-making that allows 'positive deviation' and experimentation, (iii) involving active, ongoing and experiential learning and the iterative feedback of lessons into new solutions, doing so by (iv) engaging broad sets of agents to ensure that reforms are viable, legitimate, and relevant. ${ }^{92}$

In part, the extent to which the programmes (ESP, WACPS, Special Court E, SGBV Crime Unit) were driven by problems rather than imposed solutions, took into account the local context, allowed for experiential learning and engaged a broad set of agents determined the extent to which the programmes were effective and sustainable.

Timing, context and foreign aid: In some respects, the timing and context of Liberia's gender-sensitive police reforms was ideal. There is no question that Liberia was in a desperate situation and in need of foreign aid after its 14-year conflict. Most structures were shattered; services like electricity, water, education, health and security were non-existent; residents were displaced and traumatized; crime rates were high; ex-combatants were still armed; and there was no formal rule of law. External support - security, financial, technical and human capital was welcomed by Liberians. Crowds cheered when the UN tanks rolled in, and those tanks remained in Monrovia for years after the war ended. ${ }^{93}$ The local context, then, was ripe for development support.

As mentioned earlier, donors took advantage of a post-conflict window of opportunity that included strong momentum for changing norms while starting from scratch. With a women-led peace movement that helped stop the war, a newly elected female president, a female inspector general of police, gender-sensitive donor nations and a UN mission with a mandate to incorporate gender mainstreaming in security sector reform, there was a great deal of energy behind the recruitment and responsiveness initiatives. In this new era, donors and their Liberian partners had leeway to recruit female police ambitiously and create a new unit to respond to gender-based violence.

However, analysis indicates that the timing of these projects was not always successful. With representation, the attempt to fast-track education and recruitment should have been more thorough in its training and accompanied by robust follow-up measures. WACPS was not as effective as it could have been because Liberia's entire justice system was weak. Had more resources and capacity building efforts been concentrated earlier on holistic improvements of Liberia's rule of law, it is possible that fewer WACPS cases would have been backlogged in the court system. Indeed, because WACPS cases were backlogged in courts, it is possible citizens may have lost faith in the unit over time and instead sought alternative mechanisms (e.g. settling outside of the formal system). 


\section{DEVELOPMENT ASSISTANCE FOR PEACEBUILDING}

Sustainability and capacity: Sustainability and capacity issues arose in the gender-sensitive police projects supported by bilateral donors, international NGOs and UN partners.

Donors tried to build sustainability and Liberians strived to assume ownership of projects. For instance, Dave Beer, chief superintendent at the Royal Canadian Mounted Police, who worked for the UN in Liberia, lauded Liberia's efforts to recruit more women to the police, noting that the reforms were locally led. 'This was done by the government, not by the international community', Beer said. '[Efforts] displayed not only a lot of creativity and a desire to have much more gender balance, but it was a real indicator of political will to make some substantive change. ${ }^{94}$ Liberia Representative Regina Sokan-Teah said: 'They [UNMIL] want us to take ownership of the security sector instead of leaving it in the hands of strangers. ${ }^{95}$

However, the jury was still out as to whether achievements could persist. The Liberians' lack of technical, financial and physical capacity to perform roles would continue to hinder progress on security. Through Security Council Resolution 2066 (2012), which extended UNMIL's mission through 30 September 2013, the UN reiterated its calls on the Government of Liberia to

continue to combat SGBV and, in co-ordination with UNMIL, to continue to combat impunity for perpetrators of such crimes and to provide redress, support, and protection to victims, including through the strengthening of national police capacity in this area and by raising awareness of existing national legislation on sexual violence. (Emphasis added by author) ${ }^{96}$

In 2013, the UN Secretary-General described the security situation as 'stable but fragile' and confirmed that 'addressing issues such as the quality of training, professional standards, accountability, public trust, and sustainability is central to the ability of the police to perform their duties'. ${ }^{97}$

Unique project design elements: Unique and innovative elements include the prioritization of cultural/norm change, an emphasis on awarenessraising educational campaigns, study trips, role modelling and side-by-side embedding.

Donors and the Liberian police invested not only in recruitment and responsiveness projects but also awareness-raising initiatives, whose impact should not be underestimated. For instance, UNMIL radio often featured information and shows on gender-related topics, Monrovia's billboards were plastered with messages and images about reporting rape, Liberia's international partners helped the country prepare for holidays (which tended to have higher rates of gender-based violence) and donors sponsored massive campaigns both on women's participation in security sector reform and on rape prevention. For such activities, outcomes and metrics of success are hard to track - especially in the short term - but likely contributed to norm changes in Liberia.

In terms of unique design elements that other countries could model after the Liberian experience, international actors might try to expose government officials to a wealth of experiences through study trips, role modelling and side-by-side 


\section{DEVELOPMENT ASSISTANCE FOR PEACEBUILDING}

embedding. Liberian government officials went on sponsored trips and came back with new ideas. Napoleon Abdulai, security sector reform adviser at the UNDP, said: 'In Nigeria, Ghana, Sierra Leone, Mali, you have many more women in higher positions in the security sector who make decisions. They're not leaders in a ceremonial sense. They control budgets'. ${ }^{98}$ Study trips were important because they helped instil the gender-sensitive ideas that outsiders had been pushing within Liberia to some resistance. Abdulai noted: 'People thought that it was because of the president and international community that we were pushing these things. But when you go out, you see what gender experts were saying. Then you see it in reality. ${ }^{99}$ Of note, Liberian officials did not perceive the extent of male domination in Liberian institutions until they travelled and returned as 'apostles for gender mainstreaming'. ${ }^{100}$ For instance, Liberia's House of Representatives national security committee chairman came back from a trip to Ghana fired up to make changes. 'They went to Ghana to the police headquarters', Abdulai said, 'and realized that what gender experts were saying in Liberia was actually being implemented there'. ${ }^{101}$

Role modelling was another successful component incorporated into the design of Liberia's reforms. It was critical that the president had appointed women to high-level positions at the LNP, and that those women were in the spotlight. Nielsen stressed the importance of female role models:

I'm a believer in this; I became a convert in this. The first IG [inspector general of the police] was a woman. And it was a good thing. Children learn what they see. So having an IG in the hallways - a woman, and she made a point of having senior women around her - changed the perspective of the men at the top of the LNP, especially the young officers coming up. So you were building respect. ${ }^{102}$

The presence of an all-female Indian Formed Police Unit also helped reinforce the image of women leading security efforts.

Another element of the mutual learning design included the embedding of outside experts with local police. UNPOL worked side by side with LNP leaders, enabling hourly feedback, training and mentorship. For instance, six UNPOL officers were assigned to WACPS. Not only did this regular contact help Liberian police institutionalize new practices and build their technical capacity through on-the-job training and learning, but this arrangement also helped UNPOL better understand the Liberian context and challenges. Nielsen of UNMIL said: 'This mission [UNMIL] has 39 different nations contributing police officers and, therefore, [39] professional perspectives on policing. ${ }^{103}$ Such a diversity of opinions could potentially confuse or dilute the development efforts (and sometimes did, in Liberia's case), but the variety of counterparts also let Liberians learn from a broad array of experiences and cultures.

Geography was one design element that did not work as well. Donors' efforts in Monrovia did little for Liberians in rural counties. Projects often did not heed the common refrain - 'Monrovia is not Liberia' - and rather focused primarily in the capital. To be effective going forward, donors and the government would need to adopt similar approaches and broaden their reach. 


\section{DEVELOPMENT ASSISTANCE FOR PEACEBUILDING}

Security, justice, and rule of law issues: Liberia's rule of law hindered LNP reforms from 2003 to 2013. The result was clear, explained by the UN Secretary-General's 2013 report on UNMIL: 'Effective investigation and prosecution of SGBV cases remain problematic, and out-of-court settlements are prevalent. ${ }^{104}$

Blume places the blame on several factors: 'principally a lack of Liberian capacity; mutual accusations of incompetence between UNMIL and Liberian lawyers; resistance of the Liberian judiciary to engage in reforms; and UNMIL's state-centred approach to legal reforms. Many of these issues were exacerbated by personality clashes between individuals in UNMIL and the Liberian judiciary. ${ }^{105}$

Diagnoses for the problem range widely, but a few primary themes emerge.

First, all actors would need to invest more in prevention, while still addressing investigation and prosecution issues. The UN Secretary-General's 2013 report on UNMIL stated:

Notwithstanding important progress made in strengthening response mechanisms and the reporting of crimes of sexual and gender-based violence, the prosecution of these cases remains a challenge, owing to weak institutional capacity and the high cost, both financially and socially, of the victims and their families. Efforts for prevention require much greater attention, both from the Government and international partners. ${ }^{106}$

Second, some donors privileged SGBV projects over prevention and broader justice reforms, which analysis found problematic. Schia and de Carvalho report that the international response to crime in Liberia was fragmented and ineffective, focusing on symptoms rather than causes. One of the anonymous interviewees in their paper said: 'Everyone looks at GBV at the expense of a holistic picture of the criminal justice system. The problem is the legal system as a whole.' Another interviewee lamented: 'Why can't victims of rape get justice? It's not because they're women; not because they're victims of rape; it's because nobody gets justice here!'107

Third and relatedly, reformers did not pay adequate attention to customary and traditional justice systems. One criticism is that donors took the 'start from scratch' element too far. Schia and de Carvalho write: 'What we witness in Liberia is to a large extent what Sarah Cliffe and Nick Manning have termed "the fallacy of terra nullius" - the inability of the UN to take into account pre-existing institutions and the assumption that everything must "start from zero",108 Specifically, UNMIL, the Norwegian government and other donors did not pay appropriate attention to the role of traditional/customary justice in Liberia. ${ }^{109}$ In a 2009 study of Liberia's dual justice system, the United States Institute of Peace found that only 2 per cent of criminal cases reached formal courts, 45 per cent went to traditional/customary courts and the rest never made it to any system. ${ }^{110}$

Given the importance of the informal justice system in Liberia, Schia, de Carvalho, Isser, Maturu and others believe it is essential that international actors explore Liberia's dual system of customary and statutory law to see how they 


\section{DEVELOPMENT ASSISTANCE FOR PEACEBUILDING}

might work together and complement one another, but that outside supporters have focused almost exclusively on statutory law. ${ }^{111}$ Furthermore, there was a 'propensity to apply readymade, generic solutions that resonate well with Western donors'.

Schia and de Carvalho articulate this point by tying LNP reforms to broader issues:

The problems surrounding the WACPS are in many ways symptomatic of the way in which post-conflict reconstruction is managed by international donors and the UN in general - namely that there is lack of coherence, no comprehensive and deep understanding of how the issues relate to each other, and an undue channelling of resources into projects that fit with the donors' perspective rather than the needs of the community. SGBV and the protection of women and children is no doubt an important task; it also fits within the Scandinavian priorities, and therefore is an attractive way to spend aid money. ${ }^{113}$

Maturu explains why the traditional systems often worked better for Liberians and why efforts to respond to gender-based violence have not trickled down to rural crimes:

Most magistrate courts and police stations are located in large urban centers; most Liberians are not. The average walking time to police stations and courts is 3.5 hours and can go up to 10-12 hours. In comparison, customary institutions exist in all communities at all levels, and are also much more cost effective. Many formal judicial proceedings will not go forward unless 'fees' are paid to keep cases from being neglected. The overall costs for the customary justice system are significantly lower, more consistent, and transparent, and sometimes even free. ${ }^{114}$

According to Isser et al., Liberians are extremely dissatisfied with the formal justice system, especially at the local level: '[E]ven if the formal justice system were able to deliver affordable, timely, and impartial results, it would still not be the forum of choice for many rural Liberians. ${ }^{115}$ In fact, it could be that some of the reforms to strengthen the formal system - such as the ban on handling matters of serious crimes in customary courts - might have made things worse: 'State policies aimed at regulating and limiting the customary justice system in order to comply with human rights and international standards are having unintended adverse consequences. ${ }^{, 116}$ For instance, many Liberians interviewed for the Isser $e t$ al. study believed that - because chiefs complied with the ban and because formal courts could not yet fulfil their mission - this ban led to less justice rather than more. ${ }^{117}$

On one hand, donors not taking traditional and informal systems of law more fully into account could appear at best to fall into the trap of not understanding local context, and at worst prove counterproductive and a product of cultural imperialism. However, it could be argued that Liberia's male-dominated security sector and its rape epidemic were rooted in some elements of Liberia's traditional culture and that a robust and institutionalized rule of law would be necessary to 


\section{DEVELOPMENT ASSISTANCE FOR PEACEBUILDING}

change norms and achieve justice. Thus, efforts to recruit women actively, move criminal cases to the formal system and earn citizens' trust in the formal justice system were well placed. However, they certainly needed thoughtful and accompanying reforms at the local levels.

\section{Looking Forward}

As for the LNP, lack of resources, capacity issues and gender imbalances continued to be major constraints in Liberia, as in many other post-conflict countries. However, Liberia planned to adapt new approaches to address some of the challenges discussed in this article and also to prepare for the transition of security responsibilities from UNMIL to the Government of Liberia.

In 2014, the spread of Ebola to thousands of Liberians threatened a great deal of post-war progress that the country had made on many fronts: security, economic, political and so on. By 2015, Liberia had nearly eradicated Ebola, but the setbacks were substantial.

On a more positive note, Nielsen provided a vivid picture of the extent to which community perceptions of the LNP had changed since the end of the war: "As our inspector general likes to say, "I want our children to run to the policeman, not away from them." And they do. ${ }^{118}$

\section{NOTES}

1. S. Dinnen and G. Peake, 'More Than Just Policing: Police Reform in Post-Conflict Bougainville', International Peacekeeping, Vol.20, No.5, 2013, pp.570-84; B.K. Greener, 'Statebuilding, Peacebuilding, Police and Policing in Solomon Islands', Journal of Peacebuilding \& Development, Vol.6, No.2, 2011, pp.30-42; O. Marenin, 'Styles of Policing and Economic Development in African States', Public Administration and Development, Vol.34, No.3, 2014, pp.149-61.

2. K. Erzurum and B. Eren, 'Women in Peacebuilding: A Criticism of Gendered Solutions in Postconflict Situations', Journal of Applied Security Research, Vol.9, No.2, 2014, pp.236-56; OECD, Gender and Statebuilding in Fragile and Conflict-Affected States, Paris: OECD, 2013; T.L. Tryggestad, 'The UN Peacebuilding Commission and Gender: A Case of Norm Reinforcement', International Peacekeeping, Vol.17, No.2, 2010, pp.159-71.

3. See R. Kunz, 'Gender and Security Sector Reform: Gendering Differently?', International Peacekeeping, Vol.21, No.5, 2014, pp.604-22.

4. B. Baker, 'Resource Constraint and Policy in Liberia's Post-Conflict Policing', Police Practice and Research, Vol.11, No.3, 2009, pp.184-96; M. Bøås and K. Stig, 'Security Sector Reform in Liberia: An Uneven Partnership without Local Ownership', Journal of Intervention and Statebuilding, Vol.4, No.3, 2010, pp.285-303; Marenin (see n.1 above); S. Podder, 'Bridging the "Conceptual-Contextual” Divide: Security Sector Reform in Liberia and UNMIL Transition', 


\section{DEVELOPMENT ASSISTANCE FOR PEACEBUILDING}

Journal of Intervention and Statebuilding, Vol.7, No.3, 2013, pp.353-80; K.B. Robinson and C. Valters, Progress in Small Steps: Security against the Odds in Liberia, London: Overseas Development Institute, 2015; U.C. Schroeder, F. Chappuis and D. Kocak, 'Security Sector Reform from a Policy Transfer Perspective: A Comparative Study of International Interventions in the Palestinian Territories, Liberia and Timor-Leste', Journal of Intervention and Statebuilding, Vol.7, No.3, 2013, pp.381-401.

5. Marenin (see n.1 above).

6. E. Gordon, 'Security Sector Reform, Statebuilding and Local Ownership: Securing the State or Its People?', Journal of Intervention and Statebuilding, Vol.8, No.2-3, 2014, pp.126-48.

7. Republic of Liberia, 'Poverty Reduction Strategy', 2008 (at: emansion.gov.lr/doc/ Final\%20PRS.pdf), p.14.

8. Index Mundi, 'Liberia - GDP Per Capita (Current US\$)', 2013 (at: www.indexmundi.com/ facts/liberia/gdp-per-capita); CIA Factbook, 'Liberia', 2013 (at: www.cia.gov/library/ publications/the-world-factbook/geos/li.html); Republic of Liberia (see n.7 above), p. 15. The economic drop refers specifically to the 1987 to 1995 period, in which Liberia's gross domestic product dropped 90 per cent. See Appendix A for a graph of Liberia's GDP drop.

9. See Appendices B and C for information on UNMIL's Liberia presence and funding from 2005 to 2013.

10. Norwegian Refugee Council, 'Women's Rights through Sensitization and Education (WISE)', 2011. Document given to author by project manager (at: www.nrc.no/arch/_img/9474672. pdf); C. Shiner, 'Liberia: New Study Spotlights Sexual Violence', AllAfrica.com, 2007 (at: allafrica.com/stories/200712051066.html).

11. Studies on assault against women during the war report a wide range of percentages (from 12 per cent to 92 per cent), depending on how the research questions were worded, in what county the respondents lived and whether the violence included domestic violence. In this article, data on sexual assault were derived from multiple sources, including: (1) P. Vinck, P. Pham and T. Kreutzer, 'Talking Peace: A Population-Based Survey on Attitudes about Security, Dispute Resolution and Post-Conflict Reconstruction in Liberia,' Berkeley, CA: Human Rights Center, University of California, Berkeley, 2011, p.34; (2) M. Omanyondo, Sexual GenderBased Violence and Health Facility Needs Assessment, Monrovia, Liberia: World Health Organization 2005; and (3) E. Johnson Sirleaf, 'Liberia's Gender-Based Violence National Action Plan', January 2007 (at: http://www.fmreview.org/sexualviolence).

12. Secretary-General of the United Nations, 'Twenty-Fifth Progress Report of the SecretaryGeneral on the United Nations Mission in Liberia', United Nations Security Council, 28 Feb. 2013 (at: www.un.org/ga/search/view_doc.asp?symbol=S/2013/124).

13. J. Friedman, 'Building Civilian Police Capacity: Post-Conflict Liberia, 2003-2011', Innovations for Successful Societies, Princeton University, 2011 (at: www.princeton.edu/successfulsocieties), p.2.

14. Ibid.

15. For more on Liberia's Rule of Law and Security Sector Reform, see T. Blume, 'Implementing the Rule of Law in Integrated Missions: Security and Justice in the UN Mission in Liberia', Journal of Security Sector Management, Vol.6, No.3, 2008 (at: http://www.gsdrc.org/go/display\&type= Document\&id=4887)

16. Much of the content and many of the interviews cited in this article are derived from historical case studies produced by Princeton University's research programme, Innovations for Successful Societies, especially Laura M. Bacon, 'Building an Inclusive, Responsive National Police Service: Gender-Sensitive Reform in Liberia, 2005-2011', Innovations for Successful Societies, Princeton University, 2012 (at: www.princeton.edu/successfulsocieties).

17. Ibid.

18. For more on UNSCR 1325 and the other resolutions mentioned, see United States Institute of Peace, 'What Is UN Security Council Resolution 1325 and Why Is It So Critical Today' (at: www.usip.org/gender_peacebuilding/about_UNSCR_1325), accessed 6 Jun. 2013.

19. E. Blunt, 'Liberian Leader Breaks Rape Taboo', BBC News, 2006 (at: news.bbc.co.uk/2/hi/ africa/4632874.stm).

20. The goal was originally set at 15 per cent female officers by 2014, but in 2008 the target was increased to 20 per cent by 2014, as codified in Liberia's Poverty Reduction Strategy. For more, see (1) Republic of Liberia (n.7 above); and (2) Office of the UNMIL Gender Adviser, OGA, 'Gender Mainstreaming in Peacekeeping Operations: Liberia 2003-2009. Best Practices Report', Accra, Ghana: United Nations Mission in Liberia (UNMIL), Sept. 2010. 


\section{DEVELOPMENT ASSISTANCE FOR PEACEBUILDING}

21. UN Office for the Coordination of Humanitarian Affairs, 'Women UN Peacekeepers: More Needed', IRIN Humanitarian News and Analysis, 2010 (at: www.irinnews.org/printreport. aspx? reportid $=89194$ ).

22. An Act establishing Ministry of Gender and Development. Government of Liberia, 6 August 2012 (at: www.infoliberia.org).

23. Liberia Ministry of Gender and Development, '2011 Annual Report', 2012 (at: www.mogd.gov. lr).

24. For more, see Gender Based Violence Interagency Taskforce, 'National Plan of Action for the Prevention and Management of Gender Based Violence in Liberia (GBV-POA)', 2006 (at: temp.supportliberia.com/assets/34/National_GBV_Plan_of_Action_2006.pdf).

25. In 2009, Liberia's Truth and Reconciliation Commission ruled that Johnson Sirleaf should be banned from government for 30 years because of her early support for Liberian President Charles Taylor. More information can be found in G. Gordon, 'In Liberia, Sirleaf's Past Sullies Her Clean Image', Time, 3 Jul. 2009 (at: www.time.com/time/world/article/ $0,8599,1908635,00 . h t m l)$.

26. See Appendices B1, B2, and C for more data on donors, aid inflows and development finance.

27. United Nations Security Council (2003), Resolution 1509 (at: www.un.org/ga/search/view_doc. asp?symbol=S/RES/1509\%20\%282003\%29), accessed 6 Jun. 2013.

28. United Nations Mission in Liberia, 'Mandate', 2013 (at: www.un.org/en/peacekeeping/ missions/unmil/mandate.shtml).

29. Friedman (see n.13 above).

30. Ibid.

31. Ibid., p.2.

32. Bacon (see n.16 above).

33. UN Office for the Coordination of Humanitarian Affairs, 'The New War Is Rape', IRIN Humanitarian News and Analysis, 2009 (at: www.irinnews.org/printreport.aspx? reportid=87122).

34. United Nations Mission in Liberia, 'Research on Prevalence and Attitudes to Rape in Liberia', UNMIL Legal and Judicial System Support Division Coordinator, 2008 (at: www.stoprapenow. org/uploads/advocacyresources/1282163297.pdf), p.30.

35. As cited in UNIFEM, 'Liberia: Supporting Women's Engagement in Peace Building and Preventing Sexual Violence: Community-Led Approaches', 2007 (at: www.unifem.org/afghanistan/ docs/pubs/07/DFID/liberia.pdf), p.7.

36. For an in-depth description and analysis of Liberia's customary/traditional local justice systems, see D.H. Isser, S.C. Lubkemann and S. N'Tow, 'Looking for Justice: Liberian Experiences with and Perceptions of Local Justice Options', United States Institute of Peace, 2009 (at: www.usip. org/files/resources/liberian_justice_pw63.pdf).

37. N.N. Schia and B. de Carvalho, 'Nobody Gets Justice Here!', Addressing Sexual and GenderBased Violence and the Rule of Law in Liberia, Security in Practice 5, NUPI Working Paper 761, 2009 (at: www.nupi.no/content/download/10158/102232/version/5/file/SIP-5-09-Schiade+Cavalho-pdf.pdf); S. Maturu, 'To Combat Violence in Liberia: A Need for Sharper Focus on Traditional Justice', Stimson, 2012 (at: www.stimson.org/spotlight/to-combat-sexualviolence-in-liberia-a-need-for-sharper-focus-on-traditional-justice/).

38. Republic of Liberia, 'Population and Housing Census', 2008 (at: www.emansion.gov.lr/doc/ Population_by_County.pdf).

39. LNP also engaged in other gender-sensitive initiatives, such as the drafting of a gender policy, the creation of a gender unit and the coordination of an association of female police officers. The description and evaluation of these other gender-related projects is beyond the scope of this article because (1) these projects did not engage donors to the same extent as the recruitment of female officers through the Education Support Programme (ESP) and the creation of the Women and Children Protection Section (WACPS), and (2) ESP and WACPS are arguably more innovative and unique than the initiatives mentioned above. Readers interested in learning more about the gender unit can find more information at C. Bowah and J.E. Salahub, 'Women's Perspectives on Police Reform in Liberia: Privileging the Voices of Liberian Policewomen and Civil Society', in Salahub (ed.), African Women on the Thin Blue Line: Gender-Sensitive Police Reform in Liberia and Southern Sudan, Ottawa, ON: The North-South Institute, 2011, pp.11-39, and the association of female police officers at J. Becker, C.B. Brown, A.F. Ibrahim and A. Kuranchie, 'Freedom through Association: Assessing the Contribution of Female Police Staff Associations to Gender-Sensitive Police Reform in West Africa', Canada: The North-South Institute, 23 Apr. 2012.

40. Republic of Liberia (see n.7 above), pp. 164-5; Gender Based Violence Interagency Taskforce (see n.24 above), p.32. 


\section{DEVELOPMENT ASSISTANCE FOR PEACEBUILDING}

41. In an example from another country, see N. Mandhana, 'Anti-Rape Law Means India Needs More Female Cops', The New York Times , 2 Apr. 2013 (at: india.blogs.nytimes.com/2013/04/02/antirape-law-means-india-needs-more-female-cops/); interviews with Patricia Kamara, Assistant Minister, Ministry of Gender and Development, Liberia and Vera Manly, WACPS Chief, Liberia National Police, Monrovia, Liberia, Jun. and Jul. 2011; S. Payne, 'Rape: Victims Experience Review', London: Home Office, National Archives, UK, 2009 (at: http://www.homeoffice.gov.uk/ documents/vawg-rape-review/rape-victim-experience2835.pdf?view=Binarywebarchive.

nationalarchives.gov.uk/), p.16. This is not to imply that male officers cannot investigate sexual assault cases responsibly or well. Liberia trains all of its officers - male and female - in proper investigation techniques. And the majority of LNP officers, including WACPS officers, are male.

42. More biographical information on both women can be found in Bacon (see n.16 above). Munah Sieh stepped down from her position in 2009. As of the submission of this article, she had been indicted around corruption related to irregularities in the procurement of officer uniforms, an allegation she denied, and the case was pending in the Liberian Supreme Court.

43. Correspondence with Sylvia Bisanz, Community Relations Adviser, UNPOL, UNMIL, 8 Jul. 2011.

44. Republic of Liberia, 'Liberia Demographic and Health Survey 2007', 2007 (at: http://www. measuredhs.com/publications/publication-FR201-DHS-Final-Reports.cfm), cited in L.M. Bacon, 'Liberia Leans In', ForeignPolicy.com, 2013 (at: http://www.foreignpolicy.com/ articles/2013/06/03/liberia_leans_in).

45. For many more details on the ESP programme, please see Bacon (n.16 above).

46. Correspondence with Sylvia Bisanz (see n.43 above).

47. Ibid.

48. See Appendix D for more details on the ESP programme. Some women were trained through the programme but did not join the LNP immediately. Others dropped out and never joined the LNP. Office of the UNMIL Gender Adviser (see n.20 above).

49. C. Griffiths and K. Valasek, 'Liberia Country Profile', in Miranda Gaanderse and Kristin Valasek (eds), The Security Sector and Gender in West Africa: A Survey of Police, Defence, Justice and Penal Services in ECOWAS States, Geneva: DCAF, 2011, pp.141-58, p.147.

50. Secretary-General of the United Nations www.un.org/ga/search/view_doc.asp?symbol=S/2013/ 124 (see n.12 above).

51. B. de Carvalho and N.N. Schia, 'The Protection of Women and Children in Liberia', Police Brief, 1. Norway: Norwegian Institute of International Affairs, 2009, p.1.

52. A. Boutellis, 'Interview with Kadi Fakondo, Assistant Inspector General, Sierra Leone Police', 5 May 2008 (at: www.princeton.edu/successfulsocieties/oralhistories/); United Nations Women, 'Policing with Compassion', Women as Partners in Peace and Security, October 2004 (at: www.un.org/womenwatch/osagi/resources/faces/9-Police_faces_en.pdf); Sierra Leone Police/ Ministry of Social Welfare, Gender and Children's Affairs, 'The Family Support Unit Training Manual', 2008 (at: www.britishcouncil.org/fsu_training_manual.pdf).

53. Secretary-General of the United Nations, 'Twenty-Fourth Progress Report of the SecretaryGeneral on the United Nations Mission in Liberia', United Nations Security Council, 15 Aug. 2012 (at: daccess-dds-ny.un.org/doc/UNDOC/GEN/N12/453/81/PDF/N1245381.pdf).

54. For more about the court and its relation to Liberia's plans to combat SGBV, see the court's founding document (at: legislature.gov.lr/sites/default/files/Criminal\%20Court\%20E.pdf) and (stoprapenow.org/uploads/features/SGBVemail.pdf).

55. For more about and criticism of the in camera approach in Criminal Court E, see E.S. Abdulai, 'Evaluation: Strengthening of Prosecution of SGBV Offenses through Support to the Sexual and Gender-Based Violence Crimes Unit (SGBV CU)', Independent consultant report sponsored by Republic of Liberia and UNFPA, Nov. 2010 (at: www.mdtf.undp.org/document/download/ 6383), pp.19-20.

56. Ibid.

57. UN Office for the Coordination of Humanitarian Affairs, 'Special Court for Sexual Violence Underway', IRIN: Humanitarian News and Analysis, 21 Mar. 2008 (at: www.irinnews.org/ report/77406/liberia-special-court-for-sexual-violence-underway).

58. Interview with William Mulbah, deputy director for training and development at the National Police Training Academy, Monrovia, Liberia, Jun. and Jul. 2011.

59. Ibid.

60. Bacon (see n.16 above).

61. Interview with John Nielsen, deputy commissioner of UN Police (in 2013, commissioner of UN Police), Monrovia, Liberia, Jun. and Jul. 2011.

62. Ibid. 


\section{DEVELOPMENT ASSISTANCE FOR PEACEBUILDING}

63. Interviews with Bose, Monrovia, Liberia, Jun. and Jul. 2011 and Asatu Bah-Kenneth, Monrovia, Liberia, Jun. and Jul. 2011.

64. Interviews with Abla Gadegbeku Williams, former LNP officer and deputy commissioner of the Bureau of Immigration and Naturalization, Monrovia, Liberia, Jun. and Jul. 2011.

65. Ibid.

66. Ibid.

67. Interview with Sylvia Bisanz, Community Relations Adviser, UNPOL, UNMIL, Jun.-Jul. 2011.

68. A. Boutellis, 'Interview with Paavana Reddy, Civil Society Officer for UNDP and Technical Assistant to Ministry of Gender and Development, Liberia', 17 May 2008 (at: www.princeton.edu/ successfulsocieties/oralhistories/www.princeton.edu/successfulsocieties/oralhistories/).

69. Isser et al. www.usip.org/files/resources/liberian_justice_pw63.pdf (see n.36 above).

70. UNMIL, 'New Confidence in Liberian Police Has More Women and Children Reporting Crime', 15 Jun. 2008 (at: reliefweb.int/report/liberia/new-confidence-liberian-police-hasmore-women-and-children-reporting-crime).

71. Ibid.

72. Interview with William Mulbah, Monrovia, Liberia, Jun. and Jul. 2011.

73. Interview with US Embassy official, who wished not to be named, 2011.

74. To address this problem, UNMIL along with the LNP/WACPS instituted periodic in-service or refresher courses to enable section investigators to revisit important aspects of their training. To complement in-service training, the Norwegian Refugee Council offered WACPS officers courses based on the Ministry of Justice's handbook on prosecuting sexual and gender-based crimes.

75. Interview with Bah-Kenneth (see $\mathrm{n} .63$ above).

76. Interview with Anna Stone, project manager of the SGBV project at the Norwegian Refugee Council, Monrovia, Liberia, Jun. and Jul. 2011.

77. Interviews with Korlu Kpanyor, head of WACPS Juvenile Unit, Jun. and Jul. 2011.

78. Interviews with Vildana Sedo, Acting UNPOL gender adviser, Monrovia, Liberia, Jun. and Jul. 2011.

79. Ibid.

80. Secretary-General of the United Nations (see n.53 above).

81. UN Office for the Coordination of Humanitarian Affairs, 'Liberia: Sexual Violence Projects Could Suffer Post-UNMIL', IRIN: Humanitarian News and Analysis, 18 May 2010 (at: www.irinnews.org/printreport.aspx? reportid=89127).

82. Secretary-General of the United Nations (see n.12 above).

83. Interview with Anna Stone (see n.76 above).

84. Interview with Felicia Coleman, head of SGBV unit, Monrovia, Liberia, Jun. and Jul. 2011.

85. A.M. Wolokolie, 'Liberia: Lack of Evidence Hinders Fight against Rape', The Inquirer, Monrovia, Liberia, 21 Feb. 2013 (at: allafrica.com/stories/201302211190.html).

86. J. Moore, 'Liberia's "Rape Court”: Progress for Women and Girls Delayed?', Christian Science Monitor , 10 Oct. 2010 (at: www.csmonitor.com/World/Africa/Africa-Monitor/2010/1010/ Liberia-s-Rape-Court-Progress-for-women-and-girls-delayed); Abdulai (see n.55 above), pp.11-12.

87. Abdulai (see n.55 above), p.21.

88. Ibid.

89. Ibid.

90. Ibid., p.20.

91. Interview with Felicia Coleman (see n.84 above).

92. M. Andrews, L. Pritchett and M. Woolcock. 'Escaping Capability Traps Through ProblemDriven Iterative Adaptation (PDIA)', Faculty Research Working Paper Series, Harvard, 2012, p.2 (at: https://research.hks.harvard.edu/publications/getFile.aspx?Id=841).

93. UN Office for the Coordination of Humanitarian Affairs, 'County Nominees Rejected as New Parliamentarians Meet', IRIN: Humanitarian News and Analysis, 13 Oct. 2003 (at: www. irinnews.org/printreport.aspx? reportid=46681).

94. A. Boutellis, 'Interview with Dave Beer, Chief Superintendent, Director General of International Policing, Royal Canadian Mounted Police', Innovations for Successful Societies, Princeton University, 15 Jan. 2008 (at: https://www.princeton.edu/successfulsocieties/oralhistories/).

95. Interview with Regina Sokan-Teah, Monrovia, Liberia, Jun. and Jul. 2011.

96. United Nations Security Council, 'Security Council Extends Mandate of Liberia Mission Until 30 September 2013, Unanimously Adopting Resolution 2066 (2012)', 17 Sep. 2012 (at: http:// www.un.org/press/en/2012/sc10765.doc.htm).

97. Secretary-General of the United Nations (see n.12 above). 


\section{DEVELOPMENT ASSISTANCE FOR PEACEBUILDING}

98. Interview with Napoleon Abdulai, security sector reform adviser, UNDP, Jul. Monrovia, Liberia, Jun. and Jul. 2011.

99. Ibid.

100. Ibid.

101. Ibid.

102. Interview with Nielsen (see n.61 above).

103. Ibid.

104. Secretary-General of the United Nations (see n.12 above).

105. Blume (see n.15 above).

106. Secretary-General of the United Nations (see n.12 above), emphasis added.

107. Schia and de Carvalho (see n.37 above).

108. Ibid., citing S. Cliffe and N. Manning, 'Practical Approaches to Building State Institutions', in Charles T. Call and Vanessa Wyeth (eds), Building States to Build Peace, Boulder, CO: Lynne Rienner, 2008, pp.163-84.

109. Maturu (see n.37 above).

110. Isser et al. (see n.36 above), pp.4, 25, 31, 70 , as quoted in Maturu (see n.37 above).

111. Ibid.; Schia and de Carvalho (see n.37 above), p.19.

112. Schia and de Carvalho (see n.37 above), p.19.

113. Niels Nagelhus Schia and Benjamin de Carvalho, 'Addressing Sexual and Gender-Based Violence in Liberia', Conflict Trends, p.26-33 (at: http://www.academia.edu/10158898/ Addressing_Sexual_and_Gender-Based_Violence_in_Liberia).

114. Maturu (see n.37 above).

115. Isser et al. (see n.36 above).

116. Ibid.

117. Ibid, p.5.

118. Interview with Nielsen (see n.61 above).

\section{APPENDIX A: LIBERIA GDP PER CAPITA}

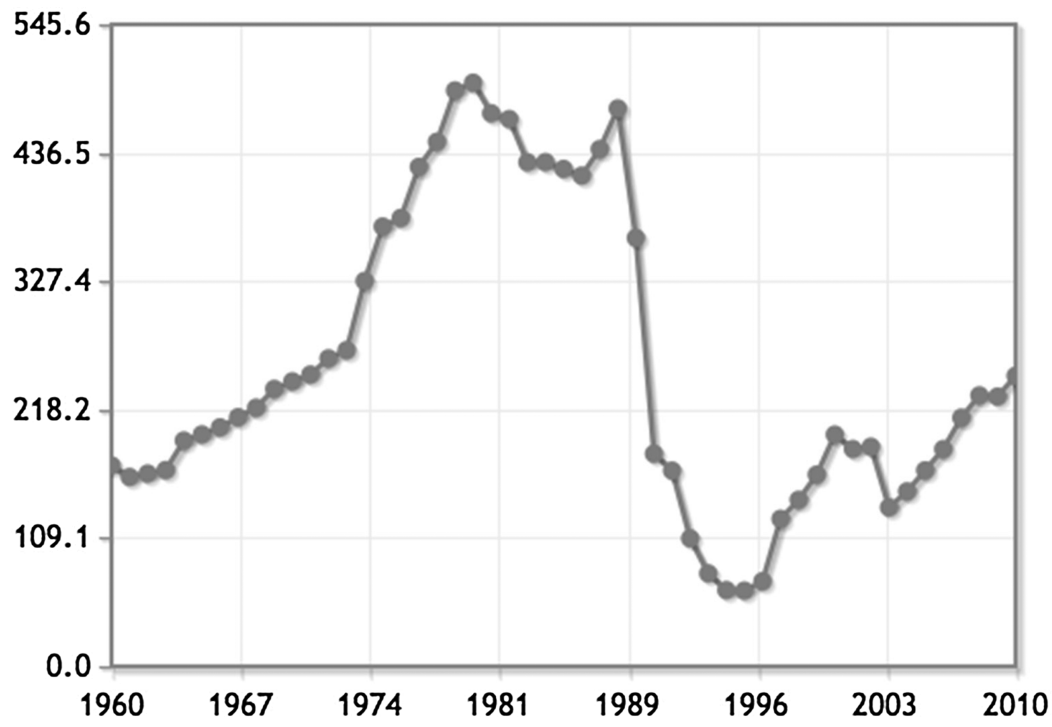

Note: $\mathrm{x}$ axis = year; $\mathrm{y}$ axis $=$ US\$.

Source: Index Mundi, 'Liberia - GDP per Capita (Current US\$)', 2013 (at: www.indexmundi.com/facts/liberia/gdp-per-capita). 


\section{DEVELOPMENT ASSISTANCE FOR PEACEBUILDING}

\section{APPENDIX B: UNMIL PRESENCE AND FUNDING}

TABLE APPENDIX B1

UNMIL PRESENCE IN 2005 AND 2013

\begin{tabular}{ll}
\hline 2005 & \multicolumn{1}{c}{2013} \\
\hline 15,000 military personnel: & 8,256 total uniformed personnel \\
250 military observers & 6,671 troops \\
160 staff officers & 125 military observers \\
1,115 police officers, including formed units; & 1,460 police (including formed units) \\
and the appropriate civilian component & 453 international civilian personnel \\
& 962 local staff \\
& 224 UN volunteers
\end{tabular}

Source: UNMIL Fact Sheet (at: www.un.org/en/peacekeeping/missions/unmil/facts.shtml).

TABLE APPENDIX B2

FUNDING ALLOCATIONS APPROVED FOR UNMIL

Fiscal year (July-June)

$2003-04^{\mathrm{a}}$

$2004-05^{\mathrm{b}}$

$2005-06^{\mathrm{c}}$

$2006-07^{\mathrm{d}}$

$2007-08^{\mathrm{e}}$

$2008-09^{f}$

2009-10

$2010-11^{\mathrm{h}}$

$2011-12^{\mathrm{i}}$

$2012-13^{\mathrm{i}}$

$2013-14^{\mathrm{k}}$
UNMIL funding (approximate, in US\$)

US $\$ 564,614,300$
US $\$ 821,986,000$
US $\$ 722,422,100$
US $\$ 717,119,700$
US $\$ 688,330,600$
US $\$ 603,708,000$
US $\$ 560,978,700$
US\$524,000,000
US\$525,559,930
US\$502,224,000
US $\$ 477,550,800$

Notes: in 2013, United Nations missions with more funding than Liberia included missions in Haiti, Democratic Republic of the Congo, Darfur, Lebanon, South Sudan and Côte d'Ivoire (www.un.org/ ga/search/view_doc.asp?symbol=A/C.5/66/17).

Sources:

a daccess-dds-ny.un.org/doc/UNDOC/GEN/N03/612/11/PDF/N0361211.pdf? OpenElement.

bdaccess-dds-ny.un.org/doc/UNDOC/GEN/N04/352/15/PDF/N0435215.pdf?OpenElement. cdaccess-dds-ny.un.org/doc/UNDOC/GEN/N07/311/85/PDF/N0731185.pdf?OpenElement. ddaccess-dds-ny.un.org/doc/UNDOC/GEN/N06/215/07/PDF/N0621507.pdf? OpenElement. edaccess-dds-ny.un.org/doc/UNDOC/GEN/N09/339/57/PDF/N0933957.pdf?OpenElement. f daccess-dds-ny.un.org/doc/UNDOC/GEN/N10/327/07/PDF/N1032707.pdf? OpenElement.

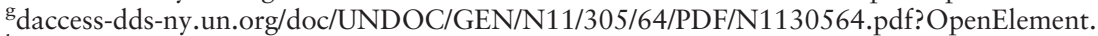
${ }^{h}$ daccess-dds-ny.un.org/doc/UNDOC/GEN/N12/314/01/PDF/N1231401.pdf?OpenElement. idaccess-dds-ny.un.org/doc/UNDOC/GEN/N13/319/70/PDF/N1331970.pdf?OpenElement. ${ }^{\mathrm{j}}$ www.un.org/ga/search/view_doc.asp?symbol=A/66/691.

kdaccess-dds-ny.un.org/doc/UNNDOC/GEN/N13/319/70/PDF/N1331970.pdf? OpenElement. 


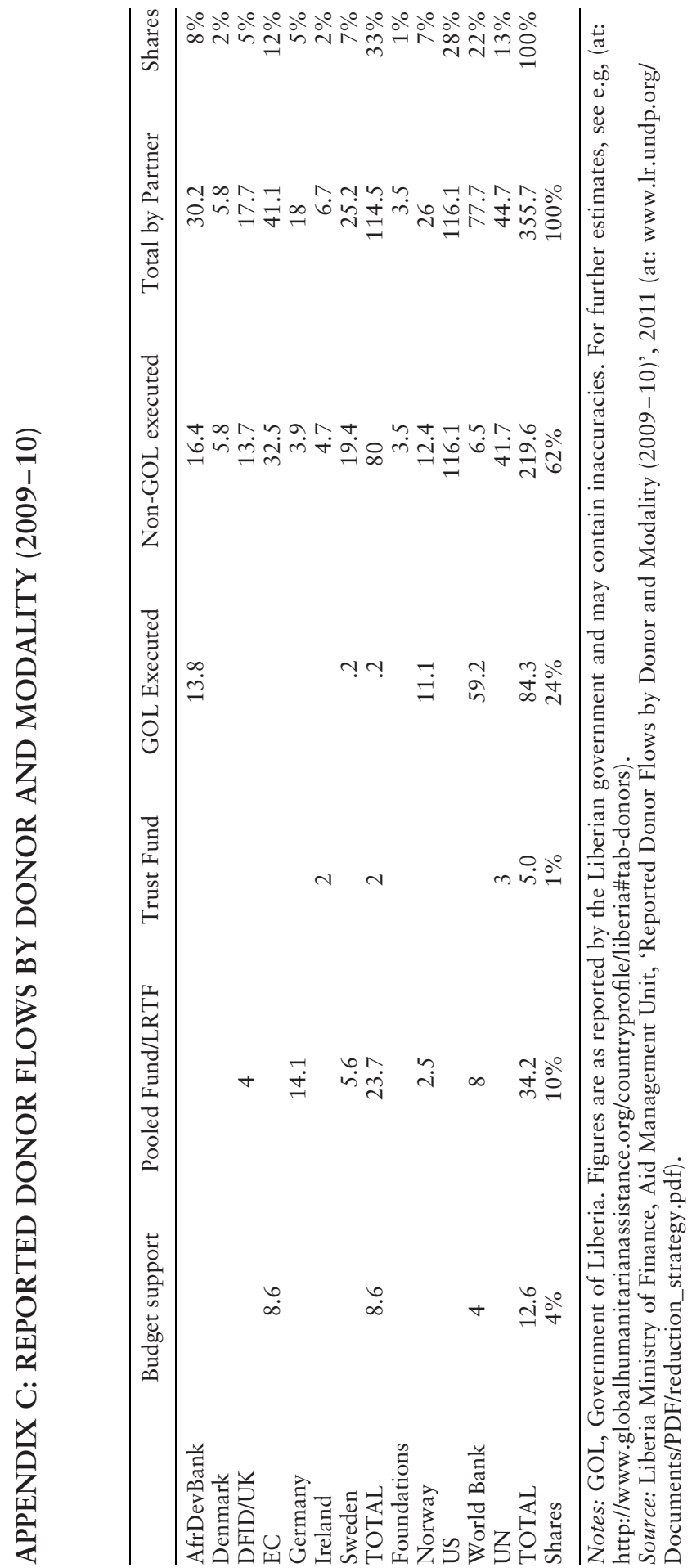




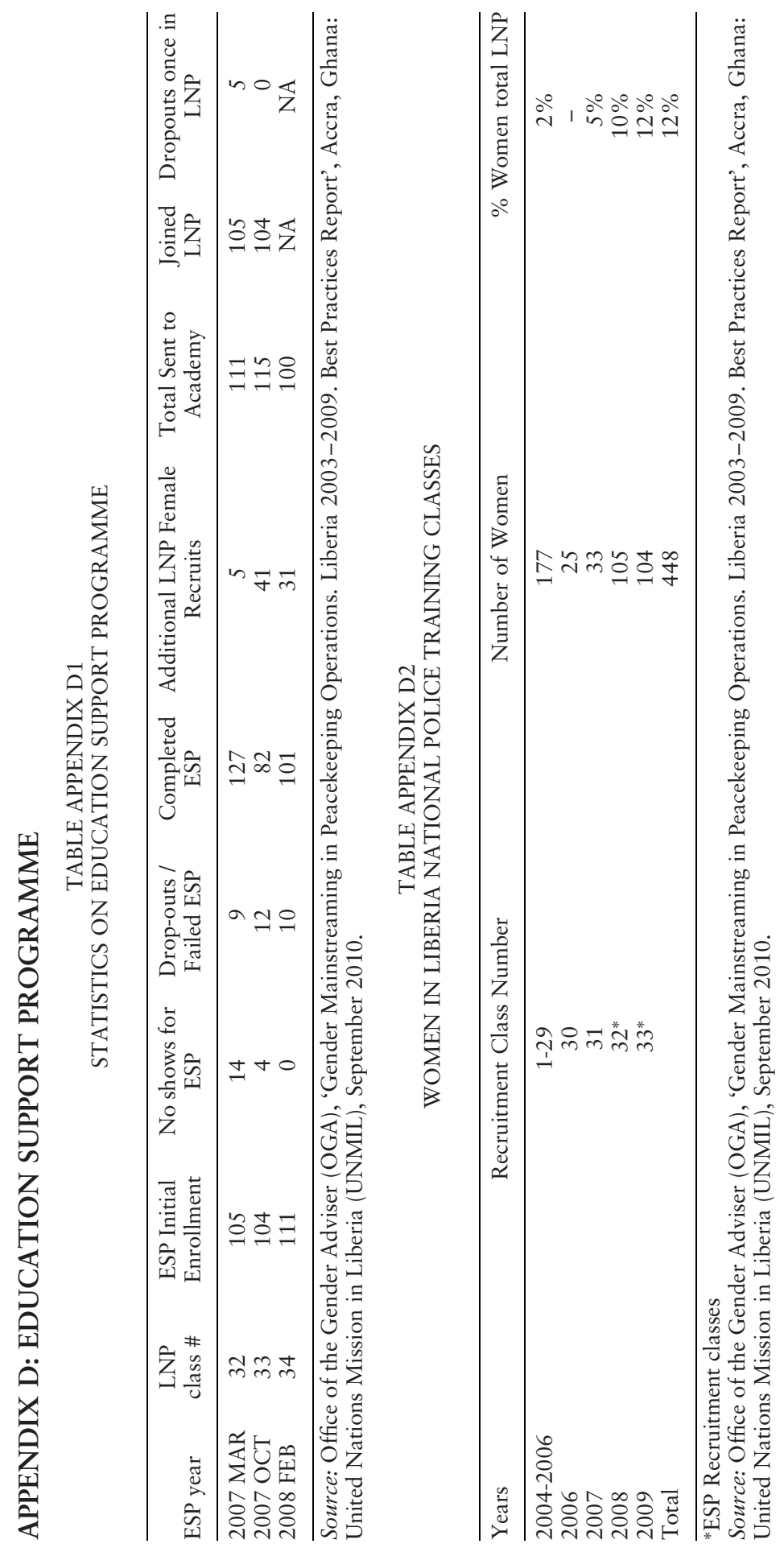




\title{
Impact Assessment of the Facilitadores Judiciales Programme in Nicaragua
}

\author{
MARTIN GRAMATIKOV, \\ MAURITS BARENDRECHT, MARGOT KOKKE, \\ ROBERT PORTER, MORLY FRISHMAN and \\ ANDREA MORALES
}

\begin{abstract}
Facilitadores Judiciales is a programme run by the Organization of the American States and the Nicaraguan judiciary. In 2010, facilitators were recruited and trained in many but not all urban municipalities. This presented an opportunity for a natural experiment to assess the impact of the programme. In our theoretical framework the impact is related to improved access to justice which is one of the prerequisites for peace and development. Before and after quantitative and qualitative studies were conducted in intervention and control areas. The quantitative results show confirmation of some of the hypothesized effects of the programme. Other effects are indicated by the numerous in-depth interviews but are not substantiated by hard data. In the communities where facilitators were introduced the people report fewer legal problems. The facilitators are decreasing the costs of justice. Achieving amicable solutions and promotion of peace and social cohesion is another example of the programme's impact.
\end{abstract}

\section{Introduction}

In this article we analyse the impact of a paralegal programme in Nicaragua. Facilitadores Judiciales (FJ) is a programme initiated at the end of the 1990s by the Organization of the American States (OAS) and the Nicaraguan Supreme Court. Community-based facilitators help the people from the local communities to solve their disputes and legal problems. Initially the FJ programme ran in rural and isolated communities of Nicaragua. In 2010, the programme gradually expanded to urban communities. This stage of the programme presented an opportunity to study the intervention and compare its effects to communities where no facilitators were active.

The article aims to identify and quantify the impact of the FJ programme and its relevance for security and peace building in Nicaragua. Two cross-sectional surveys were conducted - before and after the intervention. Urban communities with and without facilitators were randomly selected for the study. In addition, a series of interviews with facilitators, beneficiaries and important stakeholders were conducted after the intervention in order to get a deeper insight of the results of the programme. Next, the article analyses the 'drivers' for success of the FJ programme. The approach has been widely

This is an Open Access article distributed under the terms of the Creative Commons Attribution-NonCommercial-NoDerivatives License (http://creativecommons.org/Licenses/by-nc-nd/4.0/), which permits noncommercial re-use, distribution, and reproduction in any medium, provided the original work is properly cited, and is not altered, transformed, or built upon in any way. 


\section{DEVELOPMENT ASSISTANCE FOR PEACEBUILDING}

acclaimed for its positive effect on access to justice. ${ }^{1}$ In the past couple of years it has been already replicated in other countries from the region. Our interest is to identify and discuss the critical areas that determine the success of the FJ and similar programmes.

\section{Conflicts, Access to Justice and Peace}

People need justice protection for their most valuable interests and relationships. ${ }^{2}$ Security of land and tenure rights is a prototypical example of individual or communal problems that can lead to violent conflicts. Past violations of human rights is another example that requires processes and procedures to restore damages, allocate liability and achieve reconciliation. When there are no accessible and fair disputes resolution mechanisms conflicts can escalate from individual into communal level and from communal to social level. ${ }^{3}$ It should be noted that both formal and informal justice mechanisms play an important role in the fair resolution of existing disputes. ${ }^{4}$ The state is the formal duty bearer responsible for ensuring the right of access to justice. Informal providers of justice - such as the facilitators - are also expected to provide a certain level of accessibility and fairness. The negative effect of the lack of justice is clear: unresolved conflicts inhibit development, nurture violence and other human rights abuses ${ }^{5}$ and lead to political exclusion of whole groups. ${ }^{6}$

In their daily lives the people experience many problems which necessitate some form of formal or informal dispute resolution process. ${ }^{7}$ Many of these problems might not be considered by the involved parties as legal or justiciable. Regardless of how people perceive their justice needs the lack of accessible and fair remedies leads to conflict escalation and a growing feeling of injustice and disenfranchisement. Many justice problems are interconnected and do not occur randomly. Studies show that various disputes trigger each other or happen in clusters. ${ }^{8}$ Perceived lack of justice in the everyday life leads to violent self-help solutions and radicalization.

Access to justice here refers to the objective availability of rules and procedures to resolve disagreements and grievances and the subjective belief that these rules and procedures are fair and accessible. ${ }^{9}$ The FJ programme is one of the many mechanisms that aim to facilitate access to justice (see below for the specific mechanisms in 'Theory of the Intervention'). Wider and effective access to justice leads to fewer escalated disputes, a general sense of fairness and rule of law and more peaceful communities. Providing justice is one of the conditions to break the cycles of violence and insecurity. ${ }^{10}$ Nicaragua is in the process of coping with political violence but the peace in the country has been challenged by inequality and many disputes and disagreements for which the people cannot find fair resolution. In this study we question whether and how the FJ programme creates a legitimate institution for improving access to justice. To answer the question we explore how the beneficiaries experience the programme and how it affects their abilities to achieve fair resolutions to their legal problems. Our central assumption is that if the intervention improves access to justice it will contribute to the country's peaceful development. 


\section{DEVELOPMENT ASSISTANCE FOR PEACEBUILDING}

\section{The Facilitadores Judiciales Programme}

The FJ programme is based on the ideal that everyone deserves justice, and couples with the recognition that, in practice, the state has not always been able to meet the demand for justice with fair, practical and affordable solutions. Importantly, rather than being based on an imported model, the programme has been inspired by local pre-existing practices of judicial outreach by way of making use of communal social structures and leaders. The value of the programme can be seen in the way it helps ordinary people to find solutions to their justice needs in a simple, quick and affordable manner; and when this is not possible, in how it helps people to take other steps towards solving their justice-related problems.

The programme ought to be understood against the background of the judiciary's sub-optimal performance. Although Nicaragua is not currently considered a fragile state according to standard classifications, its relevance to work on peace building and conflict prevention is underscored by its history of civil war and political instability. In the 2014 Rule of Law index in 2014 Nicaragua has been ranked 85 th out of 99 countries and two before the last when compared to other countries from Latin America and the Caribbean. ${ }^{11}$ The processes of conflict prevention cannot be viewed without analysing the mechanisms for solving various types of disputes, disagreements and grievances. In an ideal world the combination of formal and informal dispute resolution processes provides accessible, fair and predictable options for dealing with disputes. Nicaragua's judicial system, however, has been said to suffer from political interference and widespread corruption. ${ }^{12}$ Even more important for understanding the significance of the programme is the assessment that the judiciary does not adequately cover the entire country, and demonstrates considerable functional deficiencies. Against this background, the use of 'proxies' located at community level, or, otherwise put, the possibility to avail communities of easily accessible authority to help with problems locally and quickly, bears a significant potential for increasing access to justice, thus improving people's lives.

The FJ programme commenced officially in 1998 as a pilot project of the OAS. It should also be noted that the Nicaraguan Supreme Court actively partnered in the project from the very beginning. Initially, the FJ built upon a long lasting practice taking place in the north of Nicaragua where local judges used community leaders as proxies in remote and isolated villages. ${ }^{13}$ In the first years of implementation (1998-2001) the FJ was piloted in remote rural and post-conflict municipalities. ${ }^{14}$ At the time it was named Facilitadores Judiciales Rurales, indicating its focus on rural communities. By 2001 there were 76 FJs working in 18 municipalities. In the second programme stage (2001-07), the OAS and the Nicaraguan Supreme Court co-operated to expand the programme further in rural and underdeveloped municipalities. During that stage the FJ programme was extended to various indigenous areas of Nicaragua. As a result, many local indigenous judges (Wihta) were integrated as FJs. In 2007, there were 1,260 active FJs in 120 municipalities. 


\section{DEVELOPMENT ASSISTANCE FOR PEACEBUILDING}

Since 2008, the Nicaraguan Supreme Court has taken a more active stance towards integrating the FJ programme into the national justice system. A National Service of Facilitators (Servicio Nacional de Facilitadores) was established with the aim of taking over the programme and funding it from the judicial budget. This policy course implies that FJs will be introduced in all municipalities of Nicaragua - rural, suburban and urban. Another corollary of the policy is that the FJs must be further integrated into the overall functioning of the judiciary.

As of May 2013, 2,762 FJs have been appointed, of which 36 per cent are women, 28 per cent work in urban areas and 4 per cent are indigenous. The programme is now present in all 17 provinces and 2 autonomous regions of Nicaragua, in all 153 municipios (notably also in all municipal capitals) in urban, suburban and rural areas.

\section{How FJ Works}

The facilitators are members of their local communities (barrios) who work on a voluntary basis in the interests of justice and the justice needs of the community. The particular barrios can range from a few hundred inhabitants to barrios of $2,000-3,000$. The urban barrios where the study took place have on average a population of about 2,500 inhabitants. FJs are elected by their communities during a meeting at which everyone present can nominate a facilitator. The facilitators must be aged at least 18 and be respected members of the community. They should have independent sources of income since they cannot charge fees for their services. There is a minimum number of citizens that need to be present at the election meeting for the vote to be valid. After the elections the local judge serving the region appoints the successful applicant as a facilitator. Next, the appointed FJs take part in practical training performed by local judges. Introduction to mediation and mediation skills are core components of the training programme. According to the programme rules there are at least four training sessions per year. In practice training is contingent on the available resources.

Essentially, FJs act as paralegals/mediators within their own communities. They typically work from their own homes, or at the scene of the dispute. They help the members of the community to solve their disputes and grievances, whether directly (facilitate immediate solution) or indirectly (information, advice, accompanying, etc.). ${ }^{15}$ Internal OAS documents ${ }^{16}$ suggest that the most frequent disputes referred to FJs are: money-related problems, disputes between neighbours, damages to crops and insults. They are barred from mediating certain kinds of cases, for example, severe criminal cases involving violence (including domestic violence), civil cases that entail change in property registration and family cases that concern custody.

The FJs perform primarily the following activities:

1. Increase awareness and provide information: FJs increase legal awareness by informing members of the community regarding laws, rights and institutions, 


\section{DEVELOPMENT ASSISTANCE FOR PEACEBUILDING}

collectively (during seminars and gathering) and individually (per specific needs that arise before them).

2. Provide legal education: Beyond merely providing information, (some) FJs provide normative/moral guidance as to what people should do (or not) to avoid trouble with the law and to live harmoniously.

3. Facilitate an immediate solution: Where possible, FJs encourage parties to reach an amicable solution through dialogue, and they solve incoming disputes through mediation and conciliation. When successful, they draft brief agreements or minutes that record the agreed solution.

4. Advise and refer: In cases that are not susceptible to immediate solution, or when the mediation attempt is unsuccessful, FJs advise victims/parties regarding their rights, options and possible redress. They refer these people to the authorities capable of solving the problem and might also provide a (semiformal) referral to court.

5. Accompany: When possible, FJs not only explain to people where to go and what to do, they actually accompany them to the right place (legal aid bureau/ministry/court, etc.) and support them in the process.

6. Liaise with local courts and assist judges: FJs also partially function as the long arm of the courts, so members of the local communities can go to them to submit documents, instead of travelling long distances to file complaints and deposit documents on their own. FJs also directly support judges by performing tasks such as delivering summons, finding witnesses, measuring land, performing inspections and making appointments on behalf of the judge.

\section{Theory of the Intervention}

According to its designers, the FJ programme should have a far-reaching impact on access to justice, societal conflict and administrative costs in the judicial sector, in particular in: ${ }^{17}$

1. Prevention of (escalation of) problems: FJs are expected to prevent the occurrence of problems through their presence as a recognized conflict resolution mechanism. Where FJs are present, it is anticipated that individuals will be more likely to honour agreements as they are aware of acting in the shadow of the law'. In addition, the presence of FJs as a local, cheap, easily accessible (both culturally and geographically) conflict resolution resource should prevent the escalation of problems beyond their initial inception.

2. More amicable solutions: The use of mediation approaches in the resolution of problems, and the greater involvement of the parties in the development of the solution to the problem should result in more amicable solutions being reached in FJ areas compared to those who continue to use the pre-existing adjudicative systems.

3. Reduced costs: The FJ service is provided to individuals free of charge in their own communities. This represents many cost savings to individuals, in terms 


\section{DEVELOPMENT ASSISTANCE FOR PEACEBUILDING}

of both financial costs (court fees, lawyer fees, transport costs), time costs (travel time, court appearances, visits to lawyers) and emotional and stress costs (caused by extended time-frames, adversarial court procedures, greater expense at risk). Accordingly, the FJ programme is expected to impact favourably on these costs.

4. Increased empowerment: Through the awareness raising activities of the FJs, and their easy availability as a source of information, we anticipate that the FJ programme will increase knowledge of laws, rights and access to justice in their communities. In turn it is expected that this increase in knowledge in these areas will improve the empowerment level of individuals, as they understand what their rights are, what the relevant laws are and how they can go about solving their problems. Accordingly, the FJ programme is expected to increase levels of empowerment in their communities.

\section{Methodology}

In 2009, a decision was taken to expand the FJ programme from rural to urban communities in Nicaragua. At the time, the available project funding allowed for only partial coverage of the urban sites. This provided a rare opportunity for a natural experiment in which some urban communities benefited from FJs whereas others did not. ${ }^{18}$ The decision on where to implement the FJ programme was based on organizational capabilities and the sites were selected at random. However, we are not aware of all factors which have influenced the decisions of the OAS regarding in which urban municipalities and barrios to expand the FJ programme. The study uses a pre- and post-intervention design, with both qualitative and quantitative data collection methods. The quantitative data were collected through pre- and post-intervention surveys that used structured interviews administered to a sample of the population. The qualitative method consisted of semi-structured qualitative interviews conducted with a broad range of project stakeholders. The pre-intervention measurements were conducted in the period February-March 2010, while the post-intervention measurements took place in February-March 2013.

\section{Quantitative Measures}

Given the detailed nature of the analysis conducted for this study, only a subset of FJ-participant communities could be included. The data presented here thus do not describe the full range of communities served, but are in our assessment suggestive of broader trends that could be explored more fully in future work. Field sites were selected as follows: from the list of new urban municipalities targeted by the OAS to receive FJ services in more than four barrios, two municipalities were selected using the randomization function in Microsoft Excel. Municipalities with more than four targeted barrios were selected to ensure that community-level effects would be present. The two selected municipalities were 


\section{DEVELOPMENT ASSISTANCE FOR PEACEBUILDING}

Cuidad Sandino and Jinotega. Within each municipality, two barrios were selected, using the same randomization procedure.

A third municipality, Juigalpa, was also selected to act as a source of control information. This municipality was selected on the basis of similarity in population, socio-economic development and access to justice, to the intervention municipalities, from those municipalities where no FJ activities were scheduled to take place. This assessment has been made largely based on the analysis of the local OAS staff. Again, two barrios were selected in this municipality.

To collect the sample, random methods were combined with some quota sampling as follows. ${ }^{19}$ Initially, each barrio was divided into four equal clusters. Within each cluster, households were randomly selected by taking each n-th house starting from a randomly selected starting point. Within each household the adult (aged over 16) who had the earliest birthday was asked to provide responses to the questionnaire. However, in order to facilitate comparison and generalization, it was attempted to match the gender distribution of the entire Nicaraguan population (50:50). This meant that at the end of each block of questionnaires, specifically men or women would be selected in order to fulfil this quota. However, it was not possible to reach a 50:50 split, and both the preand post-intervention surveys had gender ratios of approximately 60:40 female-male.

The same barrios and sampling methods (with the exception of a differently selected random starting point) were used in the pre- and post-intervention surveys. Pre-intervention quantitative interviews were carried out by students of the Universidad Nacional Autónoma de Nicaragua and of post-intervention by students of the Universidad Centroamericana in Managua. The questionnaire asked for information about previous experience with legal problems, perceived incidence of legal problems and legal empowerment. Copies of the pre- and postquestionnaires are available upon request from Martin Gramatikov.

To identify the impact of the FJ programme we employ the difference in differences (DiD) methodology. In essence, comparison of control sites pre- and postintervention tells us what might have been expected to occur in the intervention sites if the FJ programme was not implemented. Comparing this difference to the difference found in intervention sites tells us the impact that the FJ programme had. Initial comparison of treatment and control sites helps us to identify preexisting differences not attributable to the treatment. Post-intervention comparison is then made to assess the impact of the treatment, taking into account these pre-existing differences. In that way we can isolate the expected effects of the FJ programme from the trends that took place outside the programme and equally impact intervention and control sites. DiD, however, has its limitations. First, it does not tell us how comparable the control and intervention communities are in relation to factors beyond the comparison. Second, it does not account for spill-over effects. Third, DiD assumes that the intervention is uniformly applied across the intervention sites, and so variations that occur due to variations in implementation are not accounted for in a DiD analysis. 


\section{DEVELOPMENT ASSISTANCE FOR PEACEBUILDING}

\section{Analysis}

\section{Incidence of Problems}

To get a better idea about people's actual experiences with the law we asked the respondents if, in the past 12 months, they had personally encountered situations that might require legal information or assistance. It is important to note that respondents were asked about problem situations, that is, dispute with a neighbour, land dispute, purchasing defective goods and so on. All of these situations could have legal but also non-legal solutions. Our interest was to find out what strategies people undertake to solve the problems, what level of fairness they receive and what costs the resolutions incur. From there we wanted to see if there is an impact of the FJ programme on experience with and resolution of problems.

In conformity with the findings reported above, the sites where facilitators were to be introduced saw in 2010 a higher proportion of people who report one or more problems which are difficult to resolve (see Table 1). The difference is substantial, and statistically significant $\left(\right.$ Chi square ${ }^{20}=6.77$, d.f. $=1, p=$ .009). After the FJs became active, there are still more problems reported in the intervention sites than in the control sites, but the difference is much smaller. Moreover, the difference within the intervention/control condition is not statistically significant anymore.

To test further the hypotheses of DiD, we ran a multivariate binary logistics regression model with experience of problems as dependent variable and prepost intervention-control conditions and their interaction as independent predictor. This model suggests that only the pre-post condition decreases significantly the likelihood (Wald $=42.535,{ }^{21}$ d.f. $=1, p<.00$ ) that a problem will be experienced. The interaction effect is not significant which means that we cannot be reasonably certain that the relative decline of reported problems in the communities with FJs is not due to sampling or measurement errors.

When people experience legal issues they need formal or informal justice mechanisms to resolve their problems. The resolution rate (the percentage of reported problems that have been resolved) is often used as an indicator of the impact of interventions designed to improve access to justice. The results show that the resolution rate for the intervention sites increases from 2010 to 2013 almost 10 per cent whereas in the control sites there is an increase of 3 per cent (see Table 2). We should warn, however, that at this level of the analysis the numbers are small. This also affects our ability to test the hypothesized DiD effect using multivariate models.

TABLE 1

OCCURENCE OF LEGAL PROBLEMS

\begin{tabular}{lcc}
\hline & Pre- $(\%)$ & Post- $(\%)$ \\
\hline Intervention & 43.8 & 23.6 \\
Control & 31.3 & 19.4 \\
\hline
\end{tabular}


TABLE 2

PROPORTION OF RESOLVED CONFLICTS

\begin{tabular}{lcc}
\hline & Pre- $(\%)$ & Post- $(\%)$ \\
\hline Intervention & 31.9 & 41.7 \\
Control & 48.5 & 45.5 \\
\hline
\end{tabular}

It could be that the work of the FJs directly or indirectly affects the resolution of legal problems. The FJs may step in actively in disputes and resolve the issues between the parties. Or, the FJs may assist people to find and use justice mechanisms, which otherwise would be unknown or unreachable. Another indirect contribution may be that FJs assist judges, the police or the government officials and make their interventions more effective.

\section{Perceived Incidence of Problems}

The respondents from both control and intervention barrios were also asked in the pre- and post-intervention surveys to assess the perceived level of conflict. Two types of conflict situations were addressed; communal and intra-family conflicts. Examples of the former category are disputes between neighbours, unruly behaviour and excessive noise. Intra-family problems refer to situations like divorce, separation, disputes over maintenance and custody rights and inheritance. Two types of questions were asked: (1) what the perceived prevalence of problems is, and (2) whether these problems have increased or decreased over the last three years. Both these issues were rated on a five-point scale. Low values indicate that the respondents report few problems on the first type of questions or a decrease in problems on the latter. High values have the opposite meaning: high prevalence of problems and an increase of these particular types of problems.

Compared to the control sites, the number of communal problems reported developed in a positive direction in communities where FJs have been deployed (see Figure 1). The two control communities (barrios Pedro Joaquin Chamorro and Nuevo Amanecer in municipality Juigalpa) started from fewer reported communal problems (Mpre-control $=2.48 ;^{22}$ Mpre-intervention $\left.=2.87^{23}\right)$. In 2013, the number of problems reported in communities with and without FJs were almost identical (Mpost-control $=2.56$; Mpost-intervention $=2.58$ ). The multivariate model is statistically significant $\left(\mathrm{F}=7.98,{ }^{24}\right.$ d.f. $\left.=3, p<.00\right)$ showing significant effects of the intervention condition as well as the interaction between the intervention and pre-post conditions. There is no statistically significant main effect of the pre-post condition.

Next, we asked the respondents about trends: whether the number of communal problems has increased or decreased (see Figure 2). In 2010 the respondents from the control sites were more likely to have a positive view on the trend in their community (Mpre-control $=2.25$; Mpre-intervention $=2.57$ ). After the intervention both control and intervention sides report almost the same trends (Mpost-control $=2.59 ;$ Mpost-intervention $=2.62)$. Thus, the sites with FJs 
DEVELOPMENT ASSISTANCE FOR PEACEBUILDING

FIGURE 1

PREVALENCE OF COMMUNAL CONFLICTS

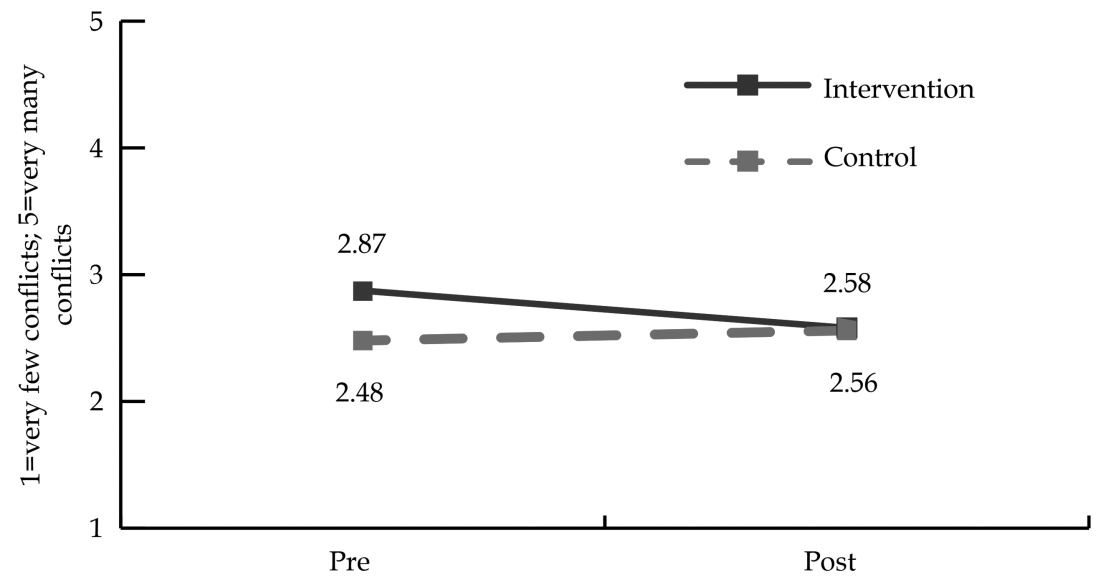

deployed improved their views on conflict-level trends compared to control sites. The multivariate model $\left(\mathrm{F}=6.64,{ }^{25}\right.$ d.f. $\left.=3, p<.00\right)$ shows that the main effects of the intervention and pre-post condition as well as their interactions are statistically significant.

A similar pattern has been found in relation to intra-family conflicts (see Figure 3). All communities were rather positive about the number of these conflicts in 2010 (Mpre-control = 1.73; Mpre-intervention = 1.83). Three years later in both the intervention and control sites people thought there were more family problems (Mpost-control $=1.73$; Mpost-intervention $=1.83)$. The intervention barrios did slightly better although in the multivariate model $\left(\mathrm{F}=5.79,{ }^{26}\right.$

FIGURE 2

DYNAMICS OF COMMUNAL CONFLICTS

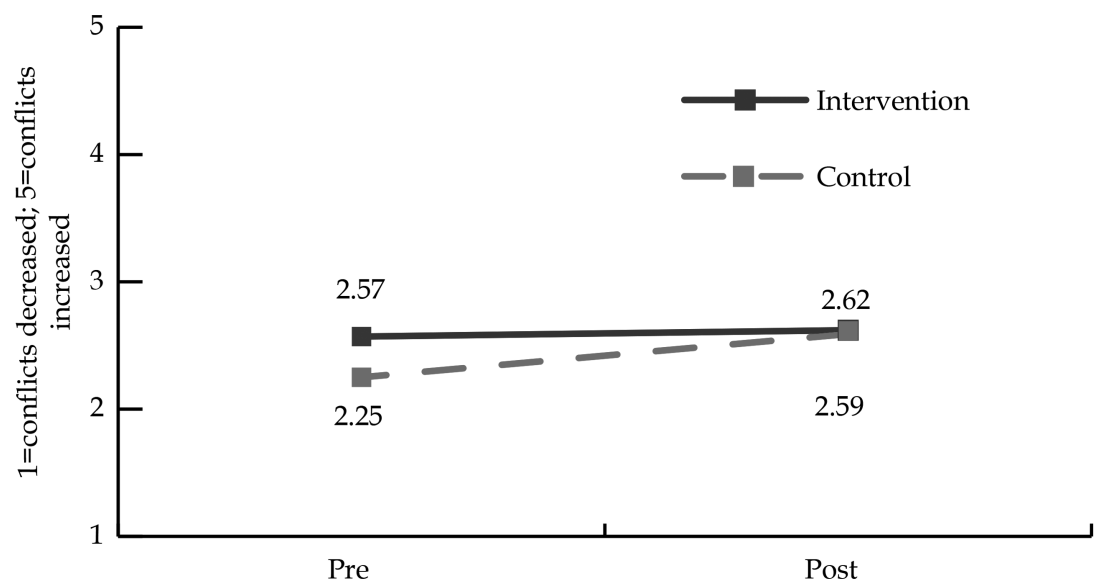




\section{DEVELOPMENT ASSISTANCE FOR PEACEBUILDING}

FIGURE 3

PREVALENCE OF FAMILY CONFLICTS

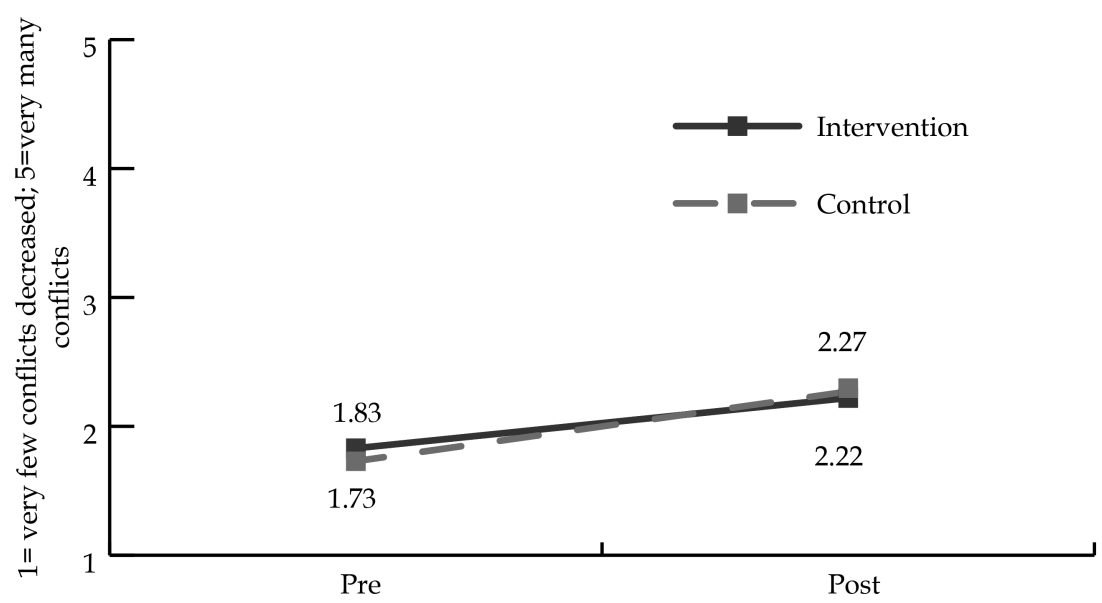

d.f. $=3, p=.001)$ the interaction effect is not statistically significant and we cannot be certain that the difference in difference is not due to sampling or measurement error.

The perceived trends in intra-family problems do not reveal significant differences between the sites with FJs and without them. However, the difference between scores in 2010 and 2013 is less negative in intervention sites than in control sites.

Part of these positive changes can be attributed to the presence of the FJs. Their mission is to help people handle justice problems through dispute resolution or referral to justice institutions. Clearly many beneficiaries shared during the indepth interviews that the FJs helped them by offering more understandable justice processes. Because of the assistance they received, the beneficiaries feel more empowered in their interactions with the authorities. It is relatively easy to see the impact that the FJ programme has on the people who directly benefit from the services of the FJs.

It is more difficult to explain the relationship between the intervention and its impact at community level. In fact, only one respondent to the post-survey in the intervention barrios said that a problem was referred to a facilitator. The FJ programme does not reach people randomly. There is a significant amount of selfselection effect that takes place. Only those who need them and are particularly determined to solve their legal problems ever go to see a FJ. The FJ intervention is not a massive programme which pro-actively reaches out directly to a significant part of the community. How is it possible then to affect the perceived and experienced legal problems at a community level?

First, the fact that the FJs are there to help with disputes and problems might be encouraging people to think that if a problem with legal implications occurs, there will be someone available to help them solve it. We did not find significant impact of the intervention on the perceived legal empowerment but the 


\section{DEVELOPMENT ASSISTANCE FOR PEACEBUILDING}

relationship might be less straightforward. Second, with their work the facilitators prevent problems from escalating. This means every time they resolve an issue there are fewer complications. Research provides ample evidence that unresolved legal problems trigger other problems. ${ }^{27}$ For instance, unfair dismissal might lead to housing and debt problems, family breakdown and so on. Thus the accessibility to the justice mechanism decreases the overall number of problems in the community. Third, the FJs support justice institutions, and notably the courts, to provide better services. This might be increasing the feeling of protection and security among the communities where the FJ programme is operational.

\section{More Amicable Solutions}

One of the key aspects of mediated agreements is that they are acceptable to both parties, and consequently, have a better chance of being upheld without the use of any compulsion. One of the ways in which this can be examined is by looking at how the fairness of solutions was rated by individuals who used non-adjudication dispute resolution mechanisms. Although this question was asked to all respondents in the pre- and post-surveys, there were not enough people who used alternative dispute resolution. Therefore we cannot test this hypothesis.

There is qualitative evidence, however, that the programme has an impact on enabling more amicable solutions in processes that are based on communication, characterized by being 'friendly' or 'pleasant' with minimal quarrels among the parties, and leading to an agreed (rather than imposed) outcome, which also has a greater potential to be stable. The interviews with FJs and others make it quite clear that a friendly negotiated solution that can last in the long run is the result the FJs aim for when they attempt to mediate:

We act and we give them a bit of a coaching talk and we tell them: 'Look, you need to be in peace with your neighbour that is what a neighbour is there for, neighbours are not there to be fighting with, they are there to have a plentiful life, to live in peace.' (FJ 4)

We have a number of examples of beneficiaries that have solved their problems through amicable processes and solutions that have developed a sense of 'communitarian consciousness':

He [the FJ] called us for a meeting for us to reach an agreement. He said it was not necessary to go so far, that we are there for each other, that we are comrades, that we are neighbours, that we live here in the community, that we should look after one another. (Beneficiary 5)

[The FJ] made him [the other party] see that I am a person who does not look for trouble with anybody [...]. So he said that this should be solved amicably. (Beneficiary 10)

Another beneficiary went out of her way to describe the FJ's pleasant manner of handling the matter: 


\section{DEVELOPMENT ASSISTANCE FOR PEACEBUILDING}

He is efficient. He does not make anyone his enemy. He has no enemies because he does everything with love, with affection, saying: 'We are friends, we know each other, we are neighbours, let's not do this again, let's change to support each other, we are here for that.' That is how he does it. (Beneficiary 10)

\section{Reduced Costs}

In Nicaragua, as in many other places, the costs of justice constitute a major hurdle for many people. One of the assumptions of the FJ programme is that it reduces the costs of access to justice for beneficiaries. The FJs perform their role on a voluntary basis. The beneficiaries receive services; information, advice, representation or actual resolution of disputes free of charge. Additionally, whereas distance can constitute an obstacle for accessing justice, the services of the FJs (except for accompanying people to other justice sector institutions) are provided on site; right there in the neighbourhood. In this way, the beneficiaries save travel costs and travel time (which constitutes opportunity costs) that they would have otherwise incurred.

In the survey, the clients were asked to identify one or more important barriers to resolution of their conflicts. We found no effect of the presence of FJs on costs being mentioned as an important barrier to dispute resolution, or the time spent on resolving disputes. It may be that the presence of facilitators reduces costs or time spent, but that is still seen as an important barrier to solving problems.

What we did find is that the individuals who experienced a problem more often report costs as one of the most important barriers to resolution in 2013 compared to 2010 (Wald $=11.390, p=.001$ ). This indicates that either the costs of solving a problem increased, or ability to pay decreased. Our data do not indicate which of these possibilities reflects reality, however, as the interview data indicate the costs of access to justice in Nicaragua can be high. In 2013, respondents were less likely to report time spent on resolving disputes as such a barrier to resolution (Wald $=22.749, p<.001$ ). These effects are replicated across both the intervention and control sites, and so may well be due to a third, external, factor.

In the majority of the in-depth interviews, the issue of the costs of justice also arose. Despite the quantitative data showing no change in the incidence of costs being an important barrier to access to justice, in the interviews, facilitators, judges and members of civil society, all saw costs as a serious issue:

Interviewer: What obstacles do people encounter while accessing justice when they have a problem?

Interviewee: Well, justice is expensive. Even if there is a constitutional decree stating that justice should be free you know that if there is no money nothing can be done here. If there is no money, there is no justice. If you want to file a claim, present charges, you need to go to a lawyer for him to draft the claim, or the necessary documents, and that has a price. (Civil society 2 ) 


\section{DEVELOPMENT ASSISTANCE FOR PEACEBUILDING}

How am I going to pay for a lawyer? They earn excessively and sometimes they don't even handle the case for their client. Right? (Beneficiary 6)

Facilitators, too, are well aware of this difficulty:

Well, access to justice, at least in Nicaragua, is expensive. While going to a lawyer, sometimes, the first thing they ask for is money, they say: 'You will give me 3,000 pesos.' That is only the initial fee afterwards they charge more, and more, and more, and more, and more and there is nothing to do about it. Sometimes for an ID card: 'You will pay me 3,500 to see how we could help you to obtain this ID card.' The same for a birth certificate. So it is very expensive. (FJ 1)

Moreover, they clearly realize that one of their advantages in the eyes of the beneficiaries is the reduced (or even eliminated) cost, and they tend to assume this is indeed a major impact of their presence in their communities as alternative paths to justice:

They [beneficiaries of the FJ programme] will not spend money on the bus ticket, they won't waste their time and the authorities won't lose their time and energy on matters that could end up in a trial and you know how much a trial costs at the courthouse! In criminal matters, the offended party looks for a lawyer and the person sued also needs to look for a lawyer. All those are expenses for the family. [...] Just by getting on the bus to go to the courthouse they are already losing money. They stop working for a day; they can't do their domestic tasks. (FJ 5)

The FJ programme aims to make justice more affordable for the people who need it. Due to budgetary restrictions both pre- and post-surveys had limited sample sizes. As a consequence, the number of respondents who reported a problem and the incurred costs of dispute resolution were not sufficient to detect effects even if there are such in the general population. Therefore this impact has been corroborated exclusively from qualitative data.

FJs are volunteers and do not collect fees from their clients. They are also located in the communities and thus are easy to reach; the physical distance is minimal. Because of the specifics of the programme, FJs often work from their homes which means that they are reachable even when the official institutions are closed for business. FJs work in a very informal way, which inevitably affects the amount of stress that people experience when they use their services. All these aspects of the FJ programme make it clear how the beneficiaries save monetary, opportunity and stress costs. It should be noted that perhaps when compared with the rural FJs, the cost reductions in the urban areas are more modest. In rural areas people are significantly more isolated from legal services. Therefore in the villages the FJs are perhaps saving significantly more costs for the people who need justice. Nevertheless, there is no doubt that the programme is saving different types of costs of justice for the beneficiaries from urban areas. 


\section{DEVELOPMENT ASSISTANCE FOR PEACEBUILDING}

\section{Increased Legal Empowerment}

Legal empowerment here refers to the ability of individuals to solve their legal problems. This was evaluated using the perspectives of individuals in qualitative interviews as well as measuring Subjective Legal Empowerment (SLE). ${ }^{28}$ SLE measures the perceived ability to solve legal problems; that is how able and confident respondents feel to solve potential future conflicts. It is anticipated that due to the presence of FJs people may feel protected and more able to use legal mechanisms to solve their problems, and thus more able and confident that they will be able to solve future problems.

Overall, SLE ratings increased between the pre- and post-measures. However, SLE ratings improved more in control communities than they did in FJ communities (see Figure 4). This is counter to the anticipated effect, but can be explained by two different hypotheses. First, other legal empowerment activities were taking place in the control communities, and these produced the large change that is seen. We do not have a comprehensive index of all empowerment programmes taking place in Nicaragua at this time, but it is not expected that there would be any significantly different activities taking place in the control sites and not in the FJ sites. The second hypothesis is that the lower starting level of SLE in the control communities gave room for a much larger rise over time. This second hypothesis is discussed further below.

When we dig deeper into the specific legal domain (for instance domestic violence, employment problems, etc.) we find that the overall increase is present in the majority of domains for respondents in the intervention sites and for all domains in the control sites. We also find, using DiD analysis, that although there is a significant effect of the pre-post condition, there is no effect of intervention condition on SLE ratings. ${ }^{29}$ Accordingly, we conclude that the FJ intervention had no significant impact upon legal empowerment that was detected in the quantitative data.

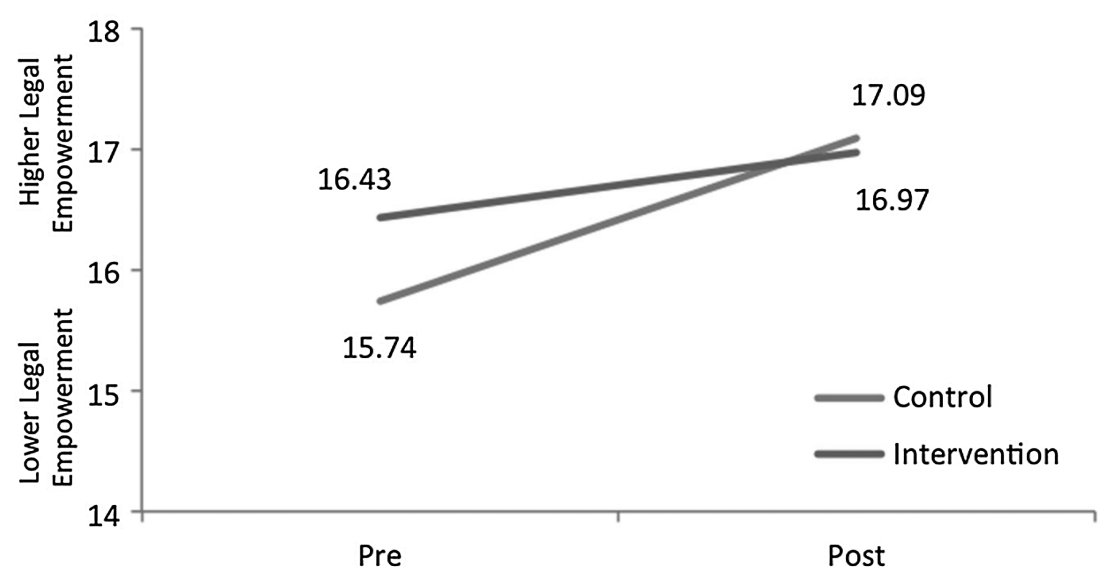


TABLE 3

DIFFERENCES IN SLE RATINGS

\begin{tabular}{lcccr}
\hline & \multicolumn{3}{c}{ Mean difference in SLE ratings (pre-post) } \\
\cline { 2 - 5 } Domain & $\begin{array}{c}\text { Intervention group } \\
\text { (standard errors in brackets) }\end{array}$ & $p$-value & $\begin{array}{c}\text { Control } \\
\text { group (SE) }\end{array}$ & $p$-value \\
\hline Violent crime & $0.296(0.082)$ & .000 & $0.388(0.129)$ & .003 \\
Domestic violence & $-0.127(0.077)$ & .098 & $0.015(0.120)$ & .901 \\
Employment & $0.283(0.074)$ & .000 & $0.505(0.107)$ & .000 \\
Neighbour & $-0.094(0.071)$ & .183 & $0.228(0.107)$ & .034 \\
Property & $0.190(0.072)$ & .009 & $0.239(0.118)$ & .043 \\
Overall SLE index & $0.547(0.239)$ & .022 & $1.357(0.390)$ & .001 \\
\hline
\end{tabular}

What is also clear is that the intervention sites started with a significantly higher level of SLE overall than the control sites $\left(t=1.993,{ }^{30}\right.$ d.f. $=478, p=$ $.047)$, but ended with non-significantly different levels $(\mathrm{t}=-0.423$, d.f. $=998$, $p=.672$ ). This indicates that the control groups actually 'caught up' on a prior deficit in relation to legal empowerment compared to intervention sites. Table 3 shows the differences in mean pre- and post-scores for both the intervention and control sites. In two domains (domestic violence and neighbour problems), there was no significant change in the intervention sites scores. In these domains, the control group showed a significant increase in SLE in relation to neighbour disputes, but no significant change in relation to domestic violence.

On the one hand, the control group has a significant improvement in SLE scores in four of the five domains, as well as overall. The intervention group, on the other hand, has a significant improvement in SLE scores in only three of the five domains, although they also have a significantly higher overall SLE rating.

These results are difficult to interpret. The initially high starting point for SLE ratings in the intervention compared to control groups, although difficult to explain, may well account for the smaller improvement of FJ sites in comparison with control sites. As mentioned, there have been many activities in Nicaragua aimed at improving legal empowerment, and it is possible that these other interventions were more focused on those areas with no FJ presence (indeed, possibly because there was no FJ presence). However, it is not possible in this article to examine in depth the relationships between different situations or conditions and the variations in legal empowerment demonstrated here.

\section{Simple Processes}

Simplicity is a key distinguishing feature of how FJs are supposed to solve problems at the community level. Their presence can be expected to make it easier to begin a process that will bring resolution to the existing justice need, and to make this process more straightforward and understandable. Before the appointment of FJs, people would typically perceive the path to justice as too difficult and complicated.

Consider for example the following quote from a criminal law judge, when he was explaining the importance of FJs by way of describing the difficulties that 


\section{DEVELOPMENT ASSISTANCE FOR PEACEBUILDING}

people typically have when facilitators are not available: '[People] think: "I will go to Court but if the judge is busy she cannot help me"' (Criminal judge 3). Or: 'I go to the police. I file an accusation and the police officer will tell me that I have to bring I don't know how many witnesses and if the investigator is busy ... Do you get my point?' (Criminal judge 3). The risk the interviewed judge is referring to is that people with a justice need might feel defeated before even starting the procedure, just because things seem difficult or overly complicated, not worthy of action. Even worse is the situation of people who simply do not know what action to take, as everything seems complicated and discouraging. Complexity of processes is a serious barrier to justice and the FJs reduce it for their constituencies.

The availability of FJs improved the situation of such people, who can now access justice much more easily, among other things because it is free, but it is also simple to go to a FJ and ask for help. For someone with a problem, setting things in motion has become as simple as making a phone call to the facilitator or going to his or her house. There is no need to file a complaint formally, submit evidence or summon witnesses. Moreover, mediation as carried out by FJs is a rather simple process: The FJ invites the other party, this is typically followed by just one meeting to resolve the dispute, the results of which, if successful, are recorded in a very short and simple written agreement.

When asked about the impact of FJs, beneficiaries are more inclined to mention things like the reduced costs of justice, and the enhanced amicability, but their answers certainly give support to the view that they also feel a difference in terms of the simplicity of the paths to justice, and that they do appreciate the fact that getting on a path to justice, as well as actually travelling it, have really become simpler.

\section{Gender Equality}

Finally, an objective of the FJ programme is to increase the levels of gender equality in the intervention groups. It is difficult to measure precisely gender equality. However, one aspect which can be looked at is the rates of violence against women. Respondents were asked how many of every 10 women they knew, did they think had experienced violence in the last 12 months. Table 4 shows the significant model that is found with the pre-post and intervention conditions. This shows us that there has been a significant drop in the perceived prevalence of violence against women between the pre- and post-time periods in both

TABLE 4

PERCEIVED EXPERIENCE OF DOMESTIC VIOLENCE

\begin{tabular}{lcrrr}
\hline Item & d.f. & Mean square & F & $p$-value \\
\hline Complete model & 3 & 59.488 & 10.902 & .000 \\
Pre-post & 1 & 0.026 & 0.005 & .945 \\
Intervention-Control & 1 & 156.967 & 28.765 & .000 \\
Pre-post and Intervention-Control interaction & 1 & 2.323 & 0.426 & .514 \\
\hline
\end{tabular}




\section{DEVELOPMENT ASSISTANCE FOR PEACEBUILDING}

intervention and control locations, from a mean of 25 in every 100 women, to just 18 in every 100 women.

Given that the intervention condition and interaction are not significant in this model, it is likely that this drop is due to an external factor. In particular, in June 2012, the highly publicized Comprehensive Law against Violence towards Women (Law 779) was passed in Nicaragua. ${ }^{31}$ This law is very well recognized and is regarded as being effective in reducing violence against women.

The impact that the FJ's programme has had on gender equality cannot be immediately inferred from the qualitative interviews. However, what can be seen is that FJs have adopted an educational role seeking a change in mentality and social patterns towards violence against women, an important aspect to achieve gender equality. Their constant efforts increase awareness on women's rights issues and educate society. FJ are speaking up, explaining laws and actively joining sensitization campaigns.

\section{Conclusions}

A sober and realistic picture emerges from the impact assessment of the expansion of the FJ programme into urban communities of Nicaragua. Our study finds that the presence of facilitators decreases the perceived level of intra-community conflicts. In the urban communities where facilitators were active the people experienced a sharper decrease of serious legal problems. The pre- and post-crosssectional surveys, however, did not identify a couple of impacts that were expected. Qualitative interviews with facilitators, beneficiaries, police officers and local authorities provide less robust indications of impact. Decreased costs of obtaining justice, easier navigation through the justice system and increased self-confidence in own abilities to deal with problems are the most important programme benefits. We interpret the fact that qualitative measures detect more effects in three ways: (1) the FJ programme needs longer time to get recognized and experienced in the communities; (2) the skills, abilities and energies of the individual facilitators vary and thus affect the value that their clients receive; and (3) access to justice interventions are not massive programmes; they target people who experience serious and difficult to resolve problems. Examples of such issues are land disputes, domestic violence and aggravated family problems.

The introduction of facilitators decreases the number of problems and empowers people to resolve their disagreements in a fair manner. This means that fewer problems escalate into cycles of violence. More problems are being resolved through some sort of a fair process and the outcomes are considered as just. Considering the trigger effects of the justice problems we can hypothesize that the intervention is preventing other problems from occurring. Respondents from the intervention areas are more confident that the level of communal disputes decreases over time. Here it should be noted that these changes do not happen in the short run. It takes time for access to justice interventions to achieve their intended impacts. The improvements that can be attributed to the FJ programme are not radical but also not negligible. With small steps the accessibility of justice in the intervention communities has been improved. This means 


\section{DEVELOPMENT ASSISTANCE FOR PEACEBUILDING}

less escalated disputes, less violence and greater sense of justice, security and peace.

There is a large body of evidence regarding the ability for the FJ programme to be scaled up beyond the borders of Nicaragua and even Latin America. However, there are characteristics that we believe may have a significant impact on existing and future follow-up programmes. The institutional arrangement affects the success and sustainability of the FJ programme. The experience from Nicaragua provides ample evidence about the crucial importance of a genuine embracement by the judiciary. Organizational and personal commitment to the values of the FJ programme is a key factor for success. Moreover, the experience shows that judges alone cannot make it a success; involvement of all relevant stakeholders is needed. It is critical that the programme is seen as beneficial by a broad range of actors - local authorities, police officers, bar members, judges and community leaders.

Furthermore, the success of the facilitators is largely dependent on their ability to gain trust from the local community and use social authority to intervene in people's justice needs. Their work is more effective in smaller communities, where the bonds between the individuals and community are stronger. Various barriers to justice make the presence of FJs in remote and isolated communities more valuable for their beneficiaries. Scaling up of the programme should consider careful selection and sequencing of intervention sites. The Nicaraguan experience shows how important it is that the programme commences in places where it is needed the most.

Lastly, further research should look deeper into the drivers for success. Understanding how such factors work and interact with the surrounding social and legal culture is crucial for the replication and scaling up of every programme. In that respect some of the identified drivers of success of the FJ programme in Nicaragua provide a salient indication of how to implement similar programmes in other countries. 


\section{DEVELOPMENT ASSISTANCE FOR PEACEBUILDING}

\section{NOTES}

1. Margot Kokke and Pedro Vuskovic, 'Legal Empowerment of the Poor in Nicaragua', SSRN, 2010 (at: ssrn.com/abstract=1674020), p.4.

2. Maurits Barendrecht, Martin Gramatikov, et al., Towards Basic Justice Care for Everyone: Challenges and Promising Approaches, The Hague: Hague Institute for the Internationalisation of Law, 2012, p.141; Commission on Legal Empowerment of the Poor, Making the Law Work for Everyone, New York: United Nations Development Programme, 2008.

3. World Bank, 'The World Development Report 2011: Conflict, Security, and Development', Washington, DC: World Bank, 2011.

4. Kieran McEvoy, 'Beyond Legalism: Towards a Thicker Understanding of Transitional Justice', Journal of Law and Society, Vol.34, No.4, 2007, pp.411-40.

5. Lars-Erik Cederman, Andreas Wimmer, et al., 'Why Do Ethnic Groups Rebel? New Data and Analysis', World Politics, Vol.62, No.1, 2010, pp.87-119.

6. World Bank (see n.3 above); Beqiraj Julinda and Lawrence McNamara, The Rule of Law and Access to Justice in the Post-2015 Development Agenda: Moving Forward but Stepping Back, London: Bingham Centre for the Rule of Law, 2014.

7. Hazel Genn, Paths to Justice: What People Do and Think about Going to Law?, Oxford: Hart Publishing, 1999; Pascoe Pleasence et al., 'Causes of Action: First Findings of the LSRC Periodic Survey', Journal of Law and Society, Vol.30, No.1, 2003, pp.11-30; Ben van Velthoven and Marijke ter Voert, Paths to Justice in the Netherlands: Looking for Signs of Social Exclusion', Leiden: Leiden University, 2004; Martin Gramatikov, Justiciable Events in Bulgaria, Sofia: Open Society Institute, 2010.

8. Ab Currie, The Legal Problems of Everyday Life: The Nature, Extent and Consequences of Justiciable Problems Experienced by Canadians, Ontario: Department of Justice, Canada, 2010: Pascoe Pleasence et al., 'Multiple Justiciable Problems: Common Clusters and Their Social and Demographic Indicators', Journal of Empirical Legal Studies, Vol.1, No.2, 2004, pp.301-29.

9. Martin Gramatikov, 'Methodological Challenges in Measuring Cost and Quality of Access to Justice', Working Paper No.005/2008, Tilburg: Tilburg University Legal Studies, 2007.

10. World Bank (see n.3 above).

11. See data.worldjusticeproject.org/\#/index/NIC, accessed 1 Jun. 2015.

12. See Bertelsmann Transformation Index report (at: http://bti-project.org/index/), accessed 1 Jun. 2015; see also country-specific information provided by the United States Department of State (at: travel.state.gov/travel/cis_pa_tw/cis/cis_985.html), accessed 1 Oct. 2013.

13. Kokke and Vuskovic (see n.1 above).

14. Margot Kokke, Marian Van Dijk, et al., 'Facilitadores Judiciales Nicaragua Impact Evaluation: Baseline Assessment', Tilburg: Tilburg Institute for Interdisciplinary Studies of Civil Law and Conflict Resolution Systems, 2010, pp.1-71 (on file with the authors).

15. For more information see www.oas.org/es/sla/facilitadores_judiciales_una_respuesta.asp, accessed 21 Aug. 2013.

16. Kokke and Vuskovic (see n.1 above).

17. See www.oas.org/es/sla/facilitadores_judiciales.asp, accessed 13 Aug. 2013.

18. See, for thorough discussion of natural and quasi-experimental designs and the threats to their internal and external validity, Bruce D. Meyer, 'Natural and Quasi-Experiments in Economics', Journal of Business and Economics Statistics, Vol.13, No.2, 1994, pp.151-61. See also www. wider.unu.edu/research/current-programme/en_GB/Experimental-Methods-Study-GovermentPerformance/, accessed 4 Oct. 2013.

19. Emmanuel Skoufias, 'Introduction to Impact Evaluation: Methods and Examples', World Bank, 12 Aug. 2013 (at: siteresources.worldbank.org/INTISPMA/Resources/Training-Events-andMaterials/050310_IE_Methods.pdf); Christopher Blattman, Alexandra Hartman and Robert Blair, 'Building Institutions at the Micro-Level: Results from a Field Experiment in Property Dispute and Conflict Resolution', 4 Oct. 2013 (at: www.american.edu/cas/economics/news/ upload/Blattman-paper.pdf).

20. Goodness of fit test; d.f. refers to degrees of freedom; $p$ refers to the significance level.

21. Wald test is used to determine how significant an explanatory variable in a model is.

22. Mean of the control group during pre-intervention study. 


\section{DEVELOPMENT ASSISTANCE FOR PEACEBUILDING}

23. Mean of the intervention group during pre-intervention study.

24. Muli-variate linear regression.

25. Kokke and Vuskovic (see n.1 above).

26. Ibid.

27. Currie (see n.8 above); Pleasence et al. (see n.7 above).

28. Martin Gramatikov and Robert B. Porter, 'Yes, I Can: Subjective Legal Empowerment', Georgetown Journal on Poverty Law \& Policy, Vol.18, No.2, 2011, pp.169-99.

29. When the pre-post condition and intervention/control conditions were entered as independent variables, with SLE ratings as dependent variables, the pre-post condition of the measure was the only significant predictor in relation to overall SLE $(p<.000)$, property $(p=.002)$, employment $(p<.000)$ and violent crime $(p<.000)$, while neither of the independent variables were predictors in relation to domestic violence, and only the interaction between the pre-post condition and the intervention/control condition was a significant predictor in relation to neighbour disputes.

30. Test for difference of means of independent samples.

31. See www.asamblea.gob.ni/Informacion\%20Legislativa, accessed 15 Aug. 2013. 


\title{
Education from the Bottom Up: UNICEF's Education Programme in Somalia
}

\author{
JAMES H. WILLIAMS and WILLIAM C. CUMMINGS
}

\begin{abstract}
Provision of education and other basic services in fragile and conflict-affected contexts can be an important means of building positive peace. However, service provision suffers when government is absent or too weak to carry out this function. In such circumstances, the peace-building function of education may be lost unless other means of provision are developed. UNICEF supported education in Somalia in 1996-2010 as part of its mandate. Though it was not the only international agency working in education in Somalia, UNICEF took a leading role for much of the early crisis period. Facing variable instability and a lack of functioning government, especially in the south-west (central/south zone), UNICEF took advantage of shifting opportunities to educate thousands of children and adults. The agency's longstanding presence and focus on children, families and communities gave it unusual credibility. Close partnerships with local NGOs permitted outreach to diverse communities and capacity to exploit emergent opportunities. Instructional content provided basic skills; negotiated with stakeholders, it was suitable for both public and Qu'ranic schools. UNICEF varied activities according to local stability and partner capacity. Basic components were introduced first, additional components added as conditions stabilized and capacity grew. Efforts were evaluated and programme elements revised. Unable to rely on central government, UNICEF engaged flexibly with sub-national governing entities including nascent zonal governments to support educational provision.
\end{abstract}

\section{Introduction}

There is a surprising intimacy between education, peace-building and conflict. ${ }^{1}$ On the one hand, in the popular imagination and discourse, education is generally understood as a good thing. Education can help build skills for employment or conflict resolution. It provides hope, a positive initiative helping to build 'positive peace'. ${ }^{2}$ Education is commonly prescribed for many of the ills of the world, including conflict. It is suggested as a means to help individuals, communities and societies learn to live together. ${ }^{3}$ The UN Secretary General's Global Education First Initiative (GEFI) identifies global citizenship as its third priority: 'Education must fully assume its central role in helping people to forge more just, peaceful, tolerant and inclusive societies.'

Education is understood to have two faces. ${ }^{5}$ The positive face includes programmes aimed explicitly at promoting peace, that is, peace education. Education can also help reduce conflict with broad provision of educational opportunity, promotion of cultural and linguistic tolerance and by 'disarming history'. 6

This is an Open Access article distributed under the terms of the Creative Commons Attribution-NonCommercial-NoDerivatives License (http://creativecommons.org/Licenses/by-nc-nd/4.0/), which permits noncommercial re-use, distribution, and reproduction in any medium, provided the original work is properly cited, and is not altered, transformed, or built upon in any way. 


\section{DEVELOPMENT ASSISTANCE FOR PEACEBUILDING}

However, too little education, inequitable distribution of education and the 'wrong kind of education' can contribute to conflict. ${ }^{7}$ Education's negative face 'shows itself in the uneven distribution of education to create or preserve privilege, the use of education as a weapon of cultural repression, and the production or doctoring of textbooks to promote intolerance. ${ }^{8}$ Recognizing the potential for harm, the Inter-Agency Network for Education in Emergencies (INEE) has worked over the past several years to promote 'conflict-sensitive programming', programmes that do not exacerbate conflict. To serve its positive peace-building function, education must at a minimum be broadly available, and not the exclusive prerogative of particular groups.

Education can also serve a state-building function. ${ }^{9}$ The provision of basic services such as education demonstrates the capacity and good political will of the state, or other governing entities. It helps to legitimate the provider (and likely to train those to whom education is provided to think in ways that support the ends as well as the legitimacy of the governing entity). This is commonly seen in non-state actors who seek to establish their credibility, often with great success, by providing basic services where the state may not (e.g. Muslim Brotherhood in Egypt prior to 2010). The state-building function of education can take place in a variety of ways, such as building trust in institutions and those that support them, developing cooperation among groups and developing understanding of state structures among the people. When the state is conceived simply in terms of a central government, the state-building capacities of education are limited to those that support development of central government. However, when state-building is understood more broadly, the state-building functions of education can also be seen more broadly. ${ }^{10}$

International leaders call education a human right and a responsibility of the state. ${ }^{11}$ Yet what is to happen when the state collapses? As the quintessential failed state, ${ }^{12}$ Somalia is an important case for discussions of state fragility and failure $^{13}$ and of the possibilities of education in such contexts. Given education's role as a potential state-building and peace-building endeavour, it seems well worth looking at the provision of educational services under conditions of extreme state fragility and collapse. Current research literature discusses education in Somalia, ${ }^{14}$ but offers little insight into the ways in which educational services may be delivered under such conditions, nor does it discuss ways in which education can serve potential state-building functions in the absence of formal state structures.

The primary contribution of the case study is the detailing of ways in which an international agency, in this case UNICEF, worked to deliver basic education services under such conditions, where many of the usual prerequisites for development work are absent. The agency was able to do so by organizing its operations flexibly so as to respond to shifting opportunities as they arose, by working with a range of local partners who had a stake in the operations of schools and by developing components of an education programme that could be added or dropped as conditions changed. The case draws on primary documents from UNICEF and the government(s) of Somalia, selected interviews and correspondence and secondary literature on education in fragile states and 


\section{DEVELOPMENT ASSISTANCE FOR PEACEBUILDING}

those affected by conflict. Documentation was challenging, as the research literature on provision of services during the Somali conflict is extremely limited. Conversely, the study's contribution is the elaboration of strategies used to begin to build positive peace through educational provision in an extremely fragile context. Still there are limitations to the heavy reliance on agency sources.

\section{Context}

Located in the Horn of Africa, Somalia is the lost orphan of East Africa. Arguably, Somalia is not a single country under a fragile state but rather three regions with varying levels of functioning statehood and fragility: the north-west zone (NWZ), the self-declared 'Republic of Somaliland'; the north-east zone (NEZ), the semiautonomous 'Puntland State of Somalia'; and the central/south zone (CSZ).

From 1991 Somalia experienced nearly two decades of civil unrest and war. The civil war and subsequent collapse of central government and its institutions left Somalia one of the world's poorest countries. The Somali people were deeply divided. During the conflict, villages and cities were indiscriminately bombed and looted, and basic services, such as water, health care and education collapsed. By 1998, the average life expectancy of a Somali was 43, the under-5 mortality rate exceeded 25 per cent. Even prior to the war, Somalia had one of the world's lowest adult literacy rates. UNICEF reported in its State of the World's Children 1998 that literacy rates for men and women in Somalia were 36 per cent and 14 per cent respectively. ${ }^{15}$

Approximately 60 per cent of Somalia's population is semi-nomadic pastoralists, organized into traditional clans who mainly live a pastoral life. The Somalia area was lightly colonized by the Italians (in the south and north-east) and the British (in the north-west). For some Somalis, colonization fostered an interest in the West and modern world economy - and hence in Western schooling. But the British and Italian colonial administrations did little to penetrate the daily lives of the majority of people, or develop a national consciousness. The predominant cultural inclination was and is towards a traditional Islamic way of life, which represents diverse views towards formal schooling, especially of girls. Most children were schooled, if at all, in Koranic schools run by religious leaders in most communities.

In 1960, Somalia gained independence as a state with its capital in Mogadishu - but there was minimal actual integration. Merger of the two former protectorates led to an initial period of nation-building, but then the president was assassinated in 1969 and there was a bloodless coup in which Mohamed Siad Barre assumed leadership, establishing a military dictatorship under Marxist precepts.

The demise of the regime in 1990 led to loss of moral authority and popular support for the regime. By 1991, the country was in a state of civil war, with the dissolution of a functioning central state. In its place regions took three different political directions. In the north-west and north-east, established civil administrative structures provide a framework for implementation that has been lacking until recently in the CSZ. Somaliland has developed a functioning if fragile democracy. The Puntland has seen a strong leader with considerable legitimacy. 


\section{DEVELOPMENT ASSISTANCE FOR PEACEBUILDING}

And the central/south region centred around Mogadishu has been a contested zone with several tribes vying for leadership, though with a recent consolidation of authority claiming a national mandate.

As of August 2012, the Federal Republic of Somalia (FRS) is the official government of the nation as a whole. It is centred in Mogadishu, in the CSZ with Hassan Sheikh Mohamud as president. The central government is working to build national institutions, even as the regional governments of Somaliland and Puntland remain in place, and are more or less active. The extent to which the FRS will assume authority over the Somaliland and the Puntland remains unclear.

Two decades without a functioning central government jeopardized provision of social services including education: unsafe schools; destruction of infrastructure and instructional materials; and vulnerable teachers. But the respective governments have devoted some energy towards revitalizing education. Alongside regional governments, a number of NGOs and international organizations have persisted; among them UNICEF, which is generally regarded as having made considerable headway both in providing services and laying critical groundwork for development of effective governance structures in the sector.

This case study overviews UNICEF's experience as it developed and adapted approaches to working in Somalia's fragile environment between 1991 and 2010. While its record is not perfect and UNICEF was not the only active international player, UNICEF remained the lead international agency supporting formal education services throughout this period of instability, conflict and collapse of central authority.

The formal education system remains among the least developed in the world. Still, it has moved from a condition of total collapse in 1991 to 2012, when over 700,000 children enrolled in school (primary gross enrolment ratio of 22 per cent), with considerable variation across regions. The majority of funding is external or community-based, yet by 2012 ministries of education were constituted in each of the three zones of Somalia and they have produced ambitious forward-looking sector plans. ${ }^{16}$ The country now receives funding from the Global Partnership for Education (GPE). UNICEF played an important role in these achievements, due to its sensitivity to local context, its flexibility in programme responses, its willingness and ability to partner with available groups and agencies, its focus on helping the larger system get running and its commitment to inclusion.

\section{Educational Development}

As in many societies, Somali children have historically been instructed through informal oral traditions and practices. Somalia is an Islamic society and Islamic educational institutions remain prevalent. Most children attend Koranic schools instead or in addition to formal schooling. During the colonial period, the British introduced an English educational system in the north-west, and the Italians introduced an Italian system elsewhere. At independence, the country had 200 primary schools and 12 secondary schools, each with its own history and standards, various languages, curricula and teaching methods. ${ }^{17}$ By the 


\section{DEVELOPMENT ASSISTANCE FOR PEACEBUILDING}

early 1970s, an integrated formal school system was established with donor assistance with some 1,400 primary schools, perhaps as many as 60 secondary schools (some boarding schools providing access to rural children), several vocational-technical institutes, a national teacher education centre and a national university. Somali became a written language using the Latin alphabet, and a large-scale literacy programme was undertaken. By the mid-1970s, however, most Western assistance was abandoned when the new government developed close relations with the USSR.

In 1981, official statistics show 152,429 students enrolled in grades one to four in 729 primary schools, 34.1 per cent of whom were female. In the same year, 87,487 students were enrolled in intermediate education (grades five to eight) in 628 schools, of whom 38.7 per cent were female. ${ }^{18}$ By way of contrast, there were an estimated 5,480 Koranic schools in the country, enrolling students from 4 or 5 years old up to 14 years old, though most students, especially girls, left before then. Enrolments in the formal schools appear to have varied substantially. For example, see Table 1 for the reported range of first grade enrolments between 1975 and 1982.

The Ogaden war with Ethiopia in 1977-78 drew government resources from education to the point the system moved towards collapse. Enrolment dropped, schools were closed and teachers sought employment elsewhere. By 1990, only 600 schools remained open, enrolling 150,000 children. ${ }^{19}$ The nation plunged into conflict. By 1991, 90 per cent of the country's school buildings were destroyed, virtually no instructional materials were available and teachers and students had abandoned the educational process, many displaced by the conflict. For two years, Somalia had virtually no formal schooling. ${ }^{20}$ In 1993, schools began to open, operated by local communities or teachers. Informal education committees were established in some areas. The United Nations Educational, Scientific and Cultural Organization (UNESCO) and UNICEF began to reprint existing primary school textbooks and teachers' guides. UNICEF provided inservice training for teachers and distributed school kits. International agencies and NGOs provided funding, training and supervision in some localities. Schools were rehabilitated by communities, international agencies and NGOs. ${ }^{21}$

Violence and instability continued, particularly in the CSZ. Yet communities, local and international NGOs and international agencies, particularly UNICEF,

TABLE 1

FIRST GRADE ENROLMENTS FROM 1975-76 TO 1981-82

\begin{tabular}{lr}
\hline Year & Enrolments \\
\hline $1975-76$ & 133,605 \\
$1976-77$ & 68,256 \\
$1977-78$ & 41,631 \\
$1978-79$ & 62,963 \\
$1979-80$ & 48,272 \\
$1980-81$ & 59,808 \\
$1981-82$ & 47,507 \\
\hline
\end{tabular}

Source: Ministry of National Planning, 1984. 


\section{DEVELOPMENT ASSISTANCE FOR PEACEBUILDING}

UNESCO's Programme of Education for Emergencies and Reconstruction (PEER) and others, continued to offer education in pockets of stability. As stability and security increased, enrolment rates grew.

Table 2 shows enrolment rates by gender and zone and by enrolment status as indicated by the 2006 Somalia Multiple Indicator Cluster Survey (MICS). ${ }^{22}$ In 2006 enrolment rates remain low, but more than half of all children are enrolled in formal school or Koranic school. Enrolment is higher among boys than girls and highest in Puntland.

Still, Somalia has the world's lowest rates of educational participation. A majority of Somalis are illiterate. Female literacy rates are substantially lower than those of men. ${ }^{23}$

During the civil war, much of Somalia faced conditions unconducive to educational development:

1. violence in many parts of the country and fragile peace elsewhere;

2. lack of a national unified government structure;

3. dispersed population and poor infrastructure (making logistics costly and complex);

4. a host of service-providing organizations with different strategies, missions and modes of operation, leading to gaps, duplication and competition;

5. low levels of basic skills in the population and lack of training infrastructure, resulting in poor service;

6. short timeframes for international assistance, due to instability and the emergency nature of much available assistance;

7. corresponding low level of ownership by Somalis of external projects.

At the same time, there were positive conditions as well. Somali communities long ago wearied of conflict and showed themselves eager to undertake development work when possible. In the vacuum of government service provision, NGOs and private providers emerged to provide local services. Most utilities, for example, are provided by non-state entities. NGOs in particular are often

TABLE 2

ENROLMENT STATUS OF CHILDREN BY GENDER AND ZONE

\begin{tabular}{lcccc}
\hline & Never enrolled & Enrolled formal school & Enrolled Koranic school & Total \\
\hline Girls & & & & \\
$\quad$ Somaliland & 43.8 & 41.9 & 14.3 & 100 \\
$\quad$ Puntland & 36.5 & 29.8 & 33.7 & 100 \\
$\quad$ Central South & 50.1 & 17.4 & 32.5 & 100 \\
Total & 46.9 & 25.5 & 27.7 & 100 \\
Boys & & & & 14.2 \\
$\quad$ Somaliland & 31.2 & 54.6 & 42.4 & 100 \\
$\quad$ Puntland & 26.1 & 18.6 & 53.8 & 100 \\
$\quad$ Central South & 27.9 & 29.4 & 42.0 & 100 \\
Total & 28.6 & & & \\
\hline
\end{tabular}

Source: Moyi, 'Who Goes to School', 2012 p.165. 


\section{DEVELOPMENT ASSISTANCE FOR PEACEBUILDING}

headed by women. As a consequence, a vibrant civil society emerged, an entrepreneurial environment that bodes well for sustainability. The range of civil society organizations means that services can reach and be managed at the local level. Clans provide a strong base of mutual aid and sharing, with certain traditional protections for the vulnerable. Koranic schools, which operated much like early childhood education centres, continued to function through the conflict and provide a legitimate, widely accepted institutional foundation for education. UNICEF and other agencies have had some success in broadening the curricula of such schools in collaboration with local leaders. Governmental structures emerged in Somaliland and Puntland, permitting longer-range planning and sustained development. Agencies working in Somalia have long recognized the need for coordination and taken steps to maximize cooperation and coverage. Conflict was neither constant nor everywhere, and there were many opportunities for local developments and initiative. Some researchers found that Somalis were often quite open to innovation. ${ }^{24}$

\section{UNICEF's Education Programme}

UNICEF resumed work in Somalia in 1993, helping to rehabilitate school buildings, re-printing existing textbooks (in collaboration with UNESCO PEER) and provide school kits (very basic set of instructional materials enabling a teacher to teach). While these kits were useful in emergency contexts, parents and communities wanted more. In response, UNICEF initiated an education programme in Somalia in 1997.

The programme emphasized formal primary education. In addition, however, UNICEF developed non-formal educational programmes for out-of-school youth and children. ${ }^{25}$ These programmes included a non-formal education initiative targeting nomadic children using Alternative Basic Education (ABE) materials, and an integrated Koranic school project in Puntland and Somaliland.

Given the effective absence of government during that time period, UNICEF used partnership-based strategies to provide services in local areas. Partnerships include work with communities; local and international NGOs; private business; and various local authorities and zonal governments. ${ }^{26}$ Though pervasive, conflict and instability were not uniform. UNICEF implemented its programme as opportunities opened up during periods (or specific localities) of relative peace, as regional governments developed capacity and as new development agencies began work in the country.

UNICEF developed, tested and scaled-up a relatively standard package of interventions, but varied introduction of components according to partner capacity and ground conditions. The agency administered its programmes through zonal offices in each of the three zones as well as four sub-zonal offices in the CSZ. As a result, UNICEF provided services, directly or indirectly, in most of the country. ${ }^{27}$

Initially delivering community-level services in response to the emergency, UNICEF increasingly supplemented this with work at the system level, 


\section{DEVELOPMENT ASSISTANCE FOR PEACEBUILDING}

coordinating activities with other government structures when possible and with NGOS and development agencies working in the country). ${ }^{28}$

\section{Components of the Education Programme}

Over time, UNICEF developed a series of components, introduced at different times according to capacity, need and access. Components included the following.

School kits: UNICEF's initial response to the Somali conflict was provision of education kits in 1993. These kits contained a minimum set of instructional materials, designed to enable a teacher to teach in any safe environment. School kits were both welcomed and controversial. A 1998 review found that kits were of limited use in many circumstances and, having been sourced externally, not sustainable. As a result, revisions were made and a teachers/school kit was developed alongside a pupil kit for 40 children (including chalk, pencils, crayons, pens, slates and notebooks). Kits were initially distributed to all primary schools in 1999 and in subsequent years. They played an important role in starting up education initiatives during the crisis phase. However, as time went on, it became obvious that additional activities were necessary. ${ }^{29}$

Curriculum and textbooks: By 1993, few schools were standing. Instructional materials were almost non-existent. Materials that did exist consisted of isolated textbooks from Somalia and elsewhere, in multiple languages, often outdated. Very few children or schools had access to a complete set of age- and languageappropriate textbooks. Initially, UNICEF together with UNESCO PEER copied existing textbooks for distribution and use. However, with awareness of the limitations of existing materials, UNICEF initiated a complete curriculum revision process for lower primary education. Twenty-four syllabi and textbooks were prepared for grades one to four in six subject areas - Somali language, Arabic, mathematics, science, social studies and Islamic studies. Curricular materials were developed to be used in Koranic schools and formal primary schools. ${ }^{30}$

UNICEF was committed to child-centred pedagogy, gender equity and an inclusive process where all points of view were welcomed. As a result, 40 Somali educationalists organized into a curriculum revision team, spending two years in a wide-reaching consultative process that led to broad support for the new textbooks, which included, notably, images of girls and boys. UNICEF organized the effort with UNESCO and international donor support. Textbooks were provided to schools throughout the country. ${ }^{31}$ In 2010 , for example, textbooks and school supplies reached 80 per cent of schools in the NEZ, 70 per cent of schools in the NWZ and 47 per cent of schools in the CSZ. ${ }^{32}$ Agency reports indicate the materials were widely accepted and utilized, even in some Koranic schools.

Training teachers: A third major component was teacher training. Working with local authorities, UNICEF organized in-service training for thousands of primary school teachers. International subject-matter experts were hired to train teacher trainers from zonal authorities around the country. A trainer's manual was developed for each subject and a 19-day course was designed to train all lower primary school teachers in the country, using a trainer of trainer's 


\section{DEVELOPMENT ASSISTANCE FOR PEACEBUILDING}

model. Teachers were trained in Somali language, mathematics, science and social studies, as well as later in Arabic language and Islamic studies. Training included child-centred, gender-sensitive instruction, as well as other instructional management techniques and data collection for Educational Management Information System (EMIS). Gender training was a central component. The training was designed as part of a three-year package of courses that would upgrade teachers' skills, providing them with the skills and certification equivalent to completion of a teacher training college programme. ${ }^{33}$ Despite these efforts, the question must be raised about whether 19 days of training is sufficient, especially given the weak educational background of many trainees.

Supervision: Teachers and community education committees (CECs) need leadership, mentoring and support. Realizing this early on, UNICEF, UNESCO and a number of NGOs supervised schools as they were able. In the late 1990s, government authorities in Somaliland and some parts of Puntland began to place supervisors to oversee schools.

More systematically, UNICEF and Education Sector Cluster (ESC)/Somali Aid Coordination Body (SACB) partners began to train supervisors. Initially the target was to prepare 1,500 supervisors for schools throughout Somalia. Supervisors were trained in community mobilization, collection of EMIS data, distribution of educational supplies, management of educational resources, improvement of school environments and training of CEC members. ${ }^{34}$

School facilities: Most schools had been severely damaged, destroyed or looted. Facilities were rehabilitated using whatever funds were available. Building standards varied widely. Schools often lacked latrines, making them unsanitary for all especially for girls. UNICEF developed guidelines for safe, low-cost school buildings made of locally available materials. Construction supervisors were trained in rehabilitating school facilities. Additionally, materials were developed to encourage parents, teachers and school directors to make schools safe, clean and child friendly. ${ }^{35}$

Community education committees: A key component of UNICEF's thinking about schooling in Somalia was community support. This was especially important in the absence of government in parts of Somalia and the ultimate unsustainability of international support. Accordingly, communities were encouraged to establish CECs, consisting of local volunteers. Depending on community, CEC members include parents, religious leaders, members of women's and youth groups or businessmen and women. CECs are trained by school supervisors in leadership, school management and administration. Most schools in the country now have CECs.

Schools' running costs are the responsibility of local communities. Communities own and/or manage almost half the schools in the country. Remaining schools are owned by individuals, local authorities and sometimes private individuals. NGOs also manage many schools. Community ownership has been particularly important in the CSZ, where local government structures are weakest. ${ }^{36}$ Community management of schools and responsibility for finance helps ensure that schools can sustain themselves when government is unable. 


\section{DEVELOPMENT ASSISTANCE FOR PEACEBUILDING}

Educational Management Information System: Lack of data was one of the greatest challenges to working in Somalia's school system. There was no information on how many teachers or children there were; how many schools were in operation; what facilities were available and needed and so on. UNICEF worked with local education officials and NGOs to initiate an annual national survey of data on primary schools in all three zones. The surveys used standard instruments to collect data on pupils, classes and schools. All primary school teachers, head teachers and supervisors were trained in use of the forms, and successful surveys have been carried out for several years.

UNICEF also worked with regional officials to provide computers and training in the compilation of data and its use in planning and policymaking. ${ }^{37}$ UNICEF and UNESCO have used the data to plan textbook distribution and teacher training.

These efforts have largely worked. UNICEF is the largest educational provider in the country, and enrolment has increased. Primary school enrolment has grown from 464,780 children in 2006-07 to an estimated 763,320 children in 2009-10. Thirty-seven per cent of new enrolments were girls. Sixty per cent of primary school students were reached with UNICEF-organized teaching and learning supplies. ${ }^{38}$

\section{How Has the Programme Worked?}

The UNICEF education programme worked as a result of several factors, which we examine below. This assessment was developed through consideration of the UNICEF programme in light of best practices for education in conflict situations; based on assessments by UNICEF staff and other observers; and selected interviews with individuals who had worked in Somalia during the period of study.

\section{Role of Local Context}

Almost all of UNICEF's interventions were adapted to the local context. Without a central government, work in the local context with local actors was the only option. Still, in several particular ways, UNICEF took advantage of the local context to deliver education. In particular:

Religious and cultural sensibilities and institutions were respected: Curriculum developers worked to develop curricula that could be used in Koranic schools. Moreover, programmes were developed to build the instructional capacity of Koranic schools to teach a broader range of subjects of a basic education curriculum. Religious leaders were consulted and engaged in educational efforts in local communities. It is not known how satisfied religious leaders were with the consultation or whether compromises were made in universal values of gender equity for example. Still, the effort was made to respect the values of the country.

UNICEF has a longstanding presence and enjoys legitimacy due to its focus on local needs: UNICEF's extended presence in Somalia gave the agency a consistency, breadth and depth of engagement. UNICEF's focus on services to children and mothers has given it an unusual legitimacy. Programming for children and 


\section{DEVELOPMENT ASSISTANCE FOR PEACEBUILDING}

mothers is rarely as controversial as, for example, programmes for adolescents. Beyond education, UNICEF works in health, nutrition and other related areas, thus adding credibility. These efforts reinforced each other, with UNICEF attending, credibly, to the needs of the child as a whole.

\section{Aid Modalities}

Assistance to the central government was impossible, so UNICEF worked with a host of organizations - community-based organizations, international NGOs and international agencies, often serving as lead agency and coordinating body. Such moves run the risk of course of undermining possibilities for central leadership, of establishing parallel systems of provision or of enhancing the power of local elites, who may not have the interests of the larger public in mind. Still the value of basic educational provision was given greatest weight. For instance:

Parallel with support to schools and communities, UNICEF provided nascent sub-zonal and zonal education systems with levels of support in line with their developing capacity and ability to absorb new ideas and demands: While supporting the community level, UNICEF maintained close contact with regional education officials, assisting them as they assumed increased responsibilities for provision of education in their areas. Arguably, the capacity of zonal education offices supported by UNICEF enabled Somalia to receive the first federal grant to be allocated by the GPE. Indeed, the Mogadishu-based Somali government has established a central education ministry for the first time in 20 years, though zonal education ministries are still most active.

A reasonable effort was devoted to monitoring and evaluation, and subsequent correction: Given challenges of access, shifting security situation on the ground and very basic conditions, UNICEF allocated resources to tracking implementation of activities and evaluating the effectiveness of programmes. Evidence of effectiveness can be seen in the ongoing revision of its programme activities, at both the level of particular support, that is, services in such and such a community, and at the macro level of learning how to implement an education programme in a context like Somalia.

The breadth of activities was consciously varied; components in particular areas were added following the acceptance of earlier components: Adopting a modular approach, UNICEF standardized components of its programme, while varying their roll-out, maximizing scarce resources and variations and limitations in absorptive capacity.

\section{Local Ownership of the Programme/Project}

UNICEF developed close partnerships with local NGOs and other local and regional organizations, which were able to reach diverse communities. UNICEF partnered directly with communities, local and international NGOs and sometimes Koranic schools and religious leaders. The agency developed contracts with private businesses, and worked with various local authorities and emergent zonal government structures. Through these partnerships, UNICEF engaged many available partners and provided services to children, families and communities otherwise beyond reach. These organizations provided a kind of civil 


\section{DEVELOPMENT ASSISTANCE FOR PEACEBUILDING}

society infrastructure to support schooling and other services in the absence of formal national government. As nascent regional and sub-regional government structures emerged, UNICEF partnered with them to lay the foundation for a larger coordinated government effort. These multiple options allowed UNICEF and its international partners to exploit opportunities offered by the variety of 'state-building' organizations Somalia produced in the absence of central government, building on Somalia's vibrant civil and private sectors and variable capacity in the different zones. In particular:

Communities were given responsibility (and provided training) to assume a primary ownership, management role in schools: After the collapse of the government education system in 1991, various community entities, such as NGOs, parents, teachers, businesses and others, assumed responsibility for starting and running schools. Whatever schooling was offered was a result of community initiative. Even now, the vast majority of Somali schools are owned by private individuals or groups. While such a radical (unintended) decentralization does ensure community ownership of schooling, the challenge is to ensure equity, quality and access across varying circumstances. At the same time, it allows for considerable resilience in the system when government is absent or unable to provide support or when security conditions permit only local activity.

Coordination was critical: Coordination was important and time-consuming as programmes and funding were coordinated with international agencies and NGOs working in education and other sectors; with more than 100 partner agencies that UNICEF worked with within Somalia; with zonal and sub-zonal governments; and with bi- and multilateral funding agencies.

In recent years, external funding has increased to help support education in Somalia. Of recent note is five-year funding from the European Union and a grant from the GPE. The EU funding is particularly welcome because it provides longer-term support than past two- and three-year funding cycles, necessitated by the lack of stability on the ground.

\section{Programme/Project Design}

UNICEF assumed many responsibilities of a functioning education ministry, ensuring provision of a full complement of complementary inputs, sufficient to enable effective, if basic, classroom instruction. For instance:

In the emergency phase, the best technology available at the time - school kits - were deployed to support instruction: Due to the destruction of school infrastructure and supplies, school kits provided a basic set of supplies for teachers to begin teaching almost anywhere.

A foundational curriculum was developed, its content carefully negotiated with stakeholders for use in both secular and Islamic schools: Of note is the legitimacy UNICEF leveraged to promote child-centred education, gender equity and inclusion, in, according to available sources, a culturally appropriate manner.

A capacity development strategy, that is, training, was developed to prepare teachers, head teachers, supervisors, and CEC members: Local actors involved in primary education - those in school, providing supervisory support to the 


\section{DEVELOPMENT ASSISTANCE FOR PEACEBUILDING}

school and in the community - were trained in the curriculum and their responsibilities vis-à-vis education.

A basic data collection system was established early on: Prior to UNICEFsupported data collection, no information existed on the numbers and locations of schools, numbers of teachers and students, overall or by grade, gender and so on. Data collection, and development of EMIS in regional education offices in Somaliland and Puntland have allowed for better planning and targeting of services and helped establish credibility for a system of schools. Teacher training covers EMIS. The Somalia Multiple Indicator Cluster Survey (MICS) was introduced to collect data on a range of indicators of child welfare, in 1995 in Somaliland, in 1999 and 2006 for the whole country, and in 2011 for Somaliland and Puntland.

UNICEF programming supported linkages between emergency provision and long-term development: Programming provided support to the system at four stages on the continuum of crisis to sustainable development: (1) emergency responsiveness; (2) access to and delivery of quality services; (3) development of institutions and system capacity at local, regional and recently, national levels; and (4) participation and empowerment of users. These efforts, along with the systemic elements of curriculum, training, information and so on, provide conditions conducive to development of appropriate policy, legal frameworks and administrative offices. ${ }^{39}$

Timing: In contrast to stable contexts of most development programmes, conditions shifted rapidly during the protracted conflict in Somalia. Reverses were common and cumulative progress slow. As a result, UNICEF had to programme with unusual flexibility.

UNICEF varied the level and nature of its activities according to capacities of partners and stability of areas at each particular time. The agency had sufficient information on varying conditions on the ground and sufficient flexibility in its programming to modulate support according to opportunity, need, and capacity. This flexibility meant that windows of opportunity could be exploited and partners mentored as conditions as capacity developed and conditions changed.

\section{Conclusion}

Bi- and multilateral development assistance is premised on a system of functioning national states. International development does not work well when states fail, as in Somalia, or when their effectiveness is undermined by fragility. Yet the development and humanitarian needs of people living in such contexts are generally greater than of people living in developing states.

Twenty-eight million children, 40 per cent of the world's total number of children not in school, live in countries affected by current or past armed conflict. To the extent that lack of educational opportunity fuels conflict, that is a great loss of opportunity for positive peace-building. Most recent conflicts are within rather than between states. Increasing numbers of non-state actors have emerged at the same time that state failure has heightened the importance of state fragility. ${ }^{40}$ Hagmann and Hoehne discuss the multiple forms that state-building, properly 


\section{DEVELOPMENT ASSISTANCE FOR PEACEBUILDING}

conceived, has taken in Somalia. ${ }^{41}$ The misconception of a central state authority as the only functional form of governance has led to the assumption that the alternative to functional central government is chaos. In this case, UNICEF recognized, by necessity no doubt, that other governing entities would have to be involved for educational services to be delivered in the complex and shifting conditions of Somalia.

Ongoing engagement with actors in different types of governing entities, especially involving groups such as communities with an interest in sustaining services, helps build the foundation for longer-term development activities involving at some point even the state. The lesson from UNICEF's work in Somalia is that some of the peace-building and state-building functions of education can begin under the most fragile of conditions.

\section{ACKNOWLEDGEMENTS AND FUNDING}

The authors gratefully acknowledge generous support for this research from the United Nations University, WIDER, Helsinki, Finland.

\section{NOTES}

1. UNICEF, 'The Role of Education in Peacebuilding: Literature Review', 2011 (at: www.unicef. org/education/files/EEPCT_Peacebuilding_LiteratureReview.pdfwww.unicef.org/education/files/ EEPCT_Peacebuilding_LiteratureReview.pdf).

2. Ibid.

3. UNESCO, 'Learning: The Treasure within', 1996 (at: http://unesdoc.unesco.org/images/0010/ 001095/109590eo.pdfhttp://unesdoc.unesco.org/images/0010/001095/109590eo.pdf).

4. GEFI, Global Education First Initiative, United Nations, 2015 (at: www.globaleducationfirst.org/ 220.htm).

5. K. Bush and D. Saltarelli, The Two Faces of Education in Ethnic Conflict: Towards a Peacebuilding Education for Children, Florence: Innocenti Research Centre, 2000.

6. Ibid, p.vi.

7. UNESCO, 'The Hidden Crisis: Armed Conflict and Education: Education for All', Global Monitoring Report, Paris: UNESCO, 2011.

8. Bush and Saltarelli (see n.5 above), p.vi.

9. See, e.g., Martin Carnoy, Education and the State, Princeton, NJ: Princeton University Press, 1984. 


\section{DEVELOPMENT ASSISTANCE FOR PEACEBUILDING}

10. For a discussion of the multiple ways 'state-building' manifested itself in Somalia, see T. Hagmann and M.V. Hoehne, 'Failures of the State Failure Debate: Evidence from the Somali Territories', Journal of International Development, Vol.21, No.1, 2009, pp.42-57.

11. GEFI (see n.4 above).

12. K. Menkhaus, 'State Failure, State-Building, and Prospects for a "Functional Failed State" in Somalia', ANNALS of the American Academy of Political and Social Science, Vol.656, No.1, 2014, pp.154-72.

13. C.T. Call, 'Beyond the "Failed State": Toward Conceptual Alternatives', European Journal of International Relations, Vol.17, No.2, 2011, pp.303-26; J.G. Gros, 'Towards a Taxonomy of Failed States in the New World Order: Decaying Somalia, Liberia, Rwanda and Haiti', Third World Quarterly, Vol.17, No.3, pp.455-71; Hagmann and Hoehne (see n.10 above).

14. S.A. Bekalo, M. Brophy and A.G. Welford, 'The Development of Education in Post-Conflict "Somaliland"', International Journal of Educational Development, Vol.23, No.4, 2003, pp.459-75; http://dx.doi.org/10.1016/S0738-0593(03)00016-6P. Moyi, 'Girl's Schooling in War-Torn Somalia', International Journal of Educational Research, Vol.53, 2012, pp.201-12; http://dx.doi.org/10.1016/j.ijer.2012.03.010P. Moyi, 'Who Goes to School? School Enrollment Patterns in Somalia', International Journal of Educational Development, Vol.32, No.1, 2012, pp.163-71. http://dx.doi.org/10.1016/j.ijedudev.2010.09.002

15. UNICEF, State of the World's Children 1998: Focus on Nutrition, New York: UNICEF, 1998.

16. See Government of Somalia, Interim Education Sector Strategic Plan, 2013-2015, Mogadishu: Ministry of Human Development and Public Service; Puntland State of Somalia, Puntland Education Sector Strategic Plan, 2012-2016, Garoowe: Ministry of Education; Somaliland Government, Somaliland Education Sector Development Plan, 2012-2016, Hargeisa: Ministry of Education and Higher Education, 2012.

17. UNICEF, Against All Odds, New York: UNICEF (at: www.unicef,org/somalia/SOM NewDawndoc.pdf), accessed 15 May 2015.

18. Ministry of National Planning, Somalia: Education and Human Resources Sector Assessment, Mogadishu: Government of Somali Democratic Republic with the United States Agency for International Development (USAID), 1984 (at: http://pdf.usaid.gov/pdf_docs/pnaap769.pdfhttp://pdf. usaid.gov/pdf_docs/pnaap769.pdf).

19. UNICEF, Against All Odds (see n.17 above).

20. Ibid.

21. Ibid.

22. Moyi, 'Girl's Schooling in War-Torn Somalia' (see n.14 above); Moyi, 'Who Goes to School?' (see n.14 above).

23. World Bank, World Bank Indicators, Washington, DC: World Bank, 2013 (at: www. tradingeconomics.com/somalia/school-enrollment-secondary-percent-gross-wb-data.htmlwww. tradingeconomics.com/somalia/school-enrollment-secondary-percent-gross-wb-data.html).

24. W.K. Cummings, Somalia Education Sector Assessment: With Special Attention to Northwest Zone, Washington, DC: BEPS/USAID, 2003 (at: www.beps.net/publications/SomaliaEducation SectorAssessmentFinalReport.doc.pdfwww.beps.net/publications/SomaliaEducationSectorAssess mentFinalReport.doc.pdf).

25. UNICEF, Against All Odds (see n.17 above).

26. UNICEF, 'Somalia: Country Programme Evaluation Report', Nairobi: UNICEF, 2002 (at: unicef. org/evaldatabase/files/SOM_02-013_cpe.pdf).

27. UNICEF, 'UNICEF Annual Report for Somalia', New York: UNICEF, 2010 (at: www.unicef. org/somalia/Somalia_2010_annual_report_final.pdfwww.unicef.org/somalia/Somalia_2010_ annual_report_final.pdf); Cummings, Somalia Education Sector Assessment (see n.24 above); UNICEF, 'Somalia' (see n.26 above); UNICEF, Against All Odds (see n.17 above).

28. UNICEF, 'UNICEF Annual Report' (see n.27 above); Cummings, Somalia Education Sector Assessment (see n.24 above); UNICEF, 'Somalia' (see n.26 above).

29. UNICEF, Against All Odds (see n.17 above).

30. UNICEF, 'UNICEF Annual Report' (see n.27 above); UNICEF, 'Somalia' (see n.26 above); UNICEF, Against All Odds (see n.17 above).

31. Ibid.

32. UNICEF, 'Education in Emergencies and Post-Crisis Transition (EEPCT): Consolidated Progress Report to the Government of the Netherlands and the European Commission', New York: UNICEF, 2011 (at: www.educationandtransition.org/wp-content/uploads/2011/07/2010_EEPCT_ Consolidated_Report_30June2011.pdf)

33. UNICEF, 'UNICEF Annual Report' (see n.27 above); UNICEF, 'Somalia' (see n.26 above); UNICEF, Against All Odds (see n.17 above). 


\section{DEVELOPMENT ASSISTANCE FOR PEACEBUILDING}

34. Ibid.

35. Cummings, Somalia Education Sector Assessment (see n.24 above); UNICEF, 'UNICEF Annual Report' (see n.27 above); UNICEF, 'Somalia' (see n.26 above); UNICEF, Against All Odds (see n.17 above).

36. Ibid.

37. Ibid.

38. UNICEF, 'UNICEF Annual Report' (see n.27 above).

39. UNICEF, 'Somalia' (see n.26 above).

40. UNESCO, 'The Hidden Crisis' (see n.7 above).

41. Hagmann and Hoehne, 'Failures of the State Failure Debate' (see n.10 above). 


\title{
The World Bank's Health Projects in Timor-Leste: The Political Economy of Effective Aid
}

\author{
ANDREW ROSSER and SHARNA BREMNER
}

The World Bank's health sector projects in Timor-Leste have been among the few operations it has funded in that country that have achieved any sort of positive results. This paper examines the factors underpinning their relative success and considers the wider lessons for the delivery of effective aid in the context of peace-building operations in fragile contexts. We argue that political economy factors played an important role in shaping the relative success of these projects, extending and revising an earlier analysis by Rosser. In terms of wider lessons, we argue for a more political understanding of the determinants of aid effectiveness. Specifically we suggest that aid effectiveness needs to be seen as a function not just of the technical quality of project design and the administrative competence of project managers but also the extent to which there is congruence between donor and local elites' agendas.

\section{Introduction}

The World Bank has invested heavily in promoting the reconstruction and development of the Democratic Republic of Timor-Leste (hereafter Timor-Leste) since Indonesia's violent withdrawal from the territory ${ }^{1}$ in 1999. It was a key part of various donor missions that planned the territory's reconstruction in 19992000 and it has overseen a substantial grant programme there ever since. Yet the returns on this investment have been modest, even by the Bank's own assessment: in a report issued in 2011, the Independent Evaluation Group (IEG), the Bank's evaluation arm, rated the vast majority of the Bank's project and sector outcomes in Timor Leste as either 'unsatisfactory' or 'moderately unsatisfactory'. ${ }^{2}$ One of the few sectors in which the Bank has achieved some positive results is health. In its review, the IEG rated the Bank's major health projects the Health Sector Rehabilitation and Development Project (HSRDP I) and the Second Health Sector Rehabilitation and Development Project (HSRDP II) - 'satisfactory' and 'moderately satisfactory' respectively. Although both projects experienced significant delays and failed to achieve results in certain areas, they were credited with having made a substantial contribution to the rehabilitation of Timor Leste's health system, improved governance within the sector and made improvements in a range of health indicators including immunization rates and health service utilization rates. ${ }^{3}$

The purpose of this article is to explore the factors that have shaped the World Bank's relative success in Timor-Leste's health sector. It also considers the wider

This is an Open Access article distributed under the terms of the Creative Commons Attribution-NonCommercial-NoDerivatives License (http://creativecommons.org/Licenses/by-nc-nd/4.0/), which permits noncommercial re-use, distribution, and reproduction in any medium, provided the original work is properly cited, and is not altered, transformed, or built upon in any way. 


\section{DEVELOPMENT ASSISTANCE FOR PEACEBUILDING}

lessons of the Bank's experience for the delivery of effective aid in the context of peace-building operations in fragile contexts. Much commentary on the HSRDPs has suggested, either implicitly or explicitly, that good design and management was a key factor in their success. ${ }^{4}$ We argue that political economy factors also played an important role, extending and revising Rosser's earlier analysis of these factors. ${ }^{5}$ In particular, we suggest that the HSRDPs benefitted from (a) a political economy context that was relatively conducive to aid effectiveness in general and (b) the fact that there was relatively little elite resistance to the World Bank's agenda in the health sector. In terms of wider lessons, the article thus reinforces arguments for a more political understanding of the determinants of aid effectiveness, in particular ones that emphasize the role of competing coalitions of interest in shaping state policy and the uses of aid. ${ }^{6}$

In presenting this analysis, we begin by examining the country context in which the two projects were established, focusing on Timor-Leste's health situation in 1999. We then examine the nature of the two projects and the results they achieved before moving on to our explanation of their relative success, bringing in the World Bank's performance in the education sector for comparative purposes. The final part of the article assesses the lessons of the Bank's experience in Timor-Leste for our understanding of the determinants of aid effectiveness in fragile contexts.

\section{The Country Context}

When the World Bank began its first operations in post-Indonesian East Timor as Timor-Leste was known during the years of Indonesian occupation (1975-99) and UN transitional administration (1999-2002) - in 1999, the territory was among the least developed in the world, reflecting centuries of oppressive and violent rule, underinvestment in the territory's economic development and the widespread destruction that accompanied Indonesia's withdrawal. While the Indonesian government transferred substantial resources to East Timor during its occupation, much of these went into funding Indonesian military forces and a bureaucracy staffed largely, at least at the most senior levels, by Indonesians. ${ }^{7}$ Development outcomes were poor. Timor's Human Development Index (HDI) was just 0.395 in 1999, placing it in 152 nd place out of the 162 countries for which HDIs were calculated that year. Poverty indicators were high, with 41 per cent of the population living below the national poverty line of $\$ 0.55$ per person per day, over half the population were illiterate and maternal mortality rates were extremely high with 420 women dying for every 100,000 live births. ${ }^{8}$

In August 1999, the Indonesian government, under international pressure, organized a plebiscite on the territory's future. This resulted in a massive vote in favour of independence and in turn triggered a wave of orchestrated violence by pro-Indonesian militias backed by the Armed Forces. In this context, troops from the International Force for East Timor (INTERFET) arrived in East Timor to restore security and address the intensifying humanitarian crisis. A team of experts known as the Joint Assessment Mission to East Timor visited 


\section{DEVELOPMENT ASSISTANCE FOR PEACEBUILDING}

the nation shortly after the arrival of INTERFET troops to examine the existing situation and identify short-term relief and reconstruction priorities, as well as longer-term development requirements. It noted that there was severe psycho-social stress, food insecurity, population displacement and that water and sanitation systems had collapsed. ${ }^{9}$

The territory's health situation was particularly precarious. During their occupation, the Indonesians had assembled a territory-wide health system, comprised of Indonesian government-run hospitals and clinics, and district-based health centres that were operated by approximately 160 doctors and 2000 nurses and midwives. In 1999, most doctors, many of whom were Indonesian, fled the territory, leaving just 30 behind. Most senior health administrators left as well. ${ }^{10} \mathrm{At}$ the same time, health care facilities were intentionally targeted during the 1999 violence, with one-third being severely damaged or destroyed entirely. An assessment conducted in January 2000 found that two-thirds of Timor's health facilities were without mains electricity or essential medical equipment, while almost half were without mains water. ${ }^{11}$ Finally, the crisis displaced huge numbers of people from their homes: between 520,000 and 620,000 people, an estimated 65-80 per cent of the total population, ended up residing in Internally Displaced Persons (IDP) camps in East Timor or West Timor. The result was that the majority of the population was without access to adequate medical care, food, shelter, clean water and sanitation for some time. There was strong concern that such conditions would lead to high levels of malnutrition, escalated risks of disease outbreaks and increases in mortality due to diarrhoeal disease, vaccine preventable diseases, malaria, upper respiratory diseases and mental health problems. ${ }^{12}$

In the immediate aftermath of the Indonesian withdrawal, civil society organizations played the key role in health service delivery. The Catholic Church and religion-based charities had provided health services throughout the years of Indonesian occupation, operating small hospitals and local clinics. ${ }^{13}$ Following the Indonesian withdrawal, they were joined by a flood of international NGOs that arrived to provide emergency services. These included the International Committee of the Red Cross, World Vision International and Médecins Sans Frontières. The efforts of the Catholic Church and other NGOs combined saw 71 health facilities established by February 2000, in comparison to the 96 facilities that were operating prior to the violence. These facilities operated at a subdistrict level or higher, meaning that health services for many Timorese were limited, particularly those residing in rural villages. ${ }^{14}$

The Joint Health Working Group (JHWG), a team of representatives from UN agencies, the NGO community and Timorese health professionals from the East Timorese Health Professionals Working Group (ETHPWG) provided an initial means of coordination. Following the establishment of the United Nations Transitional Administration in East Timor (UNTAET) in October 1999, the JHWG developed plans to establish a local health authority to rebuild and administer the health system in Timor and agreed to a minimum set of standards at a workshop in February 2000. After this workshop, an Interim Health Authority (IHA) was established as part of UNTAET. The IHA was a joint international-Timorese body - something that made it distinct 


\section{DEVELOPMENT ASSISTANCE FOR PEACEBUILDING}

from most other parts of UNTAET - and became the de facto 'Ministry of Health'. ${ }^{15}$ Led by Dr Jim Tulloch, the head of the UNTAET Office of Health, and Dr Sergio Lobo, a founding member of the ETHPWG and East Timor's only qualified surgeon, it consisted of 16 East Timorese health professionals at the central level, an additional 13 at the district level and 6 UNTAET health staff. $^{16}$

\section{The HSRDPs}

\section{Overview of Projects}

To address the burgeoning health crisis, the IHA and foreign donors agreed that two health projects should be funded through the Trust Fund for East Timor (TFET), a multi-donor facility established under World Bank and Asian Development Bank auspices to fund grants for projects in key sectors such as energy infrastructure, health, education and governance. The first, HSRDP I began in mid2000 while HSRDP II began in mid-2001. Both were supported by grants from the World Bank while the latter was also supported by a grant from the European Union. ${ }^{17}$

HSRDP I sought to provide immediate, short-term health services and prepare long-term services, frameworks and policies that were appropriate to the conditions of East Timor. ${ }^{18}$ To this end, it consisted of two main components: (1) restoring access to basic health services; and (2) health policies and health systems development. The first of these components was designed to address immediate health needs. It had a short-term focus and involved a number of subcomponents, namely:

a) a transitional strategy for service provision centred on the contracting of NGOs to provide the delivery of high priority programmes at the district level;

b) the establishment of a pharmaceutical logistics system to ensure the timely availability of drugs and medical supplies, including the construction of a central warehouse and the development and adoption of an essential drug list and standard guidelines;

c) the rehabilitation and equipping of a number of health facilities;

d) the establishment of a referral system and facilities through ambulance and radio supply;

e) capacity strengthening within the health system through training on service delivery, administration and management responsibilities; and

f) a small grants scheme to enable community organizations and professional associations to carry out health promotion activities. ${ }^{19}$

The second component of HSRDP I had a longer-term focus. It aimed to develop a functioning health system and sound health policies, and also comprised a number of subcomponents: (a) policy development to provide input into the role of the government and financing of the health sector, while 


\section{DEVELOPMENT ASSISTANCE FOR PEACEBUILDING}

supporting the development of a Health Policy Framework; (b) designing a health system, including a baseline demographic and health survey to assist future development, designing a logistics system for pharmaceuticals and the construction of health legislation and regulations; and (c) a strategy to develop human resources based on the profile of existing health staff. ${ }^{20}$

In mid-2001, donors and the successor to the IHA, the Division of Health Services, agreed that a second project should be funded to continue and expand the progress made under HSRDP I. Whereas HSRDP I focused on the provision of basic health services and the establishment of public health initiatives such as immunization programmes, HSRDP II aimed to increase the utilization of health services and increase the quality of care. It had three components: (1) supporting ongoing service delivery through technical assistance to health sector managers, particularly at a district level, as well as via the supply of pharmaceuticals to health facilities; (2) improving the range and quality of services and implementing support systems, with a particular emphasis on re-equipping hospitals, standardizing service delivery and strengthening referral systems and creating an effective Autonomous Medical Supply entity (to be named SAMES); and (3) the development and implementation of health sector policies and management systems, including through development of a Human Resource Management Strategy and financial management capacity-building activities. ${ }^{21}$

During HSRDP I, there was a heavy reliance on international NGOs to deliver health services, reflecting the fact that the government (i.e. UNTAET) lacked the capacity to deliver these services itself. Agreements were reached whereby NGOs continued to act as the primary health care providers, but were regulated by a Memorandum of Understanding between them and the government. ${ }^{22}$ HSRDP II aimed to shift the responsibility for service provision from NGOs to the government in an effort to reduce the high costs associated with international organizations, while also addressing concerns about Timorese control over the health system. District health management teams (DHMTs) replaced NGOs in the delivery of basic services at the local level and plans were made to encourage expatriate East Timorese doctors to return home, and to recruit doctors from other developing countries to take the place of Western doctors who had been employed by the NGOs. ${ }^{23}$ Both the HSRDP I and HSRDP II contained a set of key performance indicators that were used to measure project performance as well as that of the overall health system (Table 1).

\section{Outcomes}

Both projects experienced significant difficulties. There were substantial delays in the construction and rehabilitation of health centres and the rehabilitation of regional hospitals, the main hospital in Dili and the Central Lab, due to, among other things, the complexity of the World Bank's procurement procedures. ${ }^{24}$ SAMES experienced problems as a result of underqualified staff and language differences, the latter being an obstacle to knowledge and skill transfers from expatriate to local staff. Weak forecasting of demand due to a lack of good quality health data was partially responsible for US\$2.66 million in overstocked and expired drugs at SAMES in early $2004 .{ }^{25}$ A 2012 review found that stock- 
TABLE 1

HSRDP I AND II PROJECT DEVELOPMENT OBJECTIVES

\begin{tabular}{|c|c|c|c|}
\hline Indicator & $\begin{array}{l}\text { Baseline } \\
\text { value } \\
\text { (2001) }\end{array}$ & $\begin{array}{l}\text { Original target } \\
\text { values (from } \\
\text { approval } \\
\text { documents) }\end{array}$ & $\begin{array}{l}\text { Actual value achieved at } \\
\text { completion or target years }\end{array}$ \\
\hline $\begin{array}{l}\text { 1: Percentage of children under } \\
1 \text { year of age immunized } \\
\text { against measles in each } \\
\text { district }\end{array}$ & $20 \%$ & $50 \%$ & $63 \%$ \\
\hline Date achieved & $\begin{array}{l}1 \text { June } \\
2001\end{array}$ & 30 June 2003 & 31 December 2007 \\
\hline $\begin{array}{l}\text { 2: National percentage of births } \\
\text { with skilled attendance }\end{array}$ & $20 \%$ & $35 \%$ & $37.3 \%$ \\
\hline Date achieved & $\begin{array}{l}1 \text { June } \\
2001\end{array}$ & 30 June 2003 & 31 December 2007 \\
\hline $\begin{array}{l}\text { 3: Percentage of population } \\
\text { with access to basic health } \\
\text { services within two hours } \\
\text { from home }\end{array}$ & $60 \%$ & $95 \%$ & $\begin{array}{l}\text { N.A. (Note: this } \\
\text { measurement was deemed } \\
\text { unreliable by the Ministry of } \\
\text { Health) }\end{array}$ \\
\hline Date achieved & $\begin{array}{l}30 \text { June } \\
2001\end{array}$ & 30 June 2003 & 31 December 2007 \\
\hline $\begin{array}{l}\text { 4: Number of outpatient visits } \\
\text { per person per year at each } \\
\text { health facility }\end{array}$ & 1 & 2.5 & 1.9 \\
\hline Date achieved & $\begin{array}{l}30 \text { June } \\
2001\end{array}$ & 30 June 2002 & 31 December 2007 \\
\hline $\begin{array}{l}\text { 5: Percentage of health facilities } \\
\text { reporting no stock-outs of } \\
\text { essential drugs lasting more } \\
\text { than two weeks in the } \\
\text { previous quarter }\end{array}$ & $60 \%$ & $90 \%$ & $87 \%$ \\
\hline Date achieved & $\begin{array}{l}1 \text { June } \\
2001\end{array}$ & 30 March 2003 & 31 December 2007 \\
\hline
\end{tabular}

Source: World Bank, 'Implementation Completion and Results Report on Grants in the Amount of US\$12.6 Million (TF-51363) and Euro 16.2 Million (TF-51363) to Timor-Leste for a Second Health Sector Rehabilitation and Development Project', Dili: World Bank, 2009, pp.iii-iv.

outs of essential medicines were common, language differences were a continuing hurdle and a lack of coordination between the Ministry of Health, Department of Pharmacy, SAMES staff, medical practitioners and pharmacists was resulting in logistical problems. ${ }^{26}$ Finally, neither project addressed Timor Leste's shortage of qualified medical personnel. Both included components aimed at increasing the capacity of the Timorese workforce but these were focused on administrative and bureaucratic activities rather than the supply of medical personnel. ${ }^{27}$ In the end, Timor Leste struck a deal with Cuba that saw a large contingent of Cuban doctors sent to Timor to service national, regional and rural hospitals and health clinics and Timorese students studying medicine in Cuba. In 2005, a Faculty of Medicine was opened at the National University and students were no longer sent to Cuba, but were enrolled in the new Cuban-operated Faculty. ${ }^{28}$

Nevertheless, the HSRDPs made a positive contribution to the rehabilitation and development of Timor-Leste's health sector in two respects. First, they helped 


\section{DEVELOPMENT ASSISTANCE FOR PEACEBUILDING}

to transform the country's health system from a state of almost total devastation following the violence in 1999 into a functioning health service. The immediate basic health needs of the population were met due to the rehabilitation of health care facilities and other infrastructure, the procurement and distribution of essential medications and supplies and strengthened planning and implementation of health services at the district level. Project monitoring and evaluation showed increases in immunization rates and the number of births that were attended by a skilled health worker, while the average travel time from one's home to a health facility decreased for a large portion of the population following the implementation of the projects. ${ }^{29}$ The poor quality of baseline data makes it difficult to judge the precise extent of improvement in these respects. But the overall trend is fairly clear. There have also been improvements in health service utilization rates, the fertility rate and infant and maternal mortality. ${ }^{30}$

Second, the HSRDPs contributed to improved health sector governance. A major contribution of the first project was the preparation of district health plans for the 12 districts outside of Dili. This was a task that was considered to be 'beyond the capacity of the IHA alone' and was the first step towards the IHA being viewed as a legitimate government body. ${ }^{31}$ In late 2001, just over 18 months after the devastation that followed the independence vote, a Timorese-run Ministry of Health had been established and over 800 health staff had been recruited. ${ }^{32}$ The implementation of the HSRDPs also saw the production of the Health Policy Framework which outlined the strategic policy direction of the Ministry of Health, based upon its Mission Statement: 'the Mission of the Ministry of Health is to strive to ensure the availability, accessibility and affordability of health services to all East Timorese people, to regulate the health sector and to promote community and stakeholders participation'. ${ }^{33}$ Finally, despite SAMES's difficulties, its establishment provided a mechanism for the distribution of medical supplies. Its establishment was an improvement on the state of total disarray during the Indonesian occupation and following the violence in 1999.

Overall, it is probably fair to say that the two projects' achievements were modest. But compared to most other World Bank interventions in Timor Leste, their contribution to the country's development has been relatively positive. In this respect, a comparison with the Bank's projects in Timor Leste's education sector, also implemented through TFET, is informative. Remarkable progress was made in both sectors in terms of reconstructing and rehabilitating facilities and making them operational again. Huge numbers of schools and health facilities were rebuilt, large numbers of teachers and medical personnel recruited and school enrolment rates and health facility usage rates increased. But there was a marked difference in the quality and effectiveness of the services delivered. The resumption of basic health services led to significant improvements in a range of health-related indicators. By contrast, there is little evidence to suggest that school students' skills and abilities have improved. For instance, a 2009 assessment of reading ability showed that 'many children spend years in primary schools in Timor-Leste without learning to read'. 34 


\section{DEVELOPMENT ASSISTANCE FOR PEACEBUILDING}

\section{Explaining the HSRDPs' Effectiveness}

What explains this relatively positive outcome? As noted earlier, much commentary on the HSRDPs has suggested, either implicitly or explicitly, that the projects benefitted from good design and management. Yet our concern here is with the role of political factors in shaping this outcome. In an earlier paper researched and written in 2004-05, Rosser argued that the HSRDPs benefitted from a relatively favourable political economy context, reflecting five aspects of Timor Leste's political economy. ${ }^{35}$ First, donor funding for Timor Leste was relatively generous in the years immediately following Indonesia's withdrawal and for health in particular because of the 'political attractiveness of emergencies and the undeniable health needs in such situations' ${ }^{36}$ and public pressure on many Western governments to make amends for having effectively abandoned East Timor after the Indonesian invasion in 1975. Second, Timor Leste's dependence on aid income and vulnerability in security terms meant that the government had a strong incentive to cooperate closely with donors and make a concerted effort to achieve development results. To do otherwise would have jeopardized relationships crucial to the new nation's survival. Third, the country's Health Minister during the Fretilin government (2002-07), Rui Maria de Araujo, had strong technical, leadership and administrative skills. Fourth, decision-making authority both in general and in relation to health policy in particular was concentrated in the hands of the Council of Ministers (i.e. the cabinet), reflecting the ruling party Fretilin's dominance of the national parliament. This made the HSRDP's policy and institutional development work much easier politically than it would have been had the political system been more fragmented and parliament exercised strong oversight of the executive's activities. Finally, between 2000 and 2005, the country was relatively politically stable, allowing its political leaders to focus on promoting economic and social development and reducing the risk that renewed violent conflict would result in the destruction of rehabilitated health infrastructure.

Most of these conditions changed after 2005. Most notably, the country's political stability was brought to a dramatic end following the government's dismissal of roughly one-third of the country's armed forces in early 2006. The dismissal triggered widespread violence, the displacement of tens of thousands of people, an Australian-led intervention to restore stability, the resignation of then Prime Minister Mari Alkatiri, an assassination attempt on then President Jose Ramos Horta and ultimately a change of government in 2007. The subsequent Parliamentary Majority Alliance (AMP) government, a multi-party coalition, has lacked the coherence and discipline of the previous government. ${ }^{37}$ This did not prevent the government's re-election in 2012 with a slightly different configuration of political parties. But it has meant that policy making has been more contested than under the Fretilin government. Finally, since 2002 aid to Timor Leste has declined slightly in constant \$US and per capita terms and fallen dramatically as a proportion of Gross National Income (GNI), reflecting the growing importance of oil to Timor Leste's economy as a result of the exploitation of Timor Sea oil reserves. With the government less reliant on aid, donors have exercised 


\section{DEVELOPMENT ASSISTANCE FOR PEACEBUILDING}

less leverage over policy than previously. The main line of continuity with the pre2006 period has been in relation to leadership of the Health Ministry. As under the Fretilin government, this ministry has continued to be led by figures with relatively strong technical, leadership and administrative skills, although the standing of the current Minister has been undermined by a scandal related to domestic violence. ${ }^{38}$

Despite the changes since 2006, however, it is still fair to say that Timor-Leste has offered a relatively favourable political economy context to donors engaged in peace-building efforts. The country has not descended into civil war, experienced a major economic crisis (in fact, it has progressed from low income to lower middle income country status in the World Bank's classifications, thanks largely to increased oil revenues) or suffered a military coup (although it came close to one in 2006). In this respect, it has been different to many other post-conflict societies.

Noting that the broad political economy context has been relatively conducive to aid effectiveness does not explain, however, why the World Bank's experience in Timor Leste has differed so dramatically across sectors (or indeed why its performance overall has been so poor). To explain this, we need to understand the politics of each of these sectors and the extent to which this politics constrained the World Bank's ability to promote its development agenda. The point, as we will show below, is that the World Bank's agenda encountered much less resistance from domestic political elites in the health sector than in other sectors. In the health sector, domestic political elites offered tactical support to the Bank or, at least, were able to engineer an accommodation between the Bank's policy agenda and alternative policy agendas.

\section{The Political Economy of Relative Success}

To illustrate the way in which political factors have shaped outcomes for the World Bank in Timor Leste's health and education sectors, we begin by identifying the main actors involved in struggles over development policy in Timor Leste since 1999 and then examine the way in which their interests, agendas and forms of leverage over the policy-making process shaped policy outcomes in these sectors.

\section{The Contending Actors}

From the end of Indonesian occupation in Timor Leste in 1999 until the mid2000 s political and social power in that territory was concentrated in the hands of Western donors; that is, the various Western governments that have had bilateral aid programmes in the territory and the multilateral organizations over which these governments exercise enormous influence. Their power was arguably at its height in the two to three years immediately following the Indonesian withdrawal when the United Nations Transitional Administration in East Timor (UNTAET), the body established to govern the territory until independence, was formally the sovereign power. ${ }^{39}$ But they remained powerful after the territory gained independence in May 2002 because of their importance as 


\section{DEVELOPMENT ASSISTANCE FOR PEACEBUILDING}

a source of funding and their role in guaranteeing Timor Leste's security. Their influence has declined somewhat since the government of Timor Leste started to receive substantial income from the oil and gas sector in the mid-2000s. With alternative investment resources at its disposal, the government has been less dependent on donors and consequently had far greater autonomy in devising policy than in the period before the mid-2000s. In broad terms, donors' agenda has been to promote policy and institutional reforms aimed at ensuring the emergence and proper functioning of a liberal market economy and liberal democratic political system. ${ }^{40}$ In particular, it has promoted fiscal rectitude and accountability, the liberalization of trade and foreign investment regimes, the rule of law, reduced corruption and the delivery of quality public services on an affordable basis.

A second set of actors that has shaped development policy in Timor Leste since 1999 is the leadership of Fretilin, the dominant political party in the period between 2002 and 2007. The Fretilin leadership's power stemmed from two main sources: its control of parliament during this period and party members' occupation of key positions in the state apparatus. In the 2001 national elections Fretilin won 57 percent of the vote, less than expected but enough for it to secure 55 out of a total 88 seats in the national parliament. With the support of the Timorese Social Democratic Party (ASDT), which won six seats in parliament, it held enough votes to pass a national Constitution in 2001 that, in establishing a semi-presidential rather than the presidential political system, ${ }^{41}$ ensured that the party in control of parliament played the central role in policy making. After the election, the Fretilin leadership appointed party members to senior political and bureaucratic positions, giving it further influence over policy formulation as well as influence over the implementation of policy. Since losing the 2007 election, however, its influence through both mechanisms has declined. In broad terms, the Fretilin leadership supported much of the donor development agenda $^{42}$ during its time in government despite having a formal commitment to Marxism-Leninism for most of the Indonesian occupation. ${ }^{43}$ This likely reflected a tactical judgement that the party's electoral interests were best served by keeping donor funds flowing and, in so doing, providing a basis for economic survival and the re-establishment of public services. Its support for a neoliberal democratic agenda was, however, tempered by nationalist concerns to define a distinct East Timorese national identity and promote national strength and resilience. $^{44}$

A third set of actors that has shaped development policy in Timor Leste is the leadership of Falintil, the armed wing of the resistance movement during Indonesian occupation, and associated organizations. In 2001, Falintil was dissolved as its members were either decommissioned or recruited into the Armed Forces (F-FDTL). The power of the Falintil leadership has stemmed in part from its influence over the F-FDTL and its consequent ability to use violence, legitimately or illegitimately, in pursuit of its objectives; ${ }^{45}$ its ability to influence popular opinion and mobilize large numbers of people for demonstrations and other forms of collective action, reflecting the fact that Falintil leaders are widely regarded as national heroes; and its control over key parts of the state apparatus, 


\section{DEVELOPMENT ASSISTANCE FOR PEACEBUILDING}

especially the presidency and from 2007 the national parliament. Within this group, Xanana Gusmão has been the dominant figure. He was the head of Falintil during the Indonesian occupation and, following a landslide election victory in early 2002, became President of Timor Leste from 2002 to $2007 .{ }^{46}$ In the run-up to the 2007 elections, he vacated the presidency in an attempt to seize control of parliament away from Fretilin, establishing the National Congress for Timorese Reconstruction (CNRT) as an electoral vehicle. The CNRT won 24 per cent of the vote, enough to allow it to form government in coalition with a diverse group of other parties and deliver Gusmão the prime ministership (a more powerful position than the presidency). As noted above, the AMP government was re-elected in 2012. At the same time, another Falintil leader, Taur Matan Ruak was elected President.

In terms of policy, the CNRT has lacked a clear platform. ${ }^{47}$ In public statements, Gusmão has expressed support for liberal market economic policies ${ }^{48}$ and in government the CNRT has overseen an overall shift in development policy towards a more market-based approach. ${ }^{49}$ But, like the Fretilin leadership, Gusmão and the CNRT's support for neoliberal reform has most likely been tactical in nature - reflecting a desire to maintain good relations with the international community and keep donor funds flowing - and been tempered by a concern to promote national strength and resilience. It has also been tempered by a desire to ensure that the F-FDTL has adequate access to financial resources. ${ }^{50}$ Finally, the government's burgeoning oil wealth has enabled Gusmão and other AMP leaders to encourage a form of patronage politics that one observer has characterized as 'runaway state-building. ${ }^{51}$

A number of other actors have also sought to shape development policy in Timor Leste post-1999 but, in general, had much less impact than the aforementioned three sets of actors. These include the Catholic Church, the minor political parties, local NGOs and martial arts, veterans and extremist groups. During the Indonesian occupation, the Catholic Church became a lightning rod for Timorese grievances against the Indonesian government and military, reflecting the fact that Timor Leste is predominantly Catholic while Indonesia is predominantly Moslem and the fact that military rule meant that few other institutions existed in Indonesian East Timor that might perform this role. But since 1999, its role as a lightning rod for grievances has declined as the major cleavages in Timorese politics have become ones within the Timorese community, rather than between this community and Moslem outsiders. At the same time, senior Church figures were excluded from the Fretilin government, as the Fretilin leadership sought to reserve formal political authority for itself, although they did exercise influence over some issues, particularly ones of religious significance: in 2004, for instance, they persuaded the Fretilin government to endorse natural methods of family planning alongside the use of contraception as part of its family planning policy. The AMP government has 'adopted a much more engaged approach to the Church', steering significant resources its ways for anti-violence programmes, Church buildings and renovations and accommodating Church concerns on issues such as the criminalization of prostitution and abortion. ${ }^{52}$ But its role in policy making has been minor compared to the actors mentioned above, reflecting 


\section{DEVELOPMENT ASSISTANCE FOR PEACEBUILDING}

the fact that there has remained a clear separation between Church and state in Timor-Leste throughout the post-independence period.

The role of the minor political parties has similarly increased over time but remained modest compared to the aforementioned three sets of actors. During Fretilin's term in government, these parties had too few seats in the national parliament to influence legislation and the Fretilin leadership completely excluded them from the cabinet. Since the formation of the AMP government in 2007, some minor political parties have exercised greater influence over policy by virtue of their membership of the governing coalition, most notably the Democratic Party (which grew out of the student and youth movements under Indonesian occupation), the Social Democrat Party (PSD) and the Timorese Social Democratic Association (ADST). Yet none of these parties have had clear ideological and policy agendas, being more focused on securing control of political offices. At the same time, the AMP government has been so dominated by Gusmão that their role has remained minor. Gusmão reportedly tends to act 'on his own initiative' rather than in consultation with members of his own party and coalition partners and sees 'his role as a leader, not as a member of a team of ministers representing their own political parties' ${ }^{53}$

For their part, local NGOs and martial arts, veterans and extremist groups have had almost no role in the formal political process. ${ }^{54}$ In general, the only way in which these actors have been able to influence policy has been to organize demonstrations, engage in violence or otherwise cause disruption. When their attempts to cause disruption have intersected with attempts by elements such as soldiers from the F-FDTL to do the same thing, they have had some effect. But otherwise, they have exercised limited influence.

In the following sub-section, we examine the way in which contests between these sets of actors - particularly the first three - have shaped the nature of government policy in the health and education sectors and, in so doing, the extent to which the World Bank has been able to use its aid effectively.

\section{The Political Economy of Aid Effectiveness in Health and Education}

Donors' development policy agenda in Timor Leste's health and education sectors has focused on building the capacity of the state to deliver affordable basic health and education services in order: (1) to ensure that Timor Leste's poor are equipped with the skills and abilities to enable them to compete in the international labour market; and (2) to build the foundations for a functioning procedural democracy. ${ }^{55}$ In short, it has been to transform Timor Leste's poor into market citizens. ${ }^{56}$ The Fretilin and Falintil leaderships have supported this approach much more strongly in the health sector than the education sector. At the beginning of the government's 2002 Health Sector Policy Framework, Gusmão declared: 'Let us not be tempted to build and develop modern hospitals that are costly and in which only half a dozen people benefit from good treatment. Let us concentrate above all on planning intensive campaigns of sanitation, prevention, and the treatment of epidemics and endemics for the whole population. ${ }^{57}$ This statement can be seen as reflecting concern within Timor Leste about the way in which the health system and in particular the hospital system 


\section{DEVELOPMENT ASSISTANCE FOR PEACEBUILDING}

during the Indonesian occupation primarily served the interests of Indonesian military and bureaucratic officials rather than ordinary Timorese. But it also resonates with donors' concerns about the cost-effectiveness of the government's health and education programmes. Anderson has suggested that the government's deal with Cuba for the training of Timorese doctors reflected a commitment by the country's political leadership to progressive Latin American notions of 'social medicine'. ${ }^{58}$ Likewise the government's accommodation of the Catholic Church in relation to issues such as abortion and contraception indicates a willingness to back away from technocratic approaches to health on religiously sensitive issues. But, in broad terms, donors, the Fretilin leadership and the Falintil leadership have all been on the same page in relation to health policy issues. The Cuban deal arguably complemented rather than challenged the HSRDPs $^{59}$ by addressing an acknowledged gap in these projects' activities namely, insufficient attention to manpower issues. ${ }^{60}$ And the influence of the Catholic Church has only extended to a specific set of issues rather than health policy in general.

But while the Fretilin leadership and the Falintil leadership broadly supported the donor development agenda in health, their support in relation to the education part of this agenda was tempered by their simultaneous commitment to building a particular national identity. In public speeches, Gusmão has echoed donor concerns that the education system should focus on producing job-ready graduates in order to enhance national economic competitiveness and reduce unemployment. $^{61}$ But the Fretilin and Falintil leaderships have both been willing to compromise on this objective in order to promote nation-building objectives. The Fretilin and Falintil leaderships consist largely of individuals who were educated during the Portuguese colonial era and, in the case of the Fretilin leadership, spent most of the Indonesian occupation in the former Portuguese colony of Mozambique. Reflecting this background, they have promoted a particular brand of nationalism in the post-1999 period in Timor Leste that has emphasized Portuguese cultural values and the use of Portuguese language as a marker of national identity. This reduced their commitment to the donor development agenda in so far as they prioritized the use of Portuguese in the education system - a language in which less than 40 per cent of the population is considered 'literate' 62 - over the effectiveness of the education system in providing the skills and abilities needed to produce a labour force and voters. The Portuguese and Brazilian governments made it possible for the government to carry out its attempts to promote use of Portuguese through the education system by funding Portuguese language training programmes for teachers. Other (especially Anglophone) donors, however, were highly critical of the language policy, arguing that educational considerations dictated use of Bahasa Indonesia, the national language of Indonesia, or Tetun, an indigenous lingua franca, as the primary language of use in school classrooms because both are much more widely spoken in Timor Leste than Portuguese.

Notwithstanding the position of the Portuguese and Brazilian governments, then, it is clear that a contradiction emerged between donors, on the one hand, and the Fretilin leadership and F-FDTL, on the other hand, over which state 


\section{DEVELOPMENT ASSISTANCE FOR PEACEBUILDING}

capacities should be prioritized in the education sector. While all actors agreed that they should seek to build the state's capacity to deliver basic education services and, in so doing, its capacity to produce educated workers who could compete in the international labour market, the Fretilin leadership and the Falintil leadership sought to subordinate this agenda to their particular nation-building objectives. For them, it became more important that the state develop the capacity to promote a particular national identity and concept of citizenship than the capacity to deliver basic education services effectively. While the country needed to produce skilled and educated workers, their position implied, it needed to produce citizens - or, at least, particular types of citizens - first. The result of this political situation was to make realization of the donor agenda and the projects associated with it - much more difficult in the education sector than the health sector.

\section{Conclusion/Implications}

This article has examined the factors underlying the World Bank's relative success in Timor-Leste's health sector. We have argued that HSRDP I and II were relatively effective, not simply for reasons related to their design and implementation, but also because (a) they were implemented within a political economy context that was conducive to aid effectiveness in general and (b) there was relatively little elite resistance to the World Bank's policy agenda in the health sector. Whereas the Bank's education projects ran aground in the face of elite efforts to use the education system to promote a particular national identity, its health projects were advantaged by the fact that donors and elites shared the same health policy objectives. The results for the Bank were consequently stronger in the health sector than in the education sector.

In terms of wider lessons for peace-building efforts in fragile contexts, this analysis suggests that we need a more political understanding of the determinants of aid effectiveness. Specifically it suggests that aid effectiveness is a function not just of the technical quality of project design and the administrative competence of project managers but also the extent to which the agendas of donors and developing country elites align with one another. In recent years, donors have increasingly argued that aid effectiveness is a function of the extent of country ownership. This needs be viewed in explicitly political terms. Specifically, it needs to be seen as a function of political and social relationships: where the interests and agendas of donors and powerful domestic political and social groups within recipient countries are well aligned, the political commitment required to create ownership will emerge; where it does not, the situation will be characterized by resistance to the donor agenda and aid ineffectiveness.

This idea has important implications for the way in which the international development community seeks to enhance aid effectiveness in fragile contexts. First, it suggests that in making decisions about how to allocate aid, both between countries and within countries between competing sectors and activities, donors need to (1) make assessments about the likelihood their agendas will encounter resistance from powerful domestic groups; and (2) decide whether it 


\section{DEVELOPMENT ASSISTANCE FOR PEACEBUILDING}

is thus feasible to proceed with an intervention. Second, donors need to develop a better understanding of the political and social environments of the countries/ sectors/activity areas in which they operate. Donors' commitment to political and social analysis has so far been inconsistent and half-hearted. ${ }^{63}$ This needs to change. Finally, progressive civil society organizations should contest and monitor donor aid policies. One cannot assume that the donor agenda will necessarily be pro-poor, notwithstanding the fact that popular support for aid programmes in donor countries rests partly on claims about their effectiveness in promoting poverty reduction.

If the World Bank had employed a more politically informed approach in designing its aid programme in Timor Leste, its results would have depended on the quality of its political analysis and the appropriateness and effectiveness of its response to prospective elite resistance. These are difficult things to get right. However, the World Bank arguably would have given itself a much greater chance of producing successful results than by employing a technocratic approach.

\section{ACKNOWLEDGEMENTS}

We wish to thank Rachel Gisselquist for comments on an earlier draft of this article and UNU WIDER for funding the research project of which this article is a part. We also wish to thank the two anonymous reviewers who provided feedback on the article. The usual caveat applies.

\section{NOTES}

1. We describe East Timor/Timor-Leste as a 'territory' at various points in this article to account for its changing political/administrative status over time - that is, Portuguese colony, Indonesian province, UN administered territory and now independent country - as well as the fact that the UN never officially recognized East Timor's incorporation into Indonesia.

2. IEG, Timor Leste Country Program Evaluation, 2000-2010, Washington, DC: Independent Evaluation Group, 2011.

3. Ibid., pp.29-33.

4. Ibid. See also Jim Tulloch, Fadia Saadah, Rui Maria de Araujo, Rui Paulo de Jesus, Sergio Lobo, Isabel Hemming, Jane Nassim and Ian Morris, Initial Steps in Rebuilding the Health Sector in East Timor, Washington, DC: The National Academies Press, 2003; and Andrew Rosser, 'The First and Second Health Sector Rehabilitation and Development Projects in Timor Leste', in James Manor (ed.), Aid That Works: Successful Development in Fragile States, Washington, DC: World Bank, 2007, pp.123-43.

5. Rosser (see n.4 above).

6. See Jane Hutchison, Wil Hout, Caroline Hughes and Richard Robison, Political Economy and the Aid Industry in Asia, Houndmills: Palgrave Macmillan, 2014. 


\section{DEVELOPMENT ASSISTANCE FOR PEACEBUILDING}

7. Ian Patrick, 'East Timor Emerging from Conflict: The Role of Local NGOs and International Assistance', Disasters, Vol.25, No.1, 2001, p.50.

8. United Nations Development Programme, 'East Timor Human Development Report 2002', Dili: UNDP, 2002, p.1.

9. See Annex 1 of World Bank, Building a Nation: A Framework for Reconstruction and Development, Washington, DC: World Bank, 1999.

10. World Bank, Joint Assessment Mission: Health and Education Background Paper, Washington, DC: World Bank, 1999, p.1.

11. Kelly Morris, 'Growing Pains of East Timor: Health of an Infant Nation', The Lancet, Vol.357, No.9259, 2001, p.873.

12. World Health Organization, Plan of Action for Humanitarian Health Assistance and Public Health Action in Response to the Crisis in Timor, September 1999-February 2000, Geneva: World Health Organization, 2000.

13. Patrick (see n.7 above), p.58. See also Andrew McGregor, Laura Skeaff and Marianne Bevan, 'Overcoming Secularism? Catholic Development Geographies in Timor-Leste', Third World Quarterly, Vol.33, No.6, 2012, p.1135.

14. World Bank, 'Project Appraisal Document on a Proposed Grant in the Amount of \$US12.7 Million Equivalent to East Timor for a Health Sector Rehabilitation and Development Project', Washington, DC: World Bank, Human Development Sector Unit, 2000. See also Rosser (see n. 4 above), p.127.

15. La'o Hamutuk, 'Building a National Health System for East Timor', La'o Hamutuk Bulletin, Nov. 2000.

16. Tulloch et al. (see n. 4 above), p.8.

17. Ibid., p.2.

18. World Bank, 'Implementation Completion Report (TF-23768) on a Grant from the Trust Fund for Timor Leste in the Amount of \$US12.7 Million to the Democratic Republic of Timor-Leste for a Health Sector Rehabilitation and Development Project', Dili: World Bank, 2005, p.2.

19. Ibid., pp.2-3.

20. Ibid., p.3.

21. World Bank, 'Implementation Completion and Results Report on Grants in the Amount of US\$12.6 Million (TF-51363) and Euro 16.2 Million (TF-51363) to Timor-Leste for a Second Health Sector Rehabilitation and Development Project', Dili: World Bank, 2009, pp.1-3.

22. Tulloch et al. (see n.4 above) p.12.

23. World Bank, 'Project Appraisal Document on a Proposed Grant in the Amount of US\$12.6 Million Equivalent to East Timor for a Second Health Sector Rehabilitation and Development Project', Washington, DC: World Bank, Human Development Sector Unit, 2001, p.8.

24. World Bank (see n.21 above), pp.10-11.

25. Maggie Huff-Rouselle, Starting from Scratch in Timor Leste: Establishing a Pharmacentical and Medical Supplies System in a Post-Conflict Context, Washington, DC: World Bank, 2009, pp.20-1.

26. Kathleen A. Holloway, 'Timor-Leste Pharmaceuticals in Health Care Delivery - Mission Report 6-17 February 2012', New Delhi: World Health Organization, 2012.

27. IEG (see n.2 above), p.31.

28. Tim Anderson, 'Solidarity Aid: The Cuba-Timor Leste Health Program', Asian Studies Association of Australia Conference paper, Melbourne, 1-3 Jul. 2008, p.53; and 'Social Medicine in Timor Leste', Social Medicine, Vol.5, No.4, 2010, p.185.

29. World Bank (see n.21 above), pp.15-16.

30. Catherine Anderson, 'Timor Leste Case Study: Ministry of Health', in Naazneen Barma, Elisabeth Huybens and Lorena Vinuela (eds), Institutions Taking Root: Building State Capacity in Challenging Contexts, Washington, DC: World Bank, 2014, pp.305-8.

31. Tulloch et al. (see n.4 above), p.10.

32. Ibid., p.16.

33. Ministry of Health, East Timor's Ministry of Health - Health Policy Framework, Dili: Ministry of Health, 2002, p.26.

34. World Bank, 'Timor Leste: An Analysis of Early Grade Reading Acquisition', 2010 (at: http://web. worldbank.org/WBSITE/EXTERNAL/COUNTRIES/EASTASIAPACIFICEXT/0,,contentMDK:2 2540804 menuPK:3970762 pagePK:2865106 piPK:2865128 theSitePK:226301,00.html). See also Rosser (n. 4 above).

35. Rosser (see n.4 above).

36. Tulloch et al. (see n.4 above), p.29. 


\section{DEVELOPMENT ASSISTANCE FOR PEACEBUILDING}

37. Dennis Shoesmith, 'Political Parties', in Michael Leach and Damien Kingsbury (eds), The Politics of Timor Leste: Democratic Consolidation after Intervention, Ithaca, NY: Cornell Southeast Asia Program Publications, 2013, p.126.

38. Anderson (see n.30 above) and Judicial System Monitoring Programme, 'JSMP Comments to the Sergio Lobo Interlocutory Appeal', 2001 (at: http://members.pcug.org.au/ wildwood/ 01julappeal.htm).

39. Astri Suhrke, 'Peacekeepers as Nation-Builders: Dilemmas of the UN in East Timor', International Peacekeeping, Vol.8, No.4, 2001, pp.1-20.

40. Rosser (see n.4 above), pp.173-5.

41. Dennis Shoesmith, 'Timor Leste: Divided Leadership in a Semi-Presidential System', Asian Survey, Vol.43, No.2, 2003, pp.231-52.

42. George Aditjondro, Timor Lorosa'e on the Crossroads, Jakarta: Center for Democracy and Social Justice Studies, 2001, pp.6-7; Joao Saldhana, 'Anatomy of Political Parties in Timor Leste', 2006, mimeo.

43. Shoesmith (see n.41 above), pp.238-41.

44. Rosser (see n.4 above), p.178.

45. Edward Rees, 'Under Pressure: Falintil - Forcas de Defesa de Timor Leste: Three Decades of Defense Force Development in Timor Leste 1975-2004', Geneva Centre for the Democratic Control of Armed Forces Working Paper 139, 2004, p.5.

46. Shoesmith (see n.41 above), p.244.

47. Shoesmith (see n.37 above), p.132.

48. Xanana Gusmão, Timor Lives! Speeches of Freedom and Independence, Alexandria: Longueville Books, 2005, pp.162-9.

49. Tim Anderson, 'Development Strategy', in Michael Leach and Damien Kingsbury (eds), The Politics of Timor Leste: Democratic Consolidation after Intervention, Ithaca, NY: Cornell Southeast Asia Program Publications, 2013, pp.215-38.

50. Rosser (see n.4 above), pp.178-9.

51. Shoesmith (see n.37 above), pp.138-40.

52. McGregor et al. (see n.13 above), p.1139.

53. Shoesmith (see n.37 above), p.132; Saldhana (see n.42 above).

54. Richard Holloway, 'NGO Advocacy in Timor Leste - What Is Possible', in Catholic Relief Services (ed.), Aspects of Democracy in Timor Leste - NGOs Advocating for Social Change, Dili: Catholic Relief Services, 2004, pp.7-16; and Anthony Smith, 'Timor Leste: Strong Government, Weak State', Southeast Asian Affairs, 2004, pp.285-7.

55. World Bank, Timor-Leste Education: The Way Forward, Dili: World Bank, 2003, p.1; World Bank (see n.18 above), p.21.

56. Kanishka Jayasuriya, Statecraft, Welfare and the Politics of Inclusion, Basingstoke and New York: Palgrave Macmillan, 2006.

57. Ministry of Health (see n.33 above).

58. Anderson (see n.28 above).

59. By 2008, there were approximately 300 Cuban health workers in Timor-Leste, while almost 700 Timorese students were studying medicine in Cuba, and another 150 had taken up their studies at Timor's National University. The first graduates of this programme arrived back in Timor and began internships in their country's health system in late 2009/early 2010, after the completion of the HSRDP II in 2008. See Anderson (n.28 above).

60. IEG (see n.2 above), p.31.

61. Gusmão (see n.48 above), pp.29-30.

62. Ministry of Finance, Highlights of the 2010 Census Main Results in Timor-Leste, Dili: Ministry of Finance, 2010.

63. Thomas Carothers and Diane de Gramont, Development Aid Confronts Politics: The Almost Revolution, Washington, DC: Carnegie Endowment for International Peace, 2013. 



\section{Index}

Note: Bold face page numbers refer to figures and tables. Page numbers followed with " $n$ " refer to endnotes.

Abaka, Charlotte 98

Abdile, Mahdi 72-4, 76-86; see also

Finn Church Aid (FCA)'s 2012 initiative in Somalia

access of villagers to basic utilities, under NSP 25, 26

accountability of local governance structures 32-3

Accra Agenda for Action (2008) 74

Afghanistan 6, 56; female mobility 23; governance structures 23; mullah, role of local 23; NSP-funded projects see National Solidarity Programme (NSP); population 23; rural 23; village characteristics $24,37 \mathrm{n} 22$

Africa Fellows programme 76

African Development Bank (AfDB) 57

Agriculture and Rural Development Programme 49

Alkatiri, Mari 154-6, 160

Alternative Basic Education (ABE) materials 143

Arab Spring 39

Armed Forces (F-FDTL) 162-6

Audit Service of Sierra Leone (ASSL) 65

Bah-Kenneth, Asatu 95

Barre, Mohamed Siad 139

basic services, delivery of 7

Bisanz, Sylvia 99

Capacity Building (CB) 42

Carter Center (TCC) 76

cash-for-work programme $13,45,49-50$
Center for Global Development (CGD) 75

child-centred pedagogy 144

child doctor and prenatal visits, impact of NSP on 25

chlorine dispensers for clean water 4

Cliffe, Sarah 105

commitment devices 4

Common Action Plan (CAP) 57

Community and Local Development (CLD) 42

community-based paralegal programmes 7, 13

Community Development Councils (CDC) 20; creation of 27-8; elections 23; female participation in $26-7$, $28,32-3$; mandates of 32-3; relative ineffectiveness of 21; see also National Solidarity Programme (NSP) community-driven development (CDD) $5-6,13,20$; evaluations of 21 community-driven workfare programme 42

community education committees 145

Community Policing Unit, Liberia 96

Comprehensive Law against Violence towards Women (Law 779) 133

conflict-affected areas see fragile and conflict-affected state (FCAS)

conflict situations: communal problems 124-7, 125; intra-family problems 124-7, 127

Country Financial Accountability Assessment (CFAA) 57, 66, 70n29

Criminal Court E 97-8

Cummings, William C. 7

Danish Refugee Council 77

de Araujo, Rui Maria 160

de Carvalho, B. 105-6 
demand-driven approach 47-8

democratic values, impact of

NSP on 28-9

Department for International

Development (DFID) 57, 63

development assistance to fragile states

and conflict-affected areas 1-2;

successful 2-4

deworming 4

difference in differences (DiD) methodology 122, 130

Doctors without Borders 94

drinking water and electricity projects, under NSP 25

East Timorese Health Professionals Working Group (ETHPWG) 155

education: faces of 137-8; statebuilding function of 138

Educational Management Information System 146

education kits 144

education programme in Somalia 7-8, 10, 143-6; aid modalities 147; assessment 146-9; capacity development strategy 148-9; context 139-40; data collection and development of EMIS 149; linkages between emergency provision and long-term development 149; local ownership of the programme/ project 147-8; programme/project design 148-9; school enrolment, growth of 146 ; work in the local context 146-7

Education Sector Cluster (ESC) 145

Education Support Programme (ESP) 95, 98-100, 102, 109n39

Egypt's Social Fund 41

Emergency Response Unit (ERU), Liberia 98

EU aid programmes 63

evaluating outcomes 8-9

Experiments in Governance and Politics (EGAP) network 24

external validity 14

Facilitadores Judiciales (FJ) see Judicial Facilitators Programme in Nicaragua Facilitadores Judiciales Rurales 118 Falintil leadership 162-6

female participation in CDC 26-7, 28, 32-3; men's acceptance of 30, 31
Finn Church Aid (FCA)'s 2012 initiative in Somalia 6, 9; advocacy targets 77 ; 'capacity' assistance than 'technical' assistance 77; capacity of the Ministry 81-2; capacity support to Somalia's TFG 78-80; civic education workshops 80; commitment to a rights-based approach (RBA) 78; deficiencies in representation 82-3; engagement with UN Political Office for Somalia (UNPOS) 77-8; experiences 77-80; on gender equality $83-4$; impact of secondment 80-4; institutional memory 73 ; organizational memory 73; programmes outside of Somalia 76; secondment in Somalia 76-84; supporting statebuilding and local ownership through 'embedded' assistance 74-7; UNPOS endorsement 79

flexible mode of funding 49-50

fragile and conflict-affected state (FCAS) 1-4, 10, 12, 65, 67, 72-4, 76, 85-6, 118; gender-sensitive reform in a fragile state context 92-4; peace-building operations in fragile contexts see Timor Leste, health interventions in; reform aspirations and activities accepted by decisionmakers in 62; rights-based approach to development assistance in fragile context 78; Social Fund approach in see Social Fund for Development (SFD); see also Liberia; Sierra Leone; Somalia; Yemen

fragile situations, nature of 3

Fragile States Principles 2-3

Fretilin leadership 162-6

Friedman, J. 93

Gaza 6, 56

GDP per capita: Liberia 112; Sierra Leone (2003-2012) 56; Yemen 40-1 gender-based violence programme 96-7 gender equality, impact of FJ intervention 132, 132-3

gender-sensitive policing and security sector reforms of Liberia 91, 93-4

Gender Unit, Liberia 96

global citizenship 137

Global Education First Initiative (GEFI) 137 
'Good Aid' project 2, 5

Good Government in the Tropics (Judith Tendler) 5

Government of the Islamic Republic of Afghanistan 21

Gusmão, Xanana 163-5

handicraft sales and sales revenue, impact of NSP on 26

Health Sector Policy Framework, 2002164

Health Sector Rehabilitation and Development Project (HSRDP): district health management teams (DHMTs), replacement of 157; effectiveness of 160-1; first (HSRDP I) 8, 153; outcomes 157-9, 158; overview of 156-7; political factors and outcomes 161-6; second (HSRDP II) 8, 153; short-term focus 156; see also Timor Leste, health interventions in

Horta, President Jose Ramos 160

Hosh, Abdi 72, 79

household income sources, impact of NSP on 25-6, 27

Human Development Index (HDI): Sierra Leone 56; Timor 154

human rights 78, 106, 117, 138

Independent Evaluation Group (IEG) of World Bank 153

informal providers of justice 117

infrastructure projects, under NSP 25

Integrated Financial Management Information System (IFMIS) 59

Integrated Public Financial Management Reform project 57-8, 64-5

Interim Health Authority (IHA) 155-6

Internally Displaced Persons (IDP) of Timor 155

International Force for East Timor (INTERFET) 154-5

International Horn University 77

International Monetary Fund (IMF) 63

International Organization for Migration (IOM) 75

Isser, Maturu 105-6

John Snow, Inc. (JSI) 75

Joint Health Working Group (JHWG) 155
Judicial Facilitators Programme in Nicaragua 7, 11, 14, 116; activities of 119-20; control and intervention of conflict situations 124-7, 125, 127; costs of access to justice for beneficiaries, impact on 128-9; evidence of amicable solutions 127-8; experience with and resolution of problems, analysis of 123-33; first years of implementation (1998-2001) 118; gender equality, impact on 132, 132-3; impact of 120-1; judges 118-19; legal information or assistance 123; local indigenous judges (Wihta) 118; mediation process 132; National Service of Facilitators (Servicio Nacional de Facilitadores), establishment of 119; as paralegals/mediators 119; proportion of resolved conflicts 124; quantitative measures 121-2; second programme stage (2001-07) 118; Subjective Legal Empowerment (SLE), impact on 130, 130-1, 131; value of 118; working of 119-20 justice protection 117

Kabbah, President 62

Kingdon, John 15

Koranic school project in 143

Koroma, President 62

Kosovo 6, 56

Labour-Intensive Works Programme (LIWP) 42-3, 49-50; evaluations 44

Lee University School of Law (W\&L) 76

legal problems, occurence of 123 Liberia 76; economy 91; GDP per capita 112; Liberia National Police (LNP) 90; policing and security sector reforms of Liberia see policing and security sector reforms of Liberia; post-civil war context 91-4; post-war rule of law 91-2, 105-7; settlement of sexual assault cases 94; sexual and gender-based violence (SGBV) in 91; spread of Ebola in 107; stigmatization and taboos associated with rape 94; see also policing and security sector reforms of Liberia

Liberia Law Fellows Programme 76 
literacy and computation skills, impact of NSP on 29-30, 31

local technical advisers (LTAs) $59,63,65$

Manning, Nick 105

Massachusetts Institute of Technology (MIT) 76

Médecins Sans Frontiéres 155

medium-term expenditure framework

(MTEF) 58, 61, 65

microsavings 4

Millennium Development Goals 1

Ministry for Foreign Affairs of Finland (MFA) 79

Monrovia 97, 100, 103

National Action Plan 57

National Congress for Timorese

Reconstruction (CNRT) 163

National Plan of Action for Gender

Based Violence 92

National Plan of Action for the Prevention and Management of Gender Based Violence in Liberia 92

National Solidarity Programme (NSP) $6,8,10$; access of villagers to basic utilities 25,26 ; accountability of local governance structures and 32-3; aim of 20-1; basic literacy and computation skills, impact on 29-30, 31; child doctor and prenatal visits 25 ; country context 23 ; creation of CDCs 27-8; democratic values, impact on 28-9; desire to change leader decisions, impact on 27; diversity of household income sources, impact on 25-6, 27; durable positive effects of 21 ; economic perceptions and optimism of villagers, impact on 25-6, 27; evaluation of funded projects in Afghanistan 24-31, 26-8, 30-1; female economic perceptions, impact on 26; female representation in local governance 27, 28, 32-3; financial constraints 21 ; first phase of (2003-2007) 21; funded drinking water and electricity projects 25 ; gender outcomes, impact on 30, 31; handicraft sales and sales revenue, impact on 26; infrastructure projects in irrigation and transportation 25; key outcome indicators $37 \mathrm{n} 27$; men's acceptance of female participation in political activity, impact on 30,31 ; negative list $36 \mathrm{n} 11$; perceptions of government entities and local security situation, impact on 29, 30; Phase-III 36n13; programme implementation $22-3$; projects financed by 22 , 23; school attendance, impact on 25; second phase of (2007-2010) $24,37 \mathrm{n} 27$; services 25 ; villager participation in local governance, impact on 27-8, 28; women's views on female participation, impact on 30, 31; see also Afghanistan

National Strategy for Good Governance 61

New Deal for Engagement in Fragile States 2

New Deal for Engagement in Fragile States (2011) 74

Nicaragua 117; Judicial Facilitators Programme in see Judicial Facilitators Programme in Nicaragua; judicial system 118; Rule of Law index, ranking in 118

Nicaraguan Supreme Court 116, 118-19

Nielsen, John 98, 104, 107

Norwegian Refugee Council 96

NSP Impact Evaluation (NSP-IE) 6, 21, 24, 31, 33-4; see also National Solidarity Programme (NSP)

Official Development Assistance (ODA) 1

Ogaden war 141

Organization of the American States (OAS) 11, 116, 118, 122

Overseas Development Institute (ODI)'s Fellowship Scheme 75

Oxfam 49

Paris Declaration on Aid Effectiveness (2005) 63, 74

participatory approach 47

Peacebuilding and Statebuilding Goals (PSGs) 2; 'evidence gap map' review of impact evaluations 4 peace education 137 Peace Initiative Project (PiP) 77 
Pentikäinen, Antti 86

Personnel Unit, Liberia 96

Police Support Unit (PSU), Liberia 98

policing and security sector reforms

of Liberia 7, 11, 13; addressing of justice system constraints to responsiveness 97-8; all-female Indian Formed Police Unit 104; assessment of ESP and WACPS reforms 98-100; awareness-raising initiatives 97, 100, 103; challenges and constraints 93-4; changing of cultural norms 97; Community Policing Unit 96; Criminal Court E, establishment of 97-8; dual goals of representation and responsiveness 94-5; Education Support Programme (ESP) 95, 98-100, 102, 109n39, 115; Emergency Response Unit (ERU) 98; evaluation of Criminal Court $\mathrm{E}$ and SGBV Crimes Unit 100-1; gender, personnel and community services units 95; Gender Based Violence Taskforce, establishment of 92-3; gender-sensitive 91, 93-4; Gender Unit 96; initiatives to improve representation and responsiveness 94-7; international support for 93, 114; overall framing for successes and failures 101-7; Personnel Unit 96; Police Support Unit (PSU) 98; role modelling 103-4; SGBV Crimes Unit, establishment of 97-8, 105; side-by-side embedding 103-4; 'Stop Rape' campaign 97; study trips 103-4; sustainability and capacity issues 103; Traffic Patrol Unit 96; training classes 95; Women and Children's Protection Section (WACPS) 95-7, 102, 104, 106, 109n39; women representation 92, 95, 108n20

Poverty Reduction Strategy Paper (PRSP) 59

prepaid fertilizer sales 4

Problem Driven Iterative Adaptation (PDIA) 13

public expenditure and financial accountability (PEFA) 55

public financial management (PFM)

6, 9, 11; Accountant General's

Department (AGD), role of 59, 63, 65; administrative and technical capability to deliver reforms 62-3; budget evaluation 59; creation of environment conducive for future reforms $60-1$; external audit and scrutiny 59-60; factors contributing to success 60-7; implementation of Integrated Financial Management Information System (IFMIS) 59; institutional arrangements 57; legal and regulatory framework 58; manpower hearings, policy hearings and participatory budget discussions 60; medium-term expenditure framework (MTEF), implementing 58, 61, 65; MoFED's administrative and technical capability to deliver 62-3; multi-donor budget support group for 63-5, 66; parliamentary scrutiny of budgets 59-60; Performance Assessment Framework 65; planning and budgeting 58-9; political commitment to 61-2; procedures for budget execution 59; for public sector reform activities 62; reform action plans 57-8; sequencing of reforms 65-7; time of the cease-fire, at the 60-1; see also Sierra Leone

pupil kits 13

Rainfed Agriculture and Livestock Project (RALP) 44 randomized controlled trials (RCTs) 3-4, 10, 24

Red Cross 155

remedial education in small groups 4 reminders to save 4

Research and Communication on Foreign Aid (ReCom) programme (2011-13) 2

Rule of Law index, 2014118

Schia, N.N. 105-6

school attendance, impact of NSP on 25

Scott Family Liberia Fellows

Programme 6-7, 75

Sexual and Gender-Based Violence

Referral Pathway 96-7

sexual- and gender-based violence

(SGBV) 90-1, 108n11

SGBV Crimes Unit 97-8, 100-1, 105

Sieh, Beatrice Munah 95 
Sierra Leone 6, 56; Audit Service of Sierra Leone (ASSL) 65; civil service capacity and development agendas 62-3; civil war (1991-2002) 56; GDP (2003-2012) 56; Government of Sierra Leone (GoSL) 55, 57-8, 62-3; growth rates 56-7; Human Development Index (HDI) rank 56; Independent Auditor General 57; international co-operation and aid modalities 63-5; Ministry of Finance and Economic Development (MoFED) 57, 61, 63; National Public Procurement Authority and Parliament 57; primary institutions of 57; public financial management (PFM) in see public financial management (PFM); Strategy and Policy Unit 62; 'Timap' programme 7; WACPS's operations in 96

Sirleaf, Johnson 95

Small and Microenterprise

Development (SMED) 42

social capital 14

Social Democrat Party (PSD) 164

Social Fund for Development (SFD) 6, 11, 13; actual expenditures by sector and phase of activity 43; allocation of funds 48; capacity at targeting poor and deprived communities 44; capacity development and good governance, impact on 45; cash-for-work programme 49-50; demand-driven approach of 47-8; development objectives for the third phase (2004-10) 51-2; disbursals 48; effective leadership of 48; efficiency in terms of procurement performance 45-6; employment creation, impact on 46; evaluation of performance 43-6; evolution of objectives 42; expansion of 49,51 ; factors contributing to achievements 46-51; factors enabling implementation 46-7; financial and nonfinancial services 41 ; flexible mode of funding 49-50; funding raised for 42; implementation and outreach capacity 51 ; institutional assessment of 44-6; investment in the Hadhramaut Governorate 46 ; main programmes 42 ; management information systems (MIS) 48; outsourcing of shortterm activities 43; participatory approach of 47; perception of development practitioners and government officials 48; phases of operations 41-2; priorities of 42; process of project selection and implementation 47-8; quality of impacts on livelihoods 50-1; quality standard of development initiatives 45 ; reach out of 43; regional offices and branches 43; relationship with communities 52; resilience and effectiveness in delivering aid 40; sectoral activities 42; short- to longterm development goals 51; staff and project officers 43; success at delivery 41; support to local development and governance 51-2; systems and procedures 48 ; transparency aspects 46,48 ; vision and mission 52; water supply interventions 49-50; World Bank support 40-1; Yemenis' food security, impact on 49; during Yemen's 2011 economic and political crisis 45; Yemen's Local Authority Strategy, role in drafting 52; see also Yemen

Social Welfare Fund (SWF) 49-50

Somalia: average life expectancy of 139; conditions unconducive to educational development 142; 1991 crisis 139; cultural inclination 139; educational development 140-3; education in 138; enrolment status of children by gender and zone 142; Federal Government of Somalia (FGS) 72; institutions 75; levels of functioning statehood and fragility 139; literacy rates 139; Outreach and Reconciliation (SOR) Initiative 77-9, 82; political transition in 9, 72; population 139; school enrolment rates by gender and zone 141, 141, 142; Transitional Federal Government (TFG) 72, 86n1, 89n64; see also education programme in Somalia; Finn Church Aid (FCA)'s 2012 initiative in Somalia Somali Aid Coordination Body (SACB) 145 
Somalia Multiple Indicator Cluster

Survey (MICS) 142, 149

Somaliland 77, 87n16, 139-40, 143, 145, 149

'Stop Rape' campaign 97

structural violence 3

Subjective Legal Empowerment (SLE), impact of FJ intervention 130, 130-1, 131

substantial progress 6

successful aid interventions 2-4; assessing outcomes and impact 8-9; female participation 13; implications for transferability and scalability 8-14; internal organizational mechanisms 13; local support and local champions 11-12; potential 'drivers' of 9-14; programme design and management 13; responsiveness to local context 13 ; weak state capacity 12

sustainable peace 1

teachers and community education committees (CECs) 145

teachers/school kits 13

'Timap' programme 7

Timorese Social Democratic Association (ADST) 162, 164

Timor Leste, health interventions in 9, 12, 153-4; civil society organizations, role in health service delivery 155 ; country context 154-6, 160; donors' development policy agenda in 164-6; Fretilin and Falintil leaderships, role of 165-6; health facilities 155; Health Sector Policy Framework, 2002 157, 164; Portuguese language training programmes 165 ; see also Health Sector Rehabilitation and Development Project (HSRDP)

Traffic Patrol Unit, Liberia 96

Transnational Law Institute of Washington 76

United Nations Children's Fund (UNICEF) 7-8, 10, 93, 96; adaptation of local context to deliver education 146; aid modalities 147; basic data collection system 149 ; capacity development strategy 148-9; child-centred pedagogy 144; curriculum revision 144; education kits 144; emergency provision and long-term development 149; extended presence in Somalia 146-9; in-service training of teachers 144-5; Koranic school project 143; as largest educational provider 146; non-formal educational programmes for out-of-school youth and children 143; rehabilitating school facilities 145; schooling in Somalia 145; teachers and community education committees (CECs) 145; textbooks and school supplies, distribution of 144; see also education programme in Somalia

United Nations (UN) 63; Security Council Resolution 1325 on women, peace and security 92; United Nations Development Fund for Women (UNIFEM) 93; United Nations Development Programme (UNDP) 93; United Nations Educational, Scientific and Cultural Organization (UNESCO)'s Programme of Education for Emergencies and Reconstruction (PEER) 142-4; United Nations Peacebuilding Fund, 93; United Nations Population Fund (UNFPA) 93; United Nations Transitional Administration in East Timor (UNTAET) 155-7, 161; UN Mission in Liberia (UNMIL) 91-2, 94-6, 104-5, 113; UN Police (UNPOL) 93, 95-6, 104; UN Political Office for Somalia (UNPOS) 77-8

water projects 13, 25-6, 45

West African Examination Council (WAEC) 95

West Bank 6, 56

Williams, James H. 7

Wilson, Carroll 76

Women and Children's Protection Section (WACPS) 95-7, 102, 104, 106, 109n39; critical setback of 100; facilities and resources of 100 ; Juvenile Unit 100; mission 96; officer attrition 100; organizational structure 96; reports of gender-based violence 99; squads 96 


\section{INDEX}

Women in Peacebuilding Network (WIPNET) 95

women representation in security sector 92, 95, 108n 20

World Bank 6, 40-1, 49, 57, 61, 63; Aid That Works 8; experience in Timor Leste see Health Sector Rehabilitation and Development Project (HSRDP); Timor

Leste, health interventions in; Independent Evaluation Group (IEG) of 153

World Vision International 155
Yemen: 1991 crisis 39; 2011 crisis 41, 49-50; 2014 crisis 52; economic reform programme of 1995 40; economy of 39-40; fragile political situation 41; GDP per capita 40-1; level of international development aid received 46; population growth 40; Poverty Reduction Strategy 42; regional aid to 40; social and economic indicators 41; Social Fund approach see Social Fund for Development (SFD); unification of 39 Yemen National Dialogue 52 